\title{
Diagnostic tools for early evaluation of total hip performance : studies on preclinical and clinical monitoring of implant quality
}

Citation for published version (APA):

ten Broeke, R. H. M. (2014). Diagnostic tools for early evaluation of total hip performance : studies on preclinical and clinical monitoring of implant quality. [Doctoral Thesis, Maastricht University]. Maastricht University. https://doi.org/10.26481/dis.20140425rb

Document status and date:

Published: 01/01/2014

DOI:

10.26481/dis.20140425rb

Document Version:

Publisher's PDF, also known as Version of record

\section{Please check the document version of this publication:}

- A submitted manuscript is the version of the article upon submission and before peer-review. There can be important differences between the submitted version and the official published version of record.

People interested in the research are advised to contact the author for the final version of the publication, or visit the DOI to the publisher's website.

- The final author version and the galley proof are versions of the publication after peer review.

- The final published version features the final layout of the paper including the volume, issue and page numbers.

Link to publication

\footnotetext{
General rights rights.

- You may freely distribute the URL identifying the publication in the public portal. please follow below link for the End User Agreement:

www.umlib.nl/taverne-license

Take down policy

If you believe that this document breaches copyright please contact us at:

repository@maastrichtuniversity.nl

providing details and we will investigate your claim.
}

Copyright and moral rights for the publications made accessible in the public portal are retained by the authors and/or other copyright owners and it is a condition of accessing publications that users recognise and abide by the legal requirements associated with these

- Users may download and print one copy of any publication from the public portal for the purpose of private study or research.

- You may not further distribute the material or use it for any profit-making activity or commercial gain

If the publication is distributed under the terms of Article $25 \mathrm{fa}$ of the Dutch Copyright Act, indicated by the "Taverne" license above, 


\section{DIAGNOSTIC TOOLS FOR EARLY EVALUATION OF TOTAL HIP PERFORMANCE}

\section{Studies on preclinical and clinical monitoring of implant quality}

René ten Broeke 


\title{
DIAGNOSTIC TOOLS FOR EARLY EVALUATION OF TOTAL HIP PERFORMANCE
}

\section{Studies on preclinical and clinical monitoring of implant quality}

\author{
Proefschrift \\ ter verkrijging van de graad van doctor \\ aan de Universiteit Maastricht, \\ op gezag van de Rector Magnificus, \\ Prof. Dr. L.L.G. Soete \\ volgens het besluit van het College van Decanen, \\ in het openbaar te verdedigen \\ op vrijdag 25 april 2014 om 14.00 uur
}

door

René Hendrikus Maria ten Broeke

Geboren op 4 september 1957

te Haaksbergen 


\section{Colofon}

\section{Promotor:}

Prof. Dr. L.W. van Rhijn

\section{Copromotores:}

Prof. Dr. R.G.T. Geesink, emeritus hoogleraar, Universiteit Maastricht

Dr. J.J.C. Arts

\section{Beoordelingscommissie:}

Prof. Dr. R.A. de Bie (voorzitter)

Prof. Dr. C.A. van Blitterswijk (Universiteit Twente)

Dr. B. Brans

Prof. Dr. P.R.G. Brink

Dr. M. Dalstra (Aarhus University, Denemarken) 
Our greatest glory is not in never falling, but in getting up every time we do (Confucius)

Voor Annet, Charlotte en Juliëtte 


\section{Cover illustrations and Layout:}

Eric Lemmens

www.dlgraphics.nl

ISBN/EAN:

978-90-8590-057-3

The printing of this thesis was financially supported by:

Stichting Kliniek en Wetenschap Orthopaedie, Maastricht, the Netherlands

Anna Fonds / NOREF, Leiden, the Netherlands

Nederlandse Orthopaedische Vereniging,

Biomet, Dordrecht, the Netherlands

DePuy Synthes, Amersfoort, the Netherlands

Orthopaedie 2000, Maastricht, the Netherlands

Krul Orthopaedie / Smeets loopcomfort, Maastricht, the Netherlands

All rights reserved: No part of this publication may be reproduced or transmitted in any form or by any means, electronic or mechanical, including photocopy, recording, or any information storage and retrieval system, without the permission in writing of the author, or when appropriate, the publishers of the papers. 


\section{Contents}

$\begin{array}{lll}\text { Chapter } 1 & \text { General Introduction } & 9\end{array}$

Chapter 2 Randomized comparison between the Cemented Scientific 47 Hip Prosthesis ${ }^{\circledR}$ and Omnifit ${ }^{\circledR}$ : 2-year DEXA and minimum 10-year Clinical follow-up Journal of Arthroplasty 2013;28:1354-1361

Chapter 3 Bone densitometry in cemented total hip arthroplasty; different results with inclusion or exclusion of the cement mantle in a randomized controlled trial comparing two stems Submitted

Chapter 4 Results of total hip arthroplasties in the young patient; further evidence for a barrier against articular wear debris by hydroxyapatite coatings Hip International 2009;19:343-351

Chapter 5 Bone reaction to a biomimetic third generation HA-coating 113 and new surface treatment on a newly designed hip stem Journal of Bone and Joint Surgery [Br] 2011;93-B:760-768

Chapter 6 Randomised trial comparing bone remodelling around two 145 uncemented stems using modified Gruen zones Hip International 2012;22:41-49

Chapter 7 Improving peri-prosthetic bone adaptation around 163 cementless hip stems; a clinical and finite element study Med Eng Phys (2013), http://dx.doi.org/10.1016/j.medengphy.2013.12.006

Chapter 8 Application of finite element analysis in total hip design 191 optimizations; a critical appraisal from a surgeons perspective

Chapter 9 Summary and Conclusions 221

Chapter 10 Samenvatting en Conclusies

Curriculum Vitae 245

Dankwoord 


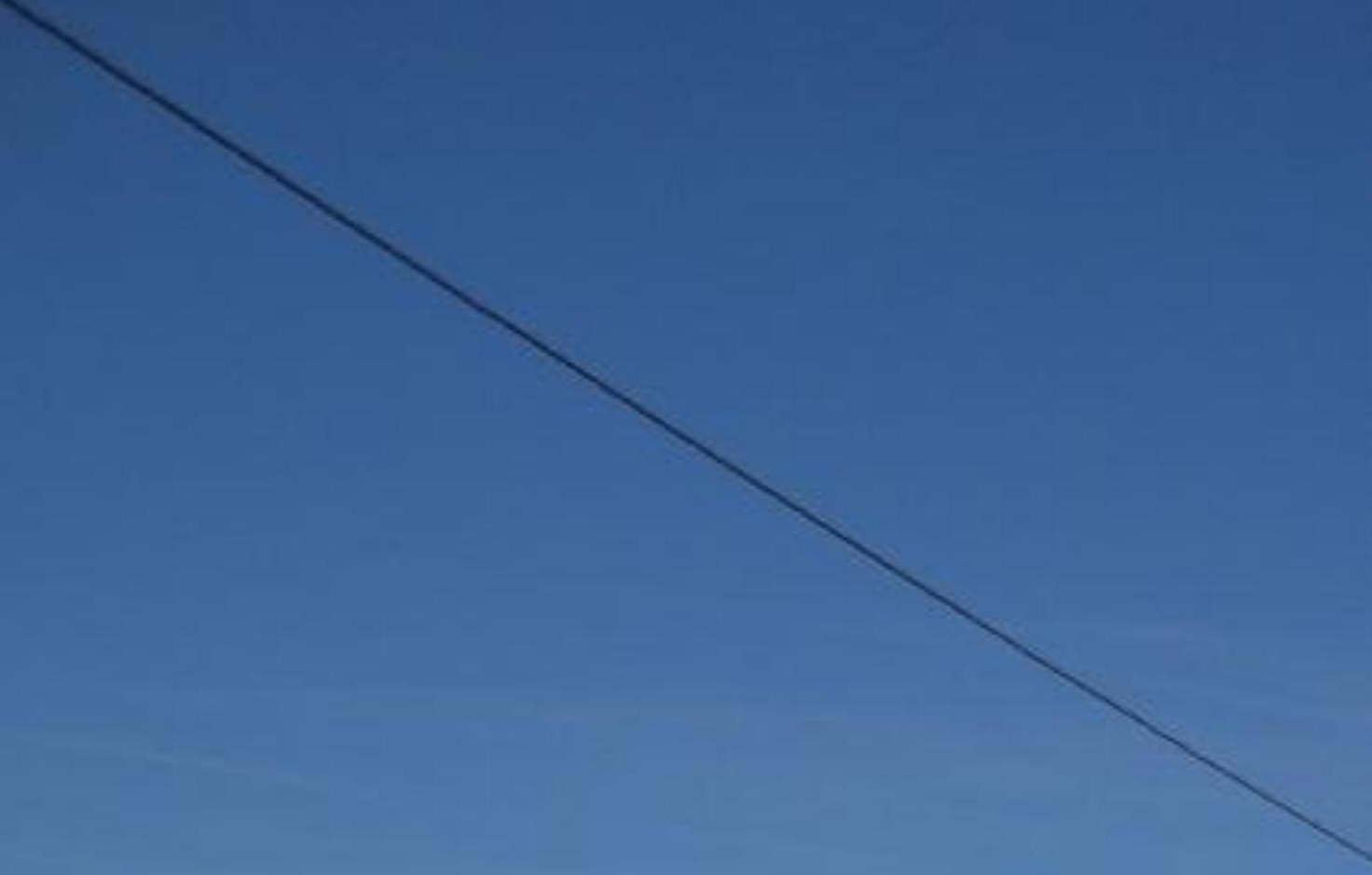




\section{CHAPTER 1}

\section{General Introduction}

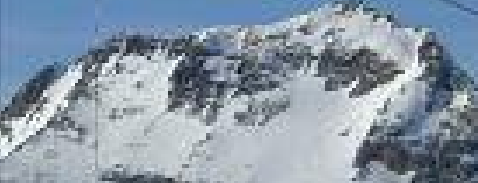

060

(104)

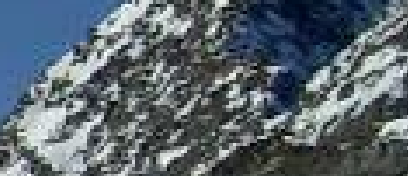

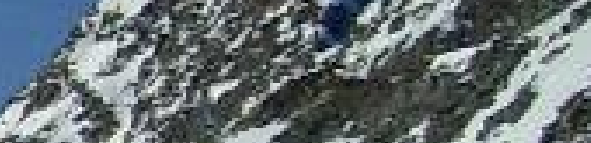

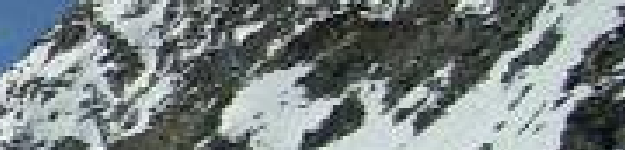

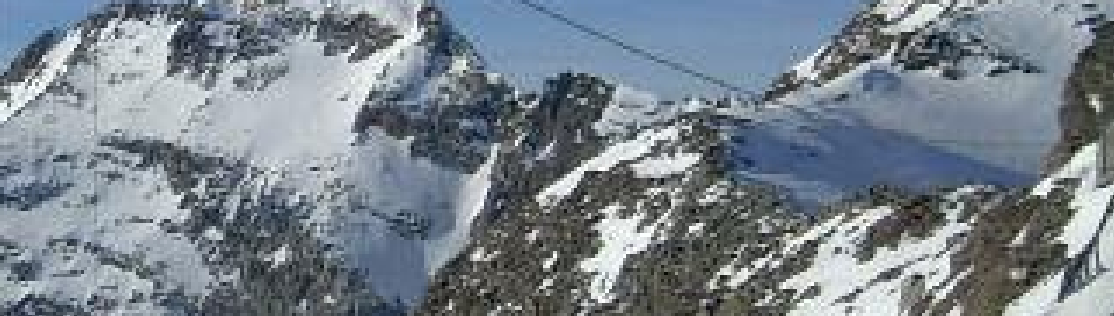

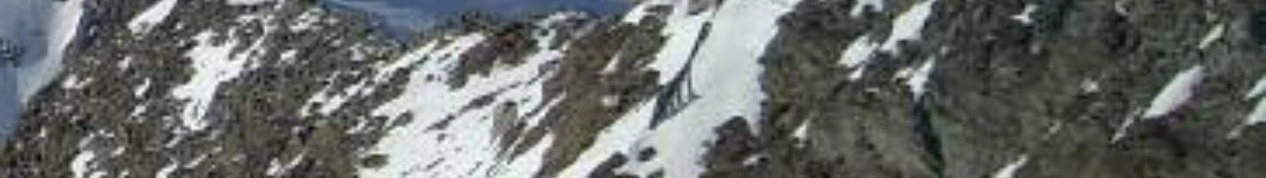

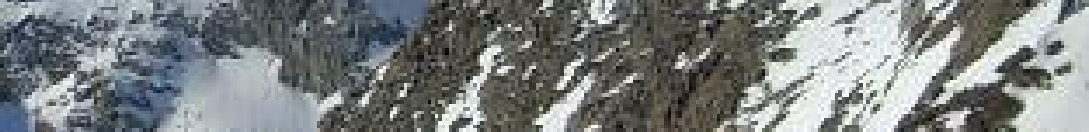

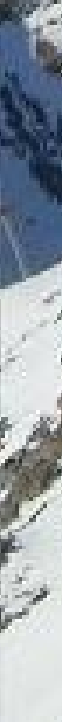

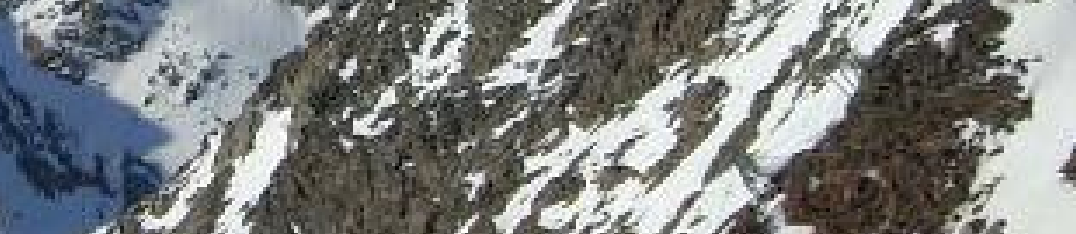

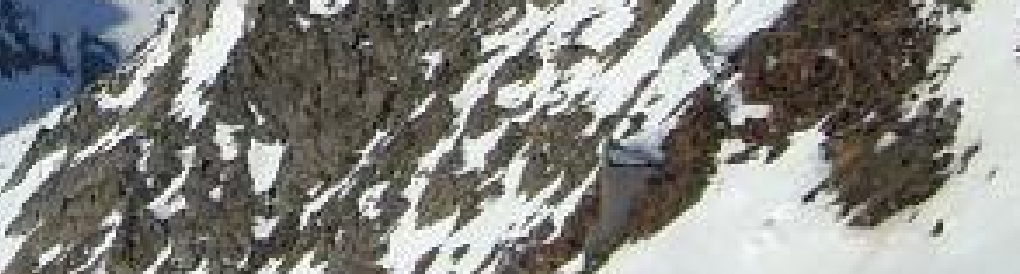
- $1.2,1$ (2.14)

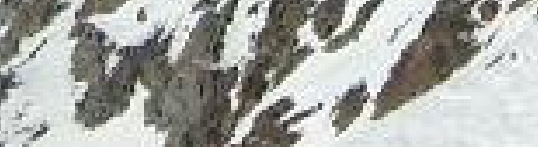

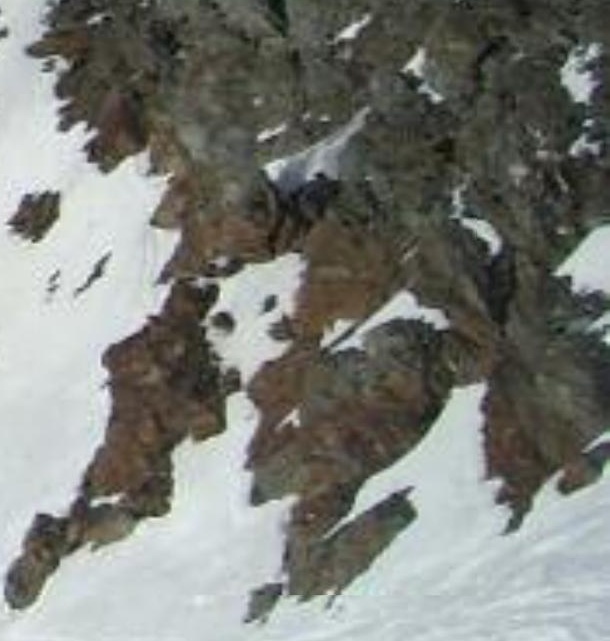

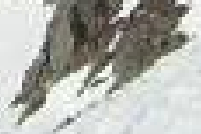


Chapter 1 


\section{General Introduction}

Total hip arthroplasty is considered to be the most successful surgical procedure both clinically and in terms of cost-reduction. ${ }^{1}$ The effectiveness of the operation for pain-relief and restoration of hip function, ${ }^{2}$ as well as the reduced dependence on health care expenditures, ${ }^{3-5}$ can explain the continuously growing numbers of this surgical intervention. ${ }^{6,7}$

In 2005 a number of 22,500 total hip prostheses were implanted in the Netherlands, ${ }^{8}$ and 202,500 in the USA in $2003 .{ }^{9}$ In coming years as a result of a projected growth of the older population and because of lowering thresholds for surgical interventions, a dramatic increase in these numbers is foreseen. ${ }^{9-11}$ In 2020 the annual number of total hip arthroplasties (THA) in the Netherlands is predicted to increase to $25,090,{ }^{11}$ and in the United States to 572,000 in $2030 .{ }^{9}$

Considering the large number of patients involved, the impact of the procedure on the quality of life, and the severe consequences of implant failure, the monitoring of total hip prostheses has become mandatory to improve their longevity. Therefore an important issue in total hip replacement nowadays is the performance of quality assurance of both existing implants and new designs. Nevertheless there is a long history of total hip prostheses put onto the market without sound scientific research, preclinical testing or prospective clinical trials to detect the risk of failure in an early stage. On most implants there are no published data of good quality, and making a choice by the orthopaedic surgeon amongst these implants therefore is insufficiently based on evidence. ${ }^{12}$ National hip implant registers, like the Swedish, ${ }^{13,14}$ the Norwegian, ${ }^{15}$ the Finnish, ${ }^{16}$ and the Danish Hip Arthroplasty Register, ${ }^{17}$ have shown that ultimately survival curves can reveal failures and detect implant designs with unacceptable revision rates. However most implants still perform well during the early postoperative years, so when the first suspicion is raised that the design may be a failure, large numbers already may have been implanted. It has been estimated that a trial of several thousands of patients followed for at least a decade would be required to show a significant improvement (30\%) of a new hip design if compared with a conventional one, when the outcome would exclusively be measured in terms of an insensitive parameter like failure. ${ }^{18}$ This is ethically not acceptable and may lead to many 


\section{Chapter 1}

claims for the orthopaedic industry. In this way several disasters happened, while insight in the relations between design changes and failure mechanisms was not developed. ${ }^{19,20}$ Examples of such clinical 'disasters' in orthopaedic hip arthroplasty, caused by a scientifically deficient introduction pathway, are the Perfecta prosthesis (Wright Medical Technology, Arlington, TN, USA), ${ }^{21}$ the Centralign prosthesis (Zimmer Inc, Warsaw, IN, USA), ${ }^{22}$ the Capital Hip prosthesis (3M Health Care Ltd, Loughborough, UK), ${ }^{23-27}$ the matte version of the Exeter stem (Howmedica, Mahwah, NJ, USA), ${ }^{28,29}$ the Boneloc cement (Polymers Reconstructive, Farum, Denmark), ${ }^{30,31}$ and the ASR Hip Resurfacing system and ASR XL Acetabular Hip system (de Puy Orthopaedics, Warsaw. IN. USA). ${ }^{32-35}$ Therefore there is an urgent need for diagnostic tools that can at least differentiate between superior and inferior implants, and assist in the evaluation of new stem (and cup) designs. They will allow clinical follow-up to be directed to patients at risk, and identify factors that may adversely affect implant fixation. Preferably however they should be able to detect potential future failures in an early postoperative or even preoperative stage. This is of particular importance for the fast growing group of young hip patients, for whom the future consequences of an unnecessary early revision procedure will have a huge impact on remaining operative solutions and their functional results. ${ }^{14,16,36,37}$

Tools in (early) postoperative assessment after THA, that have been attributed in the literature to have a potential for prediction of long-term performance of total hip prosthesis are:

- Harris Hip Score (HHS), Merle d'Aubigne score (MdA) or Lequesne index, scores for functional hip results

- Oxford Hip Score (OHS), Western Ontario and McMaster Universities Osteoarthritis Index (WOMAC), McMaster Toronto Arthritis scale (MACTAR) and Hip disability and Osteoarthritis Outcome Score (HOOS), so called disease-specific patient satisfactory scores

- $\quad$ Short Form 36 (SF-36), Short Form 12 (SF-12), Nottingham Health Profile (NHP), Sickness Impact Profile (SIP) and the EQ-5D, as generic health patient satisfactory scores

- radiological results

- radiostereophotogrammetric analysis (RSA) for migration 
- dual energy X-ray absorptiometry (DEXA) for periprosthetic bone remodelling

- histology of early retrieved implants

- $\quad$ radionuclide imaging (bone scintigraphy)

- 18 Fluoride Positron Emission Tomography (18F-PET)

The longevity of joint prostheses depends on several conditions of which mechanical stability and sound fixation of the implant to bone, cemented or uncemented, are essential. Different factors interact on these conditions (Fig. 1), and several diagnostic tools provide direct and indirect information on them (Fig. 2). ${ }^{38}$

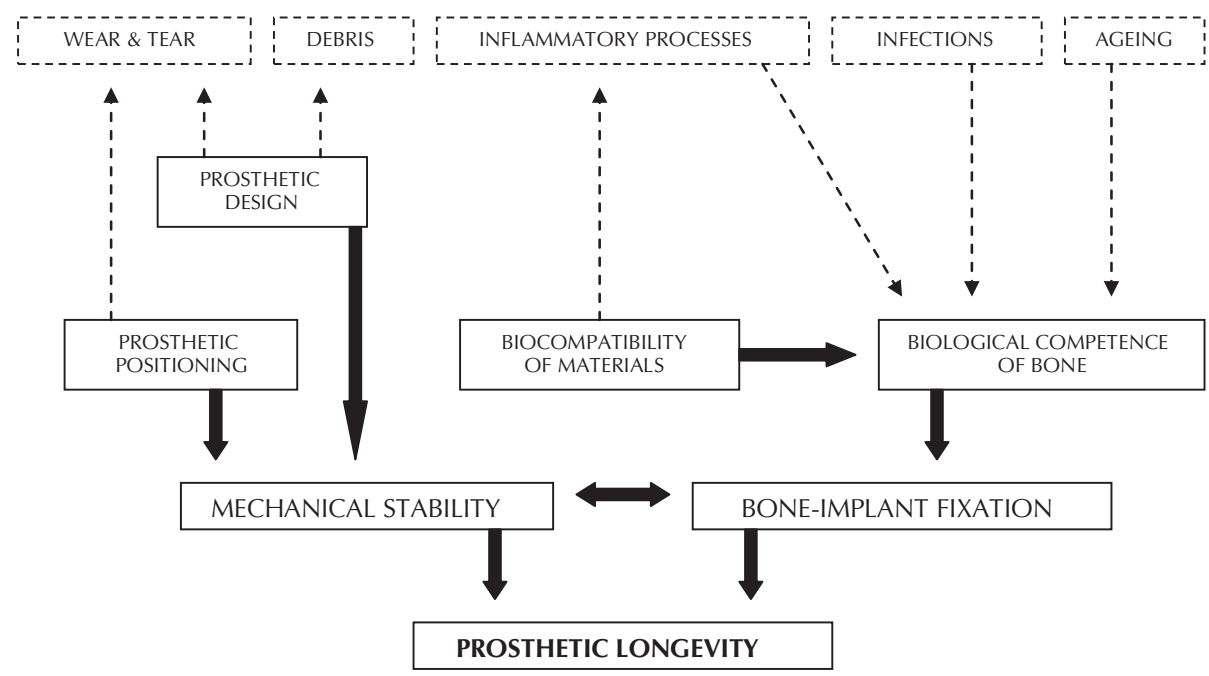

Fig. 1 Physiological and pathological processes interacting with periprosthetic bone, and consequently affecting the longevity of the prosthesis. (Adapted from Marinoni et al. ${ }^{38}$ ) 


\section{Chapter 1}

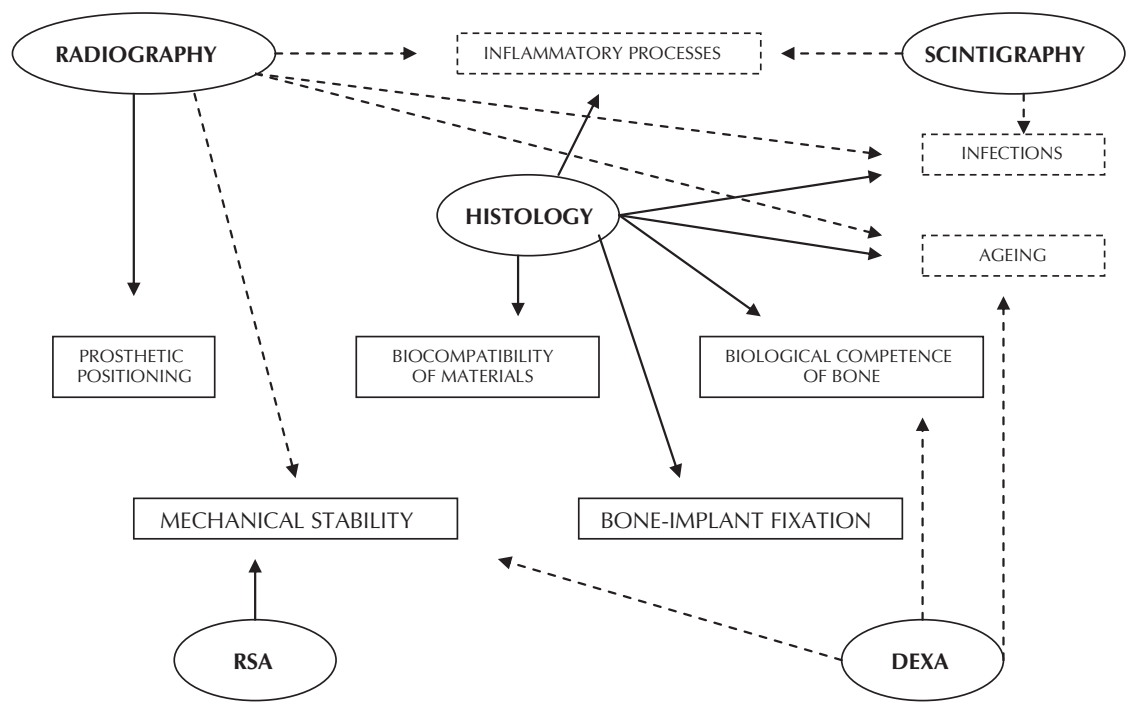

Fig. 2 Available diagnostic tools supplying direct (solid arrows) and indirect (dashed arrows) information on factors influencing prosthetic survival. Integration of this information may result in early and better insight in processes leading to ultimate implant failure. (Adapted from Marinoni et al. ${ }^{38}$ )

\section{Finite Element Analysis}

As a tool with the preoperative potential for predicting future failures of new hip implants, finite element analysis (FEA) has been suggested by biomechanics.

Finite Element Analysis (FEA) is a computer-assisted technique able to estimate loads and stresses in periprosthetic bone and interfaces. This can be used as a guideline for adaptations in implant design, choice of material, surface texture and method of fixation (cemented or uncemented). ${ }^{39-45}$ With a related technique, called numerical shape optimisation (NSO), starting from predefined goals in terms of maximally acceptable strain energies in the bone and interface stresses, the ultimate design is calculated. ${ }^{46,47}$ More recently FEA has evolved into a technique not just for estimation of stresses in and around the bone-implant construct, but for preclinical prediction of long-term implant failure. With the acquisition of more knowledge on the failure scenarios of cemented and uncemented hip implants, computer simulations could be performed of processes like interface debonding, ${ }^{48,49}$ cement damage accumulation, ${ }^{50}$ and cement creep. ${ }^{51-53}$ In this 
way efforts were made to predict aseptic loosening of particular cemented implant designs under specified loading conditions, ${ }^{54}$ muscle forces, ${ }^{55}$ and the performance of daily tasks. ${ }^{56}$ Machine testing protocols were designed mimicking these physiological circumstances to provide experimental failure data, ${ }^{57,58}$ and retrospective clinical and survival data from the hip registers were used to validate the predictions of certain implant designs. However this still remained a retrospective in vitro computer technique that had to be validated through in vivo prospective clinical data, to be able to apply it for newly developed implants.

So far the limitation of simulation-based FEA is that it remains a computer model that defines several assumptions concerning implant material properties, bone properties ${ }^{59}$ (isotropic/anisotropic), and bonded or debonded circumstances of interfaces with their coefficient of friction. ${ }^{60}$ Furthermore estimations were made of interface loading forces during daily activities (walking, stair climbing), ${ }^{56}$ hip contact forces and muscle forces. ${ }^{55}$ From this, peak tensile stresses in cement and interfaces were monitored by the software, and stem migration was calculated. It is obvious that because of all these assumptions, the extent to which FEA can realistically simulate the failure mechanisms, is limited. This probably explains the discrepancy between in vivo clinical results of failed hip reconstructions and the in vitro FE-calculations, and therefore these retrospective studies can only partially validate the technique. ${ }^{60}$

In order to asses the value of FEA in prediction of future performance of new hip implant designs, the question should be answered if there is a correlation between the preoperatively estimated periprosthetic bone stresses by FEA, and the resulting postoperative periprosthetic bone mineral density (BMD) changes as measured by for example dual energy x-ray absorptiometry (DEXA). In other words is there a prospective 'in vivo' clinical validation, in terms of periprosthetic bone remodelling, of the 'in vitro' predicted behaviour of a particular stem design?

\section{Surgeon-oriented Functional Hip Scores}

There are several well-known outcome measures of hip surgery like the Harris Hip Score (HHS), ${ }^{61}$ the Merle d'Aubigne score (MdA), ${ }^{62}$ the Charnley Score (CS), ${ }^{63}$ and the Lequesne index (L-ISH). ${ }^{64}$ These are all surgeon-oriented measurementinstruments and although considered objective, are often inaccurate and not 


\section{Chapter 1}

reproducible. ${ }^{65}$ Furthermore issues like pain, range of motion, walking distance and activities of daily living reflect more the surgeons interest than patients' satisfaction, ${ }^{66-68}$ nowadays considered to be more important for outcome measurement. Because the assessment of these functional parameters is not always performed by an unbiased observer, let alone the operating surgeon or even the (co)designer of the implant, the objectivity may be doubtful and therefore useless as an early discriminating score between superior and inferior implant designs. ${ }^{69,70}$ Furthermore the high intraobserver variability that goes with the physician's physical examination, being a part of the HHS, limits its value. ${ }^{71}$ In most cases the HHS or MdA are part of a randomised clinical trial (RCT). In order to come to a sufficient amount of material to predict future failure or success, a critical number of included cases with a substantial period of follow-up is demanded, which excludes per definition the possibility of early characterization of future implant performance. ${ }^{72,73}$

An important limitation of the HHS is the ceiling effect. At the time the HHS was developed, the score had good content validity due to the variability in implant quality, and consequently the ability of this functional score to distinguish between their results was high. ${ }^{61}$ However with improvements in implant designs and operating techniques most patients already score the maximum possible results ('the ceiling'), making this instrument unfit to detect an improvement of a new design. ${ }^{74,75}$ Because of frequent ceiling effects in trials of the HHS, it therefore has limited value in exploring the added benefit of newer hip implants or surgical techniques. ${ }^{75}$

For the same reason hip registry results are a powerful instrument for assessment of implant survival in mid- and long-term follow-up, but are less suitable to differentiate between superior and inferior prostheses in the short term, when only a small number of implantations are performed. These initial hip replacements mostly will have been performed in highly specialised centres, that may be related to the development of the implant and therefore are not unbiased either. Although the registers are certainly a good tool for post-market surveillance of new medical devices and technologies, they do not fulfil the need for an early discriminative instrument. Furthermore even after longer follow-up, survivorship analysis, which plays a crucial role in the hip registers, can be a very crude and insensitive instrument to detect failure, depending on the reason taken as an 
endpoint for failure. When exclusively revision is considered a confirmation of failure, many loose but unrevised stems will be missed. This may be caused by insufficient diagnosis, unavailability of sufficient surgical skills to perform the revision-procedure, absence of necessary resources, or an unwilling patient. ${ }^{73}$

Another drawback can be the methodological and statistical problems in the use of survival analysis, like small populations, ${ }^{73}$ and what to do with patients lost to follow-up. ${ }^{76}$

\section{Patient-oriented Outcome Scores /}

\section{Patient Reported Outcome Measures (PROMs)}

It has been recognized that more patient (than surgeon) oriented outcome scores are, although considered subjective, more valuable to determine the success of a therapeutic procedure or implant. ${ }^{67-69,77}$ Obtaining information about patient satisfaction after hip surgery through questionnaires, or more in general concerning perception of health and illness, is easier to organize, is less costly and shows higher response rates than functional scores. ${ }^{73,78}$ There are several disease-specific outcome instruments to evaluate patient satisfaction after hip arthroplasty, like the Oxford Hip Score $(\mathrm{OHS}),{ }^{79}$ the Western Ontario and McMaster Universities Osteoarthritis Index (WOMAC), ${ }^{80}$ the McMaster Toronto Arthritis scale (MACTAR) ${ }^{81}$ and the Hip disability and Osteoarthritis Outcome Score (HOOS). ${ }^{73,82}$

The OHS is a hip scoring instrument specifically designed for outcome measurement of hip arthroplasty and consisting of 12 questions focusing on pain, hip range of motion and activities of daily life. Both Dawson et al. ${ }^{79}$ and Ostendorf et al. ${ }^{83}$ showed a good reliability and correlation with clinical change, and the score has been validated in Dutch. ${ }^{84}$

In the WOMAC-index patients score on multiple items focussing on pain, stiffness and functional disability. ${ }^{80}$ These patient-relevant issues make it a widely used disease-specific, health-related quality-of-life questionnaire for measuring outcome after THA as well, ${ }^{2}$ but the OHS is considered to be more appropriate for hip arthroplasty and more feasible in terms of user friendliness and responsiveness. ${ }^{73,85}$ Like the OHS the WOMAC has proven to be valid, reliable, and responsive, ${ }^{80}$ and the version translated in Dutch showed satisfactory crosscultural validity. ${ }^{86}$ 


\section{Chapter 1}

Recently the Short QUestionnaire to ASsess physical activity (SQUASH) has been tested as a scoring system for activity levels of patients after THA, in an attempt to determine their functional results. ${ }^{87,88}$ The questionnaire was originally developed in the Netherlands to asses physical activity and monitor compliance with national and international recommendations to improve the activity level in the general population. It is composed of questions dealing with activities in household, leisure-time, sports and at work and school. Although theoretically an alternative for the WOMAC-score, it's value for predicting long term outcome is questionable. There may be a contradiction in the implication of good SQUASH-scores for the short and longer term. Although a high score on physical activity presupposes a good functioning THA, this does not necessarily correlate with good survival, and up till now this relationship has not been investigated. The major concern with respect to high activity levels after THA is the potential detrimental effect on the longevity of the implant, due to higher wear of the bearing surfaces. ${ }^{89-91}$ Another limitation in the use of these self-report instruments in general is the issue of bias, lack of reproducibility and difficulty of comparison. ${ }^{88,92}$

Apart from the disease-specific satisfaction scores there are more generic scores that relate to the patients' feeling of health, illness and physical, mental and social disability in general and are less focused on the result of a particular surgical or non-surgical intervention. In orthopaedics the Short-Form 36 (SF-36) is the bestknown and most-used, ${ }^{93}$ as well as its' shorter version the SF-12. Alternatives are the Nottingham Health Profile (NHP) ${ }^{94}$ and the Sickness Impact Profile (SIP). ${ }^{95}$ In the SF-36 there are 36 items scored concerning issues like physical and social functioning, mental and emotional (dis)ability, pain and vitality, to asses the patients' general health and quality of life. This generic measurement instrument has been translated in Dutch as well and shown to be valid and reliable. ${ }^{96}$

Another important PROM is the EQ-5D. EuroQol - 5 Dimension (EQ-5D) is an instrument which evaluates the generic quality of life. ${ }^{97}$ It consists of one question for each of the five dimensions of life that include mobility, self-care, usual activities, pain/discomfort, and anxiety/depression. The answers given to EQ-5D permit to find 243 unique health states or can be converted into an EQ-5D index, a utility score anchored at 0 for death and 1 for perfect health. It also includes a Visual Analog Scale (VAS), by which respondents can report their perceived health status 
with a grading from 0 (the worst possible health status) to 100 (the best possible health status). This instrument can also be used to evaluate the cost-effectiveness of different interventions, and may be used as a complementary consideration in clinical priority assessment. ${ }^{98}$ This generic patient related outcome measure has the advantage of being an internationally comparable score (for example with the Swedish Registry and the National Joint Registry). It is designed to compare diseases, disorders and their interventions in health care. It is validated in Dutch, is short, can be used for international comparison of outcome measurement, and is not subject to ceiling effects. ${ }^{99}$

It is generally accepted that a combination of a disease-specific and a generic health score is most valuable to characterize the effect of a total hip or knee replacement. ${ }^{73,100-102}$ The problems related to these subjective instruments however remain in terms of validity, accuracy and precision. They should be sensitive enough to detect a small but actual change in clinical result, be specific enough to monitor what you want to measure, and do this in a reliable and reproducible way. ${ }^{103}$ And most important in the light of the search for a discriminating tool for implant design, there is no evidence that the patient scores can fulfil this need. Apart from the intrinsic limitations related to these subjective instruments which were mentioned earlier, this is caused as well by the fact that changing comorbidity or even age, will strongly interfere with general health and disability scores and cause 'noise' in the actual outcome of interest. ${ }^{104-107}$

\section{Radiological results}

From postoperative radiographs important information can be derived concerning periprosthetic bone changes and implant fixation. Some of them may be predictive for early or late failure of the implant although progressive migration is considered the only pathognomonic. ${ }^{108-111}$ Nevertheless several radiological issues are consequently and closely studied to recognize the behaviour of an implant and the periprosthetic bone. The correspondence with future (early or late) failure in most cases however is disappointing, ${ }^{112}$ and in most cases this relationship has not been established at all.

For uncemented hip stems phenomena like endosteal spotwelds, absence of demarcation lines and physiological periprosthetic bone resorption through stress 


\section{Chapter 1}

shielding are considered signs of stable osseointegration, while pedestal formation, calcar hypertrophy, radiolucent halo's and areas of osteolysis on the other hand may prove instability. ${ }^{13,114}$ However clinical correlation with radiographic phenomena is usually low, and they do not consequently predict bad clinical results and implant loosening. ${ }^{115,116}$ Above mentioned phenomena count for extensively coated hip stems. ${ }^{113,114}$ However newer designs based on other principles of fixation (only proximal and not uniform or distal) will behave differently on X-ray follow up, and radiographic signs should be interpreted accordingly.

For cemented stems a fractured cement mantle will not be overlooked and is pathognomonic for gross loosening, but in the majority of cases a late observation. Radiolucent lines on the stem-cement interface mostly refer to failure as well. However the meaning of more frequent and early radiolucencies at the bonecement interface is not clear, and may be related with inadequate cementing technique with insufficient interdigitation or with debonding without clinical consequences, ${ }^{117}$ or it may even be a late result of earlier debonding of the stemcement construct. ${ }^{118}$

Malpositioning of the component, particularly varus malalignement, has been shown to be related with higher loosening risk probably due to an inadequate cement mantle and peak stresses in a nonuniform mantle, resulting in debonding with micromotion and migration. ${ }^{119-121}$ In summary, for several of these radiographic phenomena there is no clear understanding of their meaning and the way they should be interpreted, let alone any proof for their capacity to predict later failure.

The main problem with conventional radiography for both issues, implant migration and bone resorption, is that several studies have noted the potential for variability in radiographs made after total hip arthroplasty, causing the reliability of this tool to be questionable. This is due to intra- and interobserver variability, ${ }_{1}^{122-125}$ and errors that are associated with radiographic malalignment and image magnification. ${ }^{126}$ Particularly precision is hampered by changes in the type of film that is used, the exposure setting, the source-to-film distance, the variability of the $x$-ray field, and the orientation of the limb during sequential radiographic follow-

up. Early postoperative bone changes usually are small and conventional 
radiographs are too insensitive to detect, let alone quantify them. ${ }^{127}$ Particularly early implant micromotion, which has a proven predictive ability for later aseptic loosening and revision, ${ }^{108,109}$ has a poor accuracy and reproducibility using conventional $\mathrm{x}$-rays, in spite of several attempts of standardizations. ${ }^{126,128}$ To diminish variability, standardized radiographic protocols were developed with uniformity of regions of interest, both in the acetabulum (according to DeLee and Charnley ${ }^{129}$ ) and in the femur (according to Gruen et al. ${ }^{130}$ ). Special attention was payed to reproducible positioning of the patient, the distance of the patient to the $\mathrm{x}$-ray source and the film, and to precise centering of the $\mathrm{x}$-ray beam. Furthermore the application of digitisation, ${ }^{109}$ video-imaging of radiographs, ${ }^{131,132}$ the introduction of extra reference points, ${ }^{133}$ or the use of mathematical corrections of radiographs retrospectively, ${ }^{108}$ were all tried to overcome these imperfections. Nevertheless quantification of bone and interface changes or migration remains very difficult and hardly reproducible from $\mathrm{x}$-rays.

\section{Roentgen Stereophotogrammetric Analysis (RSA)}

RSA was developed to cope with this lack of precision and accuracy, intrinsically related to conventional radiographs, in determining implant migration. The technique was developed by Selvik ${ }^{134}$ and since then applied for migration studies of several implant designs. ${ }^{135-145}$ It determines the three-dimensional relative orientation of an implant and bone with an accuracy of $0.2 \mathrm{~mm}$ for axial migration. The conventional marker-based method involves insertion of tantalum markers in the bone and attached on the prosthesis, followed by sequential radiographs made simultaneously from two directions. The three-dimensional coordinates of the tantalum markers are then measured in relation to fixed markers in a calibration box, and thus movements of the implant relative to the bone can be determined along three axes. The advantage over conventional X-ray techniques therefore is that RSA can determine all changes in three-dimensional orientation, not just vertical migration, but axial rotation, varus-valgus and flexion-extension migration as well.

Because of high accuracy and precision of the technique, relatively small numbers of subjects (15-25 per patient group in a randomized clinical trial) during a short follow-up ( 2 years) are needed to establish the correlation between 


\section{Chapter 1}

migration outcome and long-term implant survival. ${ }^{110,146,147}$ There is a claim of ability to predict later aseptic loosening within the first two years after implantation. This relationship between initial subsidence $(1.2 \mathrm{~mm}$ during the first 2 postoperative years) and high risk of future loosening, has until now been established for only a small number of implant designs. ${ }^{110,148-150}$ For most designs however, migration thresholds that can discriminate good from bad predicted longterm performance, are not known. And for some stem types it has become clear that both early and late migration can be combined with good long-term survivorship, ${ }^{148,151}$ illustrating that absolute stability is not a necessary condition for good long-term implant survival. On the other hand it has been shown that stems with subsidence within safe limits, ${ }^{110,150,152}$ and low early revision rates, ${ }^{153}$ nevertheless can present with inferior long-term survival. ${ }^{152,154}$ In conclusion, initial stability is not invariably related to good long-term results, while the reverse does not absolutely predict inferior survivorship.

From several RSA studies combined with long-term follow-up studies ${ }^{155,156}$ and reports from the registries, ${ }^{154,157}$ migration beyond 'safe' thresholds appeared to be compatible with good long-term survivorship. Although this seems to be related with particular stem designs (polished, double-tapered, collarless) and should not be generalized for all implants, it is still unclear how early migration patterns and late outcome for implants of different design are related. In other words how valuable RSA is in predicting long-term outcome of implants with different design philosophies. Nevertheless within the original protocol for stepwise introduction of new implant designs onto the market, ${ }^{158}$ RSA has now been given a more prominent role for early detection of inferior designs. ${ }^{159}$ In this so called 'phased innovation' the sequence of steps for evidence-based introduction is now preclinical in vitro testing, RSA studies in small cohorts, larger randomized (multicenter) clinical trials, broader introduction onto the market and ultimately evaluation through long-term follow-up in national implant registries. This format gradually acquires broader support within the scientific field, ${ }^{160,161}$ and has also been adopted by the Dutch Orthopaedic Society as a mandatory step in the introduction pathway for new implant designs. ${ }^{162}$

There are some disadvantages of the RSA-technique as well; it is timeconsuming because of the manual definition of all markers. Nowadays automated 
measurements have accelerated the procedure of marker identification, and the reconstruction of the $3 \mathrm{D}$ position of implant in relation to bone markers. This has also eliminated observer variabilities and therefore improved accuracy and precision. $^{163}$

Furthermore RSA requires the implantation of tantalum markers in the bone and on the implant component(s). However the tantalum markers attached to the implant are often difficult to detect on stereoradiographs due to the high density of the metal, which occludes the markers. This objection with conventional RSA seems to be solved with newer RSA-techniques with contour recognition. In these 'model-based' RSA techniques no markers have to be attached to the prostheses, and the radiographic position of the implant is recognized by matching it to a virtual projection of a 3D- implant model. ${ }^{144,164,165}$

Another drawback of RSA is that it must be prospectively planned and cannot be performed retrospectively on archived films. A further disadvantage of radiostereometric analysis is that it is not available in a routine clinical setting, and still reserved for research centres. And although already available for many years, comparison of RSA-results between implant designs is difficult to interpret, because they are still not reported in a standardized way, even though some initiatives have been taken to realize this. ${ }^{147}$

\section{Radionuclide bone imaging}

Three phase bone scans (scintigraphy) can reflect abnormal uptake of the radionuclide technetium- ${ }^{99}$ demonstrating increased blood flow of an inflammatory response or increased osteogenic activity due to abnormal stress or bone repair by osteoblast activity. As such it is an established diagnostic tool in the evaluation of a painful total hip, and has the potential to differentiate between septic and aseptic reasons for implant loosening. ${ }^{166-168}$ However accuracy is not very high. ${ }^{169,170}$ In a systematic review on the accuracy of imaging techniques in the diagnosis of a loose acetabular component, bone scintigraphy had an overall (cemented and uncemented) sensitivity of only $67 \%$ and a specificity of $75 \% .{ }^{171}$ In a meta-analysis on the diagnostic performance of bone scintigraphy for aseptic loosening of the femoral component pooled sensitivity and specificity were respectively $85 \%$ and $72 \%$, while considerable interobserver variability was 


\section{Chapter 1}

found. ${ }^{172}$ So although combined with clinical and radiographic examination bone scans can be useful for detecting prosthetic problems, for early post market surveillance the information is mostly unspecific and their role in prosthesis monitoring and failure-prediction of new designs still has to be defined. ${ }^{173}$

A newer tool like ${ }^{18}$ Fluoride positron emission tomography (PET) may show higher accuracy in revealing periprosthetic bone physiology. With this imaging modality it is able to assess bone blood flow and bone metabolism through the incorporation of the fluoride tracer into the hydroxyapatite crystals of bone. ${ }^{174-177}$ The technique has been validated for accurate assessment of bone formation with histomorphometry. ${ }^{178}$ Although this modality has the potential for early follow-up of periprosthetic bone remodelling, it's role in predicting survival of total hip prostheses has not yet been evaluated.

\section{Dual Energy X-ray Absorptiometry (DEXA)}

DEXA is one of many densitometry techniques for assessment of (periprosthetic) bone remodelling. The underlying principle of the technique is analogous to dual photon absorptiometry (DPA) but in DEXA the radioactive isotope as source for the photon beam is replaced by an $\mathrm{x}$-ray tube. The $\mathrm{x}$-ray tubes provide a wide range of photon energies that must be narrowed to produce 2 distinct photo-electric energypeaks (70kV and $140 \mathrm{kV}$ for the Hologic system, Hologic Inc., Bedford, MA, USA, and $40 \mathrm{kV}$ and $70 \mathrm{kV}$ for the Lunar system, GE Medical Systems, Madison, WI, USA). These photon beams pass through bone and soft tissue, during which the degree of attenuation is determined by the tissue density which in turn is determined by the amount of mineral ( $\approx$ bone density) encountered by the beam. Bone density can be qualified by subtracting the beam intensity after passage through the intended region of interest (ROI) from the initial beam intensity. The amount of photon attenuation is compared with a calibration standard, mostly a phantom with known amount of bone mineral. ${ }^{179}$

There are many advantages of DEXA compared to DPA and earlier densitometry techniques. Radiation exposure is extremely low for DEXA with 2 to 5 mrem for proximal femoral studies, the biologically important effective dose or whole-body equivalent dose being only 0.1 mrem. ${ }^{179,180}$ These values are negligible in the context of natural background radiation of approximately 20 mrem per month. ${ }^{179}$ 
Furthermore their scan times have shortened, image resolution has improved and operation costs are lower than other densitometry techniques.

There is a marked improvement in precision with a coefficient of variation (CV) for short-term precision as low as $0.9 \%$ for the AP lumbar spine and $1.4 \%$ for the femoral neck in case of osteoporosis assessment. ${ }^{181}$ For densitometry of periprosthetic bone remodelling $\mathrm{CV}$ measured in vivo varies between $1.1 \%$ and $7.5 \%$ depending on the study and the region of interest (ROI). ${ }^{182-186}$ Although a limitation of DEXA is it's two-dimensional character instead of a true volumetric measurement, the clinical value for assessment of periprosthetic bone remodelling has been confirmed by the significant correlation between DEXA measurements and the result of quadrant analysis of sectioned femora by calibrated videodensitometry. ${ }^{187}$

For longitudinal follow-up measurements of periprosthetic bone remodelling it is essential that these systems show high stability during follow-up. An advantage of DEXA over DPA is the replacement of the isotope by an x-ray tube that produces the photon beam. This prevents decay of the isotope in time with changing densitometry results and lower precision, making DPA less suitable for detection of longitudinal BMD-changes. It has been calculated that with a CV of $2 \%$ a BMD change of at least $5.5 \%$ is necessary to detect with certainty within a $95 \%$ confidence interval. ${ }^{188}$ With a precision of $4 \%$, this figure increases to even 11.1 $\% .{ }^{179}$ All now available densitometers, both using pencil beam geometry and fan beam geometry have demonstrated good long term stability with generally good accuracy (5-10\%) and high precision (CV 1-2 \%), although precision realized in clinical practice depends more on the skill and attention of the operator than on machine performance. ${ }^{189-191}$ Generally speaking apart from accuracy and precision, several other factors can influence densitometry results profoundly during a longitudinal DEXA study on periprosthetic bone remodelling. From a theoretical point of view they can be divided in three groups:

1. factors related to the densitometry machine itself, creating small variations independent of the technician in every type of quantitative measurement;

2. factors related to the technician and the variability in performing the densitometry measurements, mainly as a result of inaccurate positioning of the femur during repeated assessments; 


\section{Chapter 1}

3. factors related to the assessment of the raw scans and the effect of intra- (and inter-) observer variability in analyzing the scans.

In short it can be said that machine related variability is checked, and if necessary corrected, through daily automated internal quality controls (QC). The densitometer is calibrated on regular basis on a more or less anthropomorphic phantom (mostly made of aluminum of hydroxyapatite) which functions as an internal reference, revealing a possible subtle 'drift' that may compromise precision. ${ }^{192,193}$ These phantoms are made of materials that resemble the density and X-ray attenuation characteristics of bone and surrounding soft tissue. Scanning results are compared to historical data and checked against limits for acceptable performance. For this purpose control tables and charts can be used, like so called Shewart charts, Shewart rules and cumulative sum charts (CUSUM). ${ }^{192-197}$

Technician related variability can be of even larger influence on scan-results. Mainly the non-identical / reproducible positioning by the operator of the leg that is to be scanned, is held responsible for the lack of precision in repeated measurements. It was shown that a change of leg rotation on the scan table can disturb precision in repeated longitudinal assessment of periprosthetic remodelling in such a way, that BMD changes should be ascribed to intra- or interobserver variability in scanning procedure and not to remodeling itself. ${ }^{198-200}$ Therefore several devices have been developed to fix the limb in identical rotation during each scan. ${ }^{201}$ Also poor performance of the operator responsible for analyzing the data is an important source for error and can attribute to artifacts more significantly than the equipment itself. ${ }^{202}$

Although a clear correlation between periprosthetic BMD changes and longterm clinical outcome and survival has not been proven, there are studies that showed early excessive periprosthetic demineralization in combination with disastrous loosening rates, suggesting that strong early BMD loss may be considered as impending loosening, ${ }^{203,204}$ or at least potentially hazardous for implant stability. In contrast, a stable course of periprosthetic femoral bone density appeared to correlate with good clinical and radiologic results. ${ }^{204-207}$ Furthermore the correlation between in vitro finite element calculated stress patterns and predicted periprosthetic bone remodelling on one side, and the in vivo assessment of bone mass redistribution with DEXA on the other, resulted in improved 
comprehension of stress-related changes in bone density. ${ }^{208-212}$ This may be useful in evaluating the effect of stem design, choice of material, type of fixation, surface treatments and implant coating.

\section{OUtline AND Aim OF the Thesis}

The aim of this thesis is to study the tools that are recommended for evaluation of performance of new and existing total hip prostheses, and their value in the process of quality assurance and post market surveillance of these implants. Particularly functional hip scores, radiographic results, assessment of implant migration with roentgen stereophotogrammetric analysis, histomorphometry, and bone densitometry are evaluated in clinical implant studies. Furthermore the preclinical application of finite element analysis to predict long-term performance of hip prostheses is reviewed.

The role of functional hip scores and of radiographic assessment of periprosthetic changes is dealt with in the long-term randomized clinical trial comparing two cemented hips stems, the Scientific Hip Prosthesis (SHP®) versus the Omnifit ${ }^{\circledR}$ (Chapter 2), and in the minimum 10 year follow-up of the uncemented HA-coated Omnifit ${ }^{\circledR}$ stem (Chapter 4).

The use and potential added value of dual energy x-ray absorptiometry (DEXA) is being studied for cemented stems in Chapter 2 and Chapter 3, and for uncemented stems in Chapter 6. In chapter 2 it is tested if preclinical finite element considerations on the $\mathrm{SHP}^{\circledR}$-design can be validated with DEXA assessment of periprosthetic bone remodelling. Chapter 3 focuses on the effect of cement mantle inclusion within the region of interest on the results of periprosthetic bone mineral density assessment. In chapter 6 bone remodelling is studied of the newly introduced Symax ${ }^{\mathrm{TM}}$ stem and compared to the uncemented Omnifit ${ }^{\circledR}$ in a 2 year randomized clinical trial.

The value of radiostereometric migration analysis as a predictor of future performance of total hip prostheses is investigated in the study of the SHP ${ }^{\circledR}$-stem (Chapter 2).

Qualitative histology, quantitative histomorphometry and scanning electron 


\section{Chapter 1}

microscopy are used in the assessment of the effect and behaviour of the new electrochemically deposited biomimetic BONIT-hydroxyapatite coating (proximal part) and the DOTIZE surface treatment (distal part) of the Symax ${ }^{\mathrm{TM}}$ hip stem (Chapter 5).

Finite element (FE) simulation studies are evaluated in Chapter 2, Chapter 7 and Chapter 8. It is examined to which extent a (preclinical) numerical simulation of implant characteristics and bone properties can lead to reliable predictions on periprosthetic bone adaptations in a clinical environment. In other words if numerical shape optimization can contribute to improve implant designs with predictable clinical outcome, and accurate anticipation of long-term implant survival. In a historical and critical review of the technique attention is mainly devoted to the integration of biological processes in computerized mechanical models, and the inevitable simplifications that are introduced with it, that may potentially compromise reliability of predictions on bone and implant behaviour. 


\section{References}

1. Learmonth ID, Young C, Rorabeck C. The operation of the century: total hip replacement. Lancet 2007;370:1508-19.

2. Etghen $\mathrm{O}$, Bruyère $\mathrm{O}$, Richy $\mathrm{F}$, et al. Health-related quality of life in total hip and total knee arthroplasty. A qualitative and systematic review of the literature. J Bone Joint Surg Am 2004;86-A:963-74.

3. Chang RW, Pellisier JM, Hazen GB. A cost-effectiveness analysis of total hip arthroplasty for osteoarthritis of the hip. JAMA 1996;275:858-65.

4. Rissanen P, Aro S, Sintonen H, et al. Costs and cost-effectiveness in hip and knee replacements. A prospective study. Int J Techn Ass Health Care 1997;13:575-88.

5. Garellick G, Malchau H, Herberts P, et al. Life expectancy and cost utility after total hip replacement. Clin Orthop 1998;346:141-51.

6. Rice DP, Fineman N. Economic implications of increased longevity in the United States. Annu Rev Public Health 2004;25:457-73.

7. Dormont B, Grignon M, Huber H. Health expenditure growth: reassessing the threat of aging. Health Econ 2006; 15:947-63.

8. Prismant. Yeardisk for the hospitals. 2005. Utrecht, The Netherland.

http://cognosserver.prismant.nl/cognos7/cgi-bin/ppdscgi.cgi?DC=Q\&E=/Prisma-LandelijkeLMR/Landelijke+LMR-infromatie+-+Verrichtingen.

9. Kurtz S, Ong K, Lau E, Mowat F, Halpern M. Projections of primary and revision hip and knee arthroplasty in the United States from 2005 to 2030. J Bone Joint Surg Am 2007;89-A:780-5.

10. Birrell F, Johnell $\mathrm{O}$, Silman A. Projecting the need for hip replacement over the next decades: influence of changing demography and treshold for surgery. Ann Rheum Dis 1999;58:569-72.

11. Ostendorf M, Johnell O, Malchau H, Dhert WJA, Schrijvers AJP, Verbout AJ. The epidemiology of total hip replacement in the Netherlands and Sweden: present status and future needs. Acta Orthop Scand 2002;73:282-6.

12. Murray DW, Carr AJ, Bulstrode CJ. Which primary total hip replacement? J Bone Joint Surg Br 1995;77-B:520-7.

13. Herberts $\mathbf{P}$, Malchau $\mathrm{H}$. Long-term registration has improved the quality of hip replacement : a review of the Swedish THR Register comparing 160,000 cases. Acta Orthop Scand 2000;71:111-21. 


\section{Chapter 1}

14. Malchau H, Herberts P, Garellick G, Söderman P, Eisler T. Prognosis of total hip replacement. $69^{\text {th }}$ Annual Meeting of the AAOS 2002, Dallas, Texas, USA.

15. Havelin LI, Engesaeter LB, Espehaug B, Furnes O, Lie SA, Vollset SE. The Norwegian arthroplasty register: 11 years and 73,000 arthroplasties. Acta Orthop Scand 2000;71:337-53.

16. Puolakka TJ, Pajamaki KJ, Halonen PJ, Pulkkinen PO, Paavolainen P, Nevalainen JK. The Finnish Arthroplasty Register: report of the hip register. Acta Orthop Scand 2001;72:433-41.

17. Dansk Hoftealloplastik Register, Arsrapport 2012. www.dhr.dk.

18. Bulstrode CJ, Murray DW, Carr AJ, Pynsent PB, Carter SR. Designer hips. BMJ 1993;306(6880):732-3.

19. Huiskes R. Failed innovation in total hip replacement. Diagnosis and proposals for a cure. Acta Orthop Scand 1993;64:699-716.

20. Walker PS. Innovation in total hip replacement - when is new better? Clin Orthop 2000;381:9-25.

21. Hodge W, Harman M, Fulford B, Dorrance L, Banks S. Early failure of cemented femoral stems in total hip arthroplasty. Transactions of the Combined Meeting of the Orthopaedic Research Societies 2001, Rhodos, Greece.

22. Sylvain GM, Kassab S, Coutts R, Santore R. Early failure of a roughened surface, precoated femoral component in total hip arthroplasty. I Arthroplasty 2001;16:141-8.

23. Massoud SN, Hunter JB, Holdsworth BJ, Wallace WA, Juliusson R. Early femoral loosening in one design of cemented hip replacement. J Bone Joint Surg Br 1997;79-B:603-8.

24. McGrath LR, Shardlow DL, Ingham E, Andrews M, Ivory J, Stone MH, Fisher J. A retrieval study of capital hip prostheses with titanium alloy femoral stems. J Bone Joint Surg Br 2001;83-B:1195-201.

25. Ramamohan N, Grigoris P, Schmolz W, Chapell AM, Hamblen DL. Early failure of stainless steel 3M Capital femoral stem. J Bone Joint Surg Br 2000;82-B (Supp/ 1);71.

26. The Royal College of Surgeons of England. An investigation of the performance of the 3M Capital Hip System. London: The Royal College of Surgeons of England, 2001.

27. Roy N, Hossain S, Ayeko C, et al. Capital Hip arthroplasty: 3-8 year follow-up of 208 primary hip replacement. Acta Orthop Scand 2002;73:400-2.

28. Howie DW, Middleton RG, Costi K. Loosening of matt and polished cemented femoral stems. J Bone Joint Surg Br 1998;80:573-6.

29. Sylvain GM, Kassab S, Coutts R, Santore R. Early failure of a roughened surface, precoated femoral component in total hip arthroplasty. J Arthroplasty 2001;16:141-8. 
30. Havelin LI, Espehaug B, Vollset SE, Engesaeter LB. The effect of the type of cement on early revision of Charnley total hip prostheses. A review of eight thousand five hundred and seventy-nine primary arthroplasties from the Norwegian Arthroplasty Register. J Bone Joint Surg Am 1995;77-A:1543-50.

31. Linder L. Boneloc - The Christiansen experience revisited. Acta Orthop Scand 1995;66:205-6.

32. Cohen D. Revision rates for metal on metal hip joints are double that of other materials. BMJ 2011;343:d5977.

33. Langton DJ, Jameson SS, Joyce TJ, Gandhi JN, Sidaginamale R, Mereddy P, Lord J, Nargol AV. Accelerating failure rate of the ASR total hip replacement. / Bone Joint Surg $\mathrm{Br}$ 2011;93-B:1011-6.

34. Steiger de RN, Hang JR, Miller LN, Graves SE, Davidson DC. Five-year results of the ASR $\mathrm{XL}$ acetabular system and the ASR hip resurfacing system: an analysis from the Australian Orthopaedic Association National Joint Replacement Registry. J Bone Joint Surg Am 2011;93-A:2287-93.

35. Smith AJ, Dieppe P, Vernon K, Porter M, Blom AW. Failure rates of stemmed metal-onmetal hip replacements: analysis of the National Joint Registry of England and Wales. Lancet 2012;379:1199-204.

36. Kilgus DJ, Dorey FJ, Finerman GA, Amstutz HC. Patient activity, sports participation, and impact loading on the durability of cemented total hip replacements. Clin Orthop 1991;269:25-31.

37. Schmalzried TP, Sheperd EF, Dorey FJ, et al. The John Charnley Award. Wear is a function of use, not time. Clin Orthop 2000;381:36-46.

38. Marinoni EC, Trevisan C, Bigoni M, Castellano S, Ortolani S, Peretti G. Metodiche di valutazione strumentale nel follow-up delle protesi totali di ginocchio. In: Monteleone A, ed. International meeting knee prosthesis. SBR, Napoli 1994;195-204.

39. Huiskes R, Chao EY. A survey of finite element analysis in orthopedic biomechanics: the first decade. J Biomech 1983;16:385-409.

40. Huiskes R. Some fundamental aspects of human joint replacement. Analysis of stresses and heat conduction in bone-prosthesis structures. Acta Orthop Scand (Suppl) 1980;185:1-208. 


\section{Chapter 1}

41. Bartel DL. The calculation of stresses in bone-prosthesis structures. In: Walker PS, ed. Human joints and their artificial replacements. Charles C. Thomas, Springfield, II, 1977:440-8

42. Crowninshield RD, Brand RA, Johnston RC, Milroy JC. An analysis of femoral component stem design in total hip arthroplasty. J Bone Joint Surg Am 1980;62-A:68-78.

43. Harrigan TP, Harris WH. A three-dimensional non-linear finite element study of the effect of cement-prosthesis debonding in cemented femoral hip components. J Biomech 1991;24:1047-58.

44. Prendergast PJ, Monaghan J, Taylor D. Materials selection in the artificial hip joint using finite element stress analysis. Clin Mater 1989;4:361-76.

45. Verdonschot N, Huiskes R. Mechanical effects of stem cement interface characteristics in total hip replacement. Clin Orthop 1996;329:326-36.

46. Huiskes R, Boeklagen R. Mathematical shape optimization of hip prosthesis design. J Biomech 1989;22:793-804.

47. Huiskes R, Boeklagen R. The application of numerical shape optimization to artificialjoint design. In: Spilker RL, Simon BR,eds. Computational Methods in Bioengineering. New York, The Mechanical Society of Mechanical Engineers 1988:185-97.

48. Lu Z, Ebramzadeh E, McKellop H, Sarmiento A. Stable partial debonding of the cement interfaces indicated by a finite element model of a total hip prosthesis. J Orthop Res 1996; 14:238-44.

49. Verdonschot $\mathrm{N}$, Huiskes R. The effects of cement-stem debonding in THA on the longterm failure probability of cement. J Biomech 1997;30:795-802.

50. Verdonschot N, Huiskes R. Cement debonding process of total hip arthroplasty stems. Clin Orthop 1997;336:297-307.

51. Lu Z, McKellop H. Effects of cement creep on stem subsidence and stresses in the cement mantle of a total hip replacement. J Biomed Mater Res 1997;34:221-6.

52. Norman TL, Thyagarajan G, Saligrama VC, Gruen TA, Blaha JD. Stem surface roughness alters creep induced subsidence and 'taper-lock' in a cemented femoral hip prosthesis. I Biomech 2001;34:1325-33.

53. Verdonschot N, Huiskes R. Subsidence of THA stems due to acrylic cement creep is extremely sensitive to interface friction. J Biomech 1996;29:1569-75.

54. Stolk J. A computerized pre-clinical test for cemented hip prostheses based on finite element techniques. Thesis, University of Nijmegen, The Netherlands 2002. 
55. Heller MO, Bergmann G, Deuretzbacher G, Dürselen L, et al. Musculo-skeletal loading conditions at the hip during walking and stair climbing. J Biomech 2001;34:883-93.

56. Morlock M, Schneider E, Bluhm A, Vollmer M, Bergmann G, Müller V, Honl M. Duration and frequency of every day activities in total hip patients. J Biomech 2001;34:873-81.

57. Maher SA, Prendergast PJ, Reid AJ, Waide DV, Toni A. Design and validation of a machine for reproducible precision insertion of femoral hip prostheses for preclinical testing. J Biomech Eng 2000;122:203-7.

58. Maher SA, Prendergast PJ. Discriminating the loosening behaviour of cemented hip prostheses using measurements of migration and inducible displacement. J Biomech 2002;35:257-65.

59. Stolk J, Verdonschot N, Cristofolini L, Toni A, Huiskes R. Finite element and experimental models of cemented hip joint reconstructions can produce similar bone and cement strains in pre-clinical tests. J Biomech 2002;35:499-510.

60. Janssen D, Aquarius R, Stolk J, Verdonschot N. Finite-element analysis of failure of the Capital Hip designs. J Bone Joint Surg Br 2005;87-B:1561-7.

61. Harris WH. Traumatic arthritis of the hip after dislocation and acetabular fractures: treatment by mold arthroplasty. An end-result study using a new method of result evaluation. J Bone Joint Surg Am 1969;51-A:737-55.

62. Merle d'Aubigné R, Postel M. Functional results of hip arthroplasty with acrylic prosthesis. J Bone Joint Surg Am 1954;36-A:451-75.

63. Charnley J. The long-term results of low-friction arthroplasty of the hip performed as a primary intervention. J Bone Joint Surg Br 1972;54-B:61-76.

64. Lequesne MG, Mery C, Samson M, Gerard P. Indexes of severity for osteoarthritis of the hip and knee. Validation - value in comparison with other assessment tests. Scand J Rheumatol 1987(Suppl);65:85-9.

65. Drake BG, Callahan CM, Dittus RS, Wright JG. Global rating systems used in assessing knee arthroplasty outcomes. J Arthroplasty 1994;9:409-17.

66. Dawson J, Carr A. Outcomes evaluation in orthopaedics. J Bone Joint Surg Br 2001;83B:313-5.

67. Brokelman RB, van Loon CJ, Rijnberg WJ. Patient versus surgeon satisfaction after total hip arthroplasty. J Bone Joint Surg Br 2003;85-B:495-8. 


\section{Chapter 1}

68. McGee MA, Howie DW, Ryan P, Moss JR, Holubowycz OT. Comparison of patient and doctor responses to a total hip arthroplasty clinical evaluation questionnaire. J Bone Joint Surg Am 2002;84-A:1745-52.

69. Lieberman JR, Dorey F, Shekelle P, Schumacher L, Thomas BJ, Kilgus DJ, Finerman GA. Differences between patients' and physicians' evaluations of outcome after total hip arthroplasty. J Bone Joint Surg Am 1996;78-A:835-8.

70. Soderman P, Malchau H. Is the Harris hip score system useful to study the outcome of total hip replacement? Clin Orthop 2001;384:189-97.

71. Poolman RW, Swiontkowski MF, Fairbank JC, Schemitsch EH, Sprague S, de Vet HC. Outcome instruments: rationale for their use. J Bone Joint Surg Am(Suppl 3) 2009;91:41-9.

72. Faulkner A, Kennedy LG, Baxter K, Donovan J, Wilkinson M, Bevan G. Effectiveness of hip prostheses in primary total hip replacement: a critical review of evidence and an economic model. Health Technol Assess 1998;2:1-133.

73. Ostendorf M. Outcome assessment of total hip arthroplasty in the Netherlands and Sweden. Thesis, University of Utrecht, The Netherlands 2004.

74. Dorey F, Amstutz HC. Survivorship analysis in the evaluation of joint replacement. J Arthroplasty 1986;1:63-9.

75. Wamper KE, Sierevelt IN, Poolman RW, Bhandari M, Haverkamp D. The Harris hip score: Do ceiling effects limit its usefulness in orthopedics? A systematic review. Acta Orthop 2010;81:703-7.

76. Murray DW, Britton AR, Bulstrode CJ. Loss to follow-up matters. J Bone Joint Surg Br 1997;79-B:254-7.

77. Bullens PH, van Loon CJ, de Waal Malefijt MC, Laan RF, Veth RP. Patient satisfaction after total knee arthroplasty: a comparison between subjective and objective outcome assessments. J Arthroplasty 2001;16:740-7.

78. Johanson NA. Outcomes assessment. In: Callaghan J, Rosenberg A, Rubash HE, eds. The Adult Hip, Vol. II. Philadelphia: Lipincott-Raven Publishers, 1988.

79. Dawson J, Fitzpatrick R, Carr A, Murray D. Questionnaire on the perceptions of patients about total hip replacement. J Bone Joint Surg Br 1996;78-B:185-90.

80. Bellamy N, Buchanan WW, Goldsmith $\mathrm{CH}$, Campbell J, Stitt LW. Validation study of WOMAC: a health status instrument for measuring clinically-important patient-relevant outcomes following total hip or knee arthroplasty in osteoarthritis. J Rheumatol 1988; 1:95-108. 
81. Tugwell P, Bombardier C, Buchanan WW, Goldsmith CH, Grace E, Hanna B. The MACTAR Patient Preference Disability Questionnaire—an individualized functional priority approach for assessing improvement in physical disability in clinical trials in rheumatoid arthritis. J Rheumatol 1987; 14:446-51.

82. Nilsdotter AK, Lohmander LS, Klassbo M, Roos EM. Hip disability and osteoarthritis outcome score (HOOS) — validity and responsiveness in total hip replacement. BMC Musculoskelet Disord 2003;4:10.

83. Ostendorf M, van Stel HF, Buskens E, Schrijvers AJ, Marting LN, Verbout AJ, Dhert WJ. Patient-reported outcome in total hip replacement. A comparison of five instruments of health status. J Bone Joint Surg Br 2004;86:801-8.

84. Hoefnagels NH, Dhert WJ, Gosens T, Bulstra SK, de Vet HCW, van Langelaan EJ, Okhuysen-Vonk S, Geesink RGT. De Oxford Heup Score, een Nederlandse patiëntenvragenlijst ter evaluatie van het resultaat van een totale heupprothese gebaseerd op de vertaling van "the 12-item questionnaire on the perceptions about THR". Tijdschrift voor Orthopaedie 2002;9:5-16.

85. Dunbar MJ, Robertsson O, Ryd L, Lidgren L. Appropriate questionnaires for knee arthroplasty. Results of a survey of 3600 patients from The Swedish Knee Arthroplasty Registry. J Bone Joint Surg Br 2001;83:339-44.

86. Roorda LD, Jones CA, Waltz M, Lankhorst GJ, Bouter LM, van der Eijken JW, Willems WJ, Heyligers IC, Voaklander DC, Kelly KD, Suarez-Almazor ME. Satisfactory cross cultural equivalence of the Dutch WOMAC in patients with hip osteoarthritis waiting for arthroplasty. Ann Rheum Dis 2004;63:36-42.

87. Wendel-Vos WGC, Schuit JA, Saris WHM, et al. Reproducibility and relative validity of the short questionnaire to assess health-enhancing physical activity. J Clin Epidemiol 2003;56:1163-9.

88. Wagenmakers R. Physical activity after total hip arthroplasty. Thesis, University of Groningen, The Netherlands 2008.

89. Schmalzried TP, Shepherd EF, Dorey FJ, et al. The John Charnley Award. Wear is a function of use, not time. Clin Orthop 2000;381:36-46.

90. Schmalzried TP, Huk OL. Patient factors and wear in total hip arthroplasty. Clin Orthop 2004;418:94-7.

91. Münger P, Röder C, Ackermann-Liebrich U, et al. Patient-related risk factors leading to aseptic stem loosening in total hip arthroplasty. Acta Orthop Scand 2006;77:567-74. 


\section{Chapter 1}

92. Sallis JF, Saelens BE. Assessment od physical activity by self-report: status, limitations, and future directions. Res Q Exerc Sport 2000;71(2 Suppl):1-14.

93. Ware JE, Jr., Kosinski M, Bayliss MS, McHorney CA, Rogers WH, Raczek A. Comparison of methods for the scoring and statistical analysis of SF-36 health profile and summary measures: summary of results from the Medical Outcomes Study. Med Care 1995;33(4 Suppl):264-79.

94. Hunt SM, McKenna SP, McEwen J, Backett EM, Williams J, Papp E. A quantitative approach to perceived health status: a validation study. J Epidemiol Community Health 1980;34:281-6.

95. de Bruin, AF, de Witte LP, Stevens F, Diederiks JP. Sickness Impact Profile: the state of the art of a generic functional status measure. Soc Sci Med 1992;35:1003-14.

96. Aaronson NK, Muller M, Cohen PD, Essink-Bot ML, Fekkes M, Sanderman R, Sprangers MA, te Velde A, Verrips E. Translation, validation, and norming of the Dutch language version of the SF-36 Health Survey in community and chronic disease populations. J Clin Epidemiol 1988;51:1055-68.

97. Jansson KA, Granath F. Health-related quality of life (EQ-5D) before and after orthopedic surgery. Acta Orthop 2011;82:82-9.

98. Jenkins PJ, Clement ND, Hamilton DF, Gaston P, Patton JT, Howie CD. Predicting the cost-effectiveness of total hip and knee replacement: a health economic analysis. Bone Joint J 2013:95-B:115-21.

99. Tidermark J, Bergström G, Svensson O, Törnkvist H, Ponzer S. Responsiveness of the EuroQol (EQ-5D) and the SF-36 in elderly patients with displaced femoral neck fractures. Qual Life Res 2003;12(8):1069-79

100. Lieberman JR, Dorey F, Shekelle P, Schumacher L, Kilgus DJ, Thomas BJ, , Finerman GA. Outcome after total hip arthroplasty. Comparison of traditional disease-specific and a quality-of-life measurement of outcome. J Arthroplasty 1997;12:639-45.

101. Lingard E, Hashimoto $\mathrm{H}$, Sledge C. Development of outcome research for total joint arthroplasty. J Orthop Sci 200;5:175-7.

102. Ritter MA, Albohm MJ. Overview: maintaining outcomes for total hip arthroplasty. The past, present, and future. Clin Orthop 1997;344:81-7.

103. Sun $\mathrm{Y}$, Sturmer T, Gunther KP, Brenner H. Reliability and validity of clinical outcome measurements of osteoarthritis of the hip and knee-a review of the literature. Clin Rheumatol 1997; 16:185-98. 
104. Greenfield S, Apolone G, McNeil BJ, Cleary PD. The importance of co-existent disease in the occurrence of postoperative complications and one-year recovery in patients undergoing total hip replacement. Comorbidity and outcomes after hip replacement. Med Care 1993;31:141-54.

105. Wolfe F. Determinants of WOMAC function, pain and stiffness scores: evidence for the role of low back pain, symptom counts, fatigue and depression in osteoarthritis, rheumatoid arthritis and fibromyalgia. Rheumatology 1999;38: 355-61.

106. Dawson J, Fitzpatrick R, Murray D, Carr A. The problem of 'noise' in monitoring patientbased outcomes: generic, disease-specific and site-specific instruments for total hip replacement. J Health Serv Res Policy 1996;1:224-31.

107. Ritter MA, Thong AE, Davis KE, Berend ME, Meding JB, Faris PM. Long-term deterioration of joint evaluation scores. J Bone Joint Surg Br 2004;86-B:438-42.

108. Walker PS, Mai SF, Cobb AG, Bentley G, Hua J. Prediction of clinical outcome of THR from migration measurements on standard radiographs. A study of cemented Charnley and Stanmore femoral stems. J Bone Joint Surg Br 1995;77-B:705-14.

109. Freeman MA, Plante-Bordeneuve P. Early migration and late aseptic failure of proximal femoral prostheses. J Bone Joint Surg Br 1994;76-B:432-8.

110. Kärrholm J, Borssen B, Löwenhielm G, Snorrason F. Does early micromotion of the femoral stem prostheses matter? 4-7-year stereoradiographic follow-up of 84 cemented prostheses. J Bone Joint Surg Br 1994;76-B:912-7.

111. Krismer M, Stöckl B, Fisher M, Bauer R, Mayrhofer P, Ogon M. Early migration predicts late aseptic failure of hip sockets. J Bone Joint Surg Br 1996;78-B:422-6.

112. Kattapuram SV, Lodwick GS, Chandler H. Porous coated total hip prostheses: radiographic analysis and clinical correlation. Radiology 1990;174:861-4.

113. Engh CA, Bobyn JD, Glassman AH. Porous-coated hip replacement, the factors governing bone ingrowth, stress shielding, and clinical results. J Bone Joint Surg Br 1987;69-B:4555.

114. Engh CA, Massin P, Suthers KE. Roentgenographic assessment of the biologic fixation of porous-surfaced femoral components. Clin Orthop 1990;257:107-128.

115. Kattapuram SV, Lodwick GS, Chandler H. Porous coated total hip prostheses: radiographic analysis and clinical correlation. Radiology 1990;174:861-4.

116. Rosenberg A. Cementless total hip arthroplasty: femoral remodelling and clinical experience. Orthopaedics 1989;12:1223-33. 


\section{Chapter 1}

117. Carlsson AS, Gentz CF. Radiographic versus clinical loosening of the acetabular component in noninfected total hip arthroplasty. Clin Orthop 1984;185:145-50.

118. Horrowitz SM, Doty SB, Lane JM, Burstein AH. Studies of the mechanism by which the mechanical failure of polymethylmethacrylate leads to bone resorption. J Bone Joint Surg Am 1993;75-A:802-13.

119. Ebramzadeh E, Sarmiento A, McKellop HA, Llinas A, Gogan W. The cement mantle in total hip arthroplasty: analysis of long-term radiographic results. J Bone Joint Surg Am 1994; 76-A:77-87.

120. Callaghan JJ, Salvati EA, Pellici PM, Wilson PD, Ranawat CS. Results of revision for mechanical failure after cemented total hip replacement, 1979 to 1982. J Bone Joint Surg Am 1985;67-A:1079-85.

121. Søballe K, Christensen F. Calcar resorption after total hip arthoplasty. J Arthroplasty 1988;3:103-7.

122. Brand RA, Yoder SA, Pedersen DR. Interobserver variability in interpreting radiographic lucencies about total hip reconstructions. Clin Orthop 1985;192:237-239.

123. West JD, Mayor MB, Collier JP. Potential errors inherent in quantitative densitometric analysis of orthopaedic radiographs. A study after total hip arthroplasties. J Bone Joint Surg Am 1987;69-A:58-64.

124. Finsen V, Anda S. Accuracy of visually estimated bone mineralization in routine radiographs of the lower extremity. Skeletal Radiol 1988;17:270-5.

125. McCaskie AW, Brown AR, Thompson JR, Gregg PJ. Radiological evaluation of the interfaces after cemented total hip replacement. Interobserver and intraobserver agreement. J Bone Joint Surg Br 1996;78-B:191-4.

126. Kirkpatrick JS, Clarke IC, Amstutz HC, Jinnah RH. Radiographic techniques for consistent visualization of total hip arthroplasties. Clin Orthop 1983;174:158-63.

127. Sychterz CJ, Engh CA. The influence of clinical factors on periprosthetic bone remodelling. Clin Orthop 1996;322:285-92.

128. Amstutz HC, Ouzounian T, Grauer D, et al. The grid radiograph : a simple technique for consistent high-resolution visualization of the hip. J Bone Joint Surg Am 1986;68-A:1052-6.

129. DeLee JG, Charnley J. Radiological demarcation of cemented sockets in total hip replacement. Clin Orthop 1976;121:20-32.

130. Gruen TA, McNeice GM, Amstutz HC. "Modes of failure" of cemented stem-type femoral components: a radiographic analysis of loosening. Clin Orthop 1979;141:17-27. 
131. Hardinge K, Porter ML, Jones PR, Hukins DWL, Taylor CJ. Measurement of total hip prostheses using image analysis: the MAXIMA hip technique. J Bone Joint Surg Br $1991 ; 73-B: 724-8$.

132. Jones PR, Hukins DW, Porter ML, et al. Aseptic loosening of the femoral component in cemented total hip replacement. J Biomed Eng 1992;14:379-84.

133. Mulroy RD, Sedlacek RC, O'Connor DO, Estok DM, Harris WH. Technique to detect migration of femoral components of total hip arthroplasties on conventional radiographs. $J$ Arthroplasty 1991; Suppl 6:1-4.

134. Selvik G. Roentgen stereophotogrammetry: a method for the study of the kinematics of the skeletal system. Acta Orthop Scand 1989;Suppl 232:1-51.

135. Mjöberg B, Hansson LI, Selvik G. Instability of total hip prostheses at rotational stress: a roentgenstereophotogrammetric study. Acta Orthop Scand 1984;55:504-6.

136. Mjöberg B, Selvik G, Hansson LI, Rosenqvist R, Önnerfält R. Mechanical loosening of total hip prostheses: a radiographic and roentgen stereophotogrammetric study. J Bone Joint Surg Br 1986;68-B :770-4.

137. Wykman A, Selvik G, Goldie I. Subsidence of the femoral component in the noncemented total hip: a roentgen stereophotogrammetric analysis. Acta Orthop Scand 1988;59:635-7.

138. Wykman A, Lundberg A. Subsidence of porous coated non-cemented femoral components in total hip arthroplasty: a roentgen stereophotogrammetric analysis. J Arthroplasty 1992;197-200.

139. Søballe K, Toksvig-Larsen S, Gelineck J, Fruensgaard S, Hansen ES, Ryd L, Lucht U, Bünger C. Migration of hydroxyapatite coated femoral stems: a roentgen stereophotogrammetric study. J Bone Joint Surg Br 1993;75-B:681-7.

140. Kärrholm I, Malchau H, Snorrason F, Herberts P, Rorabeck CH, Bourne RB, Laupacis A, Feeny D, Wong C, Tugwell P, Leslie K, Bullas R. Micromotion of femoral stems in total hip arthroplasty. J Bone Joint Surg Am 1994;76-A:156-64.

141. Onsten I, Carlsson AS, Sanzen L, Besjakov J. Migration and wear of a hydroxyapatitecoated hip prosthesis. A controlled roentgen stereophotogrammetric study. J Bone Joint Surg $\operatorname{Br} 1996 ; 78-B: 85-91$.

142. Kärrholm J. Roentgen stereophotogrammetry. Review of orthopedic applications. Acta Orthop Scand 1989;60:491-503 


\section{Chapter 1}

143. Kärrholm J, Herberts P, Hultmark P, Malchau H, Nivbrant B, Thanner J. Radiostereometry of hip prostheses. Review of methodology and clinical results. Clin Orthop 1997;344:94-110.

144. Valstar ER. Digital roentgen stereophotogrammetry. Thesis, Leiden University Medical Center, Leiden, The Netherlands, 2001.

145. Ryd L. Roentgen stereophotogrammetric analysis of prosthetic fixation in the hip and knee joint. Clin Orthop 1992;276:56-65.

146. Ryd L, Albrektsson BE, Carlsson L, Dansgard F, Herberts P, Lindstrand A, Regner L, Toksvig-Larsen S. Roentgen stereophotogrammetric analysis as a predictor of mechanical loosening of knee prostheses. J Bone Joint Surg Br 1995;77-B:377-83.

147. Valstar ER, Gill R, Ryd L, Flivik G, Börlin N, Kärrholm J. Guidelines for standardization of radiostereometry (RSA) of implants. Acta Orthop 2005;76:563-72.

148. Nieuwenhuijse MJ, Valstar ER, Kaptein BL, Nelissen RGHH. The Exeter femoral stem continues to migrate during its first decade after implantation. 10-12 years of follow-up with radiostereometric analysis (RSA). Acta Orthop 2012;83:129-34.

149. Nieuwenhuijse MJ, Valstar ER, Kaptein BL, Nelissen RGHH. Good diagnostic perfomance of early migration as a predictor of late aseptic loosening of acetabular cups. Results from ten years of follow-up with roentgen stereophotogrammetric analysis (RSA). J Bone |Joint Surg Am 2012;94-A:874-80.

150. Kobayashi A, Donnelly WJ, Scott G, Freeman MA. Early radiological observations may predict the long-term survival of femoral hip prostheses. J Bone Joint Surg Br 1997;79B:583-9.

151. Stefánsdóttir A, Franzén H, Johnsson R, Ornstein E, Sundberg M. Movement pattern of the Exeter femoral stem; a radiostereometric analysis of 22 primary hip arthroplasties followed for 5 years. Acta Orthop Scand 2004;75:408-14.

152. Kadar T, Hallan G, Aamodt A, Indrekvam K, Badawy M, Havelin LI, Stokke T, Haugan K, Espehaug B, Furnes O. A randomized study on migration of the Spectron EF and the Charnley flanged 40 cemented femoral components using radiostereometric analysis at 2 years. Acta Orthop 2011;82:538-44.

153. Thien TM, Kärrholm J. Design-related risk factors for revision of primary cemented stems. Acta Orthop 2010;81:407-12.

154. Espehaug B, Furnes O, Engesaeter LB, Havelin LI. 18 years of results with cemented primary hip prostheses in the Norwegian Arthroplasty Register. Acta Orthop 2009;80:402-12. 
155. Hook S, Moulder E, Yates PJ, Burston BJ, Whitley E, Bannister GC. The Exeter Universal stem: a minimum ten-year review from an independent centre. J Bone Joint Surg Br 2006;88-B:1584-90.

156. Carrington NC, Sierra RJ, Gie GA, Hebble MJ, Timperley AJ, Howell JR. The Exeter Universal cemented femoral component at 15 to 17 years: an update on the first 325 hips. J Bone Joint Surg Br 2009;91-B:730-7.

157. Havelin LI, Fenstad AM, Salomonsson R, Mehnert F, Furnes O, Overgaard S, Pedersen AB, Herberts P, Kärrholm J, Garellick G. The Nordic Arthroplasty Register Association: a unique collaboration between 3 national hip arthroplasty registries with 280,201 THRs. Acta Orthop 2009;80:393-401.

158. Malchau H. On the importance of stepwise introduction of new hip implant technology. Assessment of total hip replacement using clinical evaluation, radiostereometry, digitised radiography and a national hip registry. Thesis. Göteborg University, Göteborg, Sweden, 1995.

159. Malchau H. Introducing new technology: a stepwise algorithm. Spine 2000;25:285.

160. McCulloch P, Altman DG, Campbell WB, Flum DR, Glasziou P, Marshall JC, et al. No surgical innovation without evaluation: the IDEAL recommendations. Lancet 2009:374:1105-12.

161. Schemitsch EH, Bhandari M, Boden SD, Bourne RB, Bozic KJ, Jacobs JJ, et al. The evidence-based approach in bringing new orthopaedic devices to market. J Bone Joint Surg Am 2010;92-A:1030-7.

162. Swierstra BA, Vervest AM, Walenkamp GH, Schreurs BW, Spierings PT, Heyligers IC, van Susante JL. Ettema HB, Jansen MJ, Hennis PJ, de Vries J, Muller-Ploeger SB, Pols MA. Dutch guideline on total hip prosthesis. Acta Orthop 2011;82:567-76.

163. Vrooman HA, Valstar ER, Brand GJ, Admiraal DR, Rozing PM, Reiber JHC. Fast and accurate automated measurements in digitized stereophotogrammetric radiographs. J Biomech 1998;31:491-8.

164. Valstar ER, Spoor CW, Nelissen RGHH, Rozing PM. Roentgen stereophotogrammetric analysis of metal-backed hemispherical cups without attached markers. J Orthop Res 1997; 15:869-73.

165. Kaptein BL, Valstar ER, Stoel BC, Rozing PM, Reiber JH. A new model-based RSA method validated using CAD models and models from reversed engineering. J Biomech $2003 ; 36: 873-82$. 


\section{Chapter 1}

166. Oyen WJ, Claessens H, van Horn JR, Wassenaar WG, Lemmens LAM, Corstens FHM. Nuclear arthrography: a scintigraphic contribution to the evaluation of loosening of total hip prostheses. I Nucl Med 1990;31:712.

167. Resnik CS, Fratkin MJ, Cardea JA. Arthroscintigraphic evaluation of the painful total hip prosthesis. Clin Nucl Med 1986;11:242-4.

168. Horoszowski H, Ganel A, Kamhin M, Zaltzman S, Farine I. Sequential use of technetium 99m MDP and Gallium 67 citrate imaging in the evaluation of painful total hip replacement. Br J Radiol 1980;53:1169-73.

169. Ovesen $O$, Riegels-Nielsen $P$, Lindequist $S$, Jensen I, Munkner T, Torfing T, Marving J. The dignostic value of digital subtraction arthrography and radionuclide bone scan in revision hip arthroplasty. J Arthroplasty 2003;18:735-40.

170. Williamson BR, McLaughlin RE, Wang GW, Miller CW, Teates CD, Bray ST. Radionuclide bone imaging as a means of differentiating loosening and infection in patients with a painful total hip prosthesis. Radiology 1979;133:723-5.

171. Temmerman OPP. A comparison of radiographic and scintigraphic techniques to assess aseptic loosening of a total hip prosthesis. Thesis, Free University of Amsterdam, The Netherlands, 2007.

172. Temmerman OPP, Raijmakers PGHM, Berkhof J, Hoekstra OS, Teule GJJ, Heyligers IC. Accuracy of diagnostic imaging techniques in the diagnosis of aseptic loosening of the femoral component of a hip prosthesis: a meta-analysis. J Bone Joint Surg Br 2005;87B:781-5.

173. Kantor SG, Schneider R, Insall JN, Becker MW. Radionuclide imaging of asymptomatic versus symptomatic total knee arthroplasties. Clin Orthop 1990;260:118-23.

174. Lammertsma AA, Frackowiak RS. Positron emission tomography. Crit Rev Biomed Eng 1985;13:125-69.

175. Sorensen J, Ullmark G, Langstrom B, Nilsson O. Rapid bone and blood flow formation in impacted morselized allografts: positron emission tomography (PET) studies on allografts in 5 femoral component revisions of total hip artrhoplasty. Acta Orthop Scand 2003; 74:633-43.

176. Piert M, Winter E, Becker GA, Bilger K, Machulla H, Muller-Schauenburg W, Bares R, Becker HD. Allogenic bone graft viability after hip revision arthroplasty assessed by dynamic 18F Fluoride ion positron emission tomography. Eur I Nucl Med 1999;26:615-24. 
177. Ashcroft GP, Evans NT, Roeda D, Dodd M, Mallard JR, Porter RW, Smith FW.

Measurement of blood flow in tibial fracture patients using positron emission tomography. J Bone Joint SurgBr 1992;74-B:673-7.

178. Piert M, Zittel TT, Becker GA, Jahn M, Stahlschmidt A, Maier G, Machulla HJ, Bares R. Assessment of porcine bone metabolism by dynamic 18F Fluoride ion PET: correlation with bone histomorphometry. J Nucl Med 2001;42:1091-100.

179. Bonnick SL, ed. Bone densitometry in clinical practice. Application and interpretation. sec. ed. Human Press Inc., Totowa, New Jersey, 2004.

180. Kalendar WA. Effective dose values in bone mineral measurements by photoabsorptiometry an computed tomography. Osteoporosis Int 1992;2:82-7.

181. Lees B, Stevenson JC. An evaluation of dual-energy X-ray absorptiometry and comparison with dual photon absorptiometry. Osteoporosis Int. 1992;2:146-52.

182. McCarthy CK, Steinberg GG, Agren M, Leahey D, Wyman E, Baran DT. Quantifying bone loss from the proximal femur after total hip arthroplasty. J Bone Joint Surg Br 1991;73B:774-8.

183. Kiratli BJ, Heiner JP, McBeath AA, Wilson MA. Determination of bone minerasl density by dual X-rat absorptiometry in patients with uncemented total hip arthroplasty. J Orthop Res 1992; 10:836-44.

184. Kilgus DJ, Shimaoka EE, Tipton JS, Eberle RB. Dual-energy X-ray absorptiometry measurement of bone mineral density around porous-coated cementless femoral implants. J Bone Joint Surg Br 1993;75-B:279-87.

185. Trevisan C, Bigoni M, Cherubini R, Steiger P, Randelli G, Ortolani S. Dual X-ray absorptiometry for the evaluation of bone density from the proximal femur after total hip arthroplasty: analysis protocols and reproducibility. Calcif Tissue Int 1993;53:158-61.

186. Cohen B, Rushton N. Accuracy of DEXA measurement of bone mineral density after total hip arthroplasty. J Bone Joint Surg Br 1995;77-B:479-83.

187. McGovern TF, Engh CA, Zettl-Schaffer K, Hooten JP. Cortical bone density of the proximal femur following total hip arthroplasty. Clin Orthop 1995;306:145-54.

188. Cummings SR, Black DB. Should perimenopausal women be screened for osteoporosis? Ann Intern Med 1986;104:817-23.

189. Wahner HW, Fogelman I. The evaluation of osteoporosis: dual energy X-ray absorptiometry in clinical practice. Dunitz, London 1994 


\section{Chapter 1}

190. Mazess RB, Collick B, Trempe J, Barden H, Hanson J. Performance evaluation of a dual energy X-ray bone densitometer. Calcif Tissue Int 1989;44:228-32.

191. Kelly T, Slovick D, Schoenfield D, Neer R. Quantitative digital radiography versus dual photon absorptiometry of the lumbar spine. J Clin Endocr Metab 1988;67:839-44.

192. Orwoll ES, Oviatt SK, Biddle JA. Precision of dual-energy X-ray absorptiometry: development of quality control rules and their application in longitudinal studies. I Bone Miner Res 1993;8:693-9.

193. Orwoll ES, Oviatt SK, and the Nafarelin Bone Study Group. Longitudinal precision of dual-energy X-ray absorptiometry in a multicenter trial. J Bone Miner Res 1991;6:191-7.

194. Westgard JO, Barry PL, Hunt MR, Groth T. A multirule Shewart Chart for quality control in clinical chemistry. Clin Chem 1981;27:493-501.

195. Lu Y, Mathur AK, Blunt BA, et al. Dual X-ray absorptiometry quality control: comparison of visual examination and process-control charts. J Bone Miner Res 1998;11:626-37.

196. Pearson D, Cawte SA. Long-term quality control of DXA: a comparison of Shewart rules and CUSUM charts. Osteoporos Int 1997;7:338-43.

197. Garland SW, Lees B, Stevenson JC. DXA longitudinal quality control: a comparison of inbuilt quality assurance, visual inspection: multi-rule Shewart charts and Cusum analysis. Osteoporos Int 1997; 7:231-7.

198. Goh JCH, Low SL, Bose K. Effect of femoral rotation on bone mineral density measurements with dual energy X-ray absorptiometry. Calcif Tissue Int 1995;57:340-3.

199. Mortimer ES, Rosenthall L, Paterson I, Bobyn JD. Effect of rotation on periprosthetic bone mineral measurements in a hip phantom. Clin Orthop 1996;324:269-74.

200. Menke W, Petermann V, Schmitz B, Schneider T. Die Knochendichtemessung am proximalen Femur in Abhängigkeit von der Torsion des Schenkelhalses. Z Orthop 1996;134:201-4.

201. Hans D, Duboeuf F, Schott AM, Horn S, Avioli LV, Drezner MK, Meunier PJ. Efects of a new positioner on the precision of hip bone mineral density measurements. J Bone Miner Res 1997;12:1289-94.

202. Nguyen TV, Sambrook PN, Eisman JA. Sources of variability in bone mineral density measurements: implications for study design and analysis of bone loss. J Bone Miner Res 1997;12:124-35.

203. Simank H-G,Brocai DRC, Reiser D, Thomsen M, Sabo D, Lukoschek M. Ten-year results of threaded acetabular cups. J Bone Joint SurgBr 1997;79-B:366-70. 
204. Sabo D, Reiter A, Simank H-G, Thomsen M, Lukoschek M, Ewerbeck V. Periprosthetic mineralization around cementless total hip endoprosthesis: Longitudinal study and crosssectional study on titanium threaded acetabular cup and cementless Spotorno stem with DEXA. Calcif Tissues Int 1998;62:177-82.

205. Spotorno L, Romagnoli S, Ivaldo N, Grappiolo G, Bibbiani E, Blaha DJ, Gruen TA. The CLS stem: theoretical concept and results. Acta Orthop Belg 1993;59:144-8.

206. Bläsius K, Cotta H, Schneider U, Thomsen M. CLS-Multicenter-Studie-8-jährige Erfahrungen. Z Orthop 1993;131:547-52.

207. Robinson RP, Lovell TP, Green TM. Hip arthroplasty using the cementless CLS stem. A 2-4 year experience. J Arthroplasty 1994;9:177-92.

208. Oh I, Harris WH. Proximal strain distribution in the loaded femur: an in vitro comparison of the distributions in the intact femur and after insertion of different hip replacement femoral components. J Bone Joint Surg Am 1978;60-A:75-83.

209. Engh CA, Bobyn JD. The influence of stem size and extent of porous coating on femoral bone resorption after primary cementless hip arthroplasty. Clin Orthop 1988;231:7-28.

210. Huiskes R. The various stress patterns of press-fit, ingrown, and cemented femoral stems. Clin Orthop 1990;261:27-38

211. Huiskes $\mathrm{R}$, Weinans $\mathrm{H}$, van Rietbergen B. The relationship between stress shielding and bone resorption around total hip stems and the effects of flexible materials. Clin Orthop 1992;274:124-34.

212. Bobyn JD, Mortimer ES, Glassman AH, Engh CA, Miller JE, Brooks CE. Producing and avoiding stress shielding: laboratory and clinical observations of noncemented total hip arthroplasty. Clin Orthop 1992;274:79-96. 


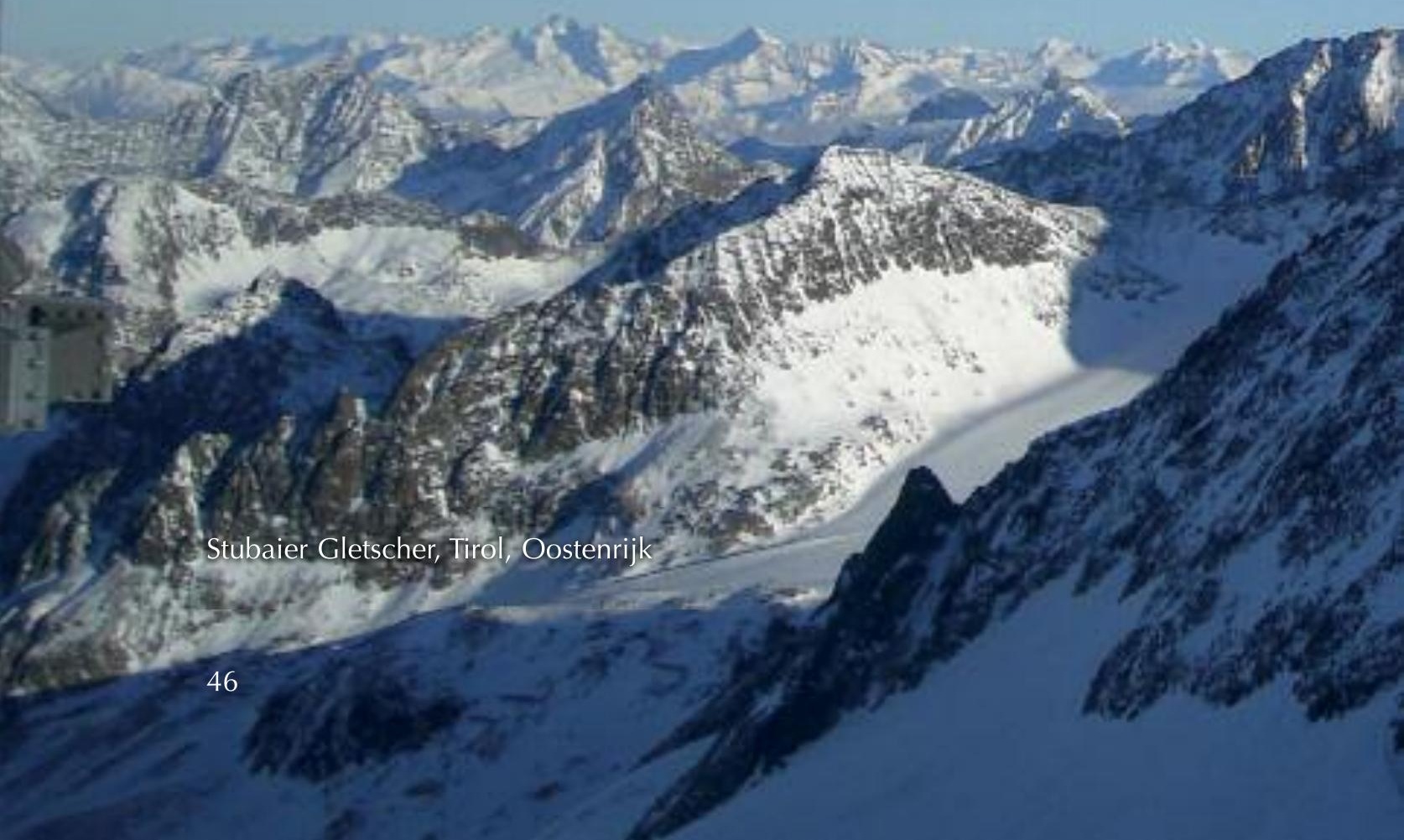




\section{CHAPTER 2}

\section{Randomized Comparison between the cemented Scientific Hip Prosthesis ${ }^{\circledR}$ and Omnifit ${ }^{\circledR}$ : 2-year DEXA and minimum 10-year Clinical follow-up}

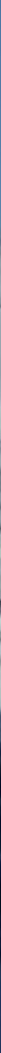




\begin{abstract}
Radiostereometry (RSA) of the cemented Scientific Hip Prosthesis $\left(\mathrm{SHP}^{\circledR}\right)$ reported excessive migration and predicted high failure rates. In a prospective randomized clinical trial we compared minimum 10 years results of the $\mathrm{SHP}^{\circledR}$ $(n=38)$ with the Omnifit ${ }^{\circledR}$-stem $(n=37)$. Two-year bone remodelling, compared with dual energy $x$-ray absorptiometry and assessed in regions of interest A-D based on the 7 Gruen zones, showed better periprosthetic bone preservation around the $\mathrm{SHP}^{\circledR}$ in all but one regions $(P<0.05)$. At 10 years Harris Hip Score was better for the $\operatorname{SHP}^{\circledR}(P=0.0001)$ but Oxford Hip Score was the same $(P=0.79)$. There were no revisions in either group, but radiographic loosening was definite in $1 \mathrm{SHP}^{\circledR}$ and $1 \mathrm{Omnifit}^{\circledR}$. Based on earlier RSA studies, the rough surface finish of the $\mathrm{SHP}^{\circledR}$ was expected to cause cement abrasion, osteolysis and inferior survival. However our clinical and remodelling results could not confirm these expectations, suggesting that the link of early migration and mid-term clinical results is not sufficiently clear for the $\mathrm{SHP}^{\circledR}$.
\end{abstract}




\section{INTRODUCTION}

Most improvements in cemented hip arthroplasty seem to be the result of adaptations in surgical, and particularly cementing technique. However the effects of changes in implant design, choice of materials, fixation principles, surface coating and surface finish, although theoretically well motivated, appeared to be less predictable.

As a product of the 'shape-closed' fixation philosophy', the Scientific Hip Prosthesis $^{\circledR}$ (SHP, Biomet, Bridgend, UK) was designed, and expected to remain bonded to the cement ${ }^{2,3}$. Numerical shape optimisation (NSO) algorithms were used to calculate the typical SHP ${ }^{\circledR}$ geometry, meant to minimize proximal and distal stress peaks in the cement mantle and at the interfaces (Fig. 1 and 2) 1,4,5. Peters et al. confirmed with cement strain analysis that a similar reduction in cement and interface stresses could be realized in vitro for the second version of the $\mathrm{SHP}^{\circledR}$ as well, compared to the conventional straight Centralign ${ }^{\circledR}$ stem $^{6}$. This version was also used in our study.
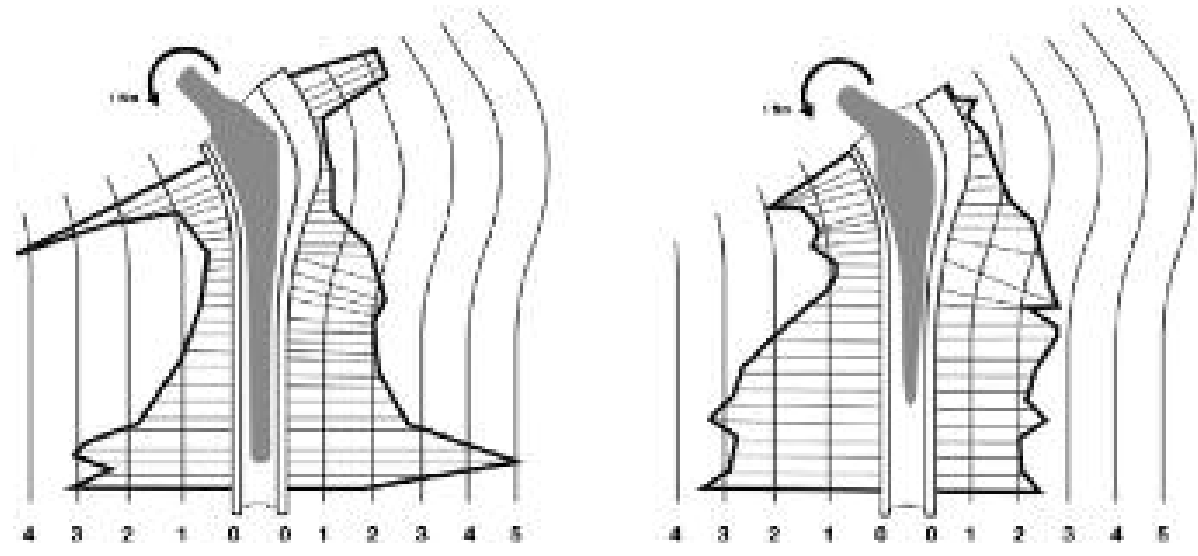

Fig. 1 Simulated strain energy density (SED) profile in cement mantle around the straight Omnifit (left) and the anatomically shaped SHP (right). The optimal stem shape reduces the high proximal and distal stress peaks in both the cement and at the interfaces. Numbers represent SED distribution $\left(\times 10^{-13} \mathrm{~N} \mathrm{~mm}^{-2}\right.$ ) (Adapted from Huiskes et al. ${ }^{8}$ ). Profiles have been validated in vitro ${ }^{10,19}$. 


\section{Chapter 2}

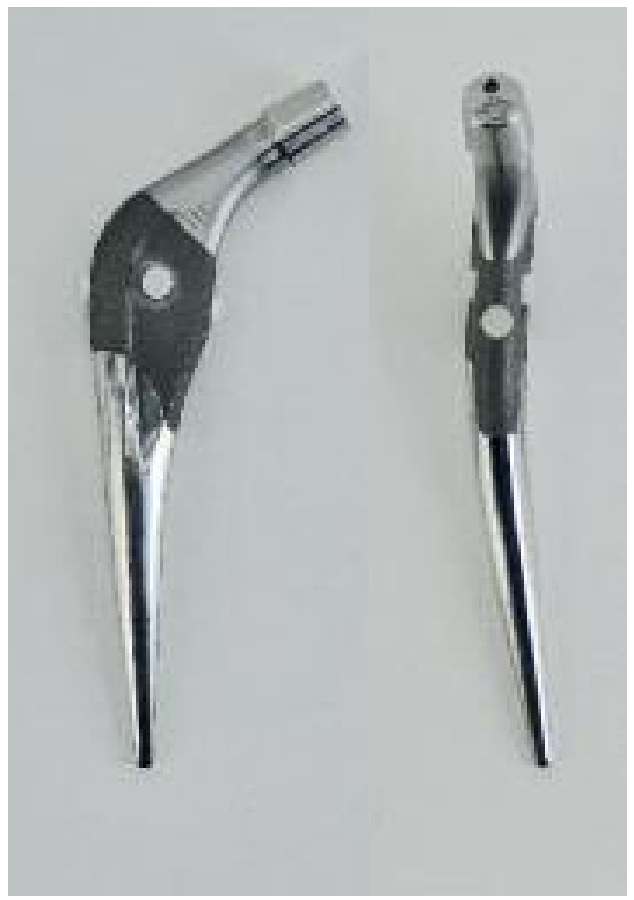

Fig. $2 A P$ and Lat view of the collarless anatomically shaped SHP stem with PMMA cement spacers (distal spacer not shown). Proximally a rigid part with rough surface finish $(R a=3.8 \mu \mathrm{m})$, distally a flexible taper with polished surface (Rab0.05 $\mu \mathrm{m}$ ). Reinforcement profile at the lateral side of the stem to resist bending forces and to reduce subsidence risk.
Although from these FE-studies it could be expected that micromotions would be minimal, already soon after its introduction RSA studies reported pronounced subsidence and rotational instability of the $\mathrm{SHP}^{\circledR}$-stem within the cement mantle ${ }^{7,8}$. This would imply debonding with a substantial risk of abrasive wear, higher stresses in the cement mantle, and increased chance of gross loosening and osteolysis. Because experience with other matt cemented stems had been associated with inferior clinical results and survival ${ }^{9-11}$, Nivbrant predicted bad survival and advised not to use the implant until their concerns would be contradicted by successful long-term results ${ }^{7}$. As migration and abrasive wear are early phenomena, one would expect early loss of periprosthetic bone in line with the 'acculumulated damage' $^{\prime}$ failure scenario ${ }^{12}$. On top of this, according to FE-predictions, reduced proximal cement stresses around the $\mathrm{SHP}^{\circledR}$ would further result in lower stress transfer to the bone with lower BMD through increased stress shielding.

In 1997 we started a prospective randomised clinical trial (RCT) comparing a slightly adapted version of the SHP ${ }^{\circledR}$ with the in our clinic currently used cemented Omnifit ${ }^{\circledR}$ prosthesis (Stryker-Osteonics ${ }^{\circledR}$, Mahwah, NJ, USA), that reported well documented, good long-term results ${ }^{13}$. Because the geometry and proximal surface finish of the initial and adapted (second) version of the $\mathrm{SHP}^{\circledR}$ are identical, and the cement strain profiles of both versions were also proven to be similar ${ }^{4,6}$, the same 
pattern of debonding and migration may be expected for this later version ${ }^{7,14}$. While comparing the $\mathrm{SHP}^{\circledR}$ with conventional straight stems, a different stress distribution had been predicted (with FE modelling) and confirmed (with photoelastic and strain gauge techniques) ${ }^{4,6,15}$. In our study the effect of this stress profile on bone remodelling was investigated, now comparing the $\mathrm{SHP}^{\circledR}$ with the straight Omnifit ${ }^{\circledR}$. Furthermore it was analyzed if the predicted inferior outcome of the SHP ${ }^{\circledR}$, based on early RSA migration results, could be validated in this clinical study. It was hypothesized that periprosthetic bone loss around the SHP ${ }^{\circledR}$ and survival of the design would be worse compared to the Omnifit ${ }^{\circledR}$. This is the first mid-to long-term RCT to report on the results of the SHP ${ }^{\circledR}$ prosthesis.

\section{Patients and Methods}

\section{Trial design and Patient selection}

In this prospective RCT 75 total hip arthroplasties (THA) in 72 patients were included. The study was approved by the local Institutional Review Board and conducted by the department of orthopaedic surgery, of the Maastricht University Medical Centre. It was carried out in line with the Helsinki declaration. Prior to enrolment of the patients informed consent was signed. Patients were allocated at random to one of either group in a 1:1 randomization ratio, receiving a Scientific Hip Prosthesis ${ }^{\circledR}$ (SHP, Biomet, Bridgend, UK) or an Omnifit ${ }^{\circledR}$ prosthesis (StrykerOsteonics $^{\circledR}$, Mahwah, NJ, USA). The allocation sequence was generated by an independent trial bureau and concealed from the operating surgeon. Participants were enrolled from sequentially numbered, identical, opaque, sealed envelopes just before the operation. The surgeon was unaware of the content and sequence of the envelopes (allocation concealment).

\section{Eligibility for inclusion}

Eligibility criteria were a diagnosis of osteoarthritis, post-traumatic arthritis or avascular necrosis, 60 - 75 years of age, and physically and mentally willing and able to comply with postoperative scheduled evaluations. Patients with a BMI $>40$ $\mathrm{kg} / \mathrm{m}^{2}$, previous surgery or an active infection to the affected hip joint, and a 


\section{Chapter 2}

disease or drug use affecting bone metabolism before or during the study, were excluded.

Between 1997 and 2002 all patients were operated; 3 of them received bilateral THA (1 with $2 \mathrm{SHP}^{\circledR} \mathrm{S}$, 1 with 2 Omnifits, 1 with a $\mathrm{SHP}^{\circledR}$ and an Omnfit) which were both included in the study protocol. Patient characteristics and baseline demographic data are presented in Table 1. There was no significant difference between the 2 study groups in terms of gender distribution, age, BMI, diagnosis and preoperative HHS (see Table 1).

\begin{tabular}{|c|c|c|}
\hline Range. & & \\
\hline & SHP $(N=38)$ & Omnifit (N=37) \\
\hline Male & 10 & 11 \\
\hline Female & 28 & 26 \\
\hline Age in years (range) & $68.7(60-76)$ & $68.9(61-76)$ \\
\hline $\mathrm{BMI}$ in $\mathrm{kg} / \mathrm{m}^{2}$ (range) & $26.9(20.1-37.5)$ & $27.7(20.1-35.0)$ \\
\hline \multicolumn{3}{|l|}{ Diagnosis } \\
\hline Primary $\mathrm{OA}$ & 38 & 37 \\
\hline
\end{tabular}

\section{Implants}

The $\mathrm{SHP}^{\circledR}$ is made of CoCrMo alloy and is collarless. It has a thin tapered distal tip and a thick tapered proximal stem. It has an anatomic geometry with a double curvature of the proximal stem, consisting of a femoral neck anteversion and a posterior bow more distally. The stem has a roughened proximal surface (radius Ra $=3.8 \mu \mathrm{m})$ and is polished distally $(\mathrm{Ra}<0.05 \mu \mathrm{m}) .4$ proximal polymethyl methacrylate (PMMA) spacers and a distal centralizer help to ensure an even cement mantle, of minimum thickness $2 \mathrm{~mm}$ (Fig. 2).

The Omnifit ${ }^{\circledR}$ has a small collar, and is a normalized (macroscopic surface structures to convert shear forces on the cement into normal forces), forged cobaltchromium stem with a satin finish (roughness of $0.9 \mu \mathrm{m}$ ) over the entire surface (Fig. 3). 


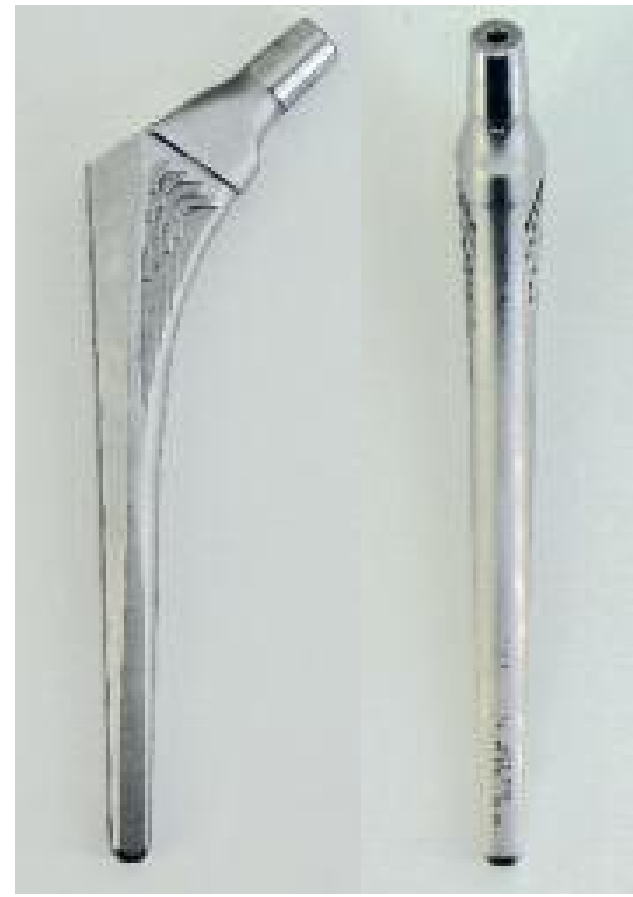

Fig. $3 \quad A P$ and Lat view of the normalized Omnifit stem, showing a straight geometry without cement spacers and with a uniform surface texture $(R a=0.9$ $\mu m)$.

The SHP ${ }^{\circledR}$ acetabular cemented cup of $\mathrm{ArCom}^{\circledR}$ UHMWPE (Argon gas packaged, direct compression moulded polyethylene, Biomet, Bridgend, UK) was used in all cases. All head components were $28 \mathrm{~mm}$ in diameter.

\section{Surgical protocol and postoperative management}

One of the authors (RtB) performed all the operations. Both hip systems were implanted according to standard orthopaedic procedures using a posterolateral approach. A third generation cementing technique was applied, using Gentamicin containing cement (Palacos R + G, Heraeus, Wehrheim, Germany) pressurized in both the acetabulum and the femur. Patients were allowed to full weight bearing from day 1 . There was no difference in physical activity postoperatively between the 2 groups as assessed with the HHS.

\section{Evaluation of bone remodelling}

Our primary outcome measure was the effect on bone remodelling of the proximal roughening and distal polishing of the $\mathrm{SHP}^{\circledR}$-stem. Therefore the Regions of Interest (ROI) are divided into 4 zones: A, B, C and D, based on the 7 Gruen zones ${ }^{16}$. ROI A represents Gruen zone 1, ROI B corresponds with Gruen zones 2 and 3 together, C with Gruen zone 7, and D with Gruen zone 5 and 6. Thus ROI A and C cover the proximal roughened part of the $\mathrm{SHP}^{\circledR}$ stem, and $\mathrm{B}$ and $\mathrm{D}$ the distal polished part. This delineation was copied exactly to the Omnifit ${ }^{\circledR}$ stem in order to generate 


\section{Chapter 2}

comparable ROls for assessment of periprosthetic bone remodelling in stems with differences in design, length and surface finish (Fig. 4).

DEXA-analysis was performed with the LUNAR DPX-L scanner (version 1.2, Lunar Corp, Wisconsin, USA) and expressed as BMD in $\mathrm{g} / \mathrm{cm}^{2}$ in the 4 ROls. The data were analyzed with special orthopaedic software provided by the manufacturer, which automatically excludes soft tissues, metal and cement (using offset and perimeter functions). Patients were placed supine on the scan table. The legs were secured in similar rotation using special stabilizing devices for the knee and foot.
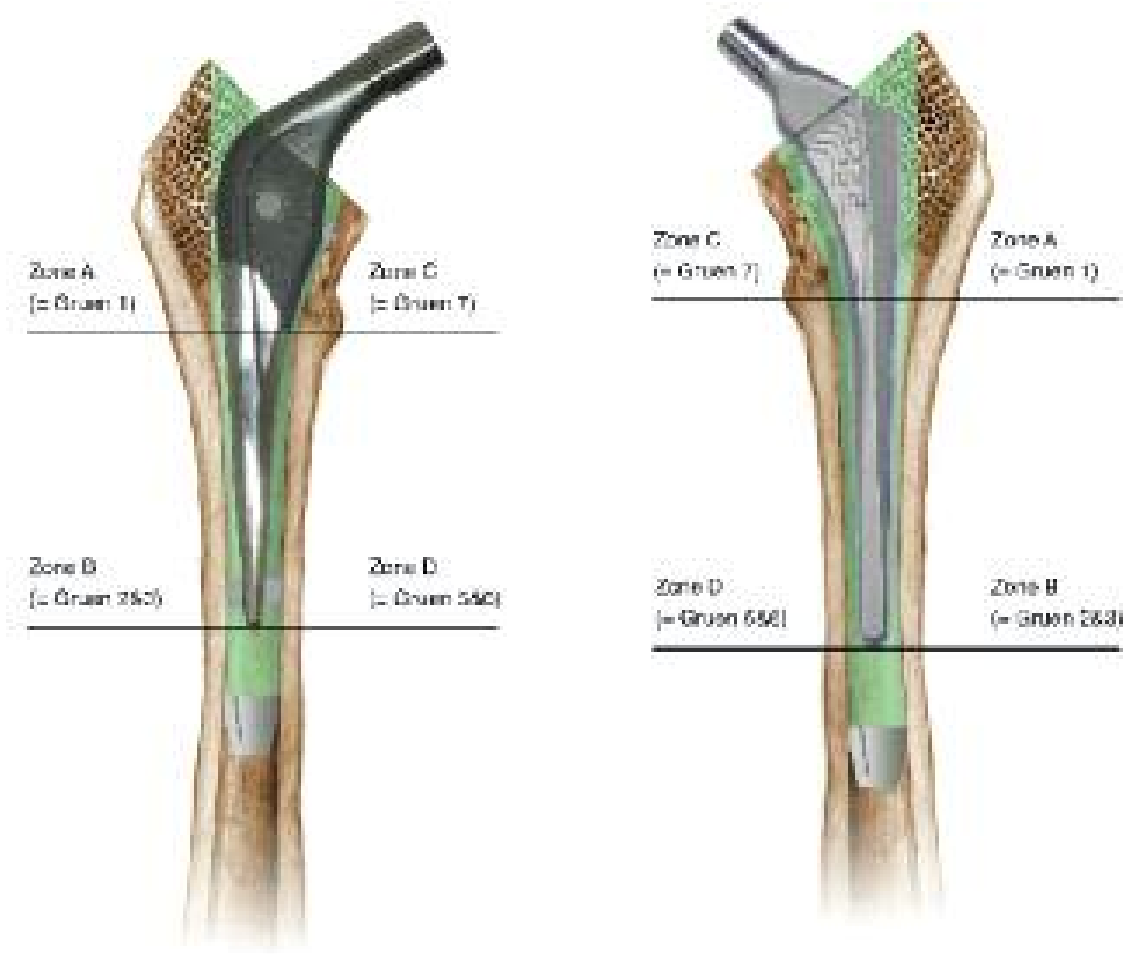

Fig. 4 Delineation of ROIs around the SHP and Omnifit based on the seven Gruen zones ${ }^{16}$. Zone $A$ and $C$ are corresponding with the roughened part of the SHP stem. This delineation is exactly transferred to the Omnifit stem in order to generate comparable ROIs for assessment of periprosthetic bone remodelling (further see text). 
To detect abnormal systemic bone metabolism during study follow-up, DEXA scanning was also determined of the lumbar spine, both preoperatively and postoperatively (at 1 and 2 years follow-up). The preoperative lumbar scan served as a baseline measurement for comparison to referenced normals.

DEXA scans were made at 7 days post-operatively (base-line reference), and at 6 weeks, 3 months, 6 months, 12 months and 2 years post-operatively. During the entire follow-up all DEXA-scans were performed by 1 technician, not part of the research team, and analysed by 1 member of the research staff blinded for the radiographic and clinical results.

\section{Radiographic evaluation}

An $\mathrm{A} / \mathrm{P}$ pelvis and lateral radiograph of the involved hip was taken, following a standard protocol. Data points collected for the femoral side included: fracture of the cement mantle, radiolucency at the cement-bone and the cement-prosthesis interface (evaluated according to the Gruen zones), stem subsidence ${ }^{17}$, calcar resorption, cementing quality (according to the method described by Barrack et al. $)^{18}$, heterotopic ossification and focal endosteal osteolysis. Migration of the femoral implant was considered confirmed if there was a change of $5 \mathrm{~mm}$ or more in the vertical distance measured between the most medial point of the lesser trochanter and the centre of rotation ${ }^{17}$. Radiographic loosening was determined according to the criteria described by Harris ${ }^{19}$. Resorption and hypertrophy were judged at 10-year follow-up and were considered positive if 2 observers agreed on the presence of these periprosthetic bone changes in any region of interest compared to immediate postoperative $\mathrm{x}$-rays ${ }^{20}$. Polyethylene wear was determined from the largest cranial or medial femoral head eccentricity in the socket according to the modified Livermore technique of Rokkum and Reigstad ${ }^{21}$, and annual linear wear rate was calculated between the first and latest post-operative X-ray.

Radiographs were made pre-operatively, within the first week postoperatively, at 6 weeks, 3 months, 6 months, and 12 months post-operatively, and from then on yearly. 


\section{Chapter 2}

\section{Clinical Evaluation}

Clinical results were registered according to the AAOS-guidelines ${ }^{22}$, and evaluated by use of the Harris Hip Score $(\mathrm{HHS})^{23}$. Patient satisfaction was scored by the Oxford Hip Score $(\mathrm{OHS})^{24}$, of which a validated Dutch translation was used ${ }^{25}$, and by the Dutch validation of the Rand-36 score ${ }^{26}$.

\section{Statistical analysis}

Longitudinal BMD results per $\mathrm{ROI}$ are expressed as relative values with the immediate postoperative DEXA measurement of the operated femur being the reference value, set at $100 \%$. Absolute and relative BMD values are described by mean and standard deviation, demographic parameters by mean and range. Differences within the group are tested with the paired Student's $t$ - and between groups with the unpaired Student's $t$-test. Differences with $p$-values lower than 0.05 are described as significant. To take into account the correlation of the observations within 1 patient, a multilevel linear regression model was used with BMD loss as dependent variable and time interval, type of prosthesis and the interaction between time interval and prosthesis as covariates. This interaction term was used to test the difference in slope between the SHP ${ }^{\circledR}$ and the Omnifit ${ }^{\circledR}$. To prevent multiplicity issues, and to reduce the number of calculations, the outcome variables (BMD-results at 2 year follow-up, and survival of the stem with revision for aseptic loosening as the endpoint at minimum 10 year follow-up) have been predefined as primary and secondary, and the sample size (and thus the power) to reject each null hypotheses at the same significance level (0.05) was determined. Evaluations were already planned at pre-specified visits at the start of the study, and no interim analysis was planned nor executed.

The statistically required sample size is based on a power-analysis performed on the minimally to detect mean difference of BMD-results between stem designs $(\delta)$, which were only known from uncemented stems at the time this study was initiated. Based on these studies we assumed this difference to be $25 \%$. By convention, an $\alpha$-error rate of 0.05 was adopted, and the $\beta$-error was set at 0.20 (power $1-\beta=80 \%$ ). We were planning a study of a continuous response variable from independent control and experimental subjects with 1 control(s) per 
experimental subject. In a previous study the response within each subject group was normally distributed with standard deviation $30 \%$. If the true difference in the experimental and control means was $20 \%$, we would need to study 36 subjects in the $\mathrm{SHP}^{\circledR}$ arm and 36 subjects in the Omnifit ${ }^{\circledR}$ arm to be able to reject the null hypothesis that the population means of these groups were equal with probability (power) 0.8 .

\section{RESULTS}

At 10-13 years follow-up 5 patients ( $3 \mathrm{SHP}^{\circledR}$ and 2 Omnifit $^{\circledR}$, all unilateral cases) had died. 11 patients were lost to follow-up $\left(7 \mathrm{SHP}^{\circledR}\right.$ and 4 Omnifit $^{\circledR}$, all unilateral cases); 4 of them became mentally too disabled to join the rest of the study, 3 were lost due to serious physical illness, 3 patients refused further participation for various non-hip related reasons, and 1 patient moved. Available follow-up data and retrospective inquiry (patients, family or general practitioner) learned that at $10+$ years none of the 11 patients lost to follow-up had hip-related complaints.

The median follow-up of the remaining 56 study patients (with 59 THAs) was 11 years (range 10-13 years in both groups). Since for both groups survival was $100 \%$ for the endpoint revision for loosening of both stem and cup, as well as for the endpoint revision for any reason, the Kaplan-Meier analysis was only performed for definite radiographic loosening at minimum 10-year follow-up as the endpoint, being $96.4 \%$ (1/28 loose) for the SHP ${ }^{\circledR}$ and $96.8 \%$ (1/31 loose) for the Omnifit ${ }^{\circledR}$.

\section{Changes in periprosthetic bone density}

All 72 patients ( $=75$ hips) but 1 (patient with unilateral SHP ${ }^{\circledR}$, deceased at 18 months because of myocardial infarction), completed the entire DEXA follow-up of 2 years. There was no statistical difference in either group between pre- and postoperative (both at 1 and 2 years) lumbar spine BMD.

The mean slope of the BMD-curve in zone A showed a loss of $1.80 \%$ per follow-up interval for the $\mathrm{SHP}^{\circledR}$ stem, while this was $2.71 \%$ for the Omnifit ${ }^{\circledR}$. The difference in slope between the curves was 0.91 , which was significant $(P=0.012)$ 


\section{Chapter 2}

with a $95 \%$ confidence interval between -1.61 (lower bound) and -0.21 (upper bound). For zones B, C and $\mathbf{D}$ results are summarized in Table 2. BMD-curves are shown in Fig. 5.

Table 2 Difference in BMD-Slope Per Time Interval Between SHP and Omnifit.

\begin{tabular}{lccccc} 
RoI & $\begin{array}{c}\text { Slope SHP - } \\
\text { curve in } \%\end{array}$ & $\begin{array}{c}\text { Slope Omnifit - } \\
\text { curve in } \%\end{array}$ & $\begin{array}{c}\text { Difference } \\
\text { SHP-Omnifit } \\
\text { in \% }\end{array}$ & $\begin{array}{c}\text { Significance } \\
\text { (P value) }\end{array}$ & $\begin{array}{c}\text { Confidence } \\
\text { Interval }\end{array}$ \\
\hline Zone A & -1.80 & -2.71 & -0.91 & 0.012 & -1.61 to -0.21 \\
Zone B & -0.95 & -1.63 & -0.67 & 0.009 & -1.18 to -0.16 \\
Zone C & -5.08 & -5.95 & -0.86 & 0.020 & -1.59 to -0.13 \\
Zone D & -2.75 & -3.23 & -0.47 & 0.061 & -0.97 to -0.21 \\
\hline
\end{tabular}
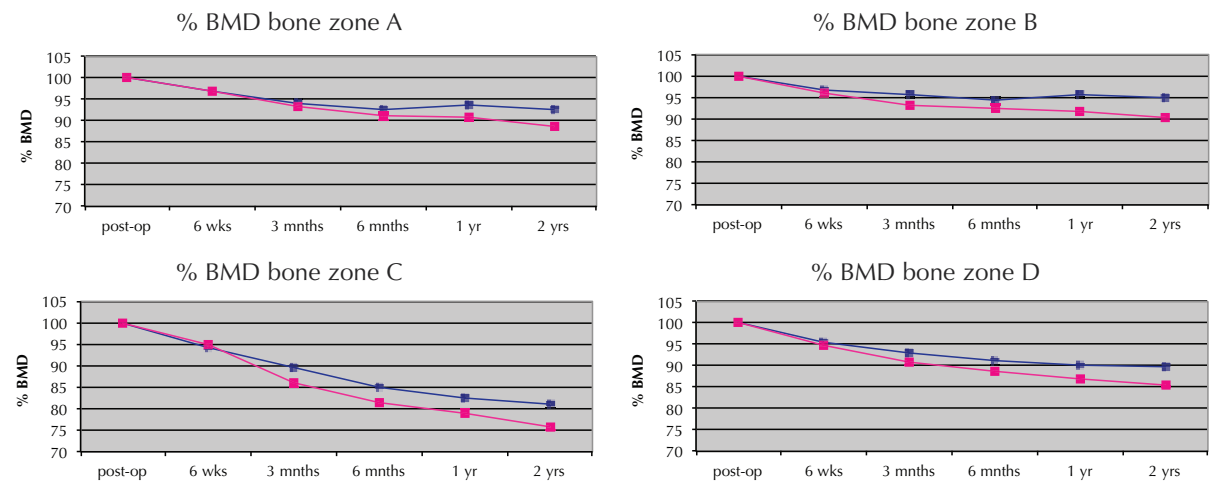

Fig. 5 Graphs showing BMD course of the zones A - D in a longitudinal DEXA-study for 2 years, comparing the mean values ( \pm standard error of the mean) for the SHP group $(\diamond)$ and the Omnifit group (घ), with the immediate postoperative BMD set at 100\% (=baseline reference).

\section{Clinical outcome}

Pre-operatively there was no significant difference in Harris Hip Score, Oxford Hip Score and Rand-36 scores between the 2 groups. With respect to the HHS there is a better outcome post-operatively for the $\mathrm{SHP}^{\circledR}$ group during the entire follow-up 
of 10 years. This difference is statistically significant at 24 months $(P=0.019)$ and 10 years $(P=0.0001$ ) (see Table 3 ). Patient satisfaction measured by the Oxford Hip Score also tends to be more positive for the $\mathrm{SHP}^{\circledR}$ group, although not statistically significant compared to the Omnifit ${ }^{\circledR}$ (see Table 3).

Table 3 Mean Results for Harris Hip Score (HHS) at 9 and 10 Years Follow-Up, and Oxford Hip
Score (OHS) at 8 Years Follow-Up for SHP and Omnifit.
SHP

Overall there is a better outcome for the SHP ${ }^{\circledR}$ than for the Omnifit ${ }^{\circledR}$ group, looking at the Rand-36 scores. Pain related questions show no significant difference, while ADL-scores at 1 year follow-up are significantly better in favour of the $\mathrm{SHP}^{\circledR}(P$-value $=0.035)$.

\section{Radiographic evaluation}

Both in the $\mathrm{SHP}^{\circledR}$ and in the Omnifit ${ }^{\circledR}$ group 1 stem showed migration within the cement mantle (at least $5 \mathrm{~mm})^{17}$. Although in these patients also a fracture of the cement mantle near the tip was seen, they were asymptomatic. Incomplete radiolucent lines $(>1 \mathrm{~mm}$ ) at the prosthesis-cement interface were seen in 1 patient (Gruen zone 3 and 5) in the $\mathrm{SHP}^{\circledR}$ group, and 3 patients (Gruen zones 3, 4 and 5) in the Omnifit ${ }^{\circledR}$ group. There were no radiolucent lines in Gruen zone 1 or 7 in either group. Neither were there continuous or progressive radiolucencies $>2 \mathrm{~mm}$ in any zone in either group at the cement-bone interface. In conclusion, according to the criteria of Harris, there was proof of definite radiographic loosening of 1 patient in both groups, but no further probable or possible loosenings. Other radiographic findings are summarized in Table 4. 


\section{Chapter 2}

Table 4 Radiographic Results of SHP Versus Omnifit.

\begin{tabular}{lcccc} 
Migration & $\begin{array}{c}\text { Broken } \\
\text { Cement }\end{array}$ & $\begin{array}{c}\text { Radiolucency } \\
\text { Stem - Cement }\end{array}$ & $\begin{array}{c}\text { Radiolucency } \\
\text { Cement - Bone }\end{array}$ \\
\hline SHP & 1 & 1 & 1 & 1 \\
Omnifit & 1 & 1 & 3 & No
\end{tabular}

At the acetabular side there were no radiographic signs of loosening in terms of progressive radiolucencies at the cup-cement or cement-bone interface. None of the cups demonstrated focal or linear osteolysis in DeLee-Charnley zones I-III. This was the case for the patients that could be assessed until 10+ years, as well as for the last taken X-ray of the patients lost to follow-up. Linear wear rate of the PE cups was in the range of $0.0-0.2 \mathrm{~mm}$ per year for both study groups. The pathological threshold (for $28 \mathrm{~mm}$ heads) of an annual $0.2 \mathrm{~mm}$ was exceeded in $2 \mathrm{Omnifit}^{\circledR}$ and $1 \mathrm{SHP}^{\circledR}$ hips $^{27,28}$.

\section{Discussion}

\section{Background and key findings}

This study was performed to investigate if preclinical considerations on hip design optimisation and early migration patterns can predict periprosthetic bone remodelling, clinical outcome and implant survival. Although pronounced subsidence and rotational instability of the $\mathrm{SHP}^{\circledR}$ stem within the cement mantle were reported $^{7,8}$, our results showed no revisions for any reason within 11 years and signs of radiographic loosening of only 1 patient in both groups. And while from both RSA and preclinical FE-analysis increased osteolysis and stress-induced bone resorption were expected, DEXA-analysis showed less instead of more bone loss around the $\mathrm{SHP}^{\circledR}$ compared to the Omnifit ${ }^{\circledR}$ in all regions of interest (statistically significant in zone A, B and C). Clinically outcome was better for the $\mathrm{SHP}^{\circledR}$ in terms of functional scores (HHS) but the same for patient satisfaction (OHS and Rand 36). 
Resorption/

Calcar Resorption

Hypertrophy

Endosteal

Ectopic

Greater Trochanter

(=ROI C)

Shaft (=All ROI's)

Cavitation

Ossification

Osteotomy

1

No

No

6

No

9

1

1

9

No

\section{Explanation and interpretation}

We do not have a clear explanation for these results that seem to contradict expectations based on earlier RSA and FE studies. However cemented implants are complex constructs where stability, fixation, and periprosthetic bone remodelling is dependent on implant geometry, interface characteristics, and on materials with variable elasticity modulus and surface finish. The translation of mutual influences between these features into mathematical formulas for FE-calculations, may insufficiently represent real biology. Consequently it is probably too complicated to predict long term fixation and bone remodelling, let alone implant survival. Recently it was suggested there may be an increased risk of revision with stems combining higher offset with a rough stem surface ${ }^{29}$. The $\mathrm{SHP}^{\circledR}$, having a CCD angle of $120^{\circ}$ versus $135^{\circ}$ for the Omnifit ${ }^{\circledR}$, may therefore cause earlier debonding due to increased lever arm, resulting in abrasive particle wear between the roughened stem and cement. However a lower CCD-angle also reduces the joint reaction force, making the net effect of this design difficult to predict. The same authors compared 3 different surface finishes of the Lubinus SP2 (Waldemar Link, Hamburg, Germany), and showed that the polished version subsided more but had smaller initial BMD loss ${ }^{30}$. They suggested that the stem motion could have contributed to favourable loading of the proximal femur. However this would contradict FE prediction because the $\mathrm{SHP}^{\circledR}$ was not expected to enlarge but to diminish the stresses on periprosthetic tissues.

Notwithstanding the proximal roughening and known detrimental effect of debonding (that is ultimately supposed to occur in all stems) ${ }^{12,14,31}$, results are 


\section{Chapter 2}

better than could be expected from RSA studies ${ }^{7,8,32}$, and studies that compared stems with essentially the same geometry but different surface finish ${ }^{1,9,11}$. Possibly the design (high E-modulus, large proximal dimensions and a stabilizing lateral flange, all aimed at less flexibility) provides maximal resistance against instability even after debonding. Furthermore the distal tip of the stem, being much thinner and therefore more flexible with higher risk of debonding ${ }^{5}$, was polished as a 'second line of defence' to prevent cement abrasion and particle wear in case of migration.

A further explanation may be that a more even cement mantle through spacers and a third generation cementing technique, may prevent gross loosening and osteolysis in case of debonding. This was also suggested in studies that illustrated greater probability of revision in case of early subsidence, but also acknowledged that failure may be different for a different design ${ }^{30,33}$. In addition micromovements of the stem within a strong intact cement mantle may be compatible with prolonged survival of the implant, provided that the amount of wear is within a certain limit ${ }^{33}$. Also in our study no accelerating PE-wear was seen in either group, suggesting that third-body wear was not substantial, which is in line with the absence of osteolysis at long-term follow-up ${ }^{34}$. Hence the good results of the $\mathrm{SHP}^{\circledR}$ may therefore also be explained by our 'case mix' mostly consisting of low demand elderly females. Although this case mix is representative for the patient group being treated with cemented hip arthroplasty in most countries, it is known from extensive experience in Sweden with other rough cemented stems (i.e. the Spectron EF Primary; Smith and Nephew, Memphis, TN), that the potentially detrimental effect of the rough surface may appear after even longer follow-up, especially in high demand comparatively young males ${ }^{29,35}$. On the other hand a recent study showed good initial (2 year) RSA-performance of the Spectron EF, while this appeared to be no guarantee for good long-term results ${ }^{36}$, stressing the importance of clinical studies to evaluate the predictions of these migration studies.

In conclusion our study may indicate the relative value of preclinical FEApredictions on remodelling, and predictions on survival from earlier RSA. It remains necessary to validate these tools by assessment of bone changes and by clinical trials. 


\section{Limitations and strengths}

We acknowledge the potential limitations of this study in the relatively small number of patients. This may harm the possibility to detect a clinically relevant difference or a difference in risk of revision. Therefore the study may seem underpowered. However our primary outcome variable was difference in BMD loss, and the standard deviation of the difference between direct postoperative $\mathrm{BMD}$ and BMD at 2 years in each group appeared to be 10 times smaller than the assumed $30 \%$, making the analysis sufficiently powered and reveal statistically significant differences between the groups. The small SD probably is the result of a more homogeneous study population compared to earlier studies and the fact that all patients have been operated by 1 surgeon, diminishing the influence of these variables.

With $14 \%$ at 11 years, the overall loss to follow up in our study is relatively high $^{37}$. This inevitably is the fate of a long term follow up study that includes an elderly population, with increasing comorbidity. Vigorous attempts to acquire information about the patients lost to follow up learned that there were no hip related pain or mobility problems in this group and no revisions. Until their last recorded assessment, all non-attenders showed good clinical scores (HHS), no signs of deterioration on X-rays, and were equally satisfied (OHS) as those who continued to attend.

Theoretically, bilateral cases should not be regarded as independent observations, and analysis with the unpaired Student's $t$-test may render invalid results $^{38}$. To determine the effect of deleting the second hip on our results, we performed a sensitivity analysis which showed that this had minimal effect and did not influence our conclusions. This was also concluded in other studies ${ }^{39,40}$.

It could be argued that long-term BMD-measurements would have provided better insight in ultimate bone effects of these 2 designs. However densitometry was limited to 2 years because the main changes due to implant driven strainadaptive bone remodelling are seen within this period, and changes in BMD after that are mostly not more than $1 \%$ per year, and are attributed to physiological ageing $^{41,42}$.

Blinding for the choice of implant was not possible for outcome assessor and patient. However evaluators of DEXA and radiography were strictly blinded for 


\section{Chapter 2}

clinical results. Both other ways to limit bias (randomization and concealment of treatment allocation) were correctly performed.

External validity of our results may be expected as similar outcome was shown in another series, supporting generalisability ${ }^{5}$. Sybesma reported $97.6 \%$ survival for aseptic loosening (97.4\% for all reasons) in a prospective clinical trial evaluating $137 \mathrm{SHP}^{\circledR}$ hips with mean follow-up of 5.6 years (range 5-7). This outcome was in line with the 5-year results of ten frequently used cemented hips reported by Espehaug ${ }^{43}$.

We used the Gruen zones as our regions of interest for bone densitometry. Whether bone adaptations are due to stem specific characteristics can only be recognized if unequal stem or coating lengths are taken into account to determine the zones for comparison ${ }^{44}$. Because the Omnifit ${ }^{\circledR}$ stem is longer than the size matched $\mathrm{SHP}^{\circledR}$, the zones 1 and 7 would be longer for the Omnifit ${ }^{\circledR}$ as well, containing relatively more cortical bone compared to the $\mathrm{SHP}^{\circledR}$. As cortical bone remodels less than cancellous bone, it would seem that bone preservation around the Omnifit ${ }^{\circledR}$ would be superior, while this should be also attributed to incomparable composition to regions of interest in terms of cancellous or cortical bone. Therefore Gruen zones 1 and 7 around both stems were taken identical in length, corresponding with the length of the roughened part of the SHP ${ }^{\circledR}$. Gruen zones 2 to 6 were divided around the rest of the stem. As only minor BMD changes were expected in these mainly cortical bone areas ${ }^{45}$, these zones were taken together as zone B and D.

Finally it has to be acknowledged that the design used in our study is not entirely the same as the one used in the reported RSA study, which therefore does not allow strong conclusions concerning Nivbrant's work. Nevertheless the geometry and proximal roughness are identical, so from the newer version with distal polishing one should expect even more instead of less subsidence, as was also seen in other polished stems ${ }^{30,46}$. The effect of the rough proximal surface on cement abrasion and resulting bone loss could then consequently be expected at least as strong.

\section{Previous literature}

Comparing our results with the literature of the $\mathrm{SHP}^{\circledR}$, others reported more migration and higher bone loss compared to other stem designs, but without 
information on $\mathrm{BMD}$ changes during the important first year ${ }^{7,8}$. Patient populations were small (Nivbrant $\mathrm{n}=20$; $\mathrm{Li} \mathrm{n}=13$ ), and a comparison was made between collarless and collared stems, which difference obviously influences migration. The value of their RSA and DEXA results could not be established because there was no correlation with clinical, radiographic or survival scores at short term follow-up (2 and 5 years respectively). There are several explanations for the difference in migration as assessed between the studies. Nivbrant ${ }^{7}$ and $\mathrm{Li}^{8}$ performed migration analysis using RSA, while we assessed implant stability with conventional radiography, which is associated with lower accuracy ${ }^{17}$. Secondly all patients within our study were over 60, while Nivbrant's included patients starting from 50, and Li from 56. The male to female ratio was 10/28 for our study, 8/12 for Nivbrant and 4/9 for Li. In other words our study involved a larger majority of elderly females, known to be less demanding with lower risk of implant instability. Thirdly there may also have been a difference in quality of the cement mantle, as poorer cementing was associated with subsidence for the $\mathrm{SHP}^{\circledR 7}$. In our study we classified $29 \mathrm{SHP}^{\circledR}$ stems $(76 \%)$ grade $\mathrm{A}$ and 9 grade $\mathrm{B}^{18}$. For Nivbrant this was $11 \mathrm{~A}$ (58\%), 7B and $1 \mathrm{C}$ while this was not specified in Li's study.

\section{Conclusion}

This first mid-to-long term prospective randomized study of the $\mathrm{SHP}^{\circledR}$ suggests the incorrectness of earlier expectations, at least for our case mix. Considering the available data ( 1 proven loosening after a minimum FU of 10 years), we found no arguments in our study population to support the negative outlook for the SHP ${ }^{\circledR}$, as based on initial RSA data. Furthermore DEXA-results show a different remodelling pattern around the SHP ${ }^{\circledR}$ than was expected from preclinical FE considerations.

Migration results of implant designs should not stand alone. For interpretation of their clinical relevance, they need correlation with long-term clinical results, radiographic scores or implant survival. Consequent follow-up is obligatory and will be performed to clarify the link between early predictions and real long term outcome. 


\section{Chapter 2}

\section{REFERENCES}

1. Huiskes R, Verdonschot N, Nivbrant B. Migration, stem shape, and surface finish in cemented total hip arthoplasty. Clin Orthop 1998; 355: 103-12.

2. Bundy KJ, Penn RW. The effect of surface preparation on metal/bone cement interfacial strength. J Biomed Mater Res 1987; 21: 773-805.

3. Crowninshield RD, Jennings JD, Laurent ML, Maloney WJ. Cemented femoral component surface finish mechanics. Clin Orthop 1998; 355: 90-102.

4. Huiskes R, Boeklagen R. Mathematical shape optimization of hip prosthesis design. J Biomech 1989; 22: 793-804.

5. Sijbesma T. From laboratory to clinic. The study of a new cemented total hip arthroplasty. Thesis, University of Groningen, The Netherlands 2002.

6. Peters $\mathrm{CL}$, Bachus KN, Craig MA, Higginbotham TO. The effect of femoral prosthesis design on cement strain in cemented total hip arthroplasty. J Arthroplasty 2001; 16: 216-24.

7. Nivbrant B, Kärrholm J, Söderlund P. Increased migration of the SHP prosthesis. Radiostereometric comparison with the Lubinus SP2 design in 40 cases. Acta Orthop Scand 1999; 70: 569-77.

8. Li MG, Rohrl SM, Wood DJ, Nivbrant B. Periprosthetic changes in bone mineral density in 5 stem designs 5 years after cemented total hip arthroplasty. No relation to stem migration. J Arthroplasty 2007; 22: 689-91.

9. Howie DW, Middleton RG, Costi K. Loosening of matt and polished cemented femoral stems. J Bone Joint Surg (Br) 1998; 80: 573-6.

10. Sporer SM, Callaghan JJ, Olejniczak JP, Goetz DD, Johnston RC. The effects of surface roughness and polymethylmethacrylate precoating on the radiographic and clinical results of the lowa hip prosthesis. A study of patients less than fifty years old. I Bone Joint Surg (Am) 1999; 81: 481-92.

11. Collis DK, Mohler CG. Comparison of clinical outcomes in total hip arthroplasty using rough and polished cemented stems with essentially the same geometry. J Bone Joint Surg (Am) 2002; 84: 586-92.

12. Verdonschot $\mathbf{N}$. Biomechanical failure scenarios for cemented total hip replacement. Thesis, University of Nijmegen, The Netherlands 1995. 
13. Rasquinha VJ, Dua V, Rodriguez JA, Ranawat CS. Fifteen-year survivorship of a collarless, cemented, normalized femoral stem in primary hybrid total hip arthroplasty with a modified third-generation cement technique. J Arthroplasty 2003; 18: 86-94.

14. Jasty M, Maloney WJ, Bragdon CR, O'Connor DO, Haire T, Harris WH. The initiation of failure in cemented femoral components of hip arthroplasties. J Bone Joint Surg (Br) 1991; 73: 551-8.

15. Spierings PTJ, Merkx MAHJ, Huiskes R. Photo-elastic stress analysis of the SHP hip stem. External Report of Orthopaedic Technology, 1989.

16. Gruen TA, McNeice GM, Amstutz HC. "Modes of failure" of cemented stem-type femoral components: a radiographic analysis of loosening. Clin Orthop 1979; 141: 17-27.

17. Malchau HJ, Kärrholm J, Wang YX, Herberts P. Accuracy of migration analysis in hip arthroplasty. Digitized and conventional radiography compared to radiostereometry in 51 patients. Acta Orthop Scand 1995; 66: 418-24.

18. Barrack RL, Mulroy Jr RD, Harris WH. Improved cementing techniques and femoral component loosening in young patients with hip arthroplasty: A 12-year radiographic review. J Bone Joint Surg (Br) 1992; 74: 385-9.

19. Harris W, McCarthy J, $\mathrm{O}^{\prime}$ Neill D. Femoral component loosening using contemporary techniques of the femoral cement fixation. J Bone Joint Surg (Am) 1982; 64: 1063-7.

20. Finsen V, Anda S. Accuracy of visually estimated bone mineralization in routine radiographs of the lower extremity. Skeletal Radiol 1988; 17: 270-5.

21. Røkkum M, Reigstad A. Polyethylene wear with an entirely HA-coated total hip replacement. 79 hips followed for 5 years. Acta Orthop Scand 1998; 69: 253-8.

22. Liang M, Katz J, Phillips C, Sledge C, Cats-Baril W. The total hip arthroplasty outcome evaluation form of the American Academy of Orthopaedic Surgeons. I Bone Joint Surg (Am) 1991; 73: 639-46.

23. Harris WH. Traumatic arthritis of the hip after dislocation and acetabular fractures: treatment by mold arthroplasty. An end-result study using a new method of result evaluation. J Bone Joint Surg (Am) 1969; 51: 737-55.

24. Dawson J, Fitzpatrick R, Carr A, Murray D. Questionnaire on the perceptions of patients about total hip replacement. J Bone Joint Surg (Br) 1996; 78: 185-90. 


\section{Chapter 2}

25. Hoefnagels NH, Dhert WJ, Gosens T, Bulstra SK, de Vet HCW, van Langelaan EJ, Okhuysen-Vonk S, Geesink RGT. De Oxford Heup Score, een Nederlandse patiëntenvragenlijst ter evaluatie van het resultaat van een totale heupprothese gebaseerd op de vertaling van "the 12-item questionnaire on the perceptions about THR". Tijdschrift voor Orthopaedie 2002; 9: 5-16.

26. Aaronson NK, Muller M, Cohen PD, Essink-Bot ML, Fekkes M, Sanderman R, Sprangers MA, te Velde A, Verrips E. Translation, validation, and norming of the Dutch language version of the SF-36 Health Survey in community and chronic disease populations. J Clin Epidemiol 1988; 51: 1055-68.

27. Dumbleton JH, Manley MT, Edidin AA. A literature review of the association between wear rate and osteolysis in total hip artrhoplasty. J Arthroplasty 2002; 17: 649-61.

28. Harris WH. "The lysis threshold": An erroneous and perhaps misleading concept? J Arthroplasty 2003; 18: 506-10.

29. Thien TM, Kärrholm J. Design-related risk factors for revision of primary cemented stems. Analysis of 3 common stems in the Swedish Hip Arthroplasty Register. Acta Orthopaedica 2010a; 81: 407-12.

30. Thien TM, Thanner J, Kärrholm J. Randomized comparison between 3 surface treatments of a single anteverted stem design: 84 hips followed for 5 years. J Arthroplasty 2010b; 25: 437-44.

31. Verdonschot N, Huiskes R. Surface roughness of debonded straight-tapered stems in cemented THA reduces subsidence but not cement damage. Biomaterials 1998; 19: 1773-9.

32. Kärrholm J, Nivbrant B, Thanner J, Anderberg C, Börlin N, Herberts P, Malchau H. Radiosteriometric evaluation of hip implant design and surface finish. Scientific exhition 67thAnnual Meeting of the AAOS. 2000, March 15-19, Orlando, USA.

33. Kärrholm J, Borssén B, Löwenhielm G, Snorrason F. Does early micromotion of femoral stem prostheses matter? 4-7 year stereoradiographic follow-up of 84 cemented prostheses. J Bone Joint Surg (Br) 1994; 76: 912-7.

34. Dowd JE, Sychterz CJ, Young AM, Engh CA. Characterization of long-term femoral-headpenetration rates: association with and prediction of osteolysis. J Bone Joint Surg (Am) 2000; 82: 1102-7.

35. Kärrholm J, Herberts P. The Swedish hip arthroplasty register, Annual report 2005. Göteborg: Dept of Orthopaedics, Sahlgrenska University Hospital; 2006. 
36. Kadar T, Hallan G, Aamodt A, Indrekvam K, Badawy M, Havelin LI, Stokke T, Haugan K, Espehaug B, Furnes O. A randomized study on migration of the Spectron EF and the Charnley flanged 40 cemented femoral components using radiostereometric analysis at 2 years. Acta Orthop 2011; 82 (5): 538-44.

37. Murray DW, Britton AR, Bulstrode CJK. Loss to follow-up matters. J Bone Joint Surg (Br) 1997; 79: 254-7.

38. Ranstam J. Problems in orthopedic research. Dependent observations. Acta Orthop Scand 2002;73(4):447-50.

39. Robertsson $\mathrm{O}$, Ranstam J. No bias of ignored bilaterality when analyzing the revision risk of knee prostheses: Analysis of a population based sample of 44,590 patients with 55,298 knee prostheses form the national Swedish Knee Arthroplasty Register. BMC Musculoskeletal Disorders 2003;4:1.

40. Lie SA, Engesaeter LB, Havelin LI, Gjessing HK, Vollset SE. Dependency issues in survival analysis of 55,782 primary hip replacements from 47,355 patients. Statist Med 2004; 23: 3227-40.

41. Kröger H, Venesmaa $\mathrm{P}$, Jurvelin J, Miettinen $\mathrm{H}$, Suomalainen $\mathrm{O}$, Alhava E. Bone density at the proximal femur after total hip arthroplasty. Clin Orthop 1998; 352: 66-74.

42. Venesmaa PK, Kröger HPJ, Jurvelin JS, Miettinen HJA, Suomalainen OT, Alhava EM. Periprosthetic bone loss after cemented total hip arthroplasty. A prospective 5-year dual energy radiographic absorptiometry study of 15 patients. Acta Orthop Scand 2003; 74(1): 31-6.

43. Espehaug B, Havelin LI, Engesaeter LB, Vollset SE, Langeland N. Early revision among 12,179 Hip Prostheses. A comparison of 10 different brands reported to the Norwegian Arthroplasty Register, 1987-1993. Acta Ortop Scand 1995; 66(6): 487-93.

44. Broeke ten RHM, Hendrickx RPM, Leffers P, Jutten LMC, Geesink RGT. Randomised trial comparing bone remodelling around two uncemented stems using modified Gruen zones. Hip Int 2012; 22: 41-9.

45. Muller S, Irgens F, Aamodt A. A quantitative and qualitative analysis of bone remodelling around custom uncemented femoral stems: a five-year DEXA follow-up. Clin Biomech 2005; 20: 277-82.

46. Alfaro-Adrian J, Gill HS, Murray DW. Should total hip arthroplasty femoral components be designed to subside? A radiostereometric analysis study of the Charnley Elite and Exeter stems. J Arthroplasty 2001; 16: 598-606. 


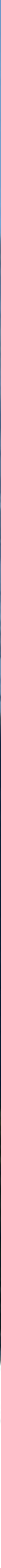




\section{CHAPTER 3}

\section{Bone densitometry in}

cemented total hip arthroplasty; different results with inclusion or exclusion of the cement mantle II a randomized controlled trial comparing two stems

René ten Broeke Liesbeth Jutten Pieter Emans Alfons Kessels Rudolph Geeskink

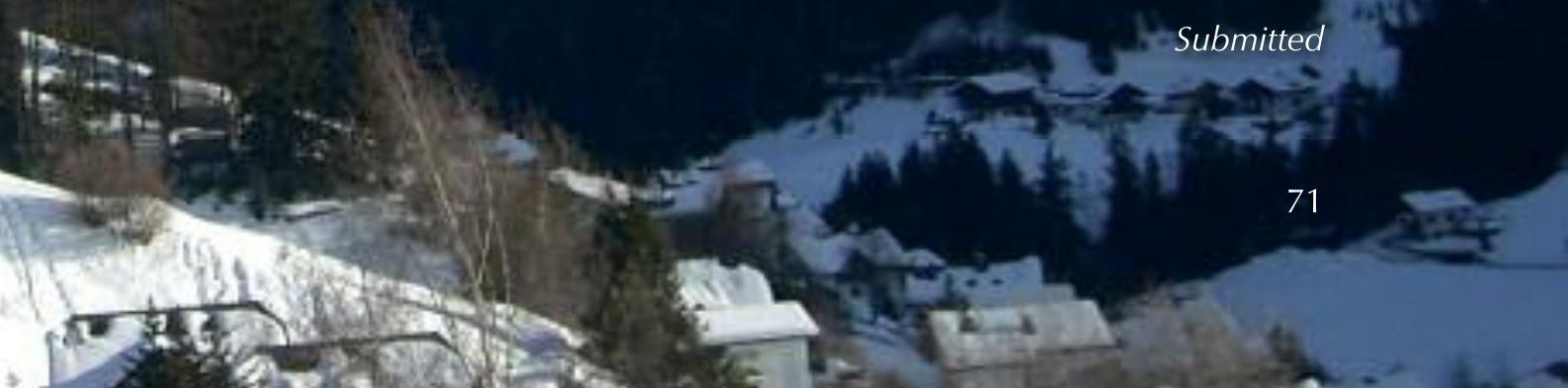




\section{ABSTRACT}

The effect of the cement mantle in the regions of interest (ROI) on the results of bone mineral density (BMD) after total hip arthroplasty (THA) is still debated.

In a prospective randomized clinical trial we analyzed 2 year results of dual-energy x-ray absorptiometry of 2 stem designs, SHP ${ }^{\circledR}$ (Biomet, UK) and

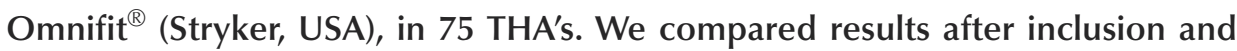
exclusion of the cement mantle using software of the densitometer. Measurements were made in the offset containing the cement ('BMD-cement'), in the perimeter outside the cement mantle ('BMD-bone') and in the combined area ('BMD-total').

In proximal Gruen zones $\mathbf{1}$ and $\mathbf{7}$ and medial distal zones $\mathbf{5}$ and $\mathbf{6}$, results for BMD-total at 2 years for both stems were consequently higher than for BMDbone. This difference was statistically significant $(P$-value $<0.005)$. These differences were not seen in the lateral distal ROI's (Gruen zones 2 and 3).

Our observations show that inclusion of the cement mantle erroneously suggests less BMD loss after cemented THA. This can be corrected using automated cement exclusion by densitometer software. We advocate measurements outside the cement mantle for more realistic assessment of bone changes after THA. 


\section{INTRODUCTION}

For total hip arthroplasty (THA), dual energy X-ray absorptiometry (DEXA) has shown to be a precise and accurate, and therefore useful tool for assessment of periprosthetic bone remodelling ${ }^{1-5}$. An important improvement for standardization of regions of interest (ROI) was the application of the Gruen-zones, which were originally designed for analysis of stem loosening on conventional radiographs ${ }^{6}$. Since then many authors have adopted these ROls for bone densitometry around uncemented $^{7-18}$ and cemented stems ${ }^{1,19-25}$.

However in earlier studies on changes in bone mineral density (BMD) around cemented THA, it was not clear whether for correct assessment of periprosthetic bone remodelling, the cement mantle should or should not be included in the chosen area of interest ${ }^{1,19,21-24,26-29}$. Although the cement induced an artefactual increase in periprosthetic $\mathrm{BMD}$, no attempts were made to distinguish between cement mantle and bone, because it was assumed that the density of the cement does not change with time ${ }^{30}$.

The theoretical advantage of including the entire periprosthetic area in the $\mathrm{ROI}$ is that it will represent all bone changes including those immediately next to the prosthesis. However the effect of the cement mantle on densitometry is so dominant that discrete implant-driven bone adaptations will be concealed. Furthermore the long-term stability of contemporary bone cements in terms of their content of contrast agents (zirconium dioxide and barium sulphate) has never been investigated. Consequently it is uncertain if and how much this may affect $\mathrm{x}$-ray opacity of the cement during longitudinal densitometry analysis of periprosthetic bone remodelling. Therefore the aim of this study was to examine the influence of the cement layer on the results of periprosthetic BMD assessment. It was hypothesized that there would be a significant difference between DEXA results with inclusion and exclusion of the cement mantle, and that exclusion of the cement would better reveal bone losses due to the prosthesis. For this study the data were used of a prospective randomised clinical trial (RCT) comparing the cemented $\mathrm{SHP}^{\circledR}$ (Biomet, Bridgend, UK) with the cemented Omnifit ${ }^{\circledR}$ prosthesis (Stryker, Mahwah, NJ, USA), to determine if this effect of the cement mantle was different for stems with different geometry. 


\section{Chapter 3}

\section{Patients and Methods}

\section{Study design and Patient selection}

In this prospective randomized comparative study 75 total hip arthroplasties (THA) in 72 patients were included. The study was approved by the local Medical Ethical Committee of the Maastricht University (registration nr: 94-030), and conducted by the department of orthopaedic surgery of the Maastricht University Medical Centre, in line with the Seoul amendment (2008) of the Helsinki Declaration of 1975.

Prior to enrolment of the patients, informed consent was signed. Patients were allocated at random in a 1:1 randomization ratio to one of either group receiving a Scientific Hip Prosthesis ${ }^{\circledR}$ (SHP, Biomet, Bridgend, UK) or an Omnifit ${ }^{\circledR}$ prosthesis (Stryker, Mahwah, NJ, USA), after a sealed envelope was drawn by an independent trial bureau just before the operation. The surgeon was unaware of the content and sequence of the envelopes (allocation concealment). Inclusion criteria were a diagnosis of osteoarthritis, post-traumatic arthritis or avascular necrosis, $60-80$ years of age, and physically and mentally willing and able to comply with postoperative scheduled clinical, radiographic and DEXA evaluations and rehabilitation. Patients with a weight classified as morbidly obese (BMI $>40$ $\mathrm{kg} / \mathrm{m}^{2}$ ), previous surgery or an active infection to the affected hip joint, and a disease or drug use affecting bone metabolism before or during the study, were excluded. Also patients with severe bone destruction of the affected hip joint which would require bone grafting and prevent full weight bearing, were considered non eligible.

Three patients received bilateral THA which were both included in the study protocol. Patient characteristics and baseline demographic data are presented in Table 1. There was no significant difference between the 2 study groups in terms of gender distribution, age, BMI, diagnosis and preoperative HHS (see Table 1).

\section{Implants}

The SHP ${ }^{\circledR}$ is made of CoCrMo alloy and is collarless. It has a thin tapered distal tip and a thick tapered proximal stem. It has an anatomic geometry with a double curvature of the proximal stem, consisting of a femoral neck anteversion and a posterior bow more distally. The stem has a roughened proximal surface (radius $\mathrm{Ra}=3.8 \mu \mathrm{m}$ ) and is 


\section{Bone densitometry in cemented total hip arthroplasty}

Table 1 Patient characteristics and baseline demographic data; parameters are given in mean and range, or mean and standard deviation

\begin{tabular}{lll}
\hline & SHP $(n=38)$ & Omnifit $(n=37)$ \\
\hline Male & 10 & 11 \\
Female & 28 & 26 \\
Age in years (range) & $68,7(60-76)$ & $68,9(61-76)$ \\
BMI in $\mathrm{kg} / \mathrm{m}^{2}$ (range) & $26,9(20,1-37,5)$ & $27,7(20,1-35,0)$ \\
Diagnosis & & 37 \\
$\quad$ Primary OA & 38 & $49.5( \pm 11.0)$ \\
Preoperative HHS $( \pm$ SD) & $49.9( \pm 13,1)$ & \\
\hline
\end{tabular}
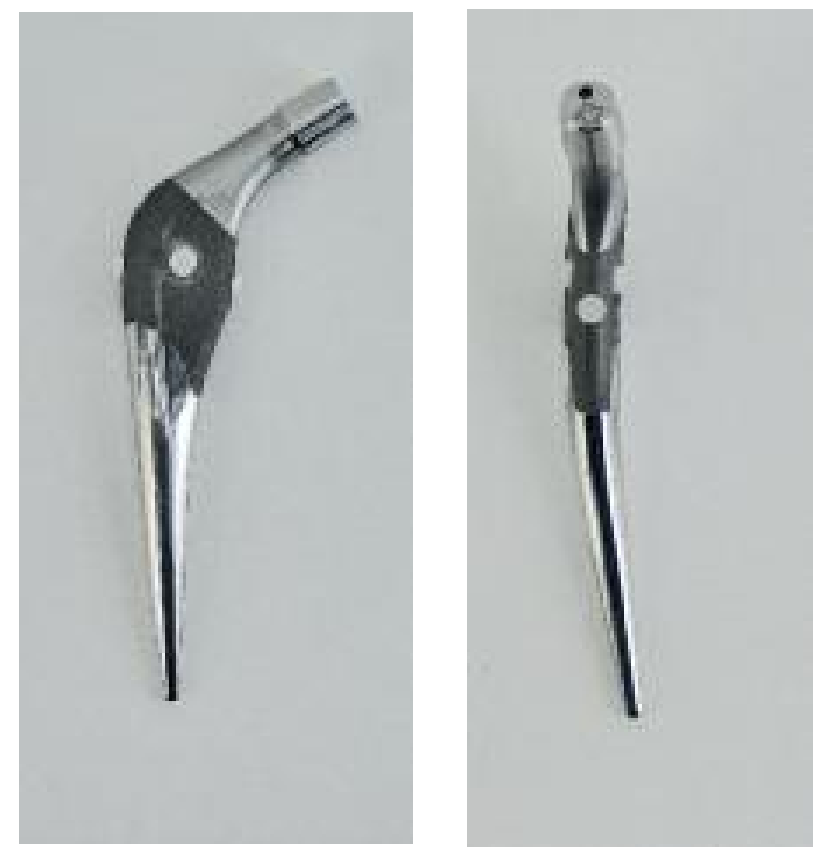

Fig. 1a AP and Lat view of the collarless anatomically shaped SHP ${ }^{\circledR}$ stem with PMMA cement spacers (distal spacer not shown) to guarantee a minimal cement thickness of $2 \mathrm{~mm}$. Proximally it shows a rigid part with rough surface finish $(\mathrm{Ra}=3.8 \mu \mathrm{m})$, distally it has a flexible taper with polished surface $(\mathrm{Ra}<0.05 \mu \mathrm{m})$ to prevent abrasive wear in case of debonding 


\section{Chapter 3}
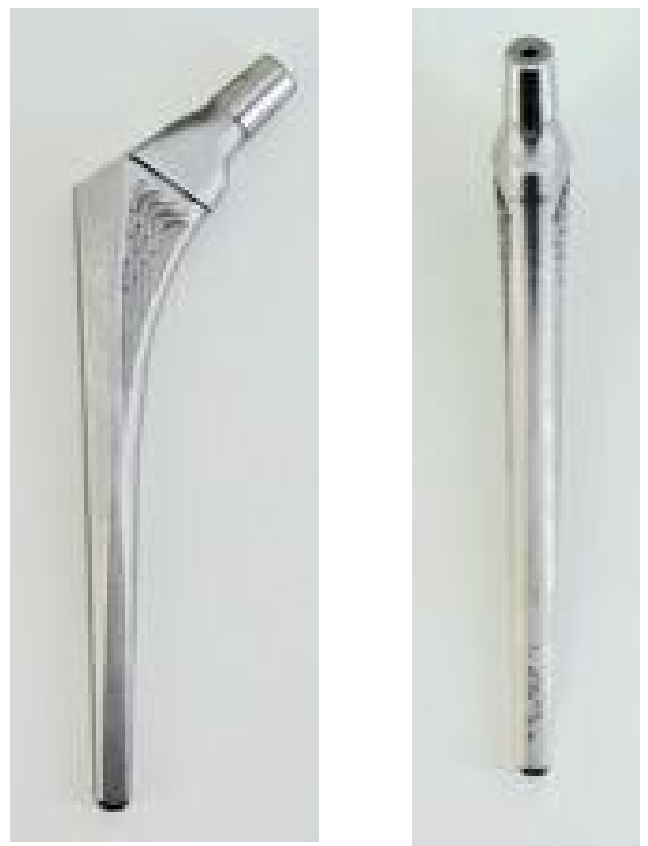

Fig. 1b AP and Lat view of the normalized Omnifit ${ }^{\oplus}$ stem, showing a straight geometry without cement spacers and with a uniform surface texture ( $\mathrm{Ra}=0.9 \mu \mathrm{m})$

polished distally $(\mathrm{Ra}<0.05 \mu \mathrm{m}) .4$ proximal polymethylmethacrylate (PMMA) spacers and a distal centralizer help to ensure an even cement mantle, of minimum thickness $2 \mathrm{~mm}$ (Fig. 1a and 3).

The Omnifit ${ }^{\circledR}$ has a small collar, and is a normalized (macrostructures to improve force transmission to bone and cement), forged cobalt-chromium (Co-Cr) stem with a satin finish (roughness of $0.9 \mu \mathrm{m}$ ) over the entire surface (Fig. 1b).

The SHP ${ }^{\circledR}$ acetabular cemented cup of $\operatorname{ArCom}^{\circledR}$ UHMWPE (Argon gas packaged, direct compression moulded polyethylene, Biomet, Bridgend, UK) was used in all cases.

\section{Surgical protocol and postoperative management}

One of the authors (RtB) performed all the operations. The stem size was templated on antero-posterior (AP) radiographs, aiming at a minimal cement mantle thickness of $2 \mathrm{~mm}$ in all Gruen zones 1 to 7 . Both hip systems were implanted according to 
standard orthopaedic procedures for total hip arthroplasty using a posterolateral approach without trochanteric osteotomy. A third generation cementing technique was used including distal femoral plugging (without metal marker to prevent artefacts during DEXA-analysis ${ }^{31}$, high pressure pulsatile lavage, drying of the bone of the femur before cementing, vacuum mixing of cement and retrograde filling of the medullary cavity with a cement gun. Gentamicin containing cement (Palacos R + G, Heraeus, Wehrheim, Germany) was used with pressurization with a silicon seal in both the acetabulum and the femur.

Patients were treated with 24 hours intravenous antibiotic prophylaxis (Augmentin $^{\circledR}$ ), DVT prophylaxis with an oral anticoagulant (Acenocoumarol) until 3 months after surgery, and prophylaxis against heterotopic ossifications with an NSAID $\left(\operatorname{Indocid}^{\circledR}\right)$ for 14 days. Patients were allowed to full weight bearing from day 1 . There was no difference in physical activity postoperatively between the two groups.

\section{Evaluation of bone remodelling}

In order to determine whether inclusion or exclusion of the cement mantle within the ROI influences DEXA results, densitometry was performed in 3 different ways. The first was scanning within a standardized offset of $3 \mathrm{~mm}$ from the implant including most if not all of the cement (called 'BMD-cement'), corresponding with the minimal thickness of the cement mantle of $2 \mathrm{~mm}$ guaranteed by the cement spacers $^{32}$. The size of the offset was adjusted using software-applications of the densitometer. The second analysis was performed in the perimeter outside this offset where no cement was present anymore (called 'BMD-bone') (Fig. 2). The last scanning technique included the entire ROI (offset + perimeter called 'BMD-total'), corresponding with the way it is performed in most DEXA studies of cemented THA. Our method was chosen to investigate if significant differences could be measured in BMD-results between the techniques, and to which extent BMDchanges are masked by the dominating density of the cement.

Because of our special interest in the effect on bone remodelling of the proximal roughening and distal polishing of the $\mathrm{SHP}^{\circledR}{ }^{\circledR}$-stem, the Regions of Interest (ROI) were divided into four zones: A, B, C and D, based on the seven Gruen zones ${ }^{6}$. ROI A represents Gruen zone 1, ROI B corresponds with Gruen zones 2 and 3 together, C with Gruen zone 7, and D with Gruen zone 5 and 6 (ten Broeke et al., unpublished 


\section{Chapter 3}

work). Thus $\mathrm{ROI} A$ and $\mathrm{C}$ cover the proximal roughened part of the $\mathrm{SHP}^{\circledR}$ stem, and $\mathrm{B}$ and $\mathrm{D}$ the distal polished part. This delineation was copied exactly to the Omnifit ${ }^{\circledR}$ stem in order to generate comparable ROIs for assessment of periprosthetic bone remodelling in stems with differences in design, length and surface finish (Fig. 3$)^{33}$.

DEXA-analysis was performed with the LUNAR DPX-L scanner (version 1.2, Lunar Corp, Wisconsin, USA) and expressed as BMD in $\mathrm{g} / \mathrm{cm}^{2}$ in the 4 ROls. The data were analyzed with special orthopaedic software provided by the manufacturer. This software automatically excludes soft tissues, metal and cement (using offset and perimeter functions), allowing an accurate measurement of periprosthetic bone density. Patients were placed in a supine position on the scan table. The legs were secured in a similar degree of rotation to bring the patellae in neutral position using special stabilizing devices for the knee and foot.

To detect abnormal systemic bone metabolism during study follow-up, DEXA scanning was also determined of the lumbar spine, both preoperatively and postoperatively (at 1 and 2 years follow-up). The preoperative lumbar scan served as a baseline measurement for comparison to referenced normals. The DEXA scan was obtained in the antero-posterior plane of the lumbar region and the operated proximal femoral region.

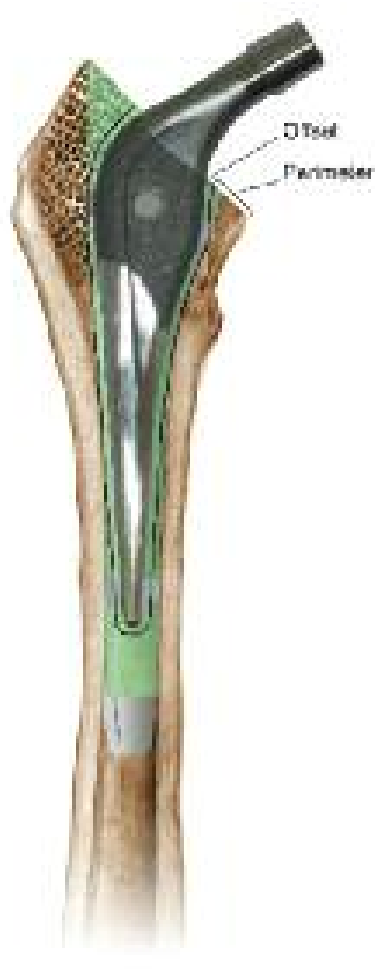

Fig. 2 Illustration showing the definition of offset (containing the cement mantle = 'BMD cement') and perimeter (con-taining exclusively bone $={ }^{\prime} B M D$ bone'). Both zones together form 'BMD total'. This can be adjusted by the densitometer software (further see text). In this fig. the SHP is shown. Densitometry around the Omnifit was performed in an identical fashion 

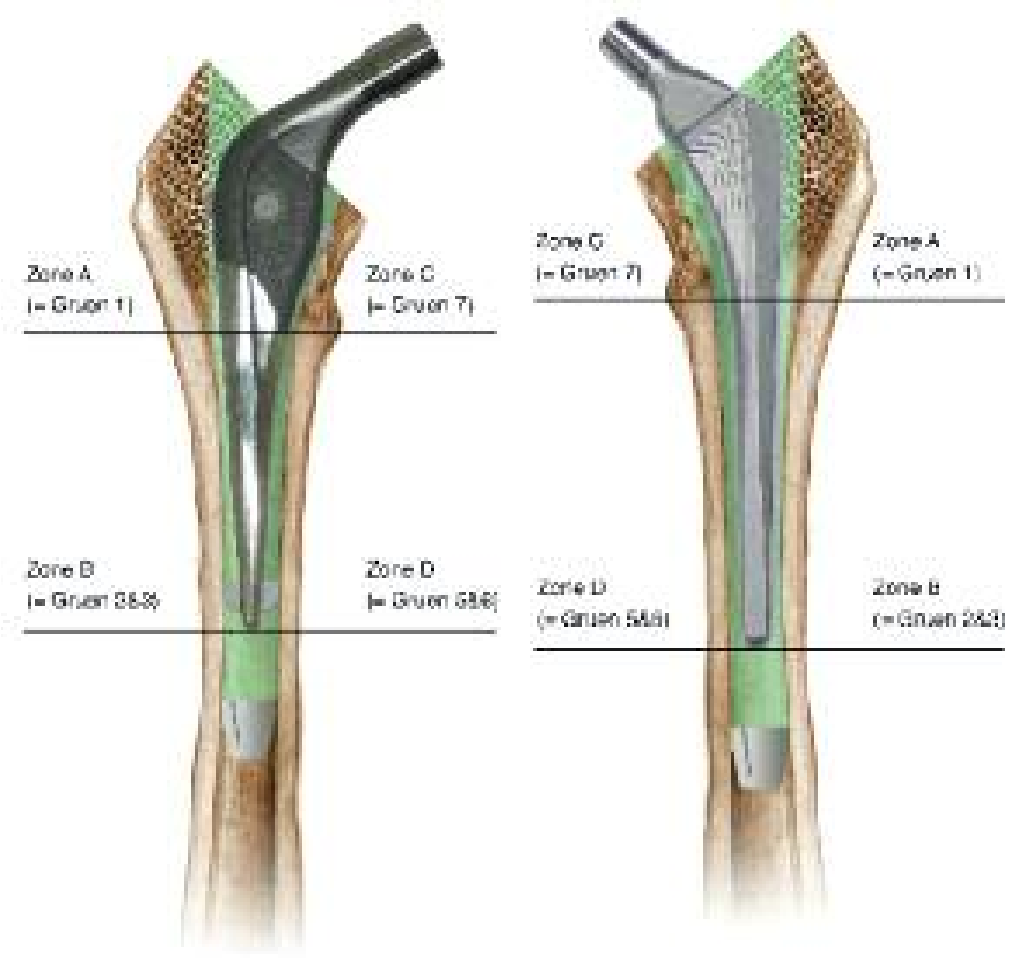

Fig. 3 Delineation of ROIs around the SHP ${ }^{\oplus}$ and Omnifit ${ }^{\oplus}$ based on the seven Gruen zones ${ }^{6}$. Zone $A$ and $C$ are corresponding with the roughened part of the SHP $P^{\circledR}$ stem. This delineation is exactly transferred to the Omnifit ${ }^{\circledR}$ stem in order to generate comparable ROIs for assessment of periprosthetic bone remodelling (further see text). PMMA cement spacers and distal centralizer on the $S H P^{\circledR}$ are shown, as well as the bioresorbable cement restrictor ${ }^{31}$

DEXA scans were made at 7 days post-operatively (base-line reference), and at 6 weeks, 3 months, 6 months, 12 months and 2 years post-operatively. All patients had all their scans made during follow-up, except for 1 patient $\left(\mathrm{SHP}^{\circledR}\right)$ who deceased after 1 year (myocardial infarction). During the entire follow-up all DEXA-scans were performed by 1 technician, and analysed by 1 member of the research staff blinded for the radiographic and clinical results, and who was not involved with the surgical procedures. None of the authors was related to the development of either implant. 


\section{Chapter 3}

\section{Radiography}

After randomization preoperative templating was performed on standardized antero-posterior (AP) radiographs to determine the implant size in order to guarantee a minimum cement mantle thickness of $2 \mathrm{~mm}$. Postoperative AP radiographs were again taken at the first day after surgery to calculate stem alignment, using a calibrated ruler. Stem axis positions within -2 and +2 degrees from the longitudinal femoral axis were considered neutral. Outside these thresholds stem position was marked as respectively valgus or varus.

\section{Statistical analysis}

Longitudinal BMD results per $\mathrm{ROI}$ are expressed as relative values with the immediate postoperative DEXA measurement of the operated femur being the reference value, set at $100 \%$. Absolute and relative BMD values are described by mean and standard error of the mean, demographic parameters by mean and range. Differences within the group are tested with the paired Student's $t$-test and between groups with the unpaired Student's $t$-test. Differences with $P$-values lower than 0.05 are described as significant.

The statistically required sample size was based on a power-analysis performed on the potential mean difference of BMD-results between stem designs $(\delta)$, which were only known from uncemented stems at the time this study was initiated. Based on these studies we assumed this difference to be $25 \%$. By convention, an $\alpha$-error rate of 0.05 was adopted, and the $\beta$-error was set at 20 (power $1-\beta=80 \%$ ). If the true difference in the experimental and control means was $20 \%$, we would need to study 36 subjects in the SHP ${ }^{\circledR}$ arm and 36 subjects in the Omnifit ${ }^{\circledR}$ arm to be able to reject the null hypothesis that the population means of these groups were equal with probability (power) 0.8.

To prevent multiplicity issues, and to reduce the number of calculations, the BMD-result at 2 year follow-up has been predefined as primary outcome variable, and the sample size (and thus the power) to reject the null hypotheses at the same significance level (0.05) was determined. Evaluations were already planned at prespecified visits at the start of the study, and no interim analysis was planned nor executed. Microsoft Office Excel 2003 (Microsoft Corporation, Redmond, Washington, USA) and SPSS software version 15.0 for Windows (SPSS Inc., Chicago, Illinois, USA) was used for data analysis. 


\section{Results}

At 2 years follow-up 1 patient (with unilateral SHP ${ }^{\circledR}$ ) had died, all other 71 patients (with 74 hips) had all their DEXA scans performed within the planned time frame (see flow diagram Fig. 4). There was no statistical difference in either group between pre- and postoperative (both at one and two years) lumbar spine BMD. Looking at the effect of inclusion or exclusion of the cement mantle on density assessment of periprosthetic bone, in the more cancellous zones $\mathrm{A}$ and $\mathrm{C}$ the BMD's for both the $\mathrm{SHP}^{\circledR}$ and the Omnifit ${ }^{\circledR}$ were always higher when measured in the offset-area containing the cement mantle (BMD-cement), compared to measurements outside the cement mantle (BMD-bone) or when taking offset and perimeter together (BMD-total). This difference between BMD-total and BMD-bone

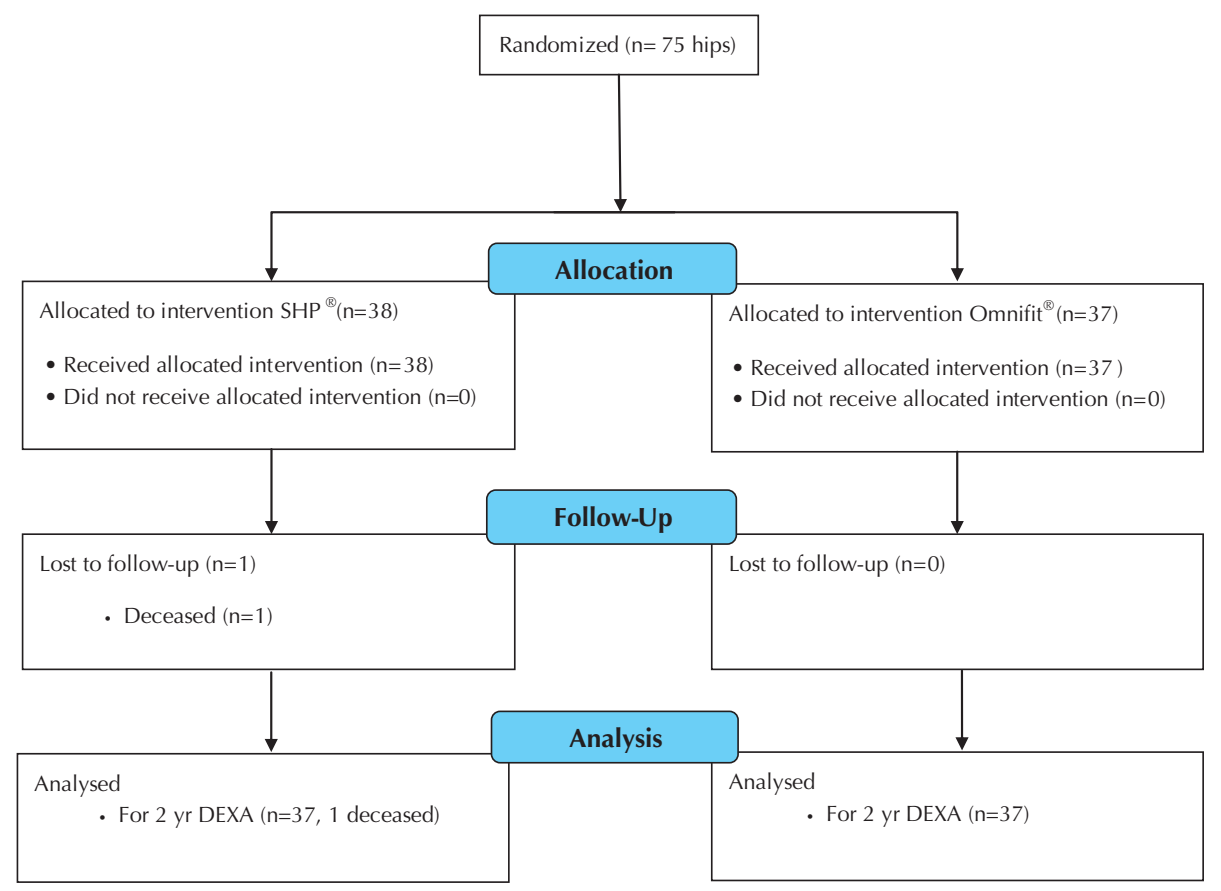

Fig. 4 Flow chart of the prospective randomized controlled trial comparing 2 year DEXA-results between the Scientific Hip Prosthesis ${ }^{\circledR}$ and the Omnifit ${ }^{\circledast}$ 


\section{Chapter 3}

was statistically significant for both stems ( $P$-value<0.005). Although this effect was smaller, it also applied for zone D (medial distal zone) and B (lateral distal zone), except for the $\mathrm{SHP}^{\circledR}$ in zone B $(P=0.48)$ (see Table 2 and Fig. 5).

Table 2 BMD percentages (with standard error of the mean -SE-, and 95\% confidence interval -CI) at 24 months of the the $S H P^{\oplus}$ and the Omnifit ${ }^{\oplus}$ are given per Roi (A-D). Measurements are specified for the $3 \mathrm{~mm}$ offset adjacent to the prosthesis (Cement), the perimeter outside the offset (Bone), and in the combined area (offset + perimeter $=$ Total).

P-values are given for the difference between BMD-bone and BMD-total.

\section{BMD values at 24 months}

\begin{tabular}{|c|c|c|c|c|c|c|c|c|}
\hline & Roi A & & & & Roi B & & & \\
\hline & Omnifit & & SHP & & Omnifit & & SHP & \\
\hline & Mean (SE) & $95 \% \mathrm{Cl}$ & Mean (SE) & $95 \% \mathrm{Cl}$ & Mean (SE) & $95 \% \mathrm{Cl}$ & Mean (SE) & $95 \% \mathrm{Cl}$ \\
\hline Bone & $86,41(2,25)$ & $81,84-90,98$ & $91,52(2,11)$ & $87,2-95,8$ & $91,50(1,71)$ & $88,02-94,97$ & $95,80(1,11)$ & $93,54-98,05$ \\
\hline Cement & $92,14(1,84)$ & $88,40-95,89$ & $95,14(1,89)$ & $91,28-99,0$ & $89,19(1,49)$ & $86,16-92,22$ & $94,29(0,87)$ & $92,52-96,06$ \\
\hline Total & $88,67(1,99)$ & $84,61-92,72$ & $92,56(1,99)$ & $88,50-96,62$ & $90,32(1,51)$ & $87,25-93,39$ & $95,07(0,99)$ & $93,05-97,09$ \\
\hline$P$-value & & & & & & & & \\
\hline $\begin{array}{l}\text { bone vs } \\
\text { total }\end{array}$ & 0,000 & & 0,001 & & 0,042 & & 0,48 & \\
\hline
\end{tabular}

BMD values at 24 months

\begin{tabular}{|c|c|c|c|c|c|c|c|c|}
\hline & \multicolumn{4}{|l|}{ Roi C } & \multicolumn{4}{|l|}{ Roi D } \\
\hline & Omnifit & & SHP & & Omnifit & & SHP & \\
\hline & Mean (SE) & $95 \% \mathrm{Cl}$ & Mean (SE) & $95 \% \mathrm{Cl}$ & Mean (SE) & $95 \% \mathrm{Cl}$ & Mean (SE) & $95 \% \mathrm{Cl}$ \\
\hline Bone & $71,49(2,09)$ & $67,25-75,74$ & $76,34(1,61)$ & $73,05-79,62$ & $83,98(1,52)$ & $80,90-87,06$ & $87,08(1,21)$ & $84,61-89,55$ \\
\hline Cement & $86,23(2,28)$ & $81,60-90,86$ & $90,43(1,51)$ & $87,36-93,50$ & $87,55(1,27)$ & $84,97-90,14$ & $92,11(0,82)$ & $90,43-93,79$ \\
\hline Total & $75,81(1,96)$ & $71,82-79,80$ & $81,08(1,32)$ & $78,40-83,76$ & $85,39(1,33)$ & $82,69-88,08$ & $89,66(1,08)$ & $87,46-91,85$ \\
\hline$P$-value & & & & & & & & \\
\hline $\begin{array}{l}\text { bone vs } \\
\text { total }\end{array}$ & 0,000 & & 0,000 & & 0,001 & & 0,001 & \\
\hline
\end{tabular}



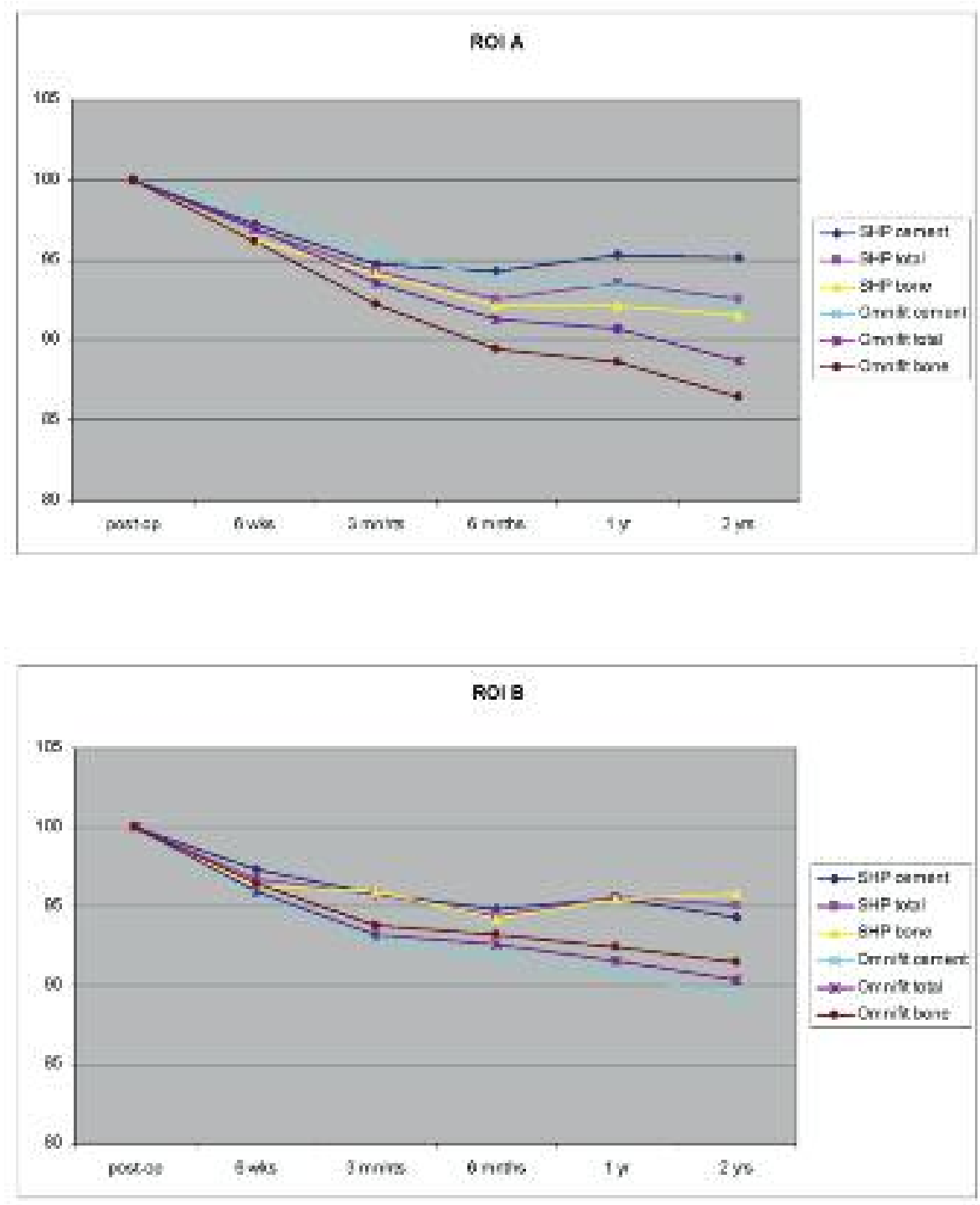

Fig. 5 Graphs showing BMD course of the zones A-D in a longitudinal DEXA-study for 2 years, comparing the SHP® and the Omnifit ${ }^{\circledast}$ stem, with the immediate postoperative BMD set at 100 $\%$ (= baseline reference). The figures show BMD in total zones (= offset + perimeter), in bone zones (= perimeter) and within the cement zones (= offset containing the cement mantle). 


\section{Chapter 3}
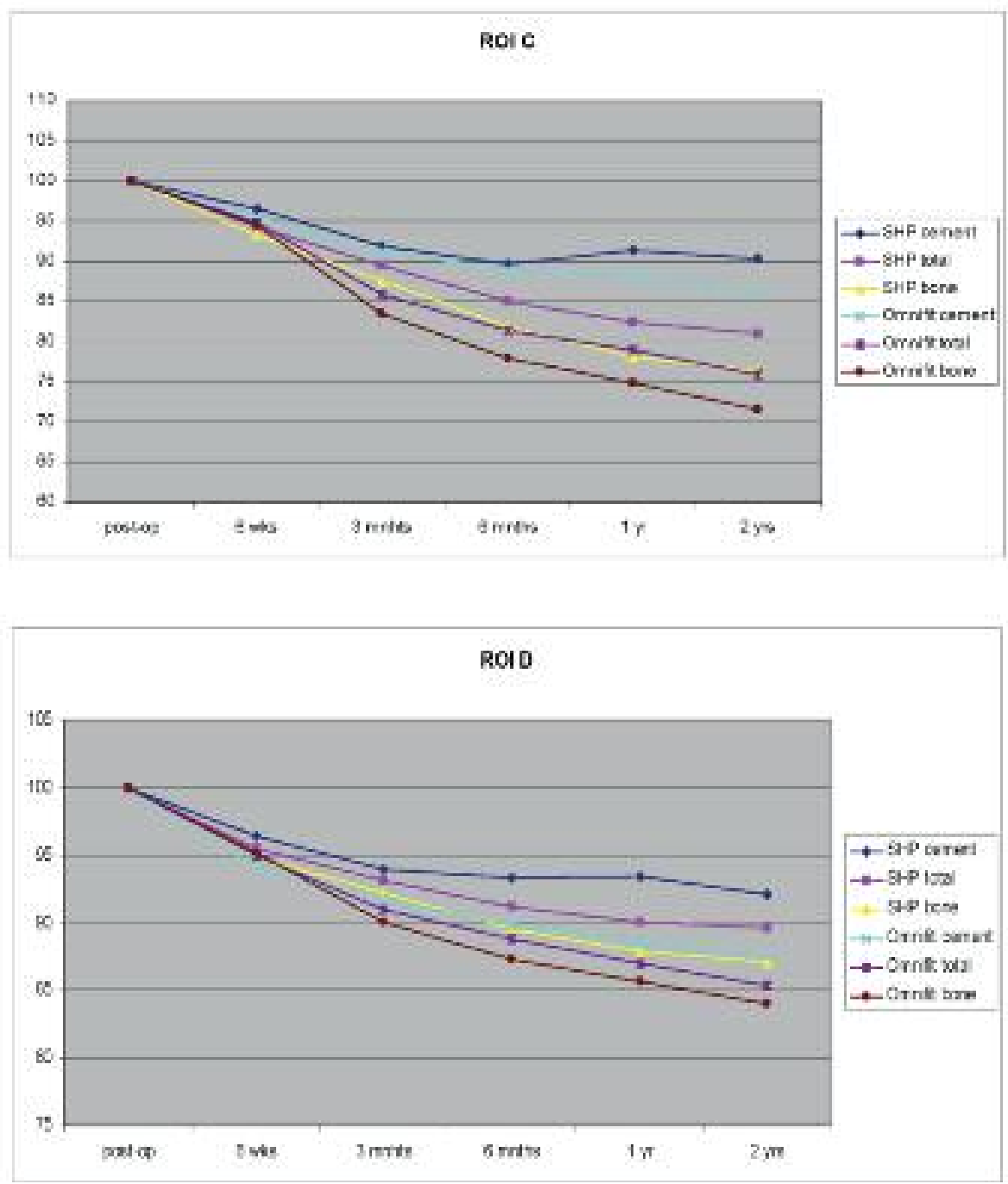

Fig. 5 continued

Considering the difference in bone remodelling between the stem designs, the BMD measured in all zones (A-D) decreased more in the Omnifit ${ }^{\circledR}$ group than in the $\mathrm{SHP}^{\circledR}$ group, irrespective of whether the assessment was performed in the cement-layer, the total-layer or the bone-layer (Fig. 5). 
Radiography showed no statistically significant difference in stem alignment between the $\mathrm{SHP}^{\circledR}$ and the Omnifit ${ }^{\circledR}$ group. In the $\mathrm{SHP}^{\circledR}$ group there were 3 out of 38 stems in varus, in the Omnifit ${ }^{\circledR}$ group this was 2 out of 37 . In both groups there was 1 stem in valgus alignment. This resulted in a homogeneous thickness of the cement mantle in $89 \%$ of the $\mathrm{SHP}^{\circledR}$ stems and $91 \%$ of the Omnifit ${ }^{\circledR}$ stems, which is in line with results in the literature ${ }^{34}$.

\section{Discussion}

\section{Background}

This study was performed to investigate the effect of the cement mantle on DEXAassessment of periprosthetic densitometry, in order to determine to which extent this would mask bone remodelling after total hip replacement.

\section{Key findings}

Considering the BMD results it is clear that in all regions of interest BMD-bone is lower than BMD-total, being lower again than BMD-cement, which can be explained by the dominating effect of the cement layer on density measurements. This effect was independent of stem design, hence independent of shape of the cement mantle. Therefore measuring in the area directly adjacent to the implant suggests better bone preservation than is actually true. In zones $\mathrm{A}$ and $\mathrm{C}$ this difference in bone loss between the 'total'-area, the 'bone'-area and the 'cement'area is largest compared to zone B and D. In the femur metaphysis ( $\approx$ zone A and C), which contains mostly cancellous bone, the effect of the implant on bone remodelling can therefore best be detected outside the cement mantle. This bonearea is wide enough to get a realistic representation of bone changes when scanning the perimeter (containing bone) and excluding the effects seen in the offset immediately next to the implant (containing mostly cement). Although bone adaptation (bone loss) theoretically is largest close to the implant ${ }^{35}$, at the same time this is mainly masked by the effect of the cement. Scanning the entire zone together, as is done in most other bone remodelling studies of cemented hip prostheses ${ }^{1,5,22-24}$, therefore creates a flattering picture of real bone loss. 


\section{Chapter 3}

In zones B and D the difference in detected bone loss between the total-area, the bone-area and the cement-area is only minor. These zones, being mainly cortical, hardly contain cancellous bone outside the cement mantle, so there will be only small differences between perimeter and offset results. Bone adaptations in this diaphyseal area will not be reflected by 'internal remodelling' resulting in BMDchange, but by 'external modelling' representing structural bone changes that can be recognized as adaptations in bone area but without changed $\mathrm{BMD}^{17}$.

\section{Previous literature}

The way how to deal with the cement mantle has been discussed in other studies as well. In cadavers it was found that PMMA-bone cement artificially increases the apparent BMD of periprosthetic ROls in the femur with up to $29 \%^{36}$. In clinical studies this was estimated to be $20 \%{ }^{22}$ and $23 \%{ }^{30}$. Sheperd showed that the prominent presence of PMMA-bone cement and its influence on apparent BMD in the ROI may mask the more discrete longitudinal changes in bone density ${ }^{37}$. Therefore Marchetti et al. ${ }^{19}$ excluded the cement mantle to compare femoral bone mass between cemented and uncemented total hip arthroplasty. However attempts to exclude the cement mantle manually from the femoral ROls gives poorer precision $^{22}$. Others as well considered it impossible to recognize the boundary, both manually as well as automatically through software applications, between bone and cement and included the cement in the ROI ${ }^{1,5,20,23,24}$. Nevertheless both this and other studies show that the presence of cement adversely affects the measurement of BMD of periprosthetic bone ${ }^{22,30,36}$. Cement is not eliminated by the automatic software used to exclude metal, because the attenuation coefficient of PMMA is not large enough to be considered metal. Therefore exclusion of pixels containing cement was always executed manually. Partial volume effects or incomplete elimination of pixels that incorporate cement then may cause an increased BMD. This may contribute to higher precision errors associated with BMD assessment around cemented hip prostheses ${ }^{20}$. For comparison between two stem designs however this effect would contribute in a similar way to this lower precision. Therefore for DEXA-analysis of bone remodelling around cemented stems, we recommend automated and reproducible exclusion of the cement mantle using offset and perimeter while scanning in Gruen zone 1 and $7(\approx$ zone 
A and C), to avoid the masking effect of cement on real bone changes caused by the prosthesis.

\section{Limitations}

A limitation of this technique is that thickness of cement mantles may vary between different studies. This makes comparison of bone remodelling between studies more difficult. However modern third generation cementing techniques and the design of reamers and broaches aim at, and usually result in, a cement mantle thickness of generally 2-3 $\mathrm{mm}$ at the femoral side in most Gruen zones 1 to $7^{38-41}$. Furthermore the cement mantle can be uneven in thickness because of the inevitable mismatch between the implant geometry and the intramedullary femoral cavity ${ }^{40,42}$. As a consequence the cement mantle will be asymmetric, and can be thicker in particular Gruen zones. This is also illustrated in the case of the $\mathrm{SHP}^{\circledR}$ in the distal diaphyseal zones (3-5), where the thickness of the cement layer increases as the stem tip gets slimmer. However maintaining the same automated offset of 3 $\mathrm{mm}$ on both the medial and lateral side will still exclude most of the mantle. Under particular circumstances however BMD assessment may be executed after adjustment of a wider offset to exclude thicker cement mantles, as long as this is consequently continued during follow-up.

Cement mantles can also be variable around stems depending on stem design (anatomical or straight), stem size, femoral canal entry and bone preparation, the use of proximal and/or distal centralizers, and pressurizations of the cement ${ }^{34,43}$. Particularly straight stems without centralizers can result in thin cement mantles in Gruen zones 8, 9 and 12, as we have also seen in the Omnifit ${ }^{\circledR}$ group $^{44,45}$. However this does not influence cement mantle thickness in the AP view, and will consequently not harm the possibility to exclude the entire mantle, while performing bone densitometry in the AP view outside the chosen offset. Therefore external validity and high generalisibility may be expected. Summarizing, automated standardized exclusion of the cement mantle is advocated to prevent the predominant effect of the cement on bone density assessment. This technique can better reveal real bone changes due to adaptive remodelling after cemented THA in the important Gruen zones 1 and 7. 


\section{Chapter 3}

\section{REFERENCES}

1. McCarthy CK, Steinberg GG, Agren M, Leahey D, Wyman E, Baran DT (1991) Quantifying bone loss from the proximal femur after total hip arthroplasty. J Bone Joint Surg Br 73:774778

2. Kilgus DJ, Shimaoka EE, Tipton JS, Eberle RW (1993) Dual-energy X-ray absorptiometry measurement of bone mineral density around porous-coated cementless femoral implants. J Bone Joint Surg Br 75:279-287

3. Trevisan C, Bigoni M, Cherubini R, Steiger P, Randelli G, Ortolani S (1993) Dual X-ray absorptiometry for the evaluation of bone density from the proximal femur after total hip arthroplasty: analysis protocols and reproducibility. Calcif Tissue Int 53:158-161

4. Kiratli BJ, Heiner JP, McBeath AA, Wilson MA (1992) Determination of bone mineral density by dual X-ray absorptiometry in patients with uncemented total hip arthroplasty. J Orthop Res 10:836-844

5. Cohen B, Rushton N (1995a) Accuracy of DEXA measurement of bone mineral density after total hip arthroplasty. J Bone Joint Surg Br 77:479-483

6. Gruen TA, McNeice GM, Amstutz HC (1979) "Modes of failure" of cemented stem-type femoral components: a radiographic analysis of loosening. Clin Orthop 141:17-27

7. Zerahn B, Storgaard M, Johansen T, Olsen C, Lausten G, Kanstrup I-L (1998) Changes in bone mineral density adjacent to two biomechanically different types of cementless femoral stems in total hip arthroplasty. Int Orthop 22:225-229

8. Nishii T, Sugano N, Masuhara K, Shibuya T, Ochi T, Tamura S (1997) Longitudinal evaluation of time related bone remodeling after cementless total hip arthroplasty. Clin Orthop 339:121-131

9. Aldinger PR, Sabo D, Pritsch M, Thomsen M, Mau H, Ewerbeck V, Breusch SJ (2003) Pattern of periprosthetic bone remodelling around stable uncemented tapered hip stems: A prospective 84-month follow-up study and a median 156-month cross-sectional study with DXA. Calcif Tissue Int 73:115-121

10. Sabo D, Reiter A, Simank HG, Thomsen M, Lukoschek M, Ewerbeck V (1998) Periprosthetic mineralization around cementless total hip endoprosthesis: Longitudinal study and cross-sectional study on titanium threaded acetabular cup and cementless Spotorno stem with DEXA. Calcif Tissue Int 62:177-182 


\section{Bone densitometry in cemented total hip arthroplasty}

11. Karachalios T, Tsatsaronis C, Efraimis G, Papadelis P, Lyritis G, Diakoumopoulos G (2004) The long-term clinical relevance of calcar atrophy caused by stress shielding in total hip arthroplasty. J Arthroplasty 19:469-475

12. Bodén H, Adolphson P, Öberg M (2004) Unstable versus stable uncemented femoral stems: a radiological study of periprosthetic bone changes in two types of uncemented stems with different concepts of fixation. Arch Orthop Trauma Surg 124:382-392

13. Okano T, Hagino H, Otsuka T, Teshima R, Yamamoto K, Hirano Y, Nakamura K (2002) Measurement of periprosthetic bone mineral density by dual-energy $\mathrm{X}$-ray absorptiometry is useful for estimating fixation between the bone and the prosthesis in an early stage. J Arthroplasty 17:49-55

14. Tanzer M, Kantor S, Rosenthall L, Bobyn JD (2001) Femoral remodelling after porouscoated total hip arthroplasty with and without hydroxyapatite-tricalcium phosphate coating. J Arthroplasty 16:552-558

15. Rosenthall L, Bobyn JD, Tanzer M (1999) Bone densitometry: influence of prosthetic design and hydroxyapatite coating on regional adaptive bone remodelling. Int Orthop 23:325-329

16. Kröger H, Venesmaa P, Jurvelin J, Miettinen H, Suomalainen O, Alhava E (1998) Bone density at the proximal femur after total hip arthroplasty. Clin Orthop 352:66-74

17. Muller S, Irgens F, Aamodt A (2005) A quantitative and qualitative analysis of bone remodelling around custom uncemented femoral stems: a five-year DEXA follow-up. Clin Biomech 20:277-282

18. Rahmy AIA, Gosens T, Blake GM, Tonino A, Fogelman I (2004) Periprosthetic bone remodelling of two types of uncemented femoral implant with proximal hydroxyapatite coating: a 3-year follow-up study addressing the influence of prosthesis design and preoperative bone density on periprosthetic bone loss. Osteoporos Int 15:281-289

19. Marchetti MM, Steinberg GG, Greene JM, Jenis LG, Baran DT (1996) A prospective study of proximal femur bone mass following cemented and uncemented hip arthroplasty. J Bone Miner Res 11(7):1033-1039

20. Markel MD, Gottsauner-Wolf F, Bogdanske JJ, Wahner HW, Chao EYS (1993) Dual energy $\mathrm{x}$-ray absorptiometry of implanted femora after cemented and press-fit total hip arthroplasty in a canine model. J Orthop Res 11:452-456

21. Cohen B, Rushton N (1995b) Bone remodelling in the proximal femur after Charnley total hip arthroplasty. J Bone Joint Surg Br 77:815-819 


\section{Chapter 3}

22. Wilkinson JM, Peel NF, Elson RA, Stockley I, Eastell R (2001) Measuring bone mineral density of the pelvis and proximal femur after total hip arthroplasty. J Bone Joint Surg $\mathrm{Br}$ 83:283-288

23. Venesmaa PK, Kröger HPJ, Jurvelin JS, Miettinen HJA, Suomalainen OT, Alhava EM (2003) Periprosthetic bone loss after cemented total hip arthroplasty. A prospective 5-year dual energy radiographic absorptiometry study of 15 patients. Acta Orthop Scand 74(1):31-36

24. Grant P, Aamodt A, Falch JA, Nordsletten L (2005). Differences in stability and bone remodeling between a customized uncemented hydroxyapatite coated and a standard cemented femoral stem. A randomized study with use of radiostereometry and bone densitometry. J Orthop Res 23:1280-1285

25. Nixon M, Taylor G, Sheldon P, Iqbal SJ, Harper W (2007) Does bone quality predict loosening of cemented total hip replacements? J Bone Joint Surg Br 89:1303-1308

26. Nivbrant B, Kärrholm J, Söderlund P (1999) Increased migration of the SHP prosthesis. Radiostereometric comparison with the Lubinus SP2 design in 40 cases. Acta Orthop Scand 70:569-577

27. Nygaard M, Zerahn B, Bruce C, Søballe K, Borgwardt A (2004) Early periprosthetic femoral bone remodelling using different bearing material combinations in total hip arthoplasties: a prospective randomised study. Eur Cells Mater 8:65-73

28. Dan D, Germann D, Burki H, Hausner P, Kappeler U, Meyer RP, Klaghofer R, Stoll T (2006) Bone loss after total hip arthoplasty. Rheumatol Int 26:792-798

29. Li MG, Rohrl SM, Wood DJ, Nivbrant B (2007) Periprosthetic changes in bone mineral density in 5 stem designs 5 years after cemented total hip arthroplasty. No relation to stem migration. J Arthroplasty 22:689-691

30. Kröger H, Miettinen H, Arnala I, Koski E, Rushton N, Suomalainen O (1996) Evaluation of periprosthetic bone using dual-energy x-ray absorptiometry. Precision of the method and effect of operation on bone mineral density. J Bone Miner Res 10:1526-1530

31. Bulstra SK, Geesink RG, Bakker D, Bulstra TH, Bouwmeester SJ, van der Linden AJ (1996) Femoral canal occlusion in total hip replacement using a resorbable and flexible cement restrictor. J Bone Joint Surg Br 78:892-898

32. Sijbesma T (2002) From laboratory to clinic. The study of a new cemented total hip arthroplasty. Thesis, University of Groningen, The Netherlands 
33. Broeke ten RHM, Hendrickx RPM, Leffers P, Jutten LMC, Geesink RGT (2012) Randomised trial comparing bone remodelling around two uncemented stems using modified Gruen zones. Hip Int 22:41-49

34. Breusch SJ, Lukoschek M, Kreutzer J, Brocai DRC, Gruen T (2001) Dependency of cement mantle thickness on femoral stem design and centralizer. J Arthroplasty 16(5):648-657

35. Rodan GA (1992) Introduction to bone biology. Bone 13:3-6

36. Hyman JE, Bouxsein ML, Reilly DT, Hayes WC (1993) Dual energy x-ray absorptiometry precisely measures bone mineral density around uncemented and cemented proximal femoral prostheses in vivo. J Bone Miner Res 8:350

37. Sheperd JA, Jablonski M (1999) Quantitation of bone density at sites of metal implants. In: Blake GM,Wahner HW, Fogelman I, eds. The evaluation of osteoporosis: dual energy x-ray absorptiometry and ultrasound in clinical practice. 2nd ed. London, Martin Dunitz Ltd, 415-427

38. Ebramzadeh E, Sarmiento A, McKellop HA, LLinsa A, Gogan W (1994) The cement mantle in total hip arthroplasty. Analysis of long-term radiographic results. J Bone Joint Surg Am 76:77-87

39. Joshi RP, Eftekhar NS, McMahon DJ, Nercessian OA (1998) Osteolysis after Charnley primary low-friction artrhoplasty. A comparison of two matched paired groups. J Bone Joint Surg Br 80:585-590

40. Morscher EW, Wirz D (2002) Current state of cement fixation in THR. Acta Orthop Belg 68:1-12

41. Macpherson GJ, Hank C, Schneider M, Trayner M, Elton R, Howie CR, Breusch SJ (2010) The posterior approach reduces the risk of thin cement mantles with a straight femoral design. Acta Orthop 81:292-295

42. Ayers D, Mann K (2003) The importance of proximal cement filling of the calcar region: a biomechanical justification. J Arthroplasty 18(7 Supp/ 1):103-109

43. Berger RA, Seel MJ, Wood K, Evans RN, D'Antonio J, Rubash HE (1997) Effect of a centralizing device on cement mantle deficiencies and initial prosthetic alignment in total hip arthroplasty. J Arthroplasty 12:434-443

44. Ostgaard HC, Helger L, Regner H, Garellick G (2001) Femoral alignment of the Charnley stem: a randomized trial comparing the original with the new instrumentation in 123 hips. Acta Orthop Scand 72:228-232

45. Valdivia GG, Dunbar MJ, Parker DA, Woolfrey MR, MacDonald SJ, McCalden RW, Rorabeck CH, Bourne RB (2001) The John Charnley Award: Three-dimensional analysis of the cement mantle in total hip arthroplasty. Clin Orthop 393:38-51 


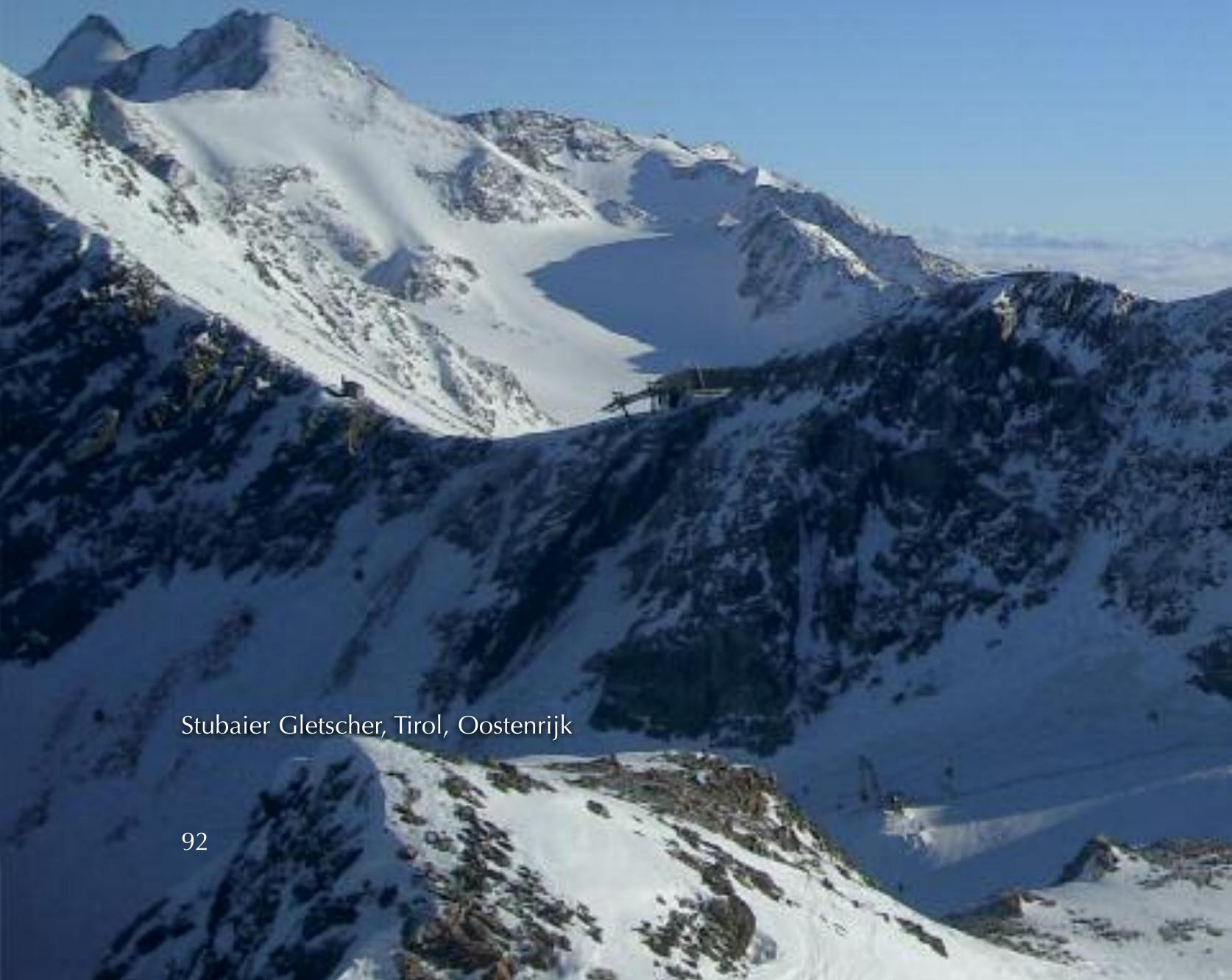




\section{CHAPTER 4}

\section{Results of total hip arthroplasties in the young patient;}

further evidence for a barrier against articular wear debris by hydroxyapatite coatings

Pieter Emans

René ten Broeke Jeroen van Mulken

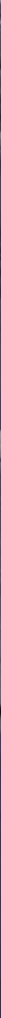




\section{ABSTRACT}

We examined the hypothesis that the circumferential osseous apposition around a HA-coated implant forms a protective barrier against articular wear debris. Sixty-five hydroxyapatite-coated total hip arthroplasties in 57 patients (age $<50$ years) with polyethylene-metal articulation were evaluated regarding PE-wear, osteolysis, and clinical outcome at a minimum of 10 years follow-up.

There was no correlation between PE-wear and osteolysis of the femoral zones or cup zones I and III. A strong Pearson correlation was found between polyethylene wear and osteolysis around cup zone II, where the cup only consisted of polyethylene $(P<0,01)$. The aseptic failure rate was $1,5 \%$ for the femoral component and $4.5 \%$ for the cup after 10 years of follow-up. The average Harris Hip Score was $\mathbf{9 0}$ and the average Engh score for fixation was 23 after 10 years. Around HA-coated parts of the prosthesis bone formation remained stable, regardless of the degree of polyethylene wear. The average linear polyethylene wear was $0,16 \mathrm{~mm} /$ year.

The circumferential osseous apposition of the HA-coated implants possibly formed a protective barrier against articular wear debris. The use of cups with a backside gap resulted in PE-wear associated osteolysis in cup zone II and may be considered to be best avoided. 


\section{INTRODUCTION}

The main purpose of a total hip arthroplasty (THA) is to relieve pain. Reduction of disability and correction of deformity are important secondary goals. A THA in the young patient should achieve a strong, permanent, stable bond with bone. Preservation of femoral and acetabular bone stock in these patients is especially important because of the higher risk of future revision operations.

The use of hydroxyapatite ( $\mathrm{HA})$ is attractive since it is well established that HA-coated implants encourage osteoconduction ${ }^{1-4}$. Contrary to most porous metallic coatings towards which gaps larger than $0,3 \mathrm{~mm}$ are not bridged, with HA-coated implants bone deficiencies up to $2 \mathrm{~mm}$ are bridged $^{3,5,6}$. In addition HA-coated implants achieve a very strong bond with living bone in a short period, even under loaded conditions. These are considered ideal features for the hip prosthesis in younger patients. Following the introduction of HA-coated THA, critics believed the coating might delaminate leading to loosening, PE wear and osteolysis $^{7-9}$. However, an association between HA loss and detrimental effects on long term fixation was never established ${ }^{10}$. Osteolysis caused by articular wear debris is a major long - term problem in both cemented and uncemented hip prostheses, and has been observed in mid - to long - term studies ${ }^{11,12}$.

In this prospective study we examine the hypothesis that the circumferential osseous apposition around a HA-coated implant forms a barrier against migration of articular wear debris ${ }^{13,14}$ and present the clinical and radiographic results of 65 primary HA-coated total hip arthroplasties in patients younger than 50 years of age with a follow-up of at least 120 months.

\section{MATERIALS AND METHODS}

Between 1986 to 1996, 65 hips (57 patients) were treated with a primary HA coated THA. Informed consent was obtained in all cases. The indication was osteoarthritis (OA) in 44, avascular necrosis in 10, rheumatoid arthritis (RA) in 5, post-traumatic joint damage in 5, and deep joint infection in one. There were 26 female and 39 male patients. At the time of surgery all patients were younger than 


\section{Chapter 4}

50 years of age (average 40 years, range 18-50 years). Several surgeons including residents performed the operations.

Routine post-operative management included 24 hours of antibiotic prophylaxis (cephalosporins) and peri- and post-operative anticoagulation using coumarin for three months. No prophylactic treatment against heterotopic ossification was given. Immediate full weight bearing was usually allowed postoperatively, using a cane or crutches for comfort during the first four to six weeks.

All patients were classified according to Charnley's categories: Category A (unilateral hip) 42, Category B (bilateral hip) 8 and Category C 7 patients (unilateral or bilateral with medical problems). Associated problems of patients in Charnley category $\mathrm{C}$ were neurological disease in 4 patients (5 hips), juvenile RA in 2 patients (3 hips), and bilateral knee osteoarthritis in one patient (1 hip).

\section{Prosthesis}

In all cases the titanium alloy (Ti6Al4V) Omnifit ${ }^{\circledR}$ stem (Osteonics, Allendale, New Jersey. now: Stryker, Mahwah, New Jersey) with a plasma spray HA-coating on $40 \%$ of the proximal stem length and a stainless steel taper-head was used. The titanium threaded Omnifit ${ }^{\circledR}$ Cup (Osteonics) with HA-coating over one half of the outer sphere area with a backside gap was used for the acetabular component combined with an ultrahigh molecular weight PE insert (10 degree gamma in air sterilized, bevelled insert) (Figure 1).

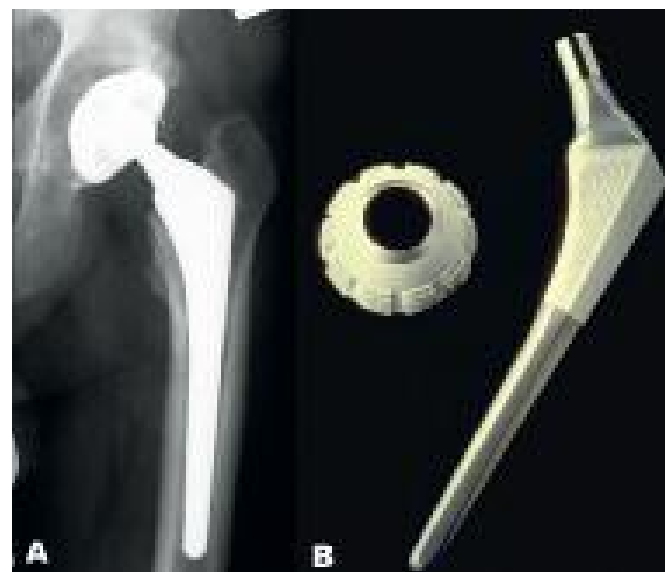

Fig. 1a Evident PE-wear and osteolysis in cup zone II.

Fig. 1b Omnifit HA-coated titanium femoral stem and cup.

\section{Clinical evaluation}

Clinical evaluation was performed by means of the Modified Harris Hip Score $(\mathrm{HHS})^{6,15}$ starting pre-operatively and then post-operatively at 3, 6, 12 months, and 
yearly there after. Pre-operatively the average Body Mass Index (BMI) of this group was 24 (range 16,1 to 35,2 ).

\section{Radiological evaluation}

For radiological evaluation an anteroposterior (AP) view of the lower pelvis was taken with a lateral view of the involved hip. For evaluation of the stem Gruen zones ${ }^{16}$ and for the cup the zones as described by DeLee and Charnley (1976) were evaluated for signs of reactive line formation, spotwelds (endostal bone formation), pedestal formation and periosteal bone reactions. The appearance of the calcar was graded as described by Engh et al. ${ }^{17}$. The PE wear was detected by head and liner eccentricity as measured by the technique of Livermore ${ }^{18}$. Heterotopic bone formations were graded according to the Brooker classification ${ }^{19}$. The implants were also graded according to Engh s radiological fixation and stability score for cementless implants ${ }^{20}$.

\section{Statistical methods.}

Survival rates were determined according to the method of Kaplan-Meier and the Pearson correlation test was used to detect a relation between clinical results and osteolysis, PE wear or reactive line formation using SPSS version 12.0.1 (SPSS, Chicago, Illinois) software. $P$ values $<0,05$ were considered significant.

\section{Results}

Seven patients had incomplete follow-up after an average follow-up of 70 months (range 60 - 96 months) because they moved or would not participate anymore. Therefore, 58 hips had a complete and 7 hips an incomplete clinical and radiological follow-up. Survival of the different components could be verified in 3 of these 7 patients by an AP and lateral radiograph. At the last assessment the remaining 4 had excellent clinical scores and no signs of loosening or excessive PE wear.

\section{Complications}

Complications are listed in Table I. One patient had a deep joint infection. The infection was a flare up of the same organism that caused the indication for this hip 


\section{Chapter 4}

Table I Complications and revision of components in the HA-Coated THA in the young patient.

\begin{tabular}{|c|c|c|c|}
\hline Complication & (n) & Treatment & (n) \\
\hline Infection & 1 & THA revision/antibiotics & 1 \\
\hline Stem and cup loosening & 1 & THA revision & 1 \\
\hline Cup loosening & 2 & Cup revision & 2 \\
\hline \multirow[t]{2}{*}{ Dislocation of hip } & \multirow[t]{2}{*}{4} & Closed reduction & 4 \\
\hline & & Exchange PE liner & 3 \\
\hline \multirow[t]{2}{*}{ Severe heterotopic bone formation } & \multirow[t]{2}{*}{4} & PAO excision & 2 \\
\hline & & None & 2 \\
\hline Intraoperative fracture & 4 & Partial weight bearing & 4 \\
\hline Post operative fracture & 1 & Revision stem & 1 \\
\hline Revision of component & (n) & Cause & (n) \\
\hline \multirow[t]{2}{*}{ Stem and cup } & \multirow[t]{2}{*}{2} & Infection & 1 \\
\hline & & Aseptic mechanical failure & 1 \\
\hline Stem & 1 & Traumatic fracture & 1 \\
\hline Cup & 2 & Aseptic mechanical failure & 2 \\
\hline \multirow[t]{4}{*}{ PE liner } & \multirow[t]{4}{*}{8} & PE wear & 5 \\
\hline & & Traumatic fracture & 1 \\
\hline & & Impingement against stem & 1 \\
\hline & & Deep groove after dislocation & 1 \\
\hline
\end{tabular}

arthroplasty (a septic destruction of the hip). The prosthesis was removed, the infected area was treated successfully with gentamicin beads and systemic antibiotics and a new prosthesis was implanted, this time with more success. Excision of peri-articular ossications was performed in 2 cases.

Survival of the different components is summarized in Figure 2 a-c. Causes of loss of different components are listed in Table I. The aseptic mechanical loosening rate of the femoral stem is $1,5 \%$ and the aseptic mechanical loosening rate of the acetabular component was $4,5 \%$. PE wear was the major cause for revision surgery 

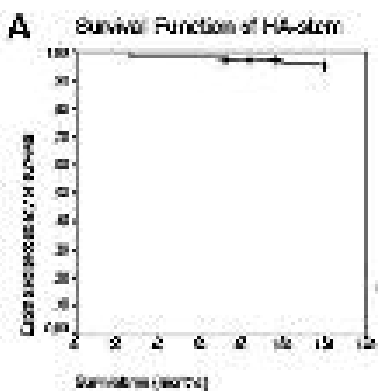

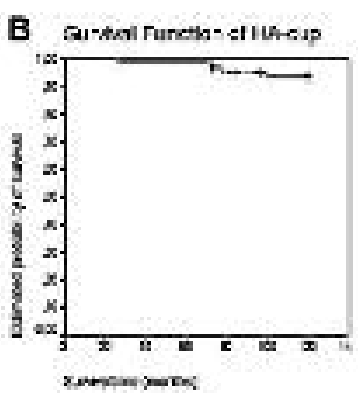

Fig. 2 Kaplan Meier survival curves of different components; 2a-Four HA-coated stems were lost to follow-up. Mechanical failure was the cause for revision of the first stem, the second revision was caused by an infection and the third stem was revised because of a traumatic femoral fracture. $2 b$ - Four HA-coated cups were revised. Infection was the cause of one revision. Cup loosening was the cause of three cup revisions, extreme PE-wear caused one of these loosenings. 2c - Survival of the PE insert. Eight inserts were revised. Polyethylene wear was the major cause for revision ( $n=5)$. Other causes were; a fracture of the insert, a deep groove after dislocation, and impingement.

Fig. 3a Harris Hip Score (0 to100).

Fig. $3 \mathrm{~b}$ Engh score ( -31 to 27 ) of 65 hips, with an interval of confidence of $95 \%$. Seven hips were lost to follow-up for clinical and radiological evaluation after an average follow-up of 70 months.
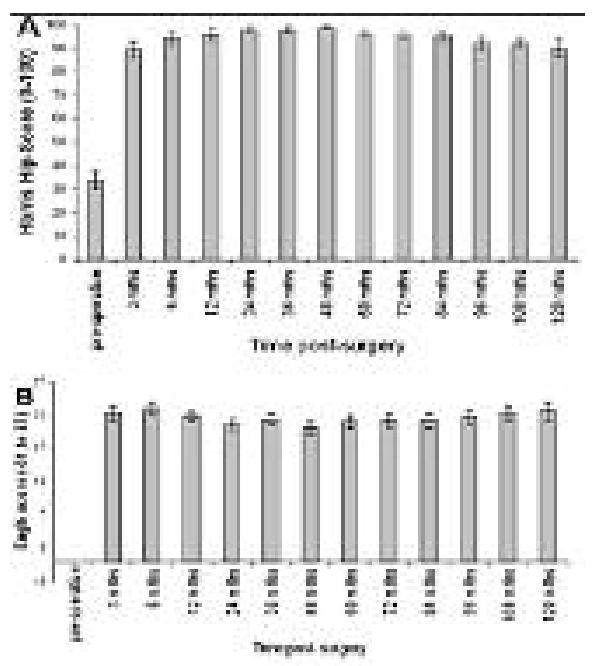


\section{Chapter 4}

of the insert. One case (after a follow - up period of 24 months) had to be revised because of a periprosthetic fracture of the femur and loosening of the cup caused by an incident during mountain climbing.

\section{Clinical results}

Clinical results are shown in Figure 3. This figure shows the average Harris Hip Score with an interval of confidence of $95 \%$. The average preoperative HHS was 34 , three months after surgery the HHS increased to an average of 89 . After ten years 2 patients had a poor $(<70) \mathrm{HHS}, 5$ patients had a fair $(70-79) \mathrm{HHS}$, the rest of the patients had a good $(80-89)$ to excellent $(>90) \mathrm{HHS}$ (average 90).

\section{Radiological results}

Bone - reactive lines.

Most of the reactive lines were seen after 6 to 12 months in Gruen zones 3, 4 and 5. During follow-up these lines gradually diminished. In $10 \%$ of the patients a reactive line was seen near the HA-coated part of the stem. This was only observed for Gruen zone 1 but no reactive lines were observed in Gruen zone 7. At four

Table II Reactive line formation per Gruen zone of HA-coated femoral stems (percentage of stems) by follow-up period

\section{Percentage reactive line formation per Gruen zone}

\begin{tabular}{lllllllllllll}
\hline Gruen & 3 & 6 & 1 & 2 & 3 & 4 & 5 & 6 & 7 & 8 & 9 & 10 \\
zone & mth & mth & yr & yr & yr & yr & yr & yr & yr & yr & yr & yr \\
\hline 1 & 0 & 0 & 2 & 7 & 6 & 12 & 12 & 9 & 14 & 15 & 8 & 12 \\
2 & 0 & 2 & 5 & 7 & 6 & 15 & 22 & 17 & 18 & 13 & 8 & 5 \\
3 & 0 & 10 & 36 & 50 & 48 & 58 & 57 & 57 & 58 & 57 & 51 & 43 \\
4 & 4 & 37 & 71 & 89 & 87 & 92 & 83 & 80 & 72 & 70 & 64 & 55 \\
5 & 0 & 20 & 38 & 36 & 33 & 52 & 48 & 48 & 44 & 40 & 36 & 27 \\
6 & 0 & 2 & 7 & 11 & 17 & 33 & 24 & 15 & 18 & 9 & 6 & 7 \\
7 & 0 & 0 & 0 & 0 & 0 & 0 & 0 & 0 & 0 & 0 & 0 & 0 \\
$\%$ stems & 4 & 49 & 79 & 95 & 88 & 96 & 84 & 85 & 78 & 77 & 68 & 63 \\
\hline
\end{tabular}


years follow-up reactive line formation around the distal stem zone was observed along $96 \%$ of the stems. After six years this type of reactive line formation decreased in all the affected Gruen zones and approached $60 \%$ of the stems at ten years of follow up (Table II).

\section{Endosteal bone apposition.}

The development of endosteal bone formation (spotwelds) is shown in table III. A typical pattern of bone formation starting at the medial distal part (Gruen zone 6) up to Gruen zone 7 was seen. The same pattern appeared between the sixth and $12^{\text {th }}$ month at the lateral side. Between 6 and twelve months, the medial spotwelds expanded into Gruen zone 7. Gradually the medial spotwelds also merged to form a bigger "weld area" on the complete medial coating area. The same pattern was seen in a later period at the proximal lateral side. All of the HA-coated stems showed positive signs of bony ongrowth after a follow-up of two years. The area of bone ongrowth expanded with time. After a maximum follow-up of more than 13 years the bone ongrowth area has expanded to virtually the whole non-coated area (Table III).

\begin{tabular}{|c|c|c|c|c|c|c|c|c|c|c|c|c|}
\hline \multicolumn{13}{|c|}{ Percentage bone formation per Gruen zone } \\
\hline Gruen & 3 & 6 & 1 & 2 & 3 & 4 & 5 & 6 & 7 & 8 & 9 & 10 \\
\hline zone & mth & mth & yr & yr & yr & yr & yr & yr & $\mathrm{yr}$ & yr & yr & $\mathrm{yr}$ \\
\hline 1 & 9 & 37 & 48 & 73 & 85 & 81 & 84 & 89 & 92 & 92 & 89 & 85 \\
\hline 2 & 15 & 63 & 75 & 100 & 100 & 100 & 100 & 98 & 98 & 100 & 100 & 98 \\
\hline 3 & 0 & 0 & 0 & 13 & 27 & 17 & 33 & 44 & 4 & 53 & 62 & 65 \\
\hline 4 & 0 & 2 & 0 & 0 & 2 & 2 & 9 & 9 & 14 & 17 & 26 & 28 \\
\hline 5 & 0 & 0 & 2 & 13 & 38 & 33 & 53 & 63 & 54 & 72 & 66 & 78 \\
\hline 6 & 32 & 73 & 89 & 96 & 98 & 96 & 100 & 100 & 98 & 100 & 98 & 100 \\
\hline 7 & 26 & 65 & 79 & 93 & 98 & 98 & 100 & 98 & 98 & 100 & 100 & 100 \\
\hline$\%$ stems & & 80 & 93 & 100 & 100 & 100 & 100 & 100 & 100 & 100 & 100 & 100 \\
\hline
\end{tabular}




\section{Chapter 4}

\section{Calcar resorption.}

The first definite calcar remodeling was seen between three and six months (Table IV). However, after ten years no severe resorption of the calcar or bone distal to level of the lesser trochanter were observed in any case.

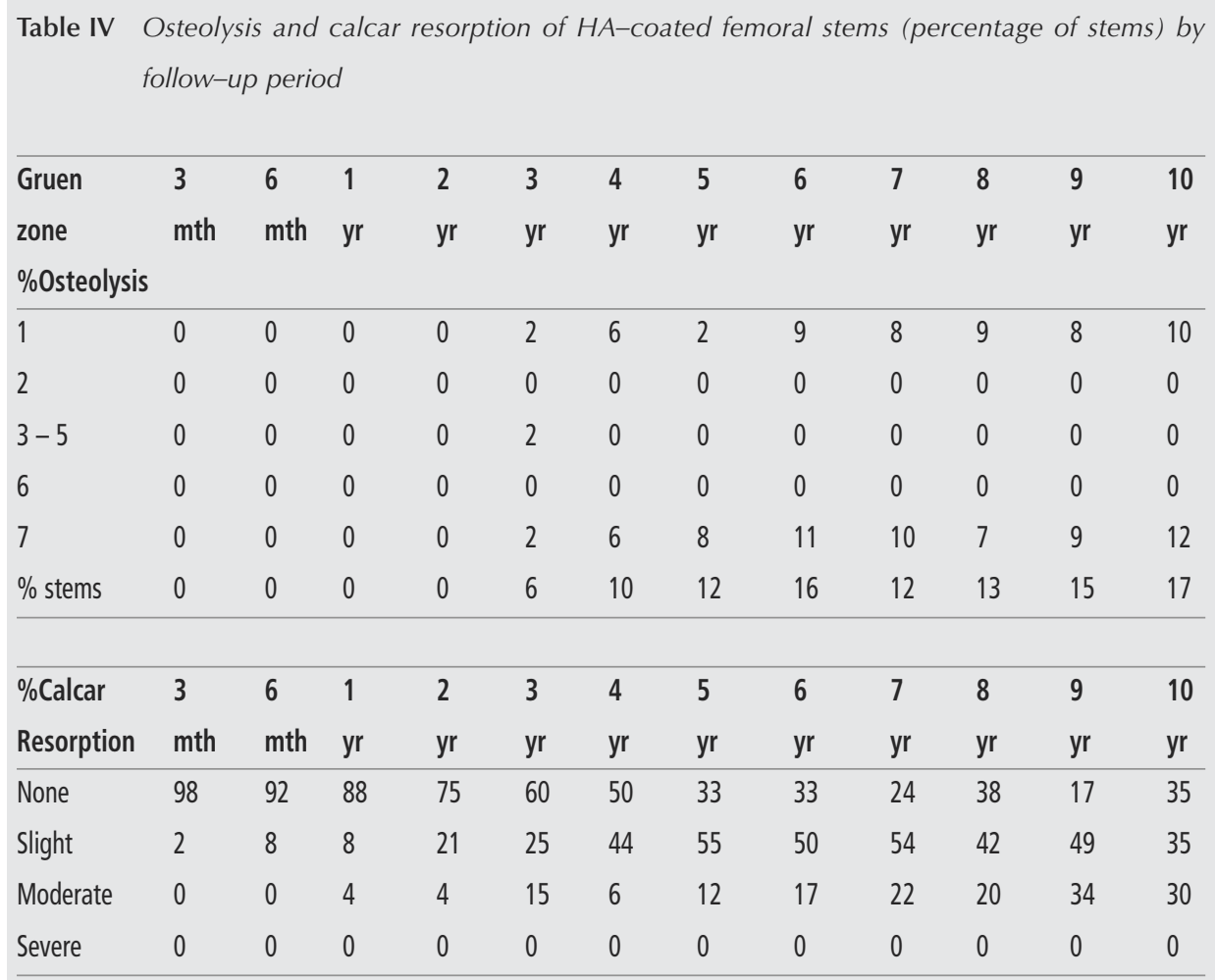

\section{Heterotopic bone formation.}

Four patients suffered from grade IV heterotopic bone formation. Two cases required excision of the mass, one after a follow-up of 126 months. Both hips regained a good range of motion. 
Osteolysis.

Osteolysis became evident after 5 years of follow-up in Gruen zones 1 and 7 in about $10 \%$ of the cases (Table IV). The percentage and degree of osteolysis around the stem remained stable up to 10 years follow-up. For the cup most of the osteolysis could be observed in zone II (Figure 1B), and up to $29 \%$ of the cups had osteolysis after 10 years of follow-up (Table V).

Table V Bone formation, reactive line formation, osteolysis around HA-threaded cups (percentage cups), and PE wear by follow-up period.

\section{DeLee and}

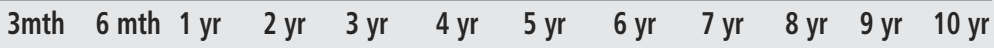

Charnley zone

\%Bone formation

\begin{tabular}{lllllllllllll}
\hline I & 9 & 57 & 70 & 88 & 94 & 10 & 97 & 94 & 94 & 96 & 96 & 90 \\
II III & 0 & 2 & 0 & 2 & 0 & 0 & 0 & 2 & 0 & 0 & 0 & 0 \\
\%Reactive & 9 & 35 & 59 & 88 & 96 & 96 & 97 & 93 & 92 & 91 & 94 & 90 \\
line formation & & & & & & & & & & & & \\
\hline I & 0 & 0 & 5 & 4 & 2 & 0 & 3 & 4 & 6 & 6 & 4 & 7 \\
II & 0 & 0 & 5 & 7 & 8 & 8 & 19 & 13 & 14 & 13 & 13 & 12 \\
III & 0 & 0 & 0 & 2 & 2 & 0 & 2 & 2 & 8 & 11 & 4 & 8 \\
\hline
\end{tabular}

\section{$\%$ Osteolysis}

\begin{tabular}{lllllllllllll}
\hline I & 0 & 0 & 0 & 0 & 2 & 4 & 4 & 6 & 2 & 2 & 5 & 3 \\
II & 0 & 0 & 0 & 0 & 6 & 15 & 9 & 13 & 11 & 11 & 20 & 29 \\
\% cups & 0 & 0 & 0 & 0 & 0 & 0 & 2 & 0 & 0 & 4 & 3 & 9 \\
\hline
\end{tabular}

PE wear

$\%$ of cases

0

$\begin{array}{llllllllll}0 & 0 & 4 & 10 & 22 & 37 & 46 & 53 & 55 & 55\end{array}$




\section{Chapter 4}

\section{Engh s radiological score.}

The scores (Engh et al (1990)) are based on the radiological features that indicate fixation and stability ${ }^{20}$. The maximum score is 27 points. Scores above 5 points are asymptomatic and have a definite bone ingrowth, scores between 0-5 have equally good clinical results but fewer signs of ingrowth, and scores below minus 5 have multiple negative signs of loosening and are likely to be symptomatic. From 3 months onwards none of our patients had a score lower than 5 points. The average Engh scores are listed in figure 3, the scores remain between 20 and 25 points with an interval of confidence of 95\% (Figure 3).

\section{Acetabular cup ingrowth}

Bone formation around the cup appeared to be a slower process than around the stem. Between 6 months and 1 year of follow-up the bone formation became evident in DeLee and Charnley zones I and III. In 70\% of the cases in zone I and in 59\% in zone III, radiological evidence of bone formation was found after 1 year follow-up. Even after long term follow-up there was minimal bone formation in zone II, (the non-metallic area of the cup), and radiolucent lines were mostly seen in zone II. In a few cases reactive line formation was seen in zone III, which is known to be a critical area for threaded cups. Details can be found in Table V. From three years on all the HA-coated cups showed radiological evidence of bone ongrowth. One case showed cup loosening after a follow-up of 118 months. The cup was revised with cemented impaction grafting.

\section{PE wear.}

In five cases the PE liner was replaced because of PE wear and late recurrent dislocations. The HHS in these five patients decreased to an average of 85,2. After exchange of the PE liner the average HHS was 97,8. Generally PE wear became radiological evident after a follow -up of 5 years. In more than $50 \%$ of the cases PE wear was found after 10 years of follow-up (Table V). Average linear wear was $1,6 \mathrm{~mm}$ and the average wear rate was $0,16 \mathrm{~mm} /$ year. Individual cases with more than $2 \mathrm{~mm}$ PE wear and the percentage of contact surface area osteolysis per different stem (Gruen Zone 1 and 7) and cup zone (cup zone 1-3) are shown in table VI. 
Table VI Individual cases with more than $2 \mathrm{~mm}$ PE wear and the percentage of contact surface area osteolysis per different stem (Gruen Zone 1 and 7) and cup zone (cup zone 1-3):

\begin{tabular}{lcccccc} 
Case & PE wear $(\mathrm{mm})$ & Stem zone 1 & Stem zone 7 & Cup Zone 1 & Cup Zone 2 & Cup Zone 3 \\
\hline 1 & 5 & 0 & 10 & 25 & 100 & 10 \\
2 & 3 & 0 & 0 & 25 & 75 & 0 \\
3 & 4 & 0 & 20 & 0 & 50 & 0 \\
4 & 2,5 & 0 & 10 & 0 & 50 & 25 \\
5 & 3 & 0 & 0 & 0 & 75 & 25 \\
6 & 4 & 0 & 0 & 0 & 50 & 0 \\
7 & 2,5 & 0 & 0 & 0 & 75 & 0 \\
8 & 3 & 0 & 0 & 25 & 74 & 0 \\
9 & 3,5 & 0 & 10 & 0 & 50 & 0 \\
10 & 4 & 0 & 0 & 0 & 50 & 0 \\
\hline
\end{tabular}

\section{Statistical results.}

A significant Pearson correlation was found between the degree of PE wear and osteolysis around the cup $(P<0,01)$. Cup zone II was particularly associated with osteolysis and a strong Pearson correlation with PE wear $(P<0,01)$. No correlation was found between PE wear and osteolysis around other cup or stem zones. No relationship was found between the degree of PE wear and clinical scores. There was also no correlation between a diminishing reactive line formation in Gruen zones 3, 4 and 5 and osteolysis in Gruen zones 1 and 7. 


\section{Chapter 4}

\section{Discussion}

In this study long-term results of HA-coated total hip arthroplasties in young patients are described with emphasis on PE wear and its correlation with osteolysis.

For the polyethylene liner, the rate of failure caused by PE wear was $9 \%$. After a follow-up of 10 years, over $50 \%$ of the cases showed evidence of PE wear. Both average linear PE wear and average wear rate were comparable to other studies using cemented and uncemented THA ${ }^{21-25}$. PE wear was the cause of re-operations in five cases (Table II). Our group previously reported on the possibility of late failure of well fixed implants as a consequence of biological reactions to PE wear debris in the young patient ${ }^{26}$. In the present study we found a considerable incidence of PE wear and no evidence for loosening of the femoral component due to this wear, and no correlation was found between PE wear and osteolysis around femoral stem. These findings and the early onset of bone formation around the HA coating of the stem support the hypothesis that the circumferential osseous apposition around a HA-coated implant forms a barrier against distal migration of articular wear debris, especially on the femoral side ${ }^{13,14}$. The relationship between PE wear and osteolysis around the cup, especially around zone II, leaves several hypotheses open. Some authors suggested that wear debris from the modular interface might be pumped through the backside gap and the insert and metal backing may act as a piston pump for PE wear particles towards cup zone II causing osteolysis $^{27-29}$. Others suggest that backside wear is not the main cause for osteolysis and that a gap may even protect the insert against wear ${ }^{30}$. Due to high failure rates of cups with backside holes, there is a tendency to avoid the use of screw holes and backside gaps in acetabular cup shells ${ }^{31,32}$. In addition, younger patients have a bigger range of motion. The use of $10^{\circ}$ beveled inserts may encourage impingement and dislocations in these patients.

The problem of PE wear in THA can be resolved by replacing the PE components with ceramic components. The tribological properties of ceramic to PE articulations are superior to those of metal to PE and result in significant lower PE wear ${ }^{33-35}$. Since 1994 we use an alumina ceramic head and an alumina ceramic liner (ceramic on ceramic). In future, the use of the recently available highly cross - linked polyethylene may reduce PE wear, and results thus far are promising ${ }^{36-38}$. 
PE wear has become the major issue in THA for the young patient. The circumferential osseous apposition towards the HA-coating of both the stem and the cup appears to form a protective barrier against distal migration of articular wear debris. The use of cups with a backside gap resulted in PE wear-associated osteolysis in cup zone II and may be best avoided. The design of the cup we employed was changed in 1994. The first results of harder materials replacing the first generation PE are very promising and may reduce the number of re-operations. 


\section{Chapter 4}

\section{REFERENCES}

1. Geesink RG. Osteoconductive coatings for total joint arthroplasty. Clin Orthop Relat Res 2002;(395):53-65.

2. Bauer TW, Geesink RC, Zimmerman R, et al. Hydroxyapatite-coated femoral stems. Histological analysis of components retrieved at autopsy. I Bone Joint Surg Am 1991;73(10):1439-52.

3. Geesink RG, de Groot K, Klein CP Bonding of bone to apatite-coated implants. The Journal of bone and joint surgery 1988;70(1):17-22.

4. Tonino AJ, Romanini L, Rossi P, et al. Hydroxyapatite-coated hip prostheses. Early results from an international study. Clin Orthop 1995;(312):211-25.

5. Geesink RG Hydroxyapatite-coated total hip prostheses. Two-year clinical and roentgenographic results of 100 cases. Clin Orthop 1990;(261):39-58.

6. Harris WH, White RE, Jr., McCarthy JC, et al. Bony ingrowth fixation of the acetabular component in canine hip joint arthroplasty. Clin Orthop 1983;(176):7-11.

7. Bloebaum RD, Dupont JA Osteolysis from a press-fit hydroxyapatite-coated implant. A case study. J Arthroplasty 1993;8(2):195-202.

8. Collier JP, Surprenant VA, Mayor MB, et al. Loss of hydroxyapatite coating on retrieved, total hip components. J Arthroplasty 1993;8(4):389-93.

9. Rothman RH, Hozack WJ, Ranawat A, et al. Hydroxyapatite-coated femoral stems. A matched-pair analysis of coated and uncoated implants. I Bone Joint Surg Am 1996;78(3):319-24.

10. Bauer TW, Taylor SK, Jiang M, et al. An indirect comparison of third-body wear in retrieved hydroxyapatite-coated, porous, and cemented femoral components. Clin Orthop Relat Res 1994;(298):11-8.

11. Bobyn JD, Mortimer ES, Glassman AH, et al. Producing and avoiding stress shielding. Laboratory and clinical observations of noncemented total hip arthroplasty. Clin Orthop 1992;(274):79-96.

12. Reigstad A, Rokkum M, Bye K, et al. Femoral remodeling after arthroplasty of the hip. Prospective randomized 5-year comparison of 120 cemented/uncemented cases of arthrosis. Acta Orthop Scand 1993;64(4):411-6. 
13. Rahbek O, Kold S, Bendix K, et al. Superior sealing effect of hydroxyapatite in porouscoated implants: experimental studies on the migration of polyethylene particles around stable and unstable implants in dogs. Acta Orthop 2005;76(3):375-85.

14. Kraemer WJ, Maistrelli GL, Fornasier V, et al. Migration of polyethylene wear debris in hip arthroplasties: a canine model. J Appl Biomater 1995;6(4):225-30.

15. Ilstrup DM, Nolan DR, Beckenbaugh RD, et al. Factors influencing the results in 2,012 total hip arthroplasties. Clin Orthop 1973;95:250-62.

16. Gruen TA, McNeice GM, Amstutz HC "Modes of failure" of cemented stem-type femoral components: a radiographic analysis of loosening. Clin Orthop 1979;(141):17-27.

17. Engh CA, Bobyn JD, Glassman AH Porous-coated hip replacement. The factors governing bone ingrowth, stress shielding, and clinical results. The Journal of bone and joint surgery 1987;69(1):45-55.

18. Livermore J, Ilstrup D, Morrey B Effect of femoral head size on wear of the polyethylene acetabular component. J Bone Joint Surg Am 1990;72(4):518-28.

19. Brooker AF, Bowerman JW, Robinson RA, et al. Ectopic ossification following total hip replacement. Incidence and a method of classification. I Bone Joint Surg Am 1973;55(8):1629-32.

20. Engh CA, Massin P, Suthers KE Roentgenographic assessment of the biologic fixation of porous-surfaced femoral components. Clin Orthop 1990;(257):107-28.

21. Archibeck MJ, Surdam JW, Schultz SC, Jr., et al. Cementless total hip arthroplasty in patients 50 years or younger. J Arthroplasty 2006;21(4):476-83.

22. Kligman $\mathbf{M}$, Michael $\mathbf{H}$, Roffman $\mathbf{M}$ The effect of abduction differences between cup and contralateral acetabular angle on polyethylene component wear. Orthopedics 2002;25(1):65-7.

23. Shih $\mathrm{CH}$, Lee PC, Chen JH, et al. Measurement of polyethylene wear in cementless total hip arthroplasty. The Journal of bone and joint surgery 1997;79(3):361-5.

24. Cates HE, Faris PM, Keating EM, et al. Polyethylene wear in cemented metal-backed acetabular cups. The Journal of bone and joint surgery 1993;75(2):249-53.

25. Cruz-Pardos A, Garcia-Cimbrelo E The Harris-Galante total hip arthroplasty: a minimum 8year follow-up study. J Arthroplasty 2001;16(5):586-97.

26. Geesink RG, Hoefnagels NH Six-year results of hydroxyapatite-coated total hip replacement. The Journal of bone and joint surgery 1995;77(4):534-47. 


\section{Chapter 4}

27. Walter WL, Clabeaux J, Wright TM, et al. Mechanisms for pumping fluid through cementless acetabular components with holes. J Arthroplasty 2005;20(8):1042-8.

28. Huk OL, Bansal M, Betts F, et al. Polyethylene and metal debris generated by nonarticulating surfaces of modular acetabular components. The Journal of bone and joint surgery 1994;76(4):568-74.

29. Wasielewski RC, Jacobs JJ, Arthurs B, et al. The acetabular insert-metal backing interface: an additional source of polyethylene wear debris. J Arthroplasty 2005;20(7):914-22.

30. Yamaguchi M, Bauer TW, Hashimoto Y Deformation of the acetabular polyethylene liner and the backside gap. J Arthroplasty 1999;14(4):464-9.

31. Schmalzried TP, Brown IC, Amstutz HC, et al. The role of acetabular component screw holes and/or screws in the development of pelvic osteolysis. Proc Inst Mech Eng $\mathrm{H}$ 1999;213(2):147-53.

32. Kim SY, Kim DH, Kim YG, et al. Early failure of hemispheric hydroxyapatite-coated acetabular cups. Clin Orthop Relat Res 2006;446:233-8.

33. Kobayashi S, Saito N, Horiuchi H, et al. Poor bone quality or hip structure as risk factors affecting survival of total-hip arthroplasty. Lancet 2000;355(9214):1499-504.

34. Minakawa $\mathrm{H}$, Stone $\mathrm{MH}$, Wroblewski BM, et al. Quantification of third-body damage and its effect on UHMWPE wear with different types of femoral head. The Journal of bone and joint surgery 1998;80(5):894-9.

35. Dorr LD, Wan Z, Longjohn DB, et al. Total hip arthroplasty with use of the Metasul metalon-metal articulation. Four to seven-year results. J Bone Joint Surg Am 2000;82(6):789-98.

36. Heisel C, Silva M, Schmalzried TP In vivo wear of bilateral total hip replacements: conventional versus crosslinked polyethylene. Arch Orthop Trauma Surg 2005;125(8):555-7.

37. Oonishi H, Kadoya Y Wear of high-dose gamma-irradiated polyethylene in total hip replacements. J Orthop Sci 2000;5(3):223-8.

38. Digas G, Karrholm J, Thanner J, et al. The Otto Aufranc Award. Highly cross-linked polyethylene in total hip arthroplasty: randomized evaluation of penetration rate in cemented and uncemented sockets using radiostereometric analysis. Clin Orthop Relat Res 2004; (429):6-16. 
Hydroxyapatite forms a barrier against articular wear debris 


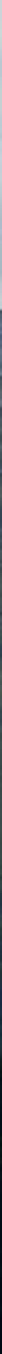

Canbier, Les Quatre Vallées, Zwitserland 


\title{
CHAPTER 5
}

Bone reaction to a Biomimetic third generation HA-coating and new surface treatment on a newly designed hip stem

HISTOLOGY, HISTOMORPHOMETRY AND SEM-ANALYSIS OF THE SYMAXTM STEM EXTRACTED FOR OTHER REASONS THAN LOOSENING

\author{
René ten Broeke \\ Antoine Alves \\ Axel Baumann \\ Chris Arts \\ Rudolph Geesink
}




\section{Abstract}

Four uncemented Symax hip stems were extracted at three weeks and nine, 13 and 32 months, respectively, for reasons other than loosening. The reasons for implant removal were infection in two cases, recurrent dislocation in one and acetabular fracture in one. They were analysed to assess the effect and behaviour of an electrochemically deposited, completely resorbable biomimetic BONIT ${ }^{{ }_{-}}$ hydroxyapatite (HA) coating (proximal part) and a DOTIZE ${ }^{\circledR}$ surface treatment (distal part) using qualitative histology, quantitative histomorphometry and scanning electron microscopy (SEM). Early and direct bone-implant bonding with signs of active remodelling of bone and the HA coating were demonstrated by histology and SEM. No loose BONIT ${ }^{\circledR}$-HA particles or delamination of the coating were observed, and there was no inflammation or fibrous interposition at the interface.

Histomorphometry showed bone-implant contact varying between $26.5 \%$ at three weeks and $\mathbf{8 3 . 5 \%}$ at 13 months at the HA-coated implant surface. The bone density in the area of investigation was between $24.6 \%$ at three weeks and $41.1 \%$ at 32 months. The DOTIZE ${ }^{\circledR}$ surface treatment of the distal part of the stem completely prevented tissue and bone apposition in all cases, thereby optimising proximal stress transfer.

The overall features of this implant, in terms of geometry and surface texture, suggest a mechanically stable design with a highly active biomimetic coating, resulting in rapid and extensive osseo-integration, exclusively in the metaphyseal part of the stem. Early remodelling of the HA coating does not seem to have a detrimental effect on short-term bone-implant coupling. There were no adverse effects identified from either the BONIT ${ }^{\circledR}-\mathrm{HA}$ coating or the DOTIZE ${ }^{\circledR}$ surface treatment. 


\section{INTRODUCTION}

Since the introduction of cementless designs for total hip arthroplasty the greatest step forward to true osseointegration was made with calciumphosphate coatings for early bone apposition and biological fixation. Of these, hydroxyapatite is the most used and documented, both in basic research ${ }^{1-8}$ as well as in short-term ${ }^{9-14}$ and long-term clinical experience, ${ }^{15,16}$ illustrating good clinical performance and a stable bone interface. Implant retrievals have shown superior bone apposition on the implant and consistent evidence of osseointegration. ${ }^{17-22}$

The majority of the experience is associated with HA-coated implants using a ('first generation') plasmaspray technique, ${ }^{23}$ because of its established technology, cost effectiveness and reproducibility. This so called 'line-of-site' coating technique has the disadvantage of coating only the outermost layer of the implant surface like paint-spray technique, which occludes deeper layers of the more open threedimensional surface textures. This will result in only bone apposition to the superficial comparatively thicker coating but not the underlying titanium, creating an extra interface. This unfavourable situation may exist for a long time owing to the relatively insoluble, highly cristalline plasmaspray coatings. Although there is no clear evidence in the literature that loss of plasmasprayed HA-coating affects the long-term performance of the implant, there is concern about deterioration of the bone-implant coupling (BIC) after degradation of the HA-coating. ${ }^{21,24,25}$ Another issue has always been that the degradation of plasmaspray HA coatings might generate so called 'third body wear'-particles which could initiate the differentiation of macrophages into osteoclasts, eventually leading to deterioration of the bone-implant bond and subsequent loosening. ${ }^{26-28}$

Newer techniques such as electrophoretic deposition, ion-beam-assisted deposition (IBAD) and solution deposition have the capability of uniformly coating superficial and deeper layers of implant surface structures, as well as the open pores of materials such as tantalum with extreme porosity, resulting in a deeper bioactive layer applied onto and particularly into the more open surface structure of the implant. This provides a larger surface area for osteoconduction and creates a deeper and tighter anchorage to bone. The so called 'biomimetic' (nature-like) coatings such as BONIT ${ }^{\circledR}$-HA (DOT GmbH, Rostock, Germany) are based on the 


\section{Chapter 5}

deposition and growth of microcrystalline calciumphosphate-molecules from supersaturated calcifying solutions (simulated body fluids - SBF). ${ }^{29-33}$ Usually these coatings are much thinner $(2-20 \mu \mathrm{m})$ than the 50-200 $\mu \mathrm{m}$ thick plasma-sprayed coatings. This diminishes the risk of fatigue-fracture and delamination, which were early concerns with thicker and more brittle coatings. These thinner and more evenly and controllably deposited coatings can be better regulated in terms of purity, cristallinity and hence resorbability, because of a better control of the physicochemical circumstances $(\mathrm{pH}$, temperature, saturation and calciumphosphate composition of the SBF) under which they are produced. ${ }^{34}$ The advantage of low

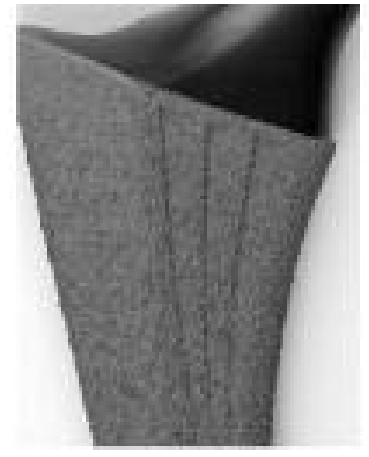

Fig. 1a

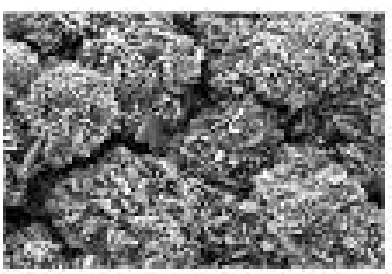

Fig. 1d

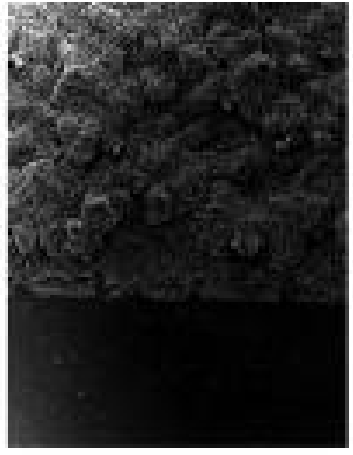

Fig. 1b

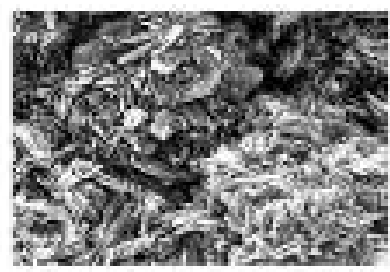

Fig. 1e

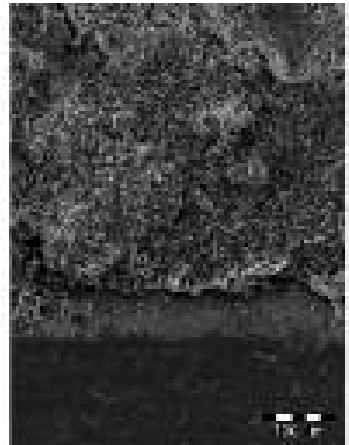

Fig. 1c

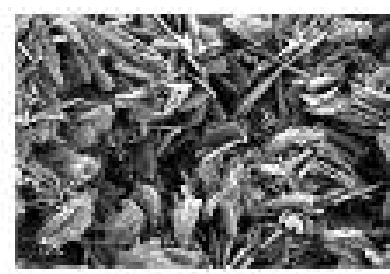

Fig. 1f

Detail of Symax ${ }^{\mathrm{TM}}$ stem with SEM photos for closer look at coating layer (Titanium Plasma Spray -TPS with BONIT ${ }^{\circledast}$ HA coating) at increasing magnification; (b) $x$ 40, (c) x 190, (d) x 500, (e) x 1000, and (f) x 2000. Typical efflorescent, needle-like structure of BONIT ${ }^{\circledR}$ HA crystals on irregular 3D-open surface texture of high porosity Titanium plasmaspray layer. 
temperature processing provides a more predictable and controlled environment for coating deposition which results in more crystallographically consistent coatings without creating undesired calcium phosphates than compared to the high temperatures (up to $20,000^{\circ} \mathrm{C}$ ) of plasma spraying. Although there are some pre-clinical studies with biomimetic coatings showing promising outcome, ${ }^{32,33,35}$ there is little clinical experience.

In this study 4 retrieved uncemented Symax ${ }^{\mathrm{TM}}$ hip stems were analyzed, by qualitative histology, quantitative histomorphometry and scanning electron microscopy (SEM). Special attention was devoted to local tolerance, potential adverse effects, bioactivity and durability of the BONIT ${ }^{\circledR}$ HA coating, thereby recording their capacity for direct implant-bone bonding and the rate of remodelling and degradation (resorption) of the coating, and the possible consequences of this process for the bone coupling of the underlying hip stem. Furthermore the effect was analyzed of the DOTIZE ${ }^{\circledR}$ treatment on the distal part of the stem, a process of anionic oxidation, which was developed to diminish bone apposition and osseointegration, in order to optimise stress transfer from the prosthesis to the bone in the proximal HA-coated area.

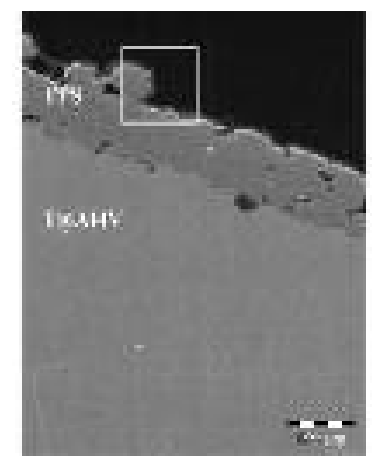

Fig. 2a

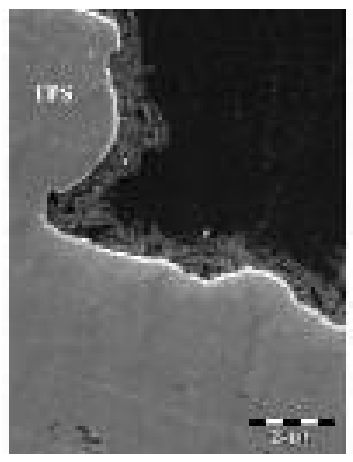

Fig. $2 b$

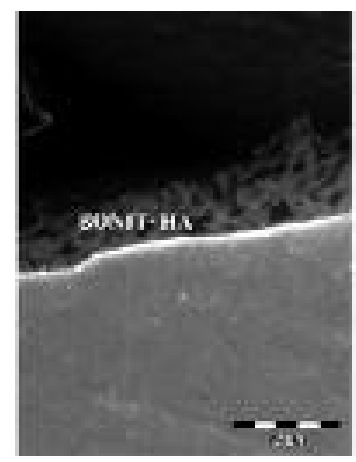

Fig. 2c

Cross-sections of implant-sample embedded into PMMA but prior to histological staining, showing Ti6Al4V of implant substrate, TPS layer and BONIT ${ }^{\circledR}$ HA coating; fig.2b showing magnified detail of fig. 2a. Maximum thickness of $10 \mathrm{~mm}$ of $B O N I T^{\circledR} H A$ coating with deep penetration into TPS layer. 


\section{Chapter 5}

\section{Materials AND Methods}

\section{Implants}

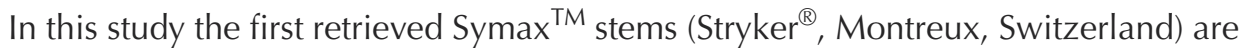
documented. The design is based on close geometrical analysis of the human femoral anatomy through conventional radiography and CT. It aims at optimal fit and fill with loading of the proximal femur (data of design studies held on file at Stryker), thereby allowing more natural stress distribution and less stress-shielding. Furthermore a uniform interface stress pattern is pursued for maintenance of optimal interface bonding. The achievement of both goals was preclinically confirmed by finite element analysis.

The Symax ${ }^{\mathrm{TM}}$ stem is forged from Ti6Al4V alloy (complying with specifications of ASTM F 136 and F 620, IMS 0070, ISO 5832-3) ${ }^{36}$. It features a proximal plasma-sprayed CP Titanium coating (ASTM F 67 and ASTM F 1580) to enhance initial stem fixation, and a biomimetic electrochemically deposited BONIT ${ }^{\circledR}$ HA coating (ISO 13779-2,

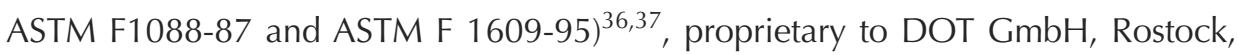
Germany (Fig. 1 and 2). Distally the stem is treated with the DOTIZE ${ }^{\circledR}$ surface process, an electrolytic conversion of titanium surfaces in which the thin native oxide film is replaced by a thicker oxidised conversion

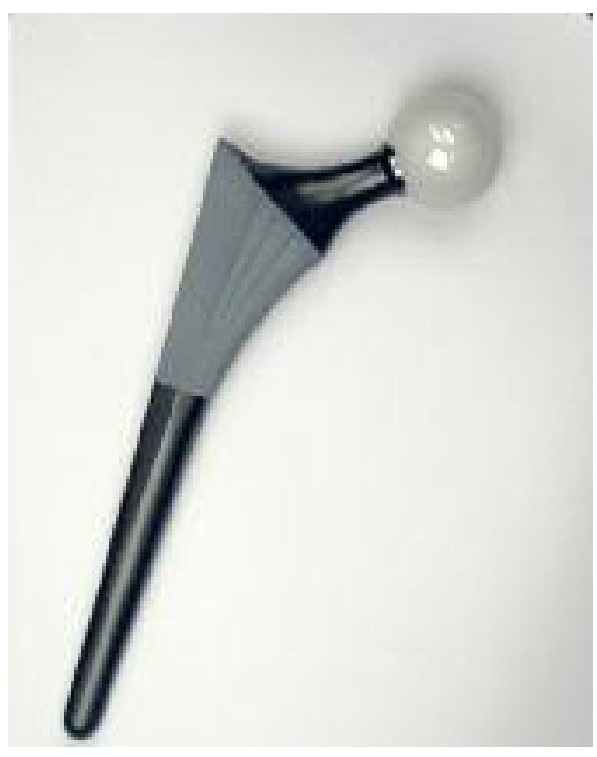
layer that reduces protein adsorption and hence distal bone apposition and osseointegration ${ }^{38,39}$ (Fig. 3).

Fig. 3 Symax ${ }^{\mathrm{TM}}$ hip stem with proximal TPSlayer and BONIT ${ }^{\circledR} H A$ coating and distal DOTIZE ${ }^{\circledR}$ surface treatment. 
The roughened, plasma-sprayed titanium surface has an open porosity of $20-40 \%$ and an average pore size between 50 and $200 \mu \mathrm{m}$. The Ca/P - ratio of the BONIT ${ }^{\circledR}$ $\mathrm{HA}$ coating is $1.6 \pm 0.1$. It is described as 'nano-crystalline'-HA ${ }^{40}$ and the X-ray diffraction (XRD) and Infra-red spectroscopy (IRS) pattern demonstrate a composition and crystalline structure very similar to bone. ${ }^{35}$ The initial electrochemically deposited coating at room temperature, is a composite of brushite $\left(\mathrm{CaHPO}_{4} \cdot 2 \mathrm{H}_{2} \mathrm{O}\right)$ converted to hydroxyapatite by $\mathrm{NaOH}$-treatment. ${ }^{33,35}$ It has a fine crystalline structure where CaP crystals are fixed on the TPS surface in the shape of platelets and pins of 15-20 $\mu \mathrm{m}$ long (Fig. 1), ${ }^{41}$ and has a high porosity of $60 \%$. This creates an exceptional capillary effect which enables complete moistening by bone marrow with early adhaesion and proliferation of osteoblastlike cells. ${ }^{33,35}$ The adhesion strength of the BONIT ${ }^{\circledR}$ HA coating on TPS (which should not be less than $15 \mathrm{MPa}$ according to ISO 13779-4) is 61.29 Mpa (s.d. 6.26 Mpa) (ASTM F 1147-99).

\section{Patients}

Between november 2004 and august 2006, 4 uncemented stems were extracted from the femur for different reasons and from different hospitals but after retrieval treated according to the same protocol. Details about these 4 cases are summarized in Table I. There were no clinical or radiological signs of loosening and the time of extraction they all appeared to be extremely well fixed, so that in 3 cases an extended femoral osteotomy (EFO) was needed to remove them (Fig. 4).

Cases 1 to 3 were implanted in another hospital, case 4 was implanted at our own department. Reason for implant removal in case 1 was an acetabular fracture. During repair the femoral component was taken out for better exposure of the acetabulum. In cases 2 and 3 there was a deep infection of the prosthesis with Staphyloccus Aureus resistant to several debridements and antibiotic treatment.. During revision of case 4 for recurrent dislocations in a non-compliant patient, as well as improving the anteversion of the acetabular component, it was decided to replace the stem as well for a design with more offset. 


\section{Chapter 5}

Table I. Details of patients who generated the four retrieved Symax ${ }^{\circledast}$ hip stems

\begin{tabular}{|c|c|c|c|c|}
\hline Case & 1 & 2 & 3 & 4 \\
\hline Age (yr) at THR* & 74 & 78 & 64 & 61 \\
\hline Gender & $\mathrm{F}$ & M & M & $M$ \\
\hline Weight (kg) & 64 & 81 & 78 & 84 \\
\hline Height (m) & 1.65 & 1.71 & 1.70 & 1.74 \\
\hline $\begin{array}{l}\text { Diagnosis at } \\
\text { primary THR }\end{array}$ & $\mathrm{OA}$ & $\mathrm{OA}$ & $\mathrm{OA}$ & $\mathrm{OA}$ \\
\hline Previous hip surgery & None & None & None & None \\
\hline $\begin{array}{l}\text { Activity level } \\
\text { with THR }\end{array}$ & $\begin{array}{l}\text { Not rehabilitated } \\
\text { after THR }\end{array}$ & $\begin{array}{l}\text { Semi-sedentary } \\
\text { due to comorbid. }\end{array}$ & $\begin{array}{l}\text { Normal activity } \\
\text { Light labor }\end{array}$ & $\begin{array}{l}\text { Light labor } \\
\text { Occasional sports }\end{array}$ \\
\hline $\begin{array}{l}\text { Reason for } \\
\text { extraction }\end{array}$ & $\begin{array}{l}\text { Acetab. fracture } \\
\text { after THR }\end{array}$ & $\begin{array}{l}\text { Deep infection } \\
\text { (Staph. Aureus) }\end{array}$ & $\begin{array}{l}\text { Deep infection } \\
\text { (Staph. Aureus) }\end{array}$ & $\begin{array}{l}\text { Recur. dislocation } \\
\text { (cup-malpos/offset) }\end{array}$ \\
\hline $\begin{array}{l}\text { Clinical signs } \\
\text { of loosening }\end{array}$ & Not applicable & None & None & None \\
\hline $\begin{array}{l}\text { Radiograph. } \\
\text { signs of loosen }\end{array}$ & Not applicable & None & None & None \\
\hline $\begin{array}{l}\text { Survival of } \\
\text { THR (yrs/mnths) }\end{array}$ & $0 / 3 / 4$ & $0 / 9$ & $1 / 1$ & $2 / 8$ \\
\hline $\begin{array}{l}\text { Surgeon's comments } \\
\text { on fixation quality }\end{array}$ & $\begin{array}{l}\text { Press fit; } \\
\text { not yet } \\
\text { osseointegrated }\end{array}$ & $\begin{array}{l}\text { Well fixed } \\
\text { (ETO }{ }^{+} \text {necessary) }\end{array}$ & $\begin{array}{l}\text { Well fixed } \\
\text { (ETO necessary) }\end{array}$ & $\begin{array}{l}\text { Well fixed } \\
\text { (ETO necessary) }\end{array}$ \\
\hline
\end{tabular}

THR, total hip replacement

$\mathrm{OA}$, osteoarthritis

ETO, extended trochanteric osteotomy 


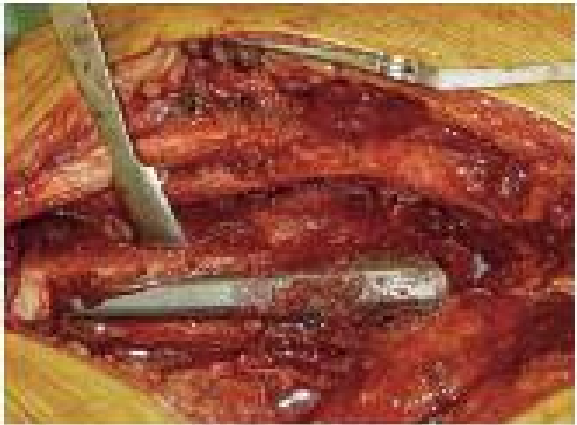

Fig. 4a

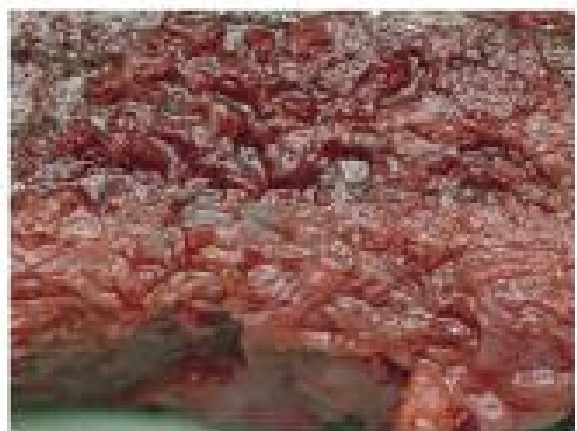

Fig. $4 c$

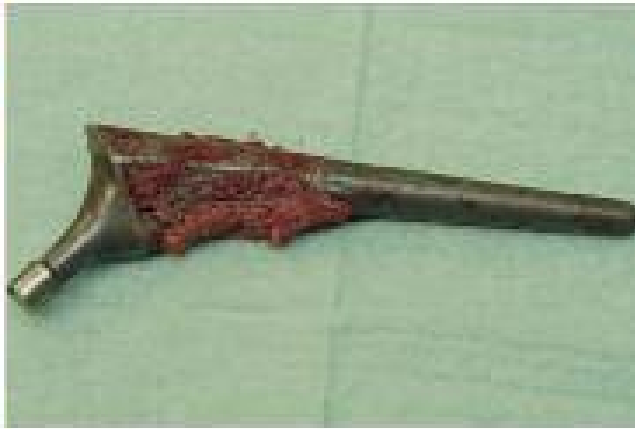

Fig. $4 \mathrm{~b}$

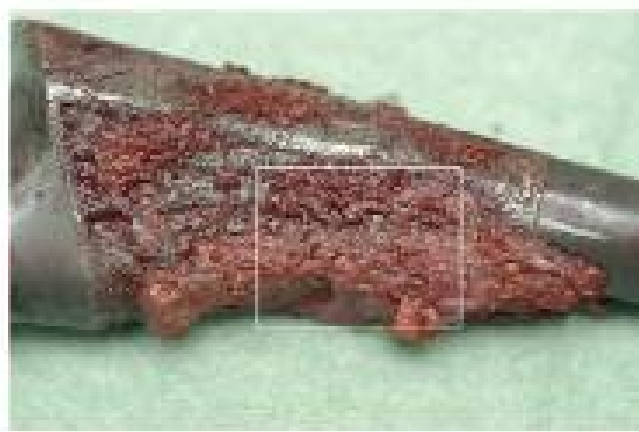

Fig. $4 d$

Intra-operative photographs of case 2. Figure 4a showing extended femoral osteotomy with lateral cortical bone separated from the implant. Clearly visible no bone attached to distal (DOTIZE ${ }^{\oplus}$ ) part of the stem. Figure $4 b$ showing the explant with bone coming with the BONIT ${ }^{\circledast} H A$ coated anterior and medial part of the implant-surface. Figure $4 c$ and $4 d$ with magnifications illustrating extensive bone attachment.

The specimens were fixed in 3.7-4.0 \% formalin, buffered with zinc sulphate acetate at pH 5.6-5.8. 


\section{Chapter 5}

Fig. 5 Macroscopic photographs of extracted implants showing hip stems of retrieval cases 1 to 4 . Cases 1 and 3 showing discoloration caused by preliminary fixation in formalin, cases 2 and 4 immediately after extraction. Case 1 - although not yet osseointegrated after 3 weeks of implantation - still presenting

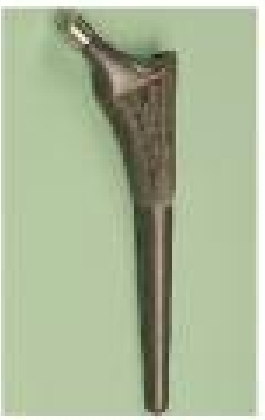

Case 1
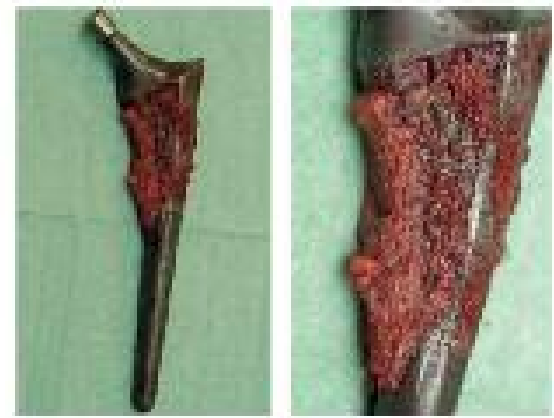

Case 2
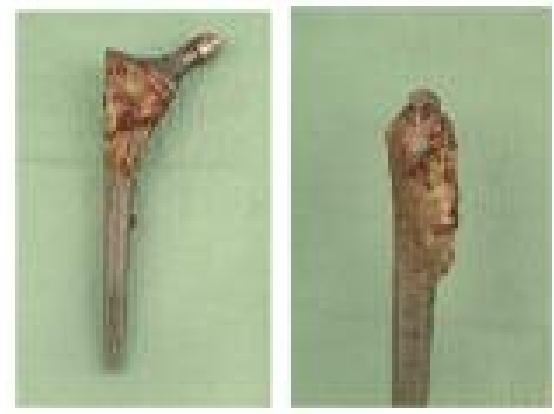

some bone apposition (see detail). Cases 2, 3 and 4 showing abundant bone coming with and strongly attached to the extracted implant. In all cases there is a complete absence of bone attachment on the distal stem treated with DOTIZE ${ }^{\oplus}$.
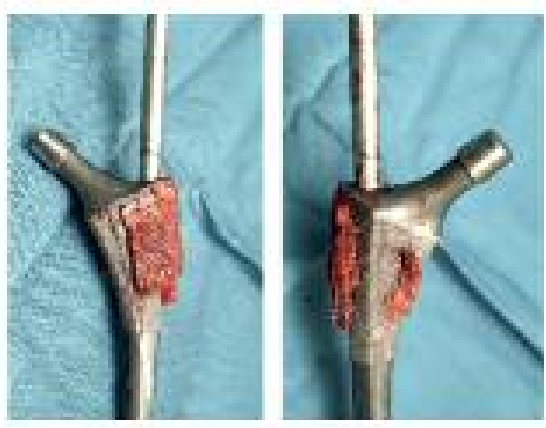

Case 3

Case 4 


\section{Specimen preparation and analysis}

Analysis was performed by an independent institute (Biomatech, Chasse-surRhône, France).

\section{Histology}

On the day of receipt, pictures of the specimens were taken prior to storage in the $10 \%$ buffered formalin ( $\mathrm{pH} 7.2-7.4$ ) (Fig. 5). After complete fixation, gross sections (approximately $1.5 \mathrm{~cm}$ thick according to the Gruen zones) were performed on the stem to isolate the investigated areas using the EXAKT microcutting system. (Apparatebau GmbH \& Co., Norderstedt, Germany) Each stem segment was dehydrated in ethanol of increasing concentration, cleared in xylene and embedded in polymethylmethacrylate (PMMA) resin.

From the stem, one to five cross-sections (approximately $30 \mu \mathrm{m}$ thick) were prepared in the Gruen zones 1A-7A, 1B-7B, 1C-7B, 2-6 and 3-5 (Fig. 6).

The sections were obtained by a microcutting and grinding technique adapted from Donath. ${ }^{42}$ These sections were stained with a modified Paragon

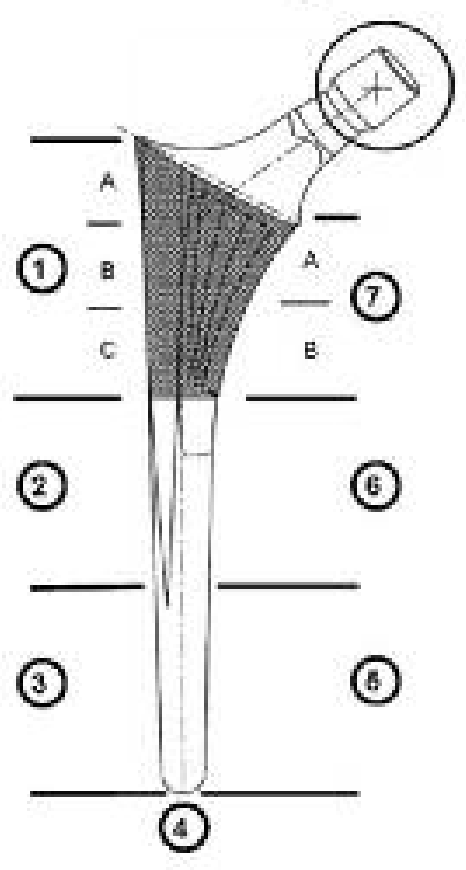
staining for qualitative histology and quantitative histomorphometry (Fig 7).

For the qualitative microscopic analysis, a Nikon microscope, Eclipse E600 (Nikon) (Nikon France, Champigny-sur-Marne, France) fitted with $\mathrm{x} 5, \mathrm{x} 10, \mathrm{x} 20$ and $\mathrm{x} 40$ objectives and coupled with a digital camera (DN 100; Nikon France) was used.

Fig. 6 Drawing showing delineation of Gruen zones 1 to 7 in the AP view. The metaphyseal zones 1 and 7 are subdivided in smaller segments $A$ to $C$. At these levels cross sections were prepared for further qualitative histology and quantitative histomorphometry (see text and fig. 7). 


\section{Chapter 5}

Histomorphometric analysis

For the quantitative analysis, the sections were evaluated using a Zeiss microscope (Axioskop; Carl Zeiss France S.A.S., Le Pecq, France) fitted with x5, x10, x20 and $\mathrm{x} 40$ objectives and equipped with a color image analyzing system (SAMBA ${ }^{\circledR}$, SAMBA Technologies, France).

The quantitative histomorphometric evaluation of the surrounding bone tissue (bone to implant contact - BIC, and bone area density - BD) was performed on seven standardised areas of investigation around the stem sections (1A-7A, 1B-7B and $1 \mathrm{C}-7 \mathrm{~B})$ and on four areas around the distal sections 2-6 and 3-5 (29 areas in total). Surfaces of the individual areas of investigation varied from 10 to $12 \mathrm{~mm}^{2}$ and were located at the tissue-implant interface (Fig. 7; Case 4).

Within the area of investigation, the bone surface was divided by the surface of the entire area to calculate the relative bone density in the vicinity of the implant (= bone density, BD). The length of the implant's interface having direct bone contact was divided by the length of the entire interface within the area of investigation in order to provide the percentage of the implant covered by bone (bone-implant contact). Means and standard deviations were calculated for each section and for the whole metaphyseal segment of the stem.

\section{SEM analysis}

The samples (blocks from the proximal part of the stem) for scanning electron microscopy were dehydrated in acetone solution, submitted to critical point for desiccation (optimal dehydration for optimized SEM pictures) and sputtered with gold palladium before observation. The analysis was conducted with an HITACHI S800 Scanning Electron Microscope (Hitachi High-Technologies Europe GmbH, Krefeld, Germany) set at $15 \mathrm{KeV}$. Any significant event was recorded and photographed. 


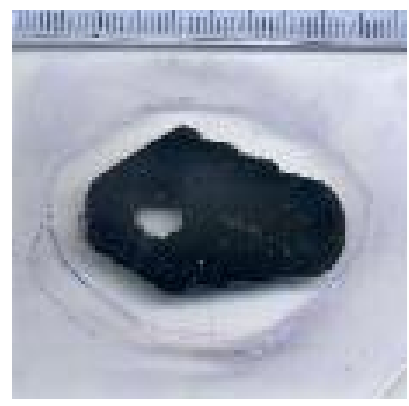

Fig. 1a7a

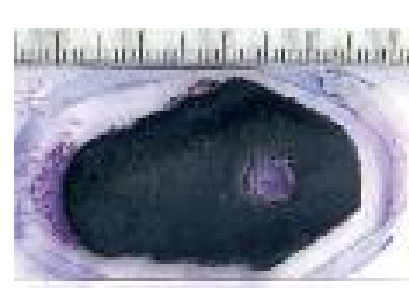

Fig. 1a7a

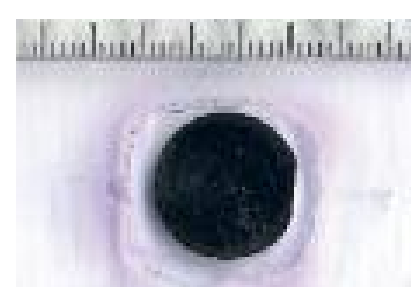

Fig. 2-6

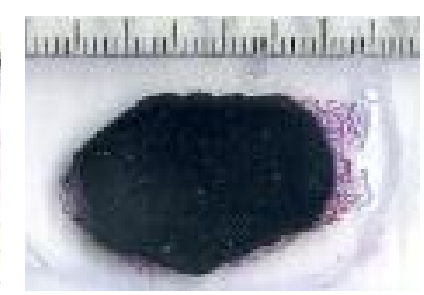

Fig. 1b7b

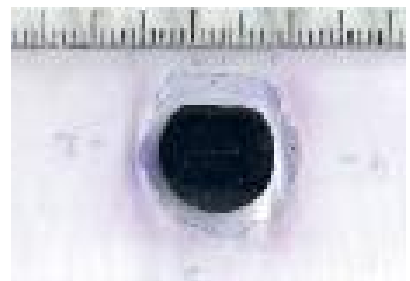

Fig. 3-5

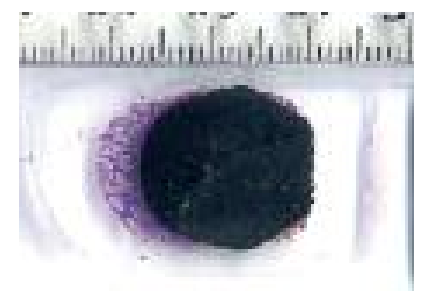

Fig. 1c7b 


\section{Chapter 5}

\section{Case 3}

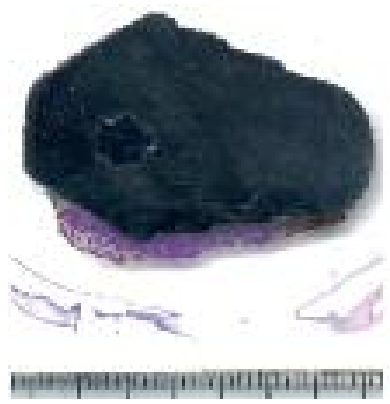

Fig. 1a7a

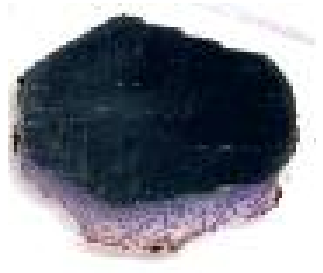

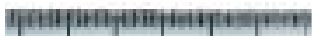

Fig. $1 b 7 b$
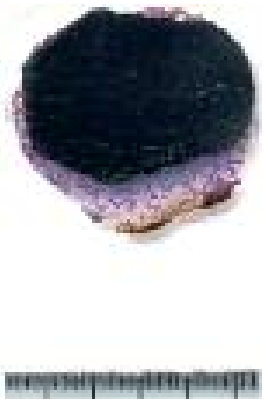

Fig. 1c7b

Case 4

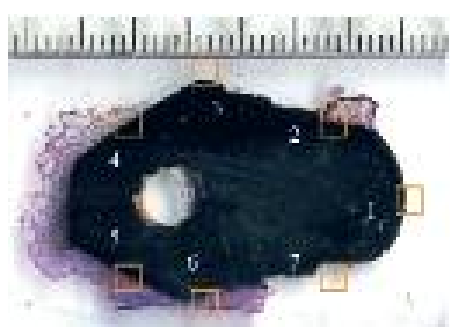

Fig. 1a7a

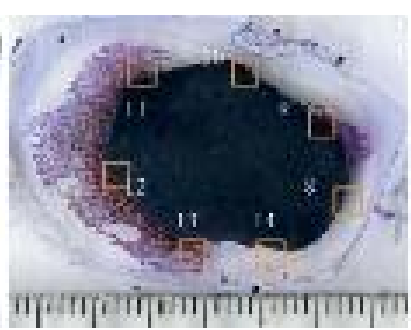

Fig. $1 b 7 b$

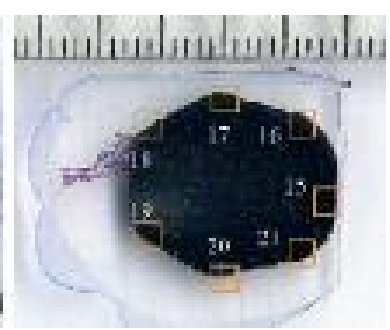

Fig. 1c7b

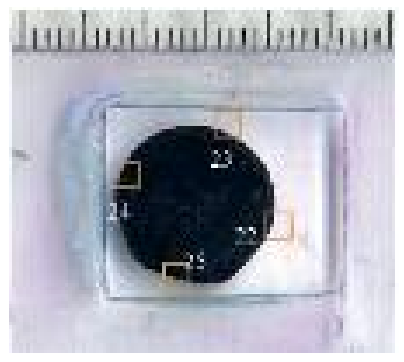

Fig. 2-6

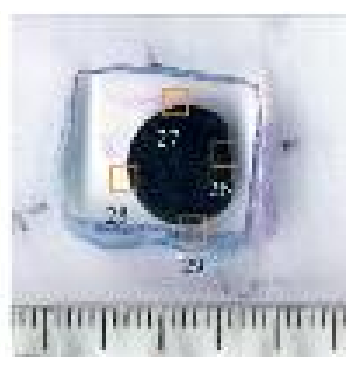

Fig. 3-5

Fig. 7 Low-magnification photomicrographs of the cross sections after Paragon-staining at subdivided Gruen zones 1A-7A, 1B-7B, 1C-7B from cases 1 to 4. Extensive and direct bone apposition without fibrous interface in areas where the bone was not separated from the implant for the purpose of extraction. Cases 2 and 4 further showing cross sections at Gruen zones 2-6 and 3-5 to illustrate complete absence of bone, as intended by the DOTIZE ${ }^{\circledR}$ treatment. In case 4 the 29 standardized areas of investigation for quantitative histomorphometry are shown. Distances are marked in centimeters. 


\section{Results}

\section{Qualitative histology.}

The retrieved specimens showed successive changes during prospective periprosthetic bone remodelling and the effects of coating loss on bone-implant coupling. Although in case 1 there was bone over only a small surface of the explant due to the short time of implantation, in all other cases there was extensive and qualitatively sound boneimplant bonding defined as a continuum of mineral from the implant to the mineralized bone matrix, without fibrous tissue interface. ${ }^{21}$ Histological examination consistently showed trabecular bridges from the surrounding host bone to the implant surface. The trabecular bridges were mainly characterized by mature lamellar bone with osteoblasts and osteocytes, at the exception of the early retrieval (case 1) showing woven bone (Fig. 8 Picture 1a). Active remodelling of bone was overall frequently observed, with coexisting osteoid lines as a sign of new bone formation (Fig. 8).

In all specimens the BONIT ${ }^{\circledR}$ HA coating had completely disappeared reflecting a fast degradation of this thin biomimetic and highly bioactive coating. There was, however, direct bone apposition onto and deep into the open surface structure of the exposed TPS layer, without any fibrous interface (Fig. 8 and 9).

Histological slides did not reveal any toxic effect of coating or TPS substrate material, nor any inflammatory reaction or histiocytic proliferation, as would have occurred with polyethylene particles. There were no signs of (polyethylene or metal) particulate debris or coating delamination. Furthermore no fibrosis or 'third body wear' - induced osteolysis was recognized. These observations suggested a good 'sealing' effect of the BONIT ${ }^{\circledR}$ HA coating. Surprisingly in the infectious cases (2 and 3) no neutrophil polymorphonuclear or lymphocytic tissue reactions at the bone-implant interface could be identified. There was no osteonecrosis or increased osteoclastic activity, nor was a fibrous coupling seen between implant and host bone, Thus, it seems that persistent deep infection did not severely compromise osseointegration when treated surgically.

In contrast to retrieval reports of other proximally or entirely HA-coated stems $^{18,19,37}$ which showed signs of progressive osseointegration in distal Gruen zones 2 - 6 and 3 - 5, our material did not show any unintended bone apposition, either macro- (Fig. 5 and 7) or microscopically (Fig. 8), in the non-HA-coated stem areas. 


\section{Chapter 5}

Fig. 8 showing histological photomicrographs of cases 1 to 4 (details see below). Extensive parts of the prosthesis surface were directly covered with mature lamellar and actively remodelled bone. No signs of inflammatory reaction were observed and no abnormal bone marrow was seen. The density of the trabecular bone tissue was marked and there was consistenly good osseous anchorage of the implant. At sites where the stem was separated from the host bone for sake of extraction there was still marked bone implant contact, but at several spots a gap was observed between bone tissue and the material, due to the retrieval procedure. No HA coating was identified after these survival periods, but the homogeneous TPS layer (200 $\mu$ m thick) was seen, well fixed to the Ti6Al4V alloy (Ti), showing a rough surface with deep ingrowth of bone. At distal sites (Gruen zones $2 \& 6$ and $3 \&$ 5) there was no bone or fibrous tissue visible and sections showed a smooth surface. The DOTIZE ${ }^{\oplus}$ treatment seems to prevent tissue attachment of any kind, and around the distal implant there were no signs of inflammation, macrophage reaction or any other adverse effect on the material. No histological signs of infection were seen in case 2 and 3.

Case 1a showing the immature woven bone (WB) but in good contact with the implant after only 3 weeks survival, as well as crushed bone with artefacts due to the retrieval procedure. In other regions of case 1, although macroscopically not visible (see Fig. 5, case 1), still a thin layer of bone apposition (white arrows, case 1b) was noted and mineralization of interfacial fibrous tissue (black arrow, case 1b). Cases 2a/3a: marked bone (B) attachment on metal surface (M), and in continuity with the surrounding trabecular bone. Cases 2c/2d/3b showing osteoid line (OL) with osteoblasts (OB in Case 2d) in close contact with TPS, as signs of active bone generation. Cases 2d/3a/4a: consistenly physiologically normal bone marrow (BM) was seen. Cases $2 b / 2 c / 4 a / 4 b$ with the typical aspect of mature lamellar bone (LB) with osteocytes (OC). Cases 2e, 3c and $4 b$ with development of Haversian canals (HC; black arrows, $x$ 4) possibly reflecting biomechanically driven corticallization, a sign of strain adaptive bone remodelling. Gruen zones 2 and 6 (Cases $2 f$ and $4 d$ ) and zones 3 and 5 (Cases $2 g$ and 4e) confirming complete absence of bone and soft tissue attachment. Cases $3 d$ and $4 c$ illustrating detachment of bone, originally in direct contact with the implant (judging from identical contours of bone and implant surface) but separated due to the retrieval procedure. This may lead to underestimation of BIC \% and BD \% in histomorphometry. 
Bone Reaction to a Biomemetic Third Generation HA-Coating
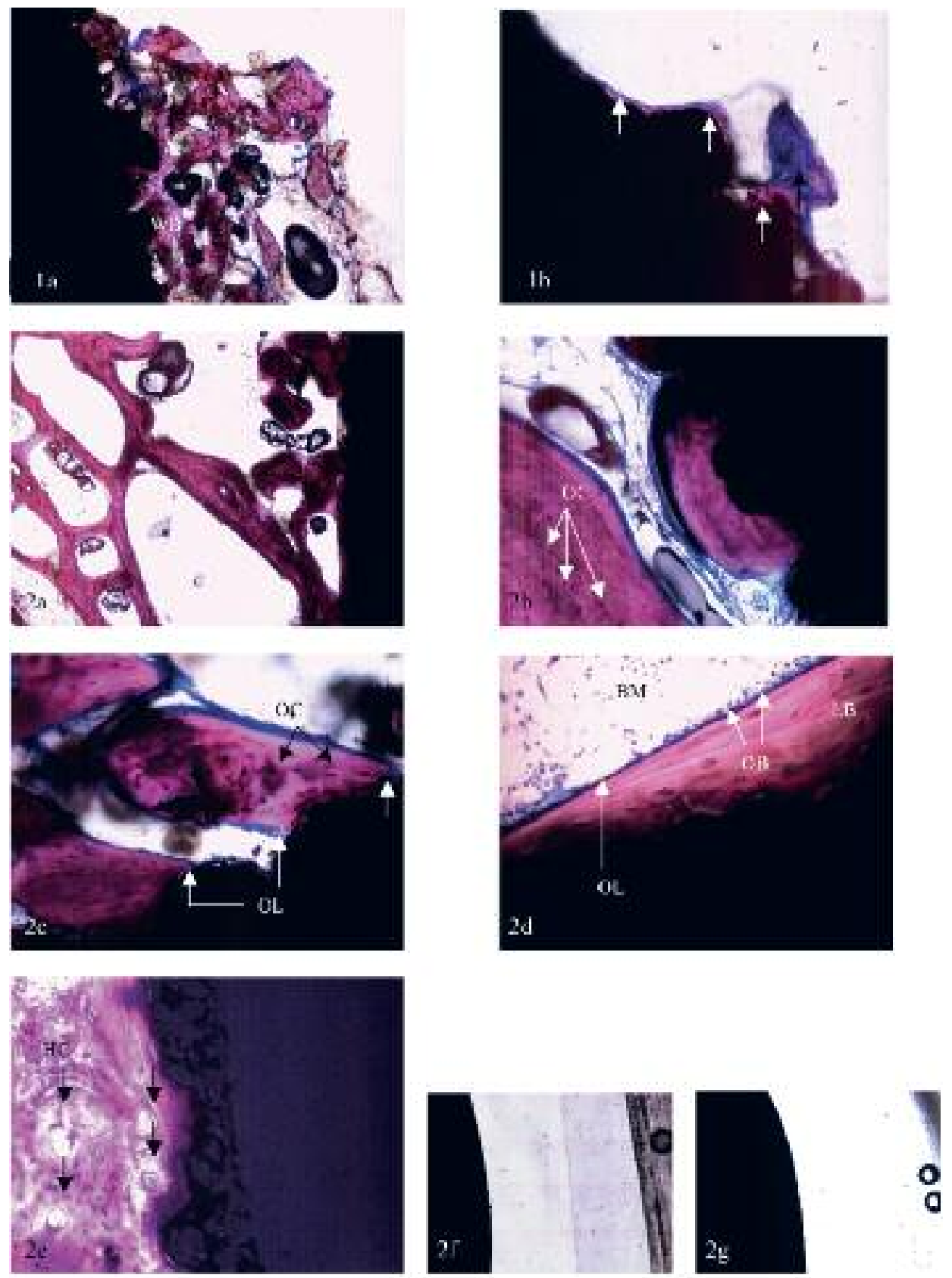

Fig. 8 
Chapter 5
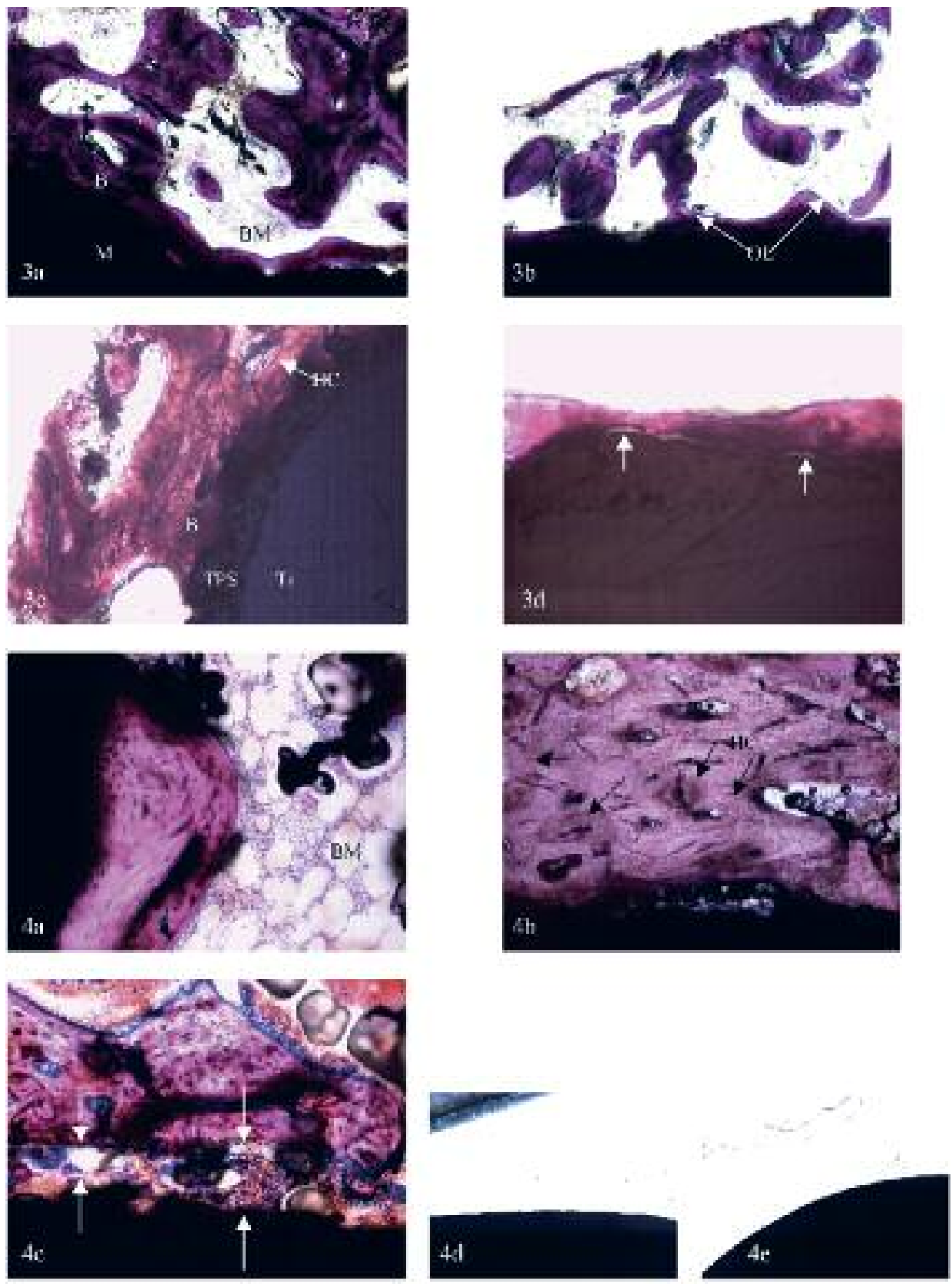

Fig. 8 continued 


\section{Quantitative histomorphometry.}

As these were not post mortem retrievals at autopsy and instead of collecting the entire femur with the stem, most of the bone had to be separated from the stem to extract it. Therefore quantitative histomorphometry (expressed as percentage boneimplant length contact and percentage bone area density) was calculated in investigated areas where bone came with the explant (referred to as 'relevant areas of interest'), for reasons of comparison with other published post mortem retrieval reports. Otherwise quantitative results would be extremely underestimated as a result of the extraction-procedure. Dividing these results over the entire implant surface, as if it were a post-mortem retrieval, is called the 'mean area of interest' (results see Table II).

In case 1 after a survival of only 3 weeks already $26.5 \%$ direct bone-implant contact $(\mathrm{BIC} \%)$ was seen in zone 1A-7A in the part macroscopically covered with bone, and $21.5 \%$ over the entire zone, illustrating the strong osteoconductive character of the BONIT ${ }^{\circledR}$ HA coating. The BD \% in this zone was $24.6 \%$ (mean 6.4 $\%$ ). For case 2, BIC \% was between $33.4 \%$ and $79.1 \%$ in the relevant a.o.i. (mean $51.7 \%$ ) and BD \% varied between $16.3 \%$ and $39.0 \%$ (mean $27.2 \%$ ). Case 3 presented a relevant BIC \% varying between $51.2 \%$ and $83.5 \%$ (mean $68.1 \%$ ) and a relevant BD \% between $26 \%$ and $39.3 \%$ (mean $32.5 \%$ ). Considering the impressive amount of bone attached to the explant (Fig. 5), and the fact that case 4 had the longest survival compared to the other retrievals, the relatively low percentage of $\mathrm{BIC}(22.3 \pm 0.3 \%)$ in the relevant a.o.i. and $14.7 \%$ overall in the metaphyseal area, was less than might be expected. These numbers however are an underestimation because, judging from its contour, the bone initially seemed to have been in close contact with the implant over a larger area, and a thin gap without fibrous tissue was believed to be a consequence of bone detachment due to the retrieval procedure (Fig. 8, case 4c)

\section{SEM analysis}

There were clear signs of direct bone-TPS contact confirming the findings of histology (Fig. 9). Bone trabeculae spread over the TPS layer without fibrous interface. A complete resorption of BONIT ${ }^{\circledR}$ HA coating was seen, apparently not being detrimental for bone-implant coupling. 


\section{Chapter 5}

Table II Histomorphometric results of retrieval cases 1 to 4; percentage bone to implant contact $(B I C \%)$ and bone density (BD \%) per relevant and mean area of interest

\begin{tabular}{lcc} 
& Case 1 & Case 2 \\
\hline Survival & $3 / 4 \mathrm{mnth}$ & $9 \mathrm{mnths}$ \\
Indication for extraction & Acet. fracture & Deep infection \\
\hline
\end{tabular}

\begin{tabular}{|c|c|c|c|c|c|}
\hline & & Relevant a.o.i. & Mean a.o.i. & Relevant a.o.i. & Mean aoi \\
\hline \multirow[t]{9}{*}{ BIC \% } & $1 A-7 A$ & 26.5 & 21.5 & 42.7 & 16.0 \\
\hline & 1B-7B & n.a. & n.a. & 33.4 & 21.4 \\
\hline & $1 C-7 B$ & n.a. & n.a. & 79.1 & 40.4 \\
\hline & Metaphyseal mean & n.a. & n.a. & 51.7 & 25.9 \\
\hline & Stand. dev. & n.a. & n.a. & 19.7 & - \\
\hline & $2-6$ & n.a. & n.a. & 0.0 & 0.0 \\
\hline & $3-5$ & n.a. & n.a. & 0.0 & 0.0 \\
\hline & Diaphyseal mean & n.a. & n.a. & 0.0 & 0.0 \\
\hline & Stand. dev. & n.a. & n.a. & 0.0 & 0.0 \\
\hline \multirow[t]{9}{*}{ BD \% } & $1 A-7 A$ & 24.6 & 6.4 & 26.5 & 7.2 \\
\hline & 1B-7B & n.a. & n.a. & 16.3 & 5.9 \\
\hline & $1 \mathrm{C}-7 \mathrm{~B}$ & n.a. & n.a. & 39.0 & 16.4 \\
\hline & Metaphyseal mean & n.a. & n.a. & 27.2 & 9.9 \\
\hline & Stand. dev. & n.a. & n.a. & 9.3 & - \\
\hline & $2-6$ & n.a. & n.a. & 0.0 & 0.0 \\
\hline & $3-5$ & n.a. & n.a. & 0.0 & 0.0 \\
\hline & Diaphyseal mean & n.a. & n.a. & 0.0 & 0.0 \\
\hline & Stand. dev. & n.a. & n.a. & 0.0 & 0.0 \\
\hline
\end{tabular}

Histomorphometry results. Relative bone-implant length contact (BIC \%) and bone density (B.D. \%) within the area of investigation. Mentioned are the values for the stem-surface with bone still attached (relevant area of investigation) and averaged over the entire surface (mean area of interest), which value should be considered as an underestimation when compared with post-mortem retrievals. The values highlighted in bold represent the areas with macroscopic bone attached, the ones highlighted in italics represent the mean over the entire metaphyseal part of this area. Further see text.

n.a. $=$ not analysed 


\begin{tabular}{|c|c|c|c|}
\hline \multicolumn{2}{|c|}{ Case 3} & \multicolumn{2}{|c|}{ Case 4} \\
\hline \multicolumn{2}{|c|}{13 mnths } & \multicolumn{2}{|c|}{32 mnths } \\
\hline \multicolumn{2}{|c|}{ Deep infection } & \multicolumn{2}{|c|}{ Recurrent dislocation } \\
\hline Relevant a.o.i. & Mean a.o.i. & Relevant a.o.i. & Mean a.o.i. \\
\hline 51.2 & 17.7 & 22.5 & 18.7 \\
\hline 69.7 & 28.6 & 22.6 & 18.3 \\
\hline 83.5 & 48.0 & 21.8 & 7.1 \\
\hline 68.1 & 31.5 & 22.3 & 14.7 \\
\hline 13.2 & 12.5 & 0.3 & - \\
\hline n.a. & n.a. & 0.0 & 0.0 \\
\hline n.a. & n.a. & 0.0 & 0.0 \\
\hline n.a. & n.a. & 0.0 & 0.0 \\
\hline n.a. & n.a. & 0.0 & 0.0 \\
\hline 39.3 & 10.4 & 23.9 & 10.5 \\
\hline 26.0 & 9.3 & 41.1 & 14.8 \\
\hline 32.2 & 19.3 & 1.6 & 0.4 \\
\hline 32.5 & 13.0 & 22.2 & 8.6 \\
\hline 5.5 & 4.5 & 16.2 & - \\
\hline n.a. & n.a. & 0.0 & 0.0 \\
\hline n.a. & n.a. & 0.0 & 0.0 \\
\hline n.a. & n.a. & 0.0 & 0.0 \\
\hline n.a. & n.a. & 0.0 & 0.0 \\
\hline
\end{tabular}




\section{Chapter 5}

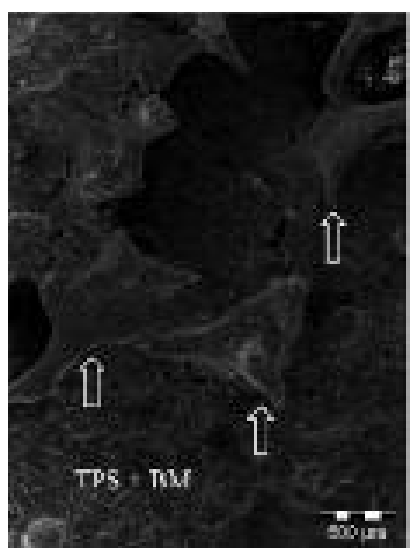

Fig. 9a

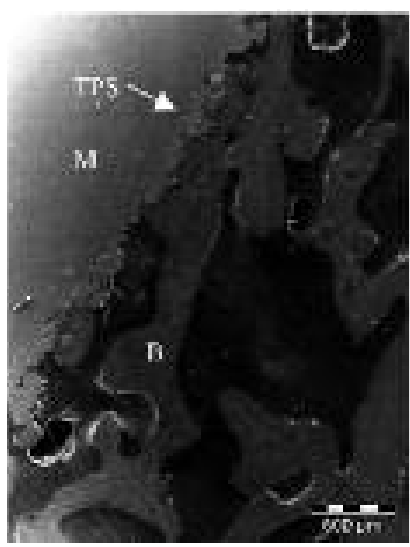

Fig. $9 d$

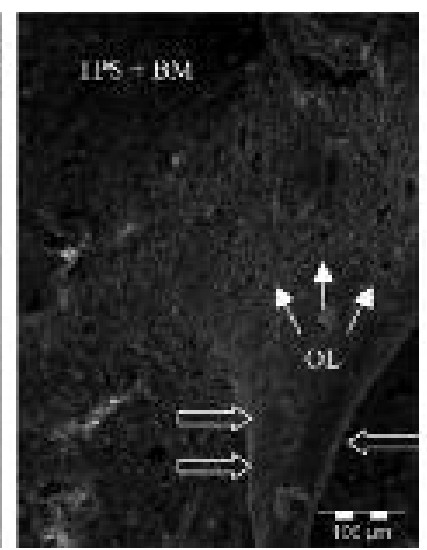

Fig. $9 b$

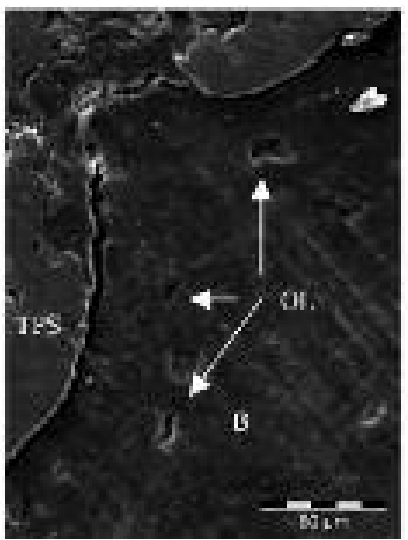

Fig. $9 \mathrm{e}$

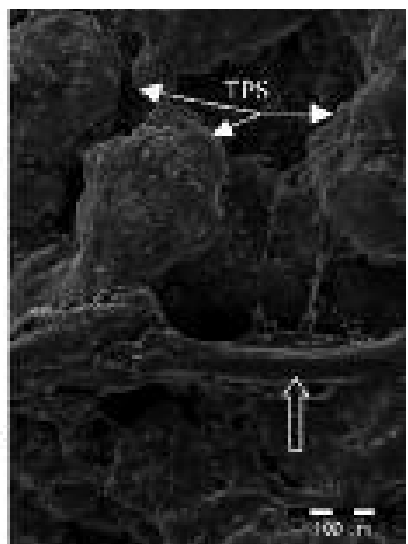

Fig. 9c

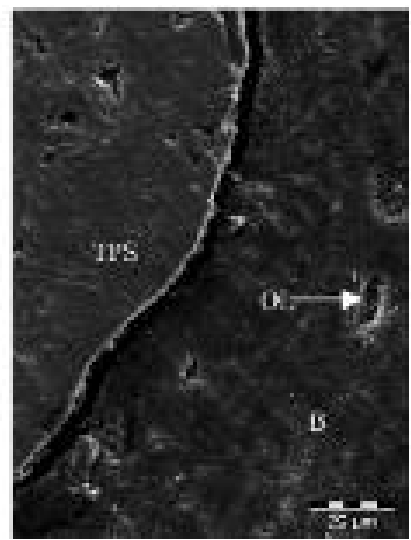

Fig. $9 f$

Fig. 9 Scanning Electron Microscopy (SEM) pictures of case 2 and 4. Fig. 9a showing 3D contour of trabecular bone (open white arrows) in close contact with TPS surface covered with bone marrow $(T P S+B M)$. Fig. $9 b$ with magnification of one bone trabecula (open white arrows) tightly anchored with the TPS layer. Osteocytic lacunae (OL; closed white arrows) as a sign of active bone remodelling. Fig. 9c with magnification of a fractured trabecula (open white arrow) and globular morphometry of TPS covered with erythrocytes in the bone marrow cavities. Fig. $9 d$ with cross-section SEM-micrograph illustrating metal (M), TPS layer and direct ingrowth of bone trabeculae $(B)$ into the implant surface without fibrous tissue interface. Further ultrastructural magnifications (Fig. 9e and f) with bone closely following the implant surface as proof of direct bone-implant coupling $(O L=$ osteocytes lacunae). The black line in between represents an electronic beam effect (= artefact, but no fibrous tissue interface). 


\section{Discussion}

This is the first retrieval study that shows that the Symax ${ }^{\text {TM }}$ stem due to the high bioactivity of the BONIT ${ }^{\circledR} \mathrm{HA}$ coating is capable of a fast and extensive bone ingrowth, both qualitatively and quantitatively, deep into the open 3D surface texture of the stem. In spite of the inherent swift remodelling of the coating, both histology as well as scanning electron microscopy show that there is no negative effect on the short term bone anchorage of the implant, and there is a high degree of sealing of the implant-bone interface. This supports the expectation that the rough and porous surface texture of the biocompatible TPS-layer and the geometry of the Symax ${ }^{\mathrm{TM}}$ stemdesign for optimal fit and fill, will be able to maintain long term osseointegration and implant stability. We found no adverse effects or signs of local intolerance on the coating, and there was no HA debris with third body wear either in isolation or phagocytosed at the interfaces or in the bone attached to the explants. The study demonstrates that the DOTIZE ${ }^{\circledR}$ treatment as intended can prevent bone apposition and osseointegration of the distal part of the stem, creating optimal stress transfer characteristics to the bone, thereby reducing stess shielding of the proximal femur.

Debate on HA-coatings focuses mainly on the following controversies; Firstly should coatings be highly bioactive and consequently more resorbable, or should they be stable to enhance bonding more permanently? ${ }^{40-43}$ Secondly, does HA resorption affect the bonding strength between implant and bone? ? $7,44,45^{2}$ Thirdly, can coatings be thin or should they be thicker?

Although stable coatings may reinforce bonding for a longer period, they are intrinsically less bioactive, while more bioactive coatings deliver a high local ion source of calcium and phosphate ions for rapid contact osteogenesis, and therefore inherently tend to disintegrate faster. ${ }^{32,46,47}$ Resorbability of coatings is determined by chemical factors ( $\mathrm{pH}$, crystal composition) and material structure (surface area, porosity), which also influence adhesion and activity of osteoblastic (precursor) cells. $^{37,48-53}$ Resorption of the coating depends strongly on osteoclastic activity, ruled by these physicochemical characteristics. ${ }^{54-56}$ Research on newer HAcoatings should therefore be directed towards finding the combination of coatings with sufficient bioactivity to encourage bone ingrowth, but which do not dissolve before mechanical stability has been achieved through ingrowth. 


\section{Chapter 5}

Degradation of HA coatings forms an essential part in the remodelling of the boneimplant interface. Thinner coatings (i.e. BONIT ${ }^{\circledR} \mathrm{HA} 2-20 \mu \mathrm{m}$ ), applied to metallic substrates achieve the strength properties of the underlying material resulting in a better mechanical stability of the coating on the implant. Being transformed through osteoclastic activity, they can prevent heavy burdens of particulate material. Thicker 'first generation' coatings however (Furlong $\pm 200 \mu \mathrm{m} 70 \mathrm{um}$ ) and to a lesser extent the 'second generation' intermediate coatings (Omnifit and ABG, $\pm 60 \mu \mathrm{m}$ ), because of their brittleness, may delaminate and theoretically release apatite particulate material with 'third body wear' and osteolysis. ${ }^{27,28}$ That this has not been shown to be a real clinical problem is possibly related to the 'sealing' capacity of the implant-bone interface through early osseointegration. ${ }^{57,58}$ During this process, particularly in thin bioactive coatings, degradation of the Ca-P layer does not seem to initiate histiocyte or giant cell proliferation and wear-induced osteolysis as polyethylene particles do. This is probably because this HA does not behave as an abrasive or foreign body particle but as a natural calciumphosphate graft that is more naturally remodelled by osteoclasts, or phagocytosed by macrophages and dissolved within their acid environment. For these and other reasons it therefore seems advantageous to apply biomimetic coatings instead of conventional plasma-spray HA coatings. Processing is possible under better control of the physico-chemical environment (neutral $\mathrm{pH}$, low-/body-temperature) with improved regulation of crystallinity and $\mathrm{Ca} / \mathrm{P}$ ratio, along with the rate of bioactivity and degradation. Then thinner coatings can be applied with theoretically a lower chance of delamination, and a better and deeper coating of the 3D-open surface texture of the implant. Depending of the surface characteristics of the implant (roughness and porosity) this will improve boneimplant anchorage and guarantee long-term osseointegration even after complete disappearance of the HA coating. Faster osseointegration will support early biological stability of the implant, thereby preventing migration and the development of a fibrous and unstable interface. This may be particularly useful in patients with poor bone quality such as those with osteoporosis. Theoretically these coatings and their way of application offer the possibility to use them as a drug delivery system for bioactive proteins (BMP's, growth factors), antibiotics or even tissue engineered bone. ${ }^{59-61}$ In the long term these deposition techniques may 
create more complete sealing of the bone-implant interface as a protection against particle ingress and subsequent wear induced periprosthetic osteolysis.

From other proximally or completely coated titanium stems it is known that, to some extent, initial proximal osseointegration is followed by progressive distal osseointegration ${ }^{62,63}$. This will cause stress shielding of the femur metaphysis with bone resorption in Gruen zones 1 and 7 as can be recognized radiologically and from periprosthetic densitometry (DEXA). This potentially detrimental effect of distal stem integration may be prevented by the DOTIZE ${ }^{\circledR}$ treatment, as retrieval results show complete absence of distal bone apposition. (Fig 2f, 2g, 4d, 4e)

Comparison of histomorphometric results of this BONIT ${ }^{\circledR} \mathrm{HA}$ coating, being one of the first clinically applied biomimetic coatings on hip stems, with plasmasprayed coatings shows good BIC \% and BD \%. Porter et al. ${ }^{21}$ compared post mortem retrievals with entire femora of plasma-sprayed HA coated implants (Bimetric - Biomet, UK), with implants of the same design but showing exposed titanium after degradation of $\mathrm{HA}$, and porous coated implants without $\mathrm{HA}$. The BIC $\%$ in these groups was respectively between 40 and $50 \%$ (HA-coating still present), $24 \pm 5 \%$ (exposed titanium after HA degradation) and $21 \pm 14 \%$ (non HA-coated porous stems), suggesting a decline in bone bonding with HA loss. The porous coated stems showed large regions with fibrous tissue interface and barely adherent bone with trabecular bridges to surrounding cancellous host bone. Tonino et al. ${ }^{19}$ showed that the mean bone ongrowth in Gruen-zones 1 and 7 of femur retrievals with the plasma-spray HA coated ABG stems (Stryker - Newbury, UK) varied between 22 and $56 \%$ of the total surface, with minimal and maximal values 6 resp. $67 \%$. Coathup et al. ${ }^{22}$ compared bone ingrowth ( BD \%) and attachment $(\sim \mathrm{BIC} \%)$ in post-mortem retrievals of one hip design (Bimetric Biomet, Bridgend, UK) proximally coated with either a plasmaspray HA porous coating, a plain plasmaspray porous coating or only grit-blasted (Interlok). Bone attachment was respectively $37.3 \pm 2.5 \%$ (porous HA), $18.9 \pm 2.0 \%$ (plain porous) and $22.6 \pm 3.7 \%$ (Interlok). Bone ingrowth in the pores was $29.1 \pm 2.0 \%$ versus $21.8 \pm 2.1 \%$ (Interlok not mentioned). Bauer et al. ${ }^{18}$ assessed the amount of bone apposition on post-mortem Omnifit retrievals (Osteonics, Allendale NewJersey, USA) with proximal plasmaspray HA coating, and found that it varied between 32 and $78 \%$ without further specification. For comparison Cook et al. ${ }^{62}$ 


\section{Chapter 5}

quantified bone ingrowth on porous coated hip stems of different designs and saw bone growth into the available pore volume of less than $10 \%$ in all cases, whereas the rest of the stem surfaces showed fibrous encapsulation.

All these results involve post mortem retrievals in which a more representative osseo-integration for a particular stem design in all Gruen zones could be analysed without disruption by the extraction procedure. For the relatively new Symax stem for which there are as yet no post mortem retrievals, we are restricted to 'relevant areas of interest'. Otherwise, the positive quantitative results of the Symax would be extremely underestimated because of the extraction procedure.

Although the amount of bone-implant contact and bone density within the relevant a.o.i. is promising, the sample size of 4 cases imposes obvious limitations on the generalizability of the results. Further investigations of retrieved cases, evaluating long-term osseointegration, are recommended. 


\section{REFERENCES}

1. Geesink RGT, De Groot K, Klein CPAT. Chemical implant fixation using hydroxyapatite. Clin Orthop 1987;225:147-70.

2. Geesink RGT, De Groot K, Klein CPAT. Bonding of bone to apatite-coated implants. J Bone Joint Surg [Br] 1988;70-B:17-22.

3. Cook SD, Thomas KA, Kay JF, Jarcho M. Hydroxyapatite-coated titanium for orthopaedic implant applications. Clin Orthop 1988;232:225-43.

4. De Groot K, Geesink RGT, Klein CPAT, Serekian P. Plasma sprayed coatings of hydroxylapatite. J Biomed Mater Res 1987;21:1375-81.

5. Søballe K. Hydroxyapatite ceramic coating for bone implant fixation. Mechanical and histological studies in dogs. Acta Orthop Scand Suppl 1993;255:1-58.

6. Cook SD, Thomas KA, Dalton JE, Volkman TK, Whitecloud III TS, Kay JF. HA coating of porous implants improves bone ingrowth and interface attachment strength. J Biomed Mater Res 1992;26:989-1001.

7. Overgaard S, Lind M, Glerup H, Bunger C, Søballe K. Porous-coated versus grit-blasted surface texture of hydroxyapatite-coated implants during controlled micromotion: mechanical and histomorphometric results. J Arthroplasty 1998;13:449-58.

8. Cook SD, Thomas KA, Kay JF, Jarcho M. Hydroxyapatite-coated porous titanium for use as an orthopedic biologic attachment system. Clin Orthop 1988;230:303-12.

9. Geesink RGT. Hydroxylapatite-coated total hip replacement five year clinical and radiological results. In: Geesink RGT, Manley MT, eds. Hydroxylapatite coatings in orthopaedic surgery. New York: Raven Press, 1993:171-208.

10. D'Antonio JA, Capello WN, Crothers OD, Jaffe WL, Manley MT. Early clinical experience with hydroxyapatite-coated femoral implants. J Bone Joint Surg [Am] 1992;74-A:995-1008.

11. Furlong RJ, Osborn JF. Fixation of hip prostheses by hydroxyapatite ceramic coatings. J Bone Joint Surg [Br] 1991;73-B:741-5.

12. Tonino AJ, Romanini L, Rossi P, Borroni M, Greco F, Garcia-Araujo C, Garcia-Dihinx L, Murcia-Mazon A, Hein W, Anderson J. Hydroxyapatite-coated hip prostheses. Early results from an international study. Clin Orthop 1995;312:211-5.

13. Geesink RGT, Hoefnagels NH. Six-year results of hydroxyapatite-coated total hip replacement. J Bone Joint Surg [Br] 1995;77-B:534-47. 


\section{Chapter 5}

14. Rossi P, Sibelli P, Fumero S, Crua E. Short-term results of hydroxyapatite-coated primary total hip arthroplasty. Clin Orthop 1995;310:98-102.

15. Capello WN, D'Antonio JA, Jaffe WL, Geesink RG, Manley MT, Feinberg JR. Hydroxyapatite-coated femoral components: 15-year minimum followup. Clin Orthop 2006;453:75-80.

16. Havelin LI, Engesaeter LB, Espehaug B, Furnes O, Lie SA, Vollset SE. The Norwegian Arthroplasty Register: 11 years and 73,000 arthroplasties. Acta Orthop Scand 2000;71:337-53.

17. Søballe K, Gotfredsen K, Brockstedt-Rasmussen H, Nielsen PT, Rechnagel K. Histologic analysis of a retrieved hydroxyapatite-coated femoral prosthesis. Clin Orthop 1991;272:255-8.

18. Bauer TW, Geesink RGT, Zimmerman R, McMahon JT. Hydroxyapatite-coated femoral stems. Histological analysis of components retrieved at autopsy. J Bone Joint Surg [Am] 1991;73-A:1439-52.

19. Tonino AJ, Therin M, Doyle C. Hydroxyapatite-coated femoral stems. Histology and histomorphometry around five components retrieved at post mortem. J Bone Joint Surg [Br] 1999;81-B:148-54.

20. Bloebaum RD, Merrell M, Gustke K, Simmons M. Retrieval analysis of a hydroxyapatitecoated hip prosthesis. Clin Orthop 1991;267:97-102.

21. Porter AE, Taak P, Hobbs LW, Coathup MJ, Blunn GW, Spector M. Bone bonding to hydroxyapatite and titanium surfaces on femoral stems retrieved from human subjects at autopsy. Biomaterials 2004;25:5199-208.

22. Coathup MJ, Blunn GW, Flynn N, Williams C, Thomas NP. A comparison of bone remodelling around hydroxyapatite-coated, porous-coated and grit-blasted hip replacements retrieved at post-mortem. J Bone Joint Surg [Br] 2001;83-B:118-23.

23. Yankee SJ,Pletka BJ, Luckey HA, Johnson WA. Process for fabricating HA coatings for biomedical applications, Thermal spray research and application. In: Proceedings of the National Thermal Spray Conference. May 20-25, 1990 Long Beach, California:433-8.

24. Donath K. Reactions of tissue to calcium phophate ceramics. In: Heimke G, ed. Osseointegrated implants in oral and ENT surgery. Boca Raton: CRC Press, 1990:99-125.

25. Wheeler SL. Eight year clinical retrospective study of titanium plasma-sprayed and hydroxyapatite-coated cylinder implants. Int J Oral Maxillofac Implants 1996 ; 11 :340-50. 
26. Harada Y, Wang JT, Doppalapudi VA, Willis AA, Jasty M, Harris WH, Nagase M, Goldring SR. Differential effects of different forms of hydroxyapatite and hydroxyapatite/tricalcium phosphate particles on human monocyte/macrophages in vitro. J Biomed Mat Res 1996;31:19-26.

27. Bloebaum R, Beeks D, Dorr LD, Savory CG, Dupont JA, Hofmann AA. Complications with hydroxyapatite particulate separation in total hip arthroplasty. Clin Orthop 1994;298:19-26.

28. Morscher EW, Hefti A, Aebi U. Severe osteolysis after third-body wear due to hydroxyapatite particles from acetabular cup coating. J Bone Joint Surg [Br] 1998;80-B:267-72.

29. Kokubo T, Kushitani H, Sakka S, Kitsugi T, Yamamuro T. Solutions able to produce in vivo surface-structure changes in bioactive glass-ceramics A-W3. J Biomed Mat Res 1990;24:721-34.

30. Barrère F, Layrolle $\mathrm{P}$, van Blitterswijk CA, de Groot K. Biomimetic calcium phosphate coatings on Ti6Al4V: Growth study of OCP. J Mater Sci Mater Med 2001;12:529-34.

31. Barrère F, Layrolle $P$, van Blitterswijk CA, de Groot K. Biomimetic calcium phosphate coatings on Ti6Al4V: A crystal growth study of Octacalcium Phosphate and inhibition by $\mathrm{Mg}^{2+}$ and $\mathrm{HCO}_{3-}$. Bone 1998;25:107S-11S.

32. Szmukler-Moncler S, Perrin D, Ahossi V, Pointaire P. Evaluation of BONIT ${ }^{\circledR}$, a fully resorbable CaP coating obtained by electrochemical deposition, after 6 weeks of healing: a pilot study in the pig maxilla. Bioceramics 2001;13:395-8.

33. Becker P, Zeggel P, Lüthen F, Nebe B, Rychly J, Neumann H-G. Resorbable calcium phosphate composite coatings. Bioceramics 2002;14:653-6.

34. Barrère F. Biomimetic calcium phosphate coatings. Physicochemistry and biological activity. Thesis, 2002, University of Twente, Enschede, The Netherlands.

35. Becker P, Neumann HG, Nebe B, Lüthen F, Rychly J. Cellular investigations on electrochemically deposited calcium phosphate composites. J Mater Sci Med 2004;15:437-40.

36. ASTM International. Standards worldwide. http://www.astm.org (date last accessed 20 April 2011).

37. International Organization for Standardization (ISO). ISO standards. http://www.oso.org (date last accessed 20 April 2011).

38. Cigada A, Cabrini M, Pedeferri P. Increasing of the corrosion resistance of the Ti6Al4V alloy by high thickness anodic oxidation. J Mat Sci Med 1992;3:408-12. 


\section{Chapter 5}

39. Becker P, Baumann A, Lüthen F, Rychly J, Kirbs A, Beck U, Neumann H-G. Spark anodization on titanium and titanium alloys. Proceedings of the 10th World Conference on Titanium, Hamburg, Germany 2003;Vol V:3339-44.

40. Joschek S, Nies B, Krotz R, Goferich A. Chemical and physiochemical characterization of porous hydroxyapatite ceramics made of natural bone. Biomaterials 2000;21:1645-58.

41. Redepenning J, Schlesinger T, Burnham S, Lippiello L, Miyano J. Characterization of electrolytically prepared brushite and hydroxyapatite coatings on orthopedic alloys. J Biomed Mater Res 1996;30:287-94.

42. Donath K, Breuner G. A method for the study of undecalcified bones and teeth with attached soft tissues: the Sage-Schliff (sawing and grinding) technique. J Oral Pathol 1982;11:318-26.

43. Klein CP, Wolke JG, Blieck-Hogervorst JM, De Groot K. Calcium phosphate plasmasprayed coatings and their stability: an in vivo study. J Biomed Mater Res 1994;28:909-17.

44. Maxian SH, Zawadsky JP, Dunn MG. Effect of $\mathrm{Ca} / \mathrm{P}$ coating resorption and surgical fit on the bone/implant interface. J Biomed Mater Res 1994;28:1311-19.

42. Overgaard S, Bromose U, Lind M, Bünger C, Søballe K. The influence of crystallinity of the hydroxyapatite coating on the fixation of implants. Mechanical and histomorphometric results. J Bone Joint Surg [Br] 1999;81-B:725-31.

43. Chou L, Marek B, Wagner WR. Effects of hydroxylapatite coating crystallinity on biosolubility, cell attachment efficiency and proliferation in vitro. Biomaterials

44. Bauer TW. Hydroxyapatite: coating controversies. Orthopedics 1995;18:885-8.

45. Søballe K, Overgaard S. The current status of hydroxyapatite coating of prostheses [editorial]. J Bone Joint Surg [Br] 1996;78-B:689-91.

46. Cleries L, Fernandez-Pradas JM, Sardin G, Morenza JL. Dissolution behaviour of calcium phosphate coatings obtained by laser ablation. Biomaterials 1998;19:1483-7.

47. Klein CPAT, de Blieck-Hogervorst JM, Wolke JG, De Groot K. Studies of the solubility of different calcium phosphate ceramics particles in vitro. Biomaterials 1990;11:509-12.

48. Klein CPAT, Driessen AA, De Groot K, van den Hooff A. Biodegradation behaviour of various calcium phosphate materials in bone tissue. J Biomed Mater Res 1983;17:769-84.

49. Boyan BD, Hummert TW, Dean DD, Schwartz Z. Role of material surfaces in regulating bone and cartilage cell response. Biomaterials 1996;17:137-46.

50. Redey SA, Nardin M, Bernache-Assolant D, Rey C, Delannoy P, Sedel L, Marie PJ. Behaviour of human osteoblastic cells on stoechiometric hydroxyapatite and type $A$ carbonate apatite: role of surface energy. J Biomed Mater Res 2000;50:353-64. 
51. Lampin M, Warocquier-Clerout, Legris C, Degrange M, Sigot-Luizart MF. Correlation between substratum roughness and wettability, cell adhesion and cell migration. J Biomed Mater Res 1997;36:99-108.

52. Anselme K. Osteoblast adhesion on biomaterials. Biomaterials 2000;21:667-81.

53. Ong JL, Hoppe CA, Cardenas HL, Cavin R, Carnes DL, Sogal A, Rakar GN. Osteoblast precursor cell activity on HA surfaces of different treatments. J Biomed Mater Res 1998;39:176-83.

54. Leeuwenburgh S, Layrolle P, Barrère F, de Bruijn J, Schoonman J, van Blitterswijk CA, de Groot K. Osteoclastic resorption of biomimetic calcium phosphate coatings in vitro. J Biomed Mater Res 2001;56:208-15.

55. Doi Y, Iwanaga H, Shibutani T, Moriwaki Y, Iwayama Y. Osteoclastic responses to various calcium phosphates in cell cultures. J Biomed Mater Res 1999;47:424-33.

56. Yamada S, Heymann D, Bouler JM, Daculsi G. Osteoclastic resorption of calcium phosphate ceramics with different hydroxyapatite/b-tricalcium phosphate ratios. Biomaterials 1997; 18:1037-41.

57. Bauer TW, Taylor SK, Jiang M, Medendorp SV. An indirect comparison of third-body wear in retrieved hydroxyapatite-coated, porous, and cemented femoral components. Clin Orthop 1994;298:11-8.

58. Rahbek O, Overgaard S, Lind M, Bendix K, Bunger C, Søballe K. Sealing effect of hydroxyapatite coating on peri-implant migration of particles. An experimental study in dogs. J Bone Joint Surg [Br] 2001;83-B:441-7.

59. Alam I, Asahina I, Ohmamiuda K, Enomoto S. Comparative study of biphasic calcium phosphate ceramics impregnated with rhBMP-2 as bone substitutes. J Biomed Mater Res 2001;54:129-38.

60. Rogers-Foy JM, Powers DL, Brosnan DA, Barefoot SF, Friedman RJ, La Berge M. Hydroxyapatite composites designed for antibiotic drug delivery and bone reconstructions: a caprine model. J Invest Surg 1999;12:263-75.

61. Itokazu M, Matsunaga T, Kumazawa S, Yang WA. Novel drug delivery system for osteomyelites using porous hydroxyapatite blocks loaded by centrifugation. J App/ Biomater 1995;6:167-9.

62. Cook SD, Barrack RL, Thomas KA, Haddad RJ, Jr. Quantitative analysis of tissue growth into human porous total hip components. J Arthroplasty 1988;3:249-62. 


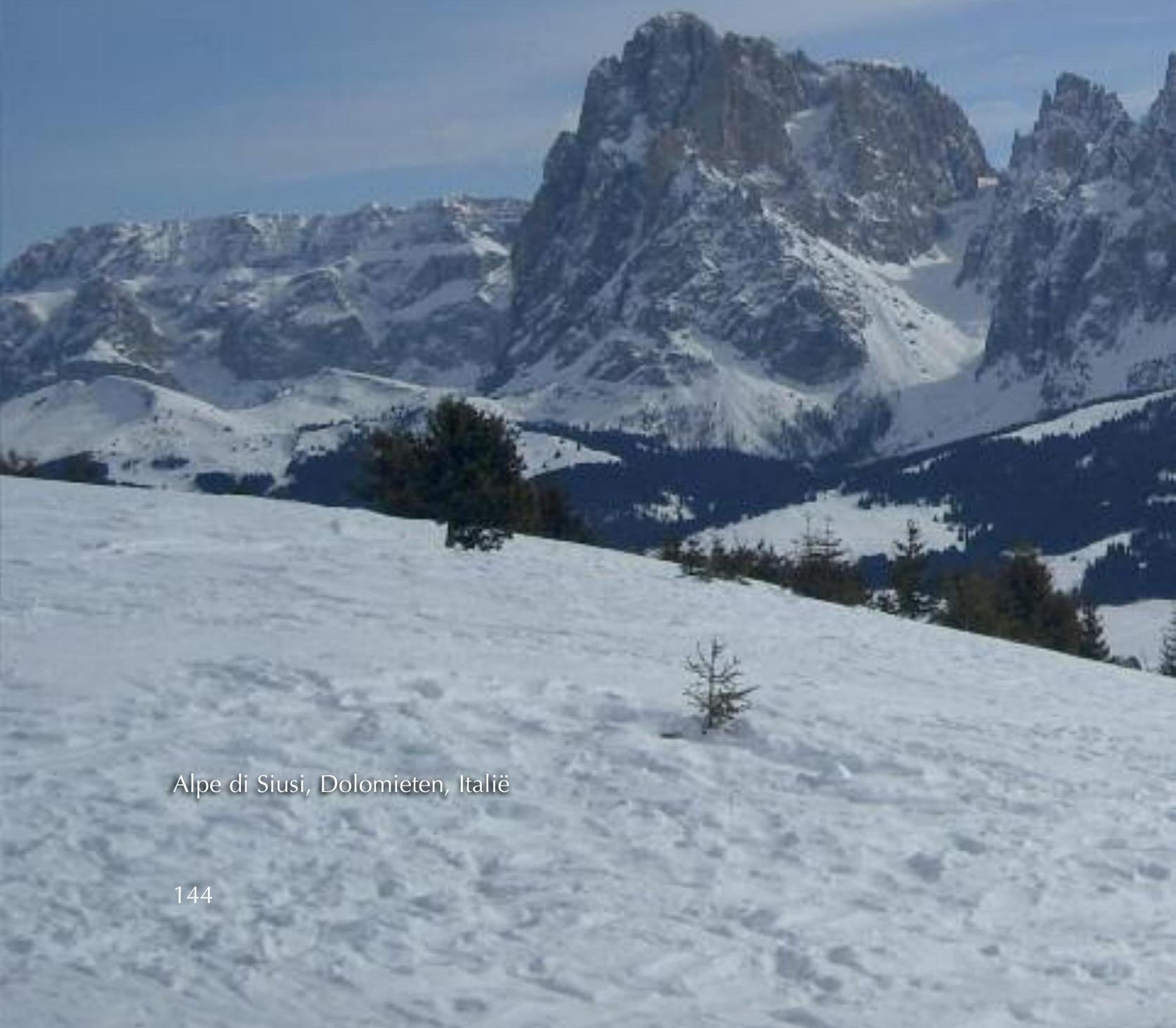




\section{CHAPTER 6}

\section{Randomised trial comparing bone remodelling around two uncemented stems using modified Gruen zones}

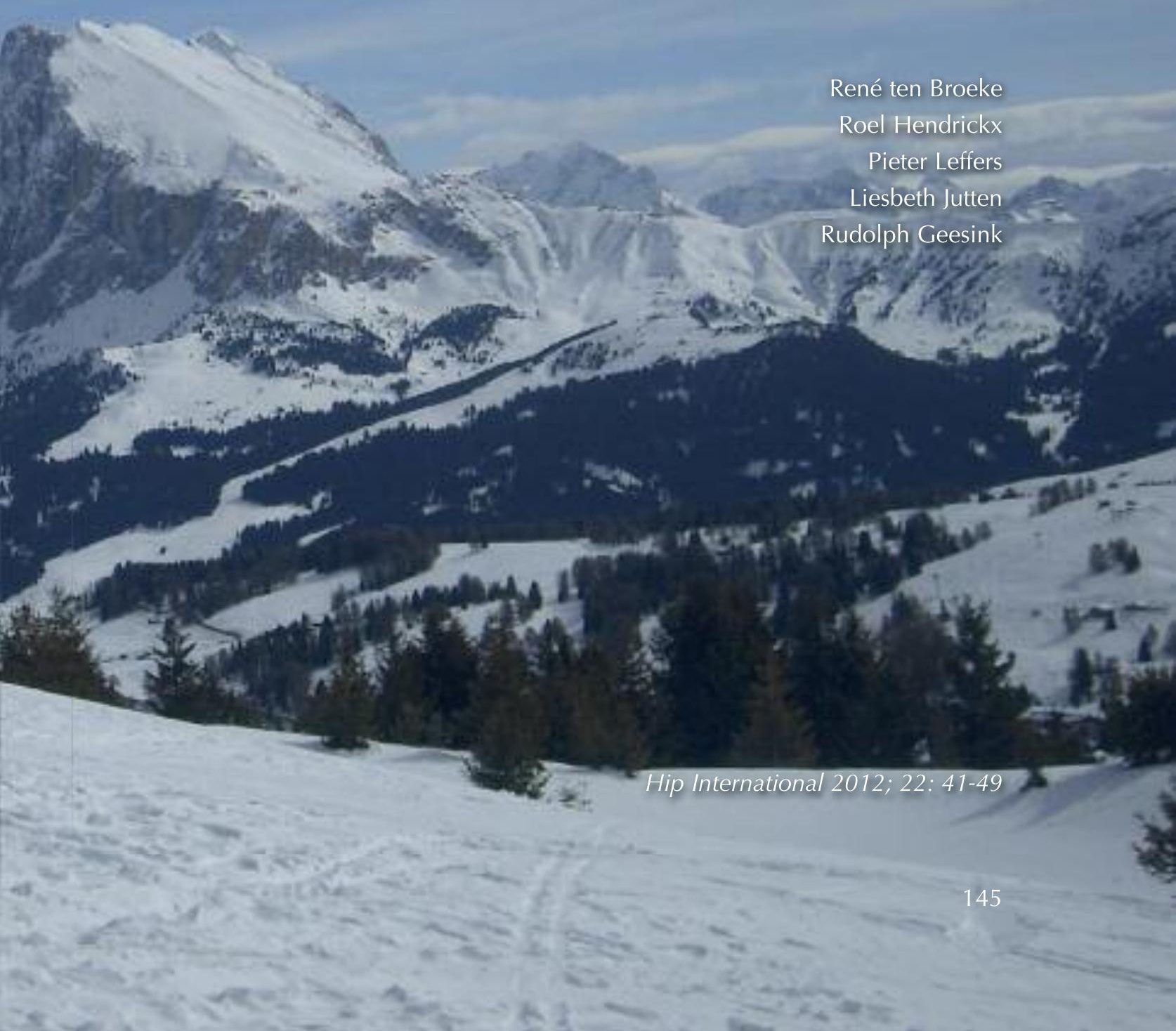




\section{ABSTRACT}

For assessment of bone remodelling around total hip arthroplasty using dualemission x-ray absorptiometry (DEXA), a variety of different systems to identify regions of interest (ROI) have been used, making comparisons between stem designs difficult. The Gruen zones are now widely used for this purpose. We present the results of a randomised clinical trial comparing 2 uncemented stem designs with proximal coating, using a modification of the Gruen zones to allow improved representation of the effect of the implant on bone mineral density (BMD) over time.

DEXA-data were used in a randomised trial with 2 years follow up, comparing the uncemented Symax ${ }^{\mathrm{TM}}(n=25)$ and Omnifit ${ }^{\circledR}(n=24)$ stems. The effect on BMD was determined using the 'standard' adapted Gruen zones, and a modification which studied an equal length and position for zones 1 and 7 around both stems, assuring that the same regions in terms of cancellous and cortical bone were compared.

The 'modified' regions of interest give lower BMD values around the Omnifit ${ }^{\circledR}$ than using the 'standard' Gruen zones ( $3.6 \%$ in zone $\left.7, P<0.05\right)$. The difference with the Symax ${ }^{\mathrm{TM}}$ BMD values, which had been concealed using the standard Gruen zones, became statistically significant in favour of the Symax ${ }^{\mathrm{TM}}$ implant.

This adaptation can detect a statistically significant difference in bone preservation in zone 7 between stems that would otherwise not have been revealed. We recommend the use of 'modified' Gruen zones for more valid comparison of remodelling caused by different implant designs. 


\section{INTRODUCTION}

Preservation of periprosthetic bone around hip prostheses is important. Following uncemented total hip arthroplasty (THA), dual energy X-ray absorptiometry (DEXA) has been shown to be a precise and accurate, and a useful tool for assessment of periprosthetic bone remodelling ${ }^{1-5}$. However since the introduction of bone densitometry for this purpose, many different classifications of regions of interest (ROI) have been applied, making comparison of BMD results between implant designs difficult. Some of these ROIs were based on implant-related landmarks ${ }^{2,6-8}$, and others on various anatomic landmarks on the femur ${ }^{1,4,9}$.

An important improvement for standardization of ROls was the application of the Gruen zones, which were originally designed for analysis of stem loosening on conventional radiographs ${ }^{10}$. Since then many authors have adopted these ROls for bone densitometry around uncemented and cemented stems ${ }^{11-22}$. For uncemented stems with porous or HA proximal coating, these zones were changed to the 'adapted Gruen-zones'; zones 1 and 7 representing the coated area, and zones 2-3

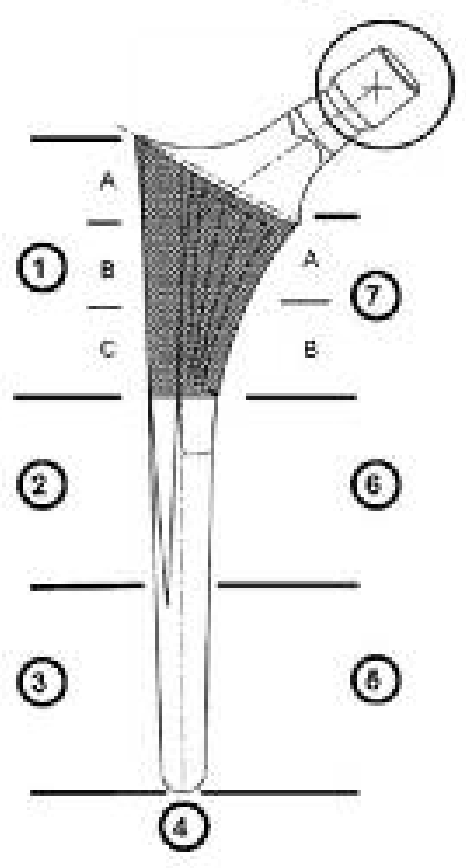
and 5-6 respectively the lateral and medial zones, equally divided around the noncoated part of the stem (Fig. 1). However, for comparing implants with differences in design, stem length and coating-area, using these adapted Gruen-zones may generate spurious conclusions, because compared regions are incomparable in terms of their relative content of cancellous and cortical bone.

Fig. 1 Drawing showing delineation of 'adapted Gruen zones' 1 to 7 in the AP view around an uncemented stem with proximal coating (in this case the Symax ${ }^{\mathrm{TM}}$ ). 


\section{Chapter 6}

Although it is well accepted that bone preservation after stem insertion is mainly driven by biomechanical factors such as stress distribution, the extent of remodelling is also related to the rate of bone metabolism. Cancellous bone is characterised by a higher bone turnover than cortical bone, which is partly due to better vascularisation ${ }^{23}$. Therefore, it may be expected that zones that mainly contain cancellous bone will show more postoperative bone loss than zones containing more cortical bone (Fig. 2). This makes comparison of bone density changes between stems with different proximal coating lengths (zone 1 and 7) potentially invalid, because the composition of the compared ROI in terms of cancellous and cortical bone is essentially different ${ }^{22}$.

For this reason we performed DEXA-analysis of bone remodelling around two stem designs with different coating length. We compared results using the original 'adapted Gruen-zones' (further referred to as 'standard' zones) with those after adjustment of the ROls (the 'modified' zones), with the objective of assessing comparable bone areas around both stems. It was hypothesised that there would be a significant difference in DEXA-results in zone 7 between the two methods, which would influence the conclusions of a comparison between two stem designs. We propose 'modified' regions of interest that more correctly attribute remodelling changes to the implant .
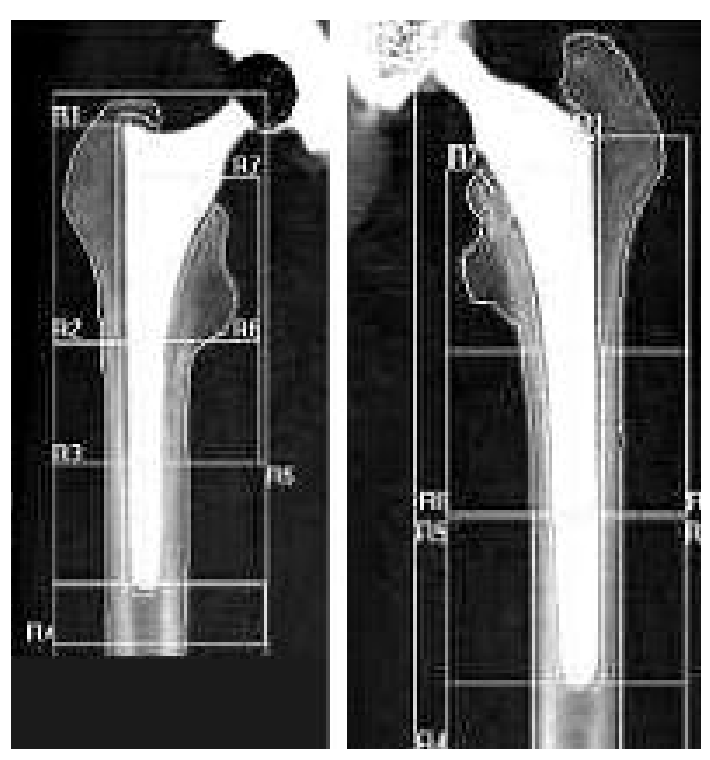

Fig. 2 DEXA-pictures of the Symax ${ }^{\mathrm{TM}}$ (left) and Omnifit ${ }^{\circledast}$ (right) stems of comparable sizes illustrating how the application of the original (or 'standard') adapted Gruen zones' will result in inclusion of more cortical bone in zone 7 in case of the Omnifit ${ }^{\circledR}$. 


\section{Patients and Methodes}

\section{Patient selection}

An individually randomised, two group, parallel controlled trial comparing bone remodelling between the uncemented $\operatorname{Symax}^{\mathrm{TM}}(\mathrm{n}=25)$ and the Omnifit ${ }^{\circledR}-\mathrm{HA}$ stem $(n=24)$ was performed. The indication for total hip arthroplasty (THA) was osteoarthritis (OA) of the hip in all cases. There were no fractures and no cases of osteonecrosis of the femoral head. Exclusion criteria were a history of hormonal therapy, any medication or illness known to affect bone metabolism, and a body mass index (BMI) higher than $35 \mathrm{~kg} / \mathrm{m}^{2}$. After obtaining signed informed consent, participants were allocated at random to the type of prosthesis by sequentially drawing sealed opaque envelopes stipulating choice of implant. The surgeon was unaware of the content and sequence of the envelopes (allocation concealment).

The original trial was approved by the local Medical Ethics Committee and performed at the Orthopaedic department of the Maastricht University Medical Centre (registration nr. 02-072). It was carried out in line with the Seoul amendment (2008) of the Helsinki declaration.

\section{Implants}

The Symax ${ }^{\text {TM }}$ stem (Stryker ${ }^{\circledR}$ EMEA, Montreux, Switzerland) is forged from Ti6AI4V alloy. It features a proximal plasma-sprayed, commercially pure (CP) Titanium coating, and a biomimetic electrochemically deposited BONIT ${ }^{\circledR}$ HA coating (proprietary to DOT GmbH, Rostock, Germany) ${ }^{24,25}$. Distally the stem is treated with the Dotize ${ }^{\circledR}$ surface process, which reduces protein adsorption and consequently distal bone apposition and osseointegration ${ }^{26-28}$.

The Omnifit ${ }^{\circledR}$ HA stem (Stryker ${ }^{\circledR}$, Mahwah, New Jersey, USA) is made of the same alloy, has a macrotextured surface and a plasma-spray HA-coating on the proximal $40 \%$ of the stem (Fig. 3).

\section{Surgical protocol and Postoperative management}

All operations were performed by 2 experienced orthopaedic surgeons (R.t.B. and R.G.) according to identical and standardised orthopaedic procedures using the postero-lateral approach without osteotomy of the greater trochanter. Patients were 


\section{Chapter 6}

treated with 24 hours intravenous antibiotic prophylaxis (Augmentin ${ }^{\circledR}$ ), DVT prophylaxis with low molecular weight heparin (Fraxiparin ${ }^{\circledR}$ ) for 6 weeks and prophylaxis against heterotopic ossification with non-steroidal anti-inflammatory medication $\left(\right.$ Indocid $\left.^{\circledR}\right)$ for 14 days. Full weightbearing was allowed from day 1 .

\section{DEXA protocol and Regions of Interest}

The primary outcome measure was periprosthetic BMD from baseline to 2 years follow up. In the first postoperative week the baseline BMD measurement was performed with the fan-beam Hologic QDR 4500A densitometer (Hologic Inc., Waltham, MA, USA) with exact positioning of the leg by stabilizing rotation using standard knee and foot support devices. A dedicated software programme was used for removal of the metal hip stem area. Quality control of the densitometer was executed through daily automatic self-calibration. There was no significant drift during the study period. All DEXA-scans were made by the same experienced independent analyst.

Follow-up evaluations were performed at 6 weeks, 3 months, 6 months, 1 year and 2 years. Analysis of the raw scans was carried out by one member of the research group (R.H.) who was not part of the surgical staff and blinded for clinical and radiographic results.

When comparing implant sizes, the HA-coating is somewhat longer on the Omnifit ${ }^{\circledR}$-stem than on the Symax ${ }^{\mathrm{TM}}$ (Fig. 3). Bone density around the Symax ${ }^{\mathrm{TM}}$ was analysed in one way. BMD around the Omnifit ${ }^{\circledast}$ was assessed in two ways. The 'standard' Gruen zones define the length of Gruen zones 1 and 7 by the length of HA coating, resulting in different lengths for these zones according to prosthesis selection. Using 'modified' Gruen zones, zones 1 and 7 around the Omnifit ${ }^{\circledR}$ are identical in length to those of the size-matched Symax ${ }^{\mathrm{TM}}$. In this way comparable bone areas were analysed for both stems. Gruen zones 2 to 6 were equally divided around the rest of the stem (Fig. 3). The appropriate matching of Symax ${ }^{\mathrm{TM}}$ and Omnifit ${ }^{\circledR}$ sizes was confirmed with templating on the preoperative X-ray.

Preoperative and (one and two year) postoperative DEXA scanning was also performed of the AP-lumbar spine, to detect abnormal systemic bone metabolism during study follow-up. The preoperative lumbar scan served as a baseline measurement for comparison. 


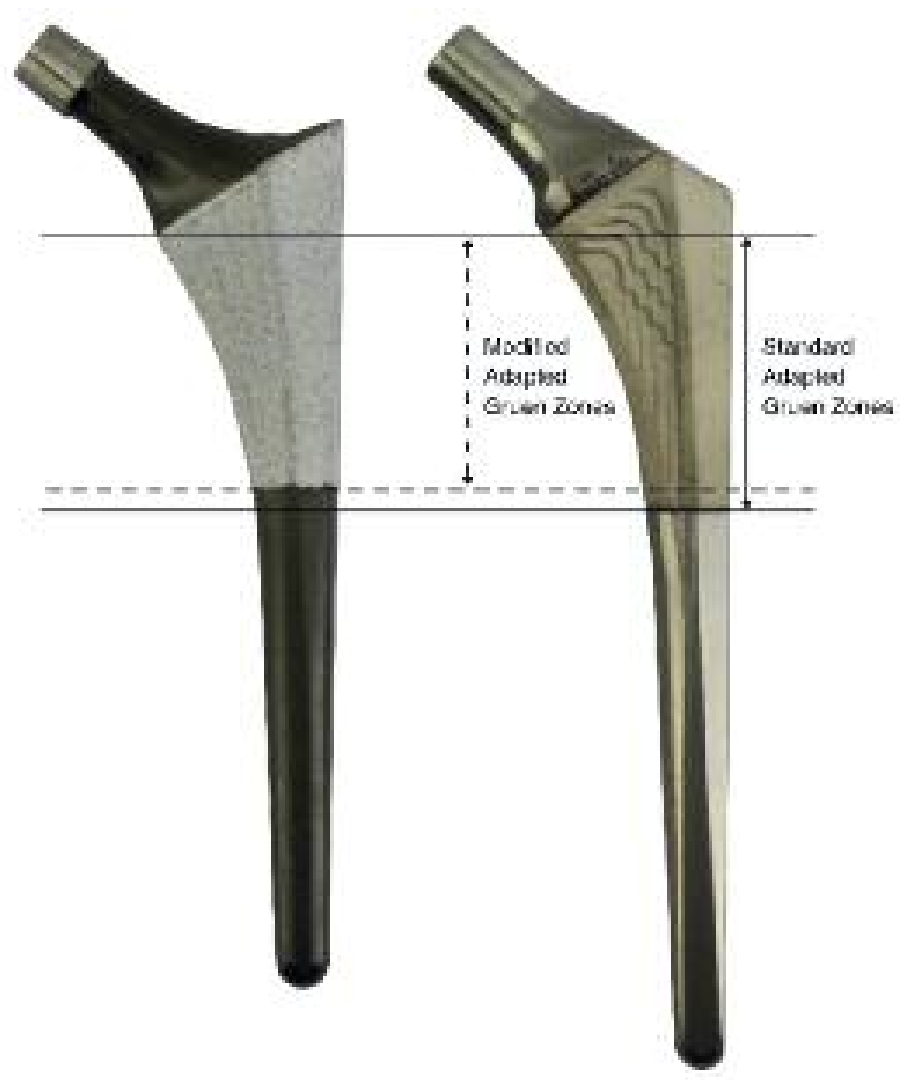

Fig. 3 Illustration of the SymaxTM (left) and Omnifit ${ }^{\circledast}$ (right) illustrating the small difference in coating length between comparable stem sizes. Good comparison of bone remodelling in zone 7 makes adjustment of the 'standard adapted Gruen zones' around the Omnifit' to the 'modified adapted Gruen zones' necessary.

\section{Radiological and clinical evaluation}

Anteroposterior (AP) pelvis and lateral radiographs of the involved hip were taken at the same follow-up as the DEXA-scans, following a standard protocol. They were scored according to Engh's criteria for implant ingrowth ${ }^{29}$. Clinical results and physical activity were assessed using the Harris Hip Score (HHS). 


\section{Chapter 6}

\section{Statistics}

Longitudinal BMD results per Gruen zone are expressed as relative values with the immediate postoperative DEXA measurement of the operated femur being the reference value (baseline), set at $100 \%$. Absolute and relative BMD values are described by their means and standard deviations, demographic parameters by mean and range. Deviations from the normal distribution were tested by the Kolomogorov-Smirnov test. Since no deviations could be observed, the unpaired Student's $t$-test for 2 independent samples was used for comparing the Symax ${ }^{\mathrm{TM}}$ and Omnifit ${ }^{\circledR}$ group for all ROls. For the Omnifit ${ }^{\circledR}$, differences between the 'standard' and the 'modified' Gruen zones were tested per region with the paired $t$-test. Differences with one-sided $P$-values equal or lower than 0.05 were considered statistically significant. Microsoft Office Excel 2003 (Microsoft Corporation, Redmond, Washington, USA) and SPSS software 15.0 for Windows (SPSS Inc., Chicago, Illinois, USA) was used for data analysis.

\section{Results}

Demographic details and initial lumbar BMD (preoperative) between patient groups showed no important differences (Table I). There was no difference in level of physical activity among patients postoperatively according to HHS recordings.

At one year follow-up all stems showed radiological evidence of stable bone ingrowth ${ }^{29}$, and none of the patients complained of hip pain at the final evaluation. At two years the lumbar spine BMD did not show a decrease when compared to the start of the study $\left(\mathrm{t}_{0}\right)$ in either group. Due to a deviation of protocol and based on anatomical considerations, one patient received a Symax ${ }^{\mathrm{TM}}$ instead of an Omnifit ${ }^{\circledR}$. This same patient was withdrawn from the study because of an intra-operative fracture requiring revision and preventing full weightbearing. All other patients consequently had all their scans performed during the entire follow-up and within the predefined timeframe. All patients who underwent randomization received the treatment to which they were originally allocated (intention to treat principle).

Results of absolute and relative BMD around the Omnifit ${ }^{\circledR}$ were different dependent on the use of 'standard' or 'modified' Gruen zones (results are shown in 
Table I Patient characteristics and baseline demographic data; Values are given as mean (and range) or frequencies (and percentage)

\begin{tabular}{lll} 
& Omnifit (24) & Symax (25) \\
\hline Age at operation in yrs, mean (range) & $60,4(39-71)$ & $60,2(46-72)$ \\
Weight in kg, mean (range) & $78,5(60-96)$ & $82,2(54-105)$ \\
Body Mass Index in kg/m², mean (range) & $27,2(22-32)$ & $27,8(22-37)$ \\
Sex: Male (\%) & $15(62.5 \%)$ & $12(48 \%)$ \\
Baseline BMD spine: normal & $16(66.6 \%)$ & $17(68.0 \%)$ \\
\multicolumn{1}{c}{ osteopenic } & $7(29.2 \%)$ & $7(28.0 \%)$ \\
\multicolumn{1}{c}{ osteoporotic } & $1(4.2 \%)$ & $1 \quad(4.0 \%)$ \\
\hline
\end{tabular}

Table II and graphically represented in Figure 4). For the Omnifit ${ }^{\circledR}$, absolute BMD was consistently lower at every follow-up using the 'modified' zones instead of the 'standard' zones. In ROI-1 this difference varied between $0.16 \mathrm{~g} / \mathrm{cm}^{2}(=1.5 \%)$ at 6 weeks, and $0.12 \mathrm{~g} / \mathrm{cm}^{2}(=1.1 \%)$ at 2 years. In ROI-7 the difference in BMD was $0.05 \mathrm{~g} / \mathrm{cm}^{2}(=1.1 \%)$ at 6 weeks, and $0.07 \mathrm{~g} / \mathrm{cm}^{2}(=3.1 \%)$ at 2 years $(P \leq 0.05)$. As can be expected, in the more cortical areas this effect was much smaller. In ROI-2 differences varied between $1.2 \%$ (6 wks.) and $0.1 \%$ ( $2 \mathrm{yrs}$.), for ROI- 6 this was $1.2 \%$ and $-0.7 \%$, for ROI- 3 this was $0.6 \%$ and $1.2 \%$, for ROI- 4 this was $0 \%$ and $0 \%$, and for ROI-5 this was $-0.6 \%$ and $0 \%$. All these differences are not statistically significant.

The difference in BMD between Symax ${ }^{\mathrm{TM}}$ and $\mathrm{Omnifit}^{\circledR}$ became more evident using the 'modified' Gruen zones. For ROI-1 the difference increased from $1.3 \%$ at 6 weeks to $2.1 \%$ at 2 years, and for ROI-7 the difference increased from $1.5 \%$ at 6 weeks ( $P=0.38$ ) to $5.8 \%$ at 2 years ( $P=0.04$ ). At 2 years the difference between the groups in zone 7 was $2.7 \%(P=0.20)$ using the 'standard' zones and became $5.8 \%$ by adapting the 'modified' zones $(P=0.04)$. The results show consistently higher $\mathrm{BMD}$ values for the Symax ${ }^{\mathrm{TM}}$. The differences in zone 7 became statistically significant from one year onward (Table III). 
Table II Perisprosthetic BMD around Omnifit ${ }^{\circledR}(\mathrm{N}=24)$ and Symax ${ }^{\mathrm{TM}}(\mathrm{N}=25)$ stem during 2 year prospective follow-up; presenting absolute values per roi, with standard deviation, and expressed as percentage of baseline reference. For the Omnifit ${ }^{\oplus}$ both 'standard' and 'modified' Gruen zones are analysed (see Fig. 3 and text)

\begin{tabular}{|c|c|c|c|c|c|c|}
\hline \multicolumn{7}{|c|}{ BMD Omnifit standard adapted Gruen zones } \\
\hline & post-op & 6 wks & 3 mnths & 6 mnths & $1 \mathrm{yr}$ & 2 yrs \\
\hline \multirow[t]{2}{*}{ ROI 1} & $1,04+0,17$ & $1,02+0,16$ & $0,98+0,18$ & $0,94+0,17$ & $0,92+0,17$ & $0,90+0,18$ \\
\hline & $100,0 \%$ & $98,1 \%$ & $94,2 \%$ & $90,4 \%$ & $88,5 \%$ & $86,5 \%$ \\
\hline \multirow[t]{2}{*}{ ROI 2} & $1,70+0,27$ & $1,69+0,28$ & $1,64+0,27$ & $1,64+0,28$ & $1,63+0,26$ & $1,64+0,26$ \\
\hline & $100,0 \%$ & $99,4 \%$ & $96,5 \%$ & $96,5 \%$ & $95,9 \%$ & $96,5 \%$ \\
\hline \multirow[t]{2}{*}{ ROI 3} & $1,69+0,18$ & $1,66+0,21$ & $1,62+0,22$ & $1,65+0,19$ & $1,68+0,19$ & $1,70+0,21$ \\
\hline & $100,0 \%$ & $98,2 \%$ & $95,9 \%$ & $97,6 \%$ & $99,4 \%$ & $100,6 \%$ \\
\hline \multirow[t]{2}{*}{ ROI 4} & $1,78+0,21$ & $1,77+0,21$ & $1,76+0,23$ & $1,76+0,21$ & $1,77+0,25$ & $1,78+0,23$ \\
\hline & $100,0 \%$ & $99,4 \%$ & $98,9 \%$ & $98,9 \%$ & $99,4 \%$ & $100,0 \%$ \\
\hline \multirow[t]{2}{*}{ ROI 5} & $1,73+0,26$ & $1,72+0,27$ & $1,72+0,28$ & $1,72+0,27$ & $1,77+0,29$ & $1,77+0,23$ \\
\hline & $100,0 \%$ & $99,4 \%$ & $99,4 \%$ & $99,4 \%$ & $102,3 \%$ & $102,3 \%$ \\
\hline \multirow[t]{2}{*}{ ROI 6} & $1,65+0,24$ & $1,63+0,26$ & $1,62+0,27$ & $1,64+0,28$ & $1,66+0,29$ & $1,68+0,28$ \\
\hline & $100,0 \%$ & $98,8 \%$ & $98,2 \%$ & $99,4 \%$ & $100,6 \%$ & $101,8 \%$ \\
\hline \multirow[t]{2}{*}{ ROI 7} & $1,20+0,23$ & $1,13+0,20$ & $1,06+0,21$ & $1,02+0,20$ & $0,99+0,20$ & $1,00+0,22$ \\
\hline & $100,0 \%$ & $94,2 \%$ & $88,3 \%$ & $85,0 \%$ & $82,5 \%$ & $83,3 \%$ \\
\hline \multicolumn{7}{|c|}{ BMD Omnifit modified adapted Gruen zones } \\
\hline & post-op & $6 \mathrm{wks}$ & 3 mnths & 6 mnths & $1 \mathrm{yr}$ & 2 yrs \\
\hline \multirow[t]{2}{*}{ ROI 1} & $0,89 \pm 0,17$ & $0,86 \pm 0,16$ & $0,83 \pm 0,17$ & $0,80 \pm 0,17$ & $0,79 \pm 0,17$ & $0,78 \pm 0,19$ \\
\hline & $100,0 \%$ & $96,6 \%$ & $93,3 \%$ & $89,9 \%$ & $88,8 \%$ & $87,6 \%$ \\
\hline \multirow[t]{2}{*}{ ROI 2} & $1,67 \pm 0,28$ & $1,64 \pm 0,26$ & $1,60 \pm 0,27$ & $1,61 \pm 0,28$ & $1,60 \pm 0,28$ & $1,61 \pm 0,27$ \\
\hline & $100,0 \%$ & $98,2 \%$ & $95,8 \%$ & $96,4 \%$ & $95,8 \%$ & $96,4 \%$ \\
\hline \multirow[t]{2}{*}{ ROI 3} & $1,70 \pm 0,18$ & $1,66 \pm 0,22$ & $1,62 \pm 0,21$ & $1,65 \pm 0,19$ & $1,68 \pm 0,19$ & $1,69 \pm 0,20$ \\
\hline & $100,0 \%$ & $97,6 \%$ & $95,3 \%$ & $97,1 \%$ & $98,8 \%$ & $99,4 \%$ \\
\hline \multirow[t]{2}{*}{ ROI 4} & $1,78 \pm 0,22$ & $1,77 \pm 0,21$ & $1,75 \pm 0,22$ & $1,74 \pm 0,21$ & $1,78 \pm 0,25$ & $1,78 \pm 0,24$ \\
\hline & $100,0 \%$ & $99,4 \%$ & $98,3 \%$ & $97,8 \%$ & $100,0 \%$ & $100,0 \%$ \\
\hline \multirow[t]{2}{*}{ ROI 5} & $1,72 \pm 0,25$ & $1,72 \pm 0,26$ & $1,70 \pm 0,27$ & $1,67 \pm 0,39$ & $1,77 \pm 0,29$ & $1,76 \pm 0,23$ \\
\hline & $100,0 \%$ & $100,0 \%$ & $98,8 \%$ & $97,1 \%$ & $102,9 \%$ & $102,3 \%$ \\
\hline \multirow[t]{2}{*}{ ROI 6} & $1,60 \pm 0,27$ & $1,60 \pm 0,28$ & $1,57 \pm 0,29$ & $1,59 \pm 0,30$ & $1,61 \pm 0,31$ & $1,64 \pm 0,30$ \\
\hline & $100,0 \%$ & $100,0 \%$ & $98,1 \%$ & $99,4 \%$ & $100,6 \%$ & $102,5 \%$ \\
\hline \multirow[t]{2}{*}{ ROI 7} & $1,16 \pm 0,23$ & $1,08 \pm 0,20$ & $1,01 \pm 0,21$ & $0,97 \pm 0,20$ & $0,93 \pm 0,20$ & $0,93 \pm 0,22$ \\
\hline & $100,0 \%$ & $93,1 \%$ & $87,1 \%$ & $83,6 \%$ & $80,2 \%$ & $80,2 \%$ \\
\hline \multicolumn{7}{|c|}{ BMD Symax adapted Gruen zones } \\
\hline \multirow{3}{*}{ ROI 1} & post-op & 6 wks & 3 mnths & 6 mnths & $1 \mathrm{yr}$ & 2 yrs \\
\hline & $0,96+0,17$ & $0,95+0,18$ & $0,92+0,19$ & $0,89+0,18$ & $0,87+0,19$ & $0,87+0,19$ \\
\hline & $100,0 \%$ & $97,9 \%$ & $94,8 \%$ & $91,8 \%$ & $89,7 \%$ & $89,7 \%$ \\
\hline \multirow[t]{2}{*}{ ROI 2} & $1,74+0,29$ & $1,71+0,31$ & $1,67+0,30$ & $1,65+0,29$ & $1,67+0,29$ & $1,68+0,30$ \\
\hline & $100,0 \%$ & $98,3 \%$ & $96,0 \%$ & $94,8 \%$ & $96,0 \%$ & $96,6 \%$ \\
\hline \multirow[t]{2}{*}{ ROI 3} & $1,76+0,21$ & $1,70+0,21$ & $1,70+0,20$ & $1,69+0,22$ & $1,73+0,20$ & $1,73+0,19$ \\
\hline & $100,0 \%$ & $96,6 \%$ & $96,6 \%$ & $96,0 \%$ & $98,3 \%$ & $98,3 \%$ \\
\hline \multirow[t]{2}{*}{ ROI 4} & $1,85+0,22$ & $1,82+0,21$ & $1,82+0,23$ & $1,84+0,21$ & $1,87+0,21$ & $1,89+0,21$ \\
\hline & $100,0 \%$ & $98,4 \%$ & $98,4 \%$ & $99,5 \%$ & $101,1 \%$ & $102,2 \%$ \\
\hline \multirow[t]{2}{*}{ ROI 5} & $1,77+0,22$ & $1,74+0,22$ & $1,72+0,23$ & $1,76+0,23$ & $1,80+0,24$ & $1,83+0,24$ \\
\hline & $100,0 \%$ & $98,3 \%$ & $97,2 \%$ & $99,4 \%$ & $101,7 \%$ & $103,4 \%$ \\
\hline ROI 6 & $1,66+0,18$ & $1,63+0,20$ & $1,62+0,20$ & $1,64+0,20$ & $1,67+0,21$ & $1,71+0,20$ \\
\hline & $100,0 \%$ & $98,2 \%$ & $97,6 \%$ & $98,8 \%$ & $100,6 \%$ & $103,0 \%$ \\
\hline ROI 7 & $1,29+0,20$ & $1,22+0,18$ & $1,17+0,19$ & $1,13+0,21$ & $1,12+0,22$ & $1,11+0,22$ \\
\hline & $100,0 \%$ & $94,6 \%$ & $90,7 \%$ & $87,6 \%$ & $86,8 \%$ & $86,0 \%$ \\
\hline
\end{tabular}



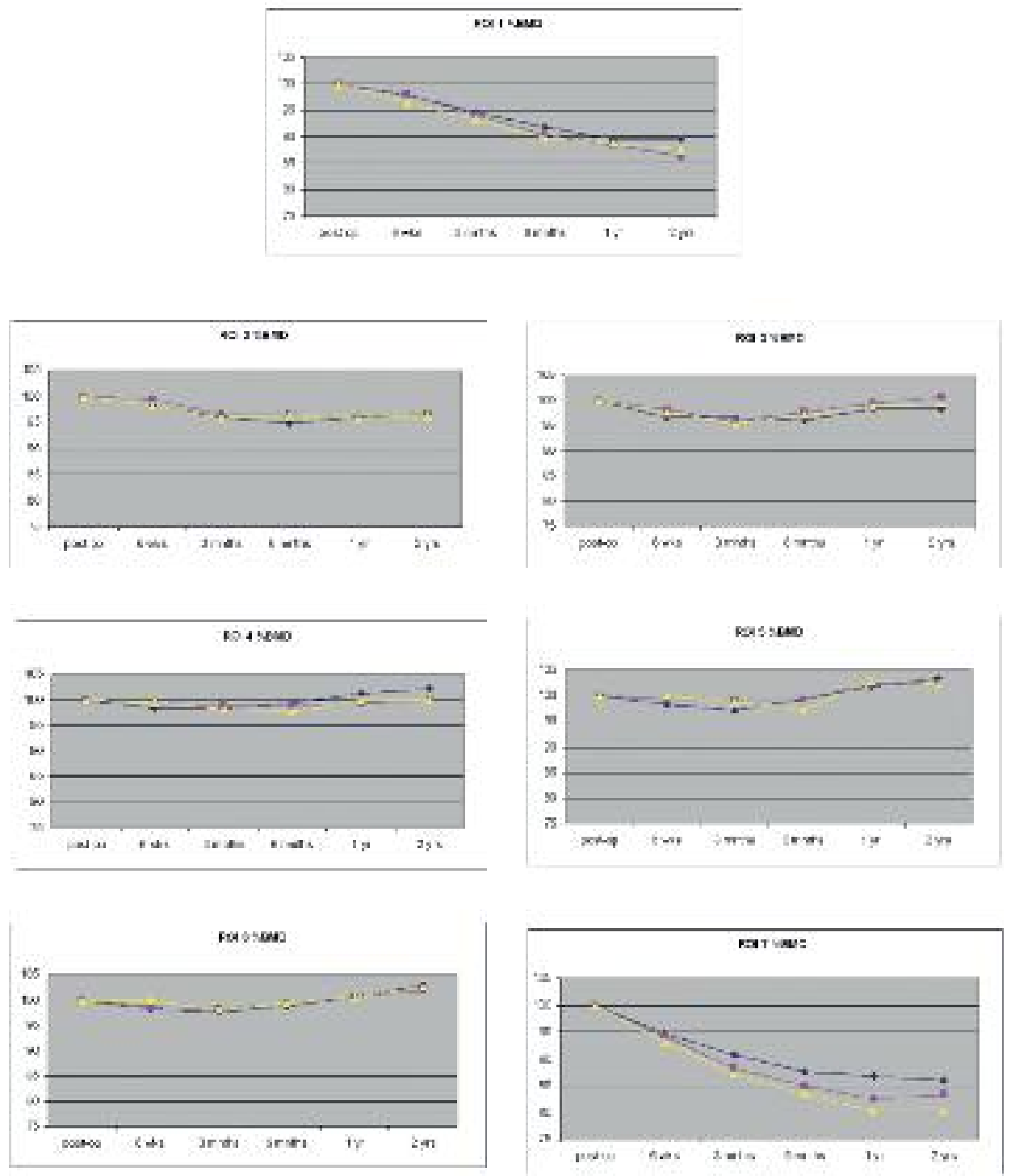

Fig. 4 Graphs showing mean relative BMD of the ROIs 1 to 7 during 2 year follow-up, comparing the SymaxTM $(\bullet)$ with both the 'standard Gruen zones' (⿴) and the 'modified Gruen zones' (A) around the Omnifit ${ }^{\oplus}$ stem, with the immediate postoperative BMD set at $100 \%$ (= baseline reference). $B M D=$ bone mineral density 


\section{Chapter 6}

Table III P-values of differences in BMD between the Symtax ${ }^{\circledast}$ and the Omnifit ${ }^{\circledR}$ using 'standard' and 'modified' zones.

\begin{tabular}{llllll} 
& 6 weeks & 3 months & 6 months & 1 year & 2 year \\
\hline Symax versus Omnifit standard & 0.47 & 0.26 & 0.28 & 0.10 & 0.20 \\
Symax versus Omnifit modified & 0.38 & 0.08 & 0.11 & 0.01 & 0.04 \\
\hline
\end{tabular}

\section{Discussion}

\section{Background}

As a result of the modification of Gruen zones we observed a difference in BMD around the Omnifit ${ }^{\circledR t}$ between the original ('standard') and the 'modified' Gruen zones varying between 0 and $3.1 \%$ in ROI 1 and 7 , being higher using the 'standard' zones. Because the more distal zones are mainly cortical, their relative compositions do not change much when using the 'modified' Gruen zones. Consequently there is no clear difference in BMD between the two methods in zones 2 to 6 . The improved preservation of bone stock around the Symax ${ }^{\mathrm{TM}}$ stem compared to the Omnifit ${ }^{\circledR}$ became clearer using 'modified' zones, and also statistically significant. This difference was not revealed using the 'standard' zones.

The difference between the Symax ${ }^{\mathrm{TM}}$ and $\mathrm{Omnifit}^{\circledR}$ in proximal coating length, and consequently the difference in length of zone 1 and 7 using 'standard' zones, is small. Nevertheless the effect on BMD results is evident, and emphasises the value of the modification. In case of larger differences in coating length this phenomenon might be even more important because the 'standard' zones might reveal more prominent differences in proximal BMD. This would (superficially) suggest remodelling differences between the implants, but in fact would simply represent incomparable ROIs. A clear example of this is seen in the study of Rahmy et $\mathrm{a}^{22}$. He compared a Mallory Head (MH) (Biomet, Warsaw, Indiana, USA) with an Anatomique Benoist Girard (ABG) (Stryker, Newbury, UK), both uncemented stems made of titanium alloy with a proximal HA coating. The authors mainly attributed the difference in remodelling to design-related loading patterns. However the large stem and coating length in combination with the use of 
'standard' Gruen zones as an important cause for the relatively small bone loss around the $\mathrm{MH}$ (- 6.2 \% versus $-16.5 \%$ for the $\mathrm{ABG})$, was not recognised. Because of the length of the proximal coating on the $\mathrm{MH}$ stem, the adapted Gruen zones 1 and 7 are much larger compared to the same ROls around the shorter ABG stem. As a result these larger ROls contain more cortical bone, which undergoes less remodelling and therefore suggests better preservation of bone stock. In their study it remains unclear whether prosthetic properties or the choice of ROls contributes most to the apparent difference in remodelling between the compared implants.

In our study there were no differences in lumbar spine BMD between the implant groups at the start of the study and at 2 years follow-up, illustrating that differences in bone remodelling between the groups could not be explained by metabolic bone disease in either group, or by difference in age-related bone density changes.

Bone remodelling can be considered as a surface phenomenon, as the remodelling cycle is initiated by osteoclastic removal of bone from the bone surface. Therefore, the remodelling potential of bone is dependent on the amount of internal pore surface in the bone for bone apposition or resorption, as observed by Martin et $\mathrm{al}^{30}$. This may explain why cancellous bone tends to remodel more extensively than cortical bone, and stress shielding will have more effect in the proximal metaphysis than in the diaphysis of the femur ${ }^{31}$. At the same time the cancellous bone in Gruen zones 1 and 7 is characterised by better vascularisation responsible for higher bone metabolism, and consequently stronger remodelling effects ${ }^{23}$. Muller et $\mathrm{al}^{21}$ discriminated between quantitative bone loss, expressed as relative change of bone mineral content (BMC) compared to the initial value at operation, and qualitative bone changes, to stress the geometrical adaptations in terms of bone volume and shape. The first, also called 'internal remodelling', is responsible for changes in periprosthetic bone density (BMD), and can be compared with what is measured in most other studies. It can be considered as the way in which cancellous bone reacts to loading, explaining the changes in Gruen zones 1 and 7. Qualitative modelling or 'external modelling' represents structural bone changes that mainly take place in cortical bone. They are recognised as adaptations in bone area (like cortical hypertrophy) without a change in BMD, seen in zones 2 to 6. 


\section{Chapter 6}

It can be argued that for correct comparison of periprosthetic bone remodelling, the regions of interest should be exclusively related to anatomic landmarks on the femur, independent of implant or coating dimensions ${ }^{1,4,9}$, leading to fixed sizes of ROls for all compared stems. However, this would prevent assessment of the remodelling effects of bioactive coatings, applied to variable parts of the surface. Whether bone adaptations are due to implant specific characteristics can only be judged if Gruen zone differences, caused by unequal stem or coating lengths, are taken into account but not allowed (on their own) to determine the zones of comparison. 


\section{REFERENCES}

1. McCarthy CK, Steinberg GG, Agren M, Leahey D, Wyman E, Baran DT. Quantifying bone loss from the proximal femur after total hip arthroplasty. J Bone Joint Surg Br 1991; 73: 774-8.

2. Kilgus DJ, Shimaoka EE, Tipton JS, Eberle RW. Dual-energy X-ray absorptiometry measurement of bone mineral density around porous-coated cementless femoral implants. J Bone Joint Surg Br 1993; 75: 279-87.

3. Trevisan C, Bigoni M, Cherubini R, Steiger P, Randelli G, Ortolani S. Dual X-ray absorptiometry for the evaluation of bone density from the proximal femur after total hip arthroplasty: analysis protocols and reproducibility. Calcif Tissue Int 1993; 53: 158-61.

4. Kiratli BJ, Heiner JP, McBeath AA, Wilson MA. Determination of bone mineral density by dual X-ray absorptiometry in patients with uncemented total hip arthroplasty. J Orthop Res 1992; 10: 836-44.

5. Cohen B, Rushton N. Accuracy of DEXA measurement of bone mineral density after total hip arthroplasty. J Bone Joint Surg Br 1995; 77: 479-83.

6. Ang KC, Das De S, Goh JCH, Low SL, Bose K. Periprosthetic bone remodelling after cementless total hip replacement. J Bone Joint Surg Br 1997; 79: 675-9.

7. Ohta H, Kobayashi S, Saito N, Nawata M, Horiuchi H, Takaoka K. Sequential changes in periprosthetic bone mineral density following total hip arthroplasty: a 3-year follow-up. J Bone Miner Metab 2003; 21: 229-33.

8. Herrera A, Panisello JJ, Ibarz E, Cegoñino J, Puértolas JA, Gracia L. Long-term study of bone remodelling after femoral stem: A comparison between dexa and finite element simulation. J Biomech 2007; 40: 3615-25.

9. Theis JC, Beadel G. Changes in proximal femoral bone mineral density around a hydroxyapatite-coated hip joint arthroplasty. J Orthop Surg 2003; 11: 48-52.

10. Gruen TA, McNeice GM, Amstutz HC. "Modes of failure" of cemented stem-type femoral components: a radiographic analysis of loosening. Clin Orthop 1979; 141: 17-27.

11. Zerahn B, Storgaard M, Johansen T, Olsen C, Lausten G, Kanstrup I-L. Changes in bone mineral density adjacent to two biomechanically different types of cementless femoral stems in total hip arthroplasty. Int Orthop 1998; 22: 225-9.

12. Nishii T, Sugano N, Masuhara K, Shibuya T, Ochi T, Tamura S. Longitudinal evaluation of time related bone remodeling after cementless total hip arthroplasty. Clin Orthop 1997; 339: 121-31. 


\section{Chapter 6}

13. Aldinger PR, Sabo D, Pritsch M, et al. Pattern of periprosthetic bone remodelling around stable uncemented tapered hip stems: a prospective 84-month follow-up study and a median 156-month cross-sectional study with DXA. Calcif Tissue Int 2003; 73: 115-21.

14. Sabo D, Reiter A, Simank HG, Thomsen M, Lukoschek M, Ewerbeck V. Periprosthetic mineralization around cementless total hip endoprosthesis: Longitudinal study and crosssectional study on titanium threaded acetabular cup and cementless Spotorno stem with DEXA. Calcif Tissue Int 1998; 62: 177-82.

15. Karachalios T, Tsatsaronis C, Efraimis G, Papadelis P, Lyritis G, Diakoumopoulos G. The long-term clinical relevance of calcar atrophy caused by stress shielding in total hip arthroplasty. J Arthroplasty 2004; 19: 469-75.

16. Bodén $\mathrm{H}$, Adolphson P, Öberg $\mathrm{M}$. Unstable versus stable uncemented femoral stems: a radiological study of periprosthetic bone changes in two types of uncemented stems with different concepts of fixation. Arch Orthop Trauma Surg 2004; 124: 382-92.

17. Okano T, Hagino H, Otsuka T, Teshima R, Yamamoto K, Hirano Y, Nakamura K. Measurement of periprosthetic bone mineral density by dual-energy $\mathrm{X}$-ray absorptiometry is useful for estimating fixation between the bone and the prosthesis in an early stage. J Arthroplasty 2002; 17: 49-55.

18. Tanzer M, Kantor S, Rosenthall L, Bobyn JD. Femoral remodelling after porous-coated total hip arthroplasty with and without hydroxyapatite-tricalcium phosphate coating. J Arthroplasty 2001; 16: 552-8.

19. Rosenthall L, Bobyn JD, Tanzer M. Bone densitometry: influence of prosthetic design and hydroxyapatite coating on regional adaptive bone remodelling. Int Orthop 1999; 23: 325-9.

20. Kröger H, Venesmaa P, Jurvelin J, Miettinen H, Suomalainen O, Alhava E. Bone density at the proximal femur after total hip arthroplasty. Clin Orthop 1998; 352: 66-74.

21. Muller S, Irgens F, Aamodt A. A quantitative and qualitative analysis of bone remodelling around custom uncemented femoral stems: a five-year DEXA follow-up. Clin Biomech 2005; 20: 277-82.

22. Rahmy AIA, Gosens T, Blake GM, Tonino A, Fogelman I. Periprosthetic bone remodelling of two types of uncemented femoral implant with proximal hydroxyapatite coating: a 3-year follow-up study addressing the influence of prosthesis design and preoperative bone density on periprosthetic bone loss. Osteoporos Int 2004; 15: 281-9.

23. Rodan GA. Introduction to bone biology. Bone 1992; 13: 3-6. 
24. Becker P, Zeggel P, Lüthen F, Nebe B, Rychly J, Neumann H-G. Resorbable calcium phosphate composite coatings. Bioceramics 2002; 14: 653-6.

25. Becker P, Neumann HG, Nebe B, Lüthen F, Rychly J. Cellular investigations on electrochemically deposited calcium phosphate composites. J Mater Sci Med 2004; 15: 437-40.

26. Cigada A, Cabrini M, Pedeferri P. Increasing of the corrosion resistance of the Ti6Al4V alloy by high thickness anodic oxidation. J Mat Sci Med 1992; 3: 408-12.

27. Becker P, Baumann A, Lüthen F, Rychly J, Kirbs A, Beck U, Neumann H-G. Spark anodization on titanium and titanium alloys. Proceedings of the 10th World Conference on Titanium, Hamburg, Germany 2003; Vol V: 3339-44.

28. Broeke ten RH, Alves A, Baumann A, Arts JJ, Geesink RG. Bone reaction to a biomimetic third-generation hydroxyapatite coating and new surface treatment for the Symax hip stem. J Bone Joint Surg Br 2011; 93: 760-8.

29. Engh CA, Bobyn JD, Glassman AH. Porous coated hip replacement. The factors governing bone ingrowth, stress shielding, and clinical results. J Bone Joint Surg Br 1987; 69: 45-55.

30. Martin RB. The effects of geometric feedback in the development of osteoporosis. J Biomechanics 1972; 5: 447-55.

31. Miller JD, McCreadie BR, Alford Al, Hankenson KD, Goldstein SA. Form and function of bone. In: Einhorn TA, O'Keefe RJ, Buckwalter JA, eds. Orthopaedic Basic Science, 3rd edition, Chapter 8. Rosemont, Illinois. American Academy of Orthopaedic Surgeons 2007; 129-59. 



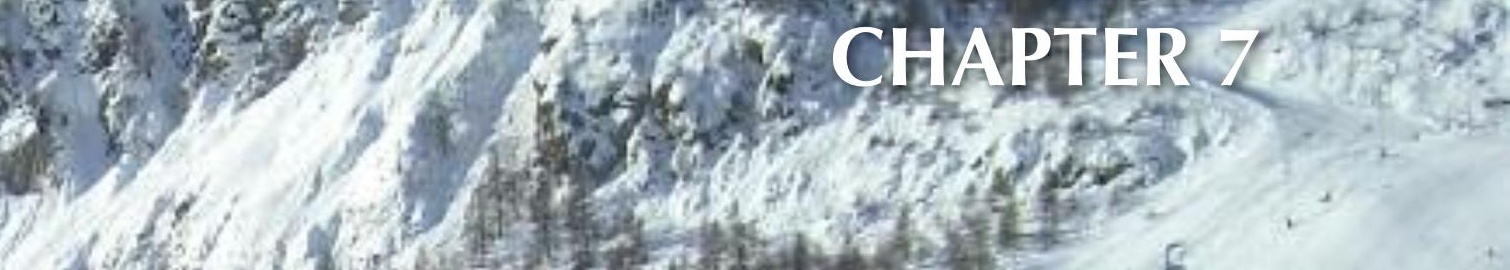

Sil

improving pet iperosthetic

6) 12 to

44. Alone adaptation around L:tige

- cenieniless lip stems;

a cling calcanof innite el ement study

is

Med Eng Phys (2013), http://dx.doi.org/10.1016/j.medengphy.2013.12.006

Epub ahead of print 


\section{AbStract}

This study assessed whether the Symax ${ }^{\mathrm{TM}}$ implant, a modification of the Omnifit stem (in terms of shape, proximal coating and distal surface treatment), would yield improved bone remodelling in a clinical DEXA study, and if these results could be predicted in a finite element (FE) simulation study.

In a randomized clinical trial, 2 year DEXA measurements between the uncemented Symax ${ }^{\mathrm{TM}}$ and Omnifit ${ }^{\circledR}$ stem (both $\mathrm{n}=25$ ) showed bone mineral density (BMD) loss in Gruen zone 7 of $14 \%$ and $20 \%$, respectively $(P<0.05)$. In contrast, the FE models predicted a $28 \%$ (Symax $^{\mathrm{TM}}$ ) and $26 \%$ (Omnifit ${ }^{\circ}$ ) bone loss. When the distal treatment to the Symax ${ }^{\mathrm{TM}}$ was not modelled in the simulation, bone loss of $35 \%$ was predicted, suggesting the benefit of this surface treatment for proximal bone maintenance.

The theoretical concept for enhanced proximal bone loading by the Symax $^{\mathrm{TM}}$, and the predicted remodelling pattern were confirmed by DEXAresults, but there was no quantitative match between clinical and FE findings. This was due to a simulation based on incomplete assumptions concerning the yet unknown biological and mechanical effects of the new coating and surface treatment.

Study listed under ClinicalTrials.gov with number NCT 01695213. 


\section{INTRODUCTION}

Successful biologic fixation of uncemented total hip prostheses is inevitably associated with resorptive bone remodelling, because of load sharing and stress protection of bone by the implant. This has been a concern in the early generations of stems where proximal femoral bone loss up to $62 \%$ was detected, both experimentally as well as clinically ${ }^{1,2}$. This bone resorption may in the long term compromise implant support, cause periprosthetic bone fracture and challenge revision procedures. Therefore in the development of new total hip designs, a need is felt for diagnostic tools that can discriminate between superior and inferior implants. Such tools should be able to predict unacceptable clinical outcome like excessive bone loss, high risk of loosening and revision, in an early postoperative or even preoperative stage.

For this purpose finite element analysis (FEA) has been used to estimate loads and stresses in periprosthetic bone and interfaces ${ }^{3,4}$. Through Numerical Shape Optimization (NSO) the optimal geometry and material of an implant were calculated, based on predefined goals in terms of maximally acceptable strains and stresses in the bone and interfaces ${ }^{5}$.

The major limitation of the FE-technique is that it remains a computer model that makes several assumptions on implant material properties, bone properties ${ }^{6}$, implant-bone interface conditions ${ }^{7}$, and loading-boundary conditions (interface loading forces during daily activities, hip and muscle forces) ${ }^{8}$. It is obvious that because of all these assumptions, the extent to which FE-models can realistically simulate failure mechanisms, is uncertain.

Despite these limitations, it is generally accepted that FEA can adequately predict qualitative bone remodelling around implants as these FE-models are suitable to address the relationship between mechanical stimuli and bone remodelling ${ }^{9}$. Bone remodelling is often expressed as the postoperative change in periprosthetic bone mineral density (BMD) as measured by dual energy $\mathrm{X}$-ray absorptiometry (DEXA). In recent years several studies have been performed to retrospectively correlate 2-D and 3-D FEA predictions with the effects on bone density ${ }^{10-12}$. Attempts were focused on finding a quantitative relationship between absolute values of stress in the bone at implantation, and subsequent remodelling 


\section{Chapter 7}

changes in terms of BMD-values. By analyzing bone remodelling around a known implant one can propose changes to its design in order to improve the load transfer between implant and bone and reduce bone resorption.

As an example the Symax ${ }^{\mathrm{TM}}$ stem has been developed from the Omnifit ${ }^{\circledR}$ design in order to modify the press fit characteristics of the proximal stem geometry. A more bioactive biomimetic BONIT ${ }^{\circledR}-\mathrm{HA}$ coating, applied to the proximal part of the stem, should also result in faster, deeper and more extensive bone-implant contact, as could be confirmed from a recent human retrieval study $^{13}$, and from experimental studies in animals ${ }^{14}$. It has been shown that osteoconductive coatings like hydroxyapatite may be used to promote proximal stress transfer, diminishing effects of stress shielding ${ }^{1,15,16}$. Furthermore the Dotize ${ }^{\circledR}$ treatment on the distal part of the stem was used to prevent bone apposition in that area, and enhance loading of the proximal femur ${ }^{13}$.

In this study periprosthetic bone stock preservation around the two stem designs was compared in a prospective randomized clinical trial (RCT). Secondly it was assessed whether the results of the clinical trial could have been predicted by the FE simulations.

\section{Material AND Methods}

\section{Implants}

The Omnifit ${ }^{\circledR}$ HA stem (Stryker ${ }^{\circledR}$, Mahwah, New Jersey, USA) is forged from Ti6Al4V alloy, has a macrotextured surface and a plasmaspray HA-coating on the proximal $40 \%$ of the stem (Fig. 1). The HA coating has a thickness of $50 \mu \mathrm{m}(45-$ 65 ) with a porosity of $<3 \%$. The HA after spraying has a relatively high crystalline phase of $65 \%$. The implant is a successful and well documented uncemented HAcoated stem ${ }^{17-19}$.

The uncemented Symax ${ }^{\mathrm{TM}}$ hip stem (Stryker ${ }^{\circledR}$ EMEA, Montreux, Switzerland) was based on shape optimization of the Omnifit ${ }^{\circledR}$ stem. Preclinical design studies consisted of CT-investigations combined with finite element analyses to optimize fit and fill with even stress distribution without peak stresses in the bone and at the interface. It is also made of Ti6Al4V, features a proximal plasma-sprayed CP 


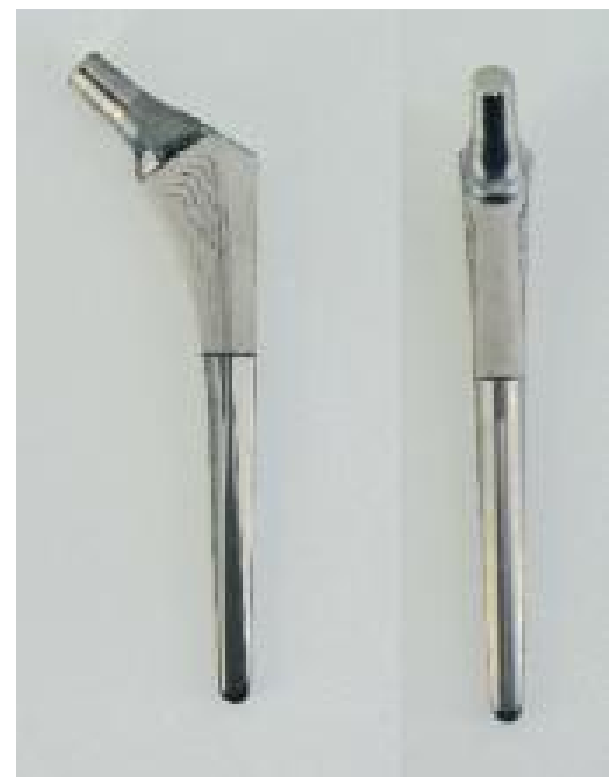

Fig. 1 The HA Omnifit ${ }^{\circledast}$ hip stem, geometrically a straight double wedge design, is made of Ti-alloy, has a macro-textured surface of which the proximal $40 \%$ is plasma sprayed HA-coated, and has a distal matte finish, all aimed at proximal fixation. The HA-coating is highly crystalline $(65 \%)$ explaining slow resobability.

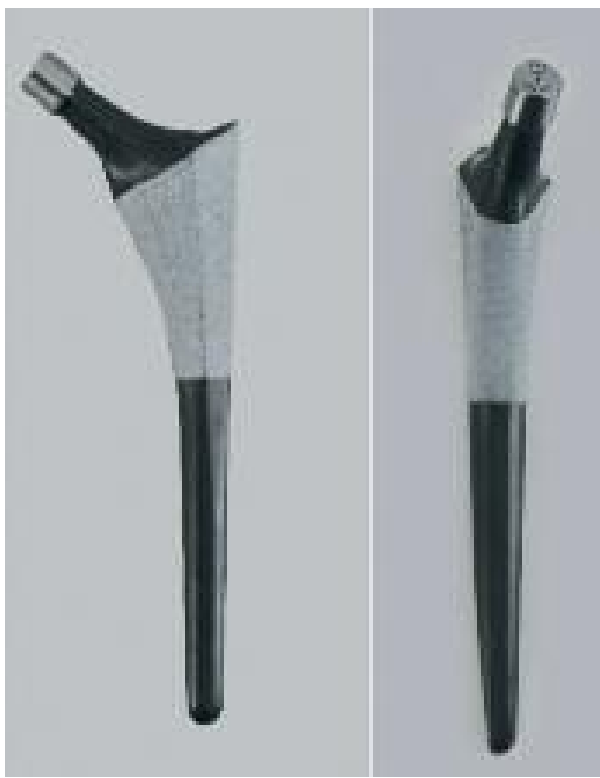

Fig. 2 Illustrations of the SymaxTM stem in AP (left) and lateral (right) vue, showing a straight stem with the neck in an anteverted position. It features a proximal plasma-sprayed CP Titanium layer, with a biomimetic electrochemically deposited BONIT ${ }^{\circledR}$ HA coating of very high porosity of $60 \%$, and only 10-20 um thick. Distally the stem is treated with the Dotize ${ }^{\circledast}$ surface process, which reduces distal bone apposition and osseointegration.

Titanium coating with an open porosity of 20-40 \% to enhance initial stem fixation, and a biomimetic electrochemically deposited $\mathrm{BONIT}^{\circledR}-\mathrm{HA}$ coating with a high porosity of $60 \%$, and 10-20 $\mu \mathrm{m}$ thick (proprietary to DOT GmbH, Rostock, Germany) (Fig. 2) ${ }^{20}$. The adhesion strength of both HA-coatings is comparable and about $65 \mathrm{MPa}$. 


\section{Chapter 7}

Distally the stem is treated with the Dotize ${ }^{\circledR}$ surface process, an electrolytic conversion of titanium surfaces in which the thin native oxide film is replaced by a thicker oxidized surface layer that reduces protein adsorption and consequently distal bone apposition and osseointegration ${ }^{20}$.

\section{Clinical Trial Study}

\section{Design and patient selection}

A prospective, individually randomized, two group, parallel comparative trial was performed between the uncemented Symax ${ }^{\mathrm{TM}}(n=25)$ and the Omnifit ${ }^{\circledR}-\mathrm{HA}$ stems $(n=25)$. The indication for total hip arthroplasty (THA) was in all cases osteoarthritis $(\mathrm{OA})$ of the hip. Exclusion criteria were a history of hormonal therapy, any medication or illness known to affect bone metabolism, and a Quetelet index (BMI) higher than 35. After signing the appropriate informed consent forms, patients were allocated at random to one of either group in a 1:1 randomization ratio. The allocation sequence was generated by an independent trial bureau and concealed from the operating surgeon. Participants were enrolled from sequentially numbered, identical, opaque, sealed envelopes just before the operation, the surgeon being unaware of the content and sequence of the envelopes (allocation concealment). Both groups were comparable in terms of patient demographics (see Table 1). The study was approved by the local Institutional Review Board prior to the start of the study (registration no.:

Table 1 Patient characteristics and baseline demographic data

\begin{tabular}{lcc} 
& Omnifit & Symax $^{\circledR}$ \\
\hline Mean age at operation in years (range) & $60.4(39-71)$ & $60.2(46-72)$ \\
Weight in kg (range) & $78.5(60-96)$ & $82.2(54-105)$ \\
Body Mass Index (range) & $27.2(22-32)$ & $27.8(22-37)$ \\
Male/Female & $15 / 9$ & $12 / 13$ \\
Normal start BMD & 16 & 17 \\
Osteopenic/osteoporotic start BMD & $7 / 1$ & $7 / 1$
\end{tabular}


02-072), is listed in the Clinical Trials Registry (ClinicalTrials.gov identifier: NCT 01695213), and was carried out in line with the Seoul amendment (2008) of the Helsinki declaration.

\section{Surgical protocol and postoperative management}

All operations were performed randomly by the same 2 staff surgeons (R.t.B. or R.G.) according to completely identical and standardized orthopaedic procedures using the postero-lateral approach. Patients were treated with 24 hours intravenous antibiotic prophylaxis (Augmentin ${ }^{\circledR}$ ), DVT prophylaxis with a small molecular heparin (Fraxiparin ${ }^{\circledR}$ ) during 6 weeks and standard prophylaxis against heterotopic ossifications with an NSAID (Indocid ${ }^{\circledR}$ ) for 14 days. Patients were allowed to full weightbearing from day 1 .

\section{DEXA protocol}

In the first postoperative week the baseline BMD measurement was performed with the Hologic QDR 4500A densitometer (Hologic Inc., Waltham, MA, USA) according to the protocol, including exact positioning of the leg with stabilizing rotation using standard knee and foot support devices. Quality control of the densitometer was executed through daily automatic self-calibration, not showing any significant drift during the study period. Considering a difference in length of HA-coating between the stem-designs, the periprosthetic regions of interest (ROI) were placed around the stem according to adapted Gruen zones in such a way that ROI 1 and 7 covered comparable bone areas, and ROls 2 - 6 were equally divided around the rest of the stem (Fig. 3). DEXA scans were taken from the AP lumbar spine in the first postoperative week, serving

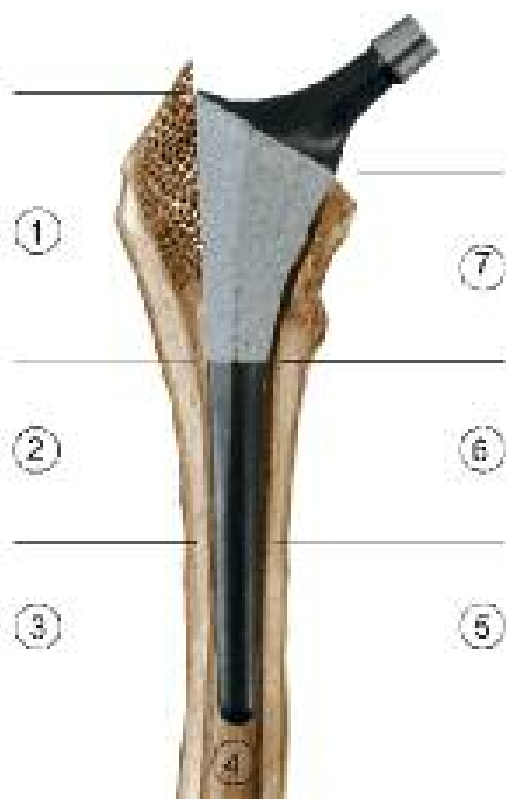

Fig. 3 Drawing showing delineation of Gruen zones 1 - 7 in the AP view around the Symax ${ }^{\mathrm{TM}}$ stem. 


\section{Chapter 7}

as a baseline measurement for comparison to referenced normals. This was repeated at 24 months follow-up to monitor any systemic changes in bone, not related to the effect of the THA. All DEXA-scans were done by the same independent analyst.

Follow up evaluations were performed at 6 weeks, 3 months, 6 months, 1 year and 2 years, and analysis of all raw scans was independently done by one member of the research staff (R.H.) without involvement of the operating surgeon.

\section{Statistics of the clinical trial}

Longitudinal BMD results (in $\mathrm{g} / \mathrm{cm}^{2}$ ) per Gruen zone are expressed as relative values with the immediate postoperative DEXA measurement of the operated femur being the reference value, set at $100 \%$. Absolute and relative BMD values are described by mean and standard deviation, demographic parameters by mean and range. Since no deviations from normal distribution could be observed, comparing the Symax ${ }^{\mathrm{TM}}$ and Omnifit ${ }^{\circledR}$ group in any of the ROls, the one-sample $t$ test in cases of paired data (comparisons within a group) and the two-sample $t$-test in cases of unpaired data (comparisons between groups) was used.

The statistically required sample size is based on a power-analysis performed on the ability to detect a minimal mean difference of BMD-results between stem designs (ठ). Based on earlier studies we assumed this difference to be $25 \%$. By convention, an $\alpha$-error rate of 0.05 was adopted, and the $\beta$-error was set at 0.20 (power $1-\beta=80$ $\%$. We were planning a study of a continuous response variable from independent control and experimental subjects with 1 control(s) per experimental subject. In a previous study the response within each subject group was normally distributed with standard deviation $25 \%$. If the true difference in the experimental and control means was $20 \%$, we would need to study 25 subjects in the Symax ${ }^{\mathrm{TM}}$ arm and 25 subjects in the Omnifit ${ }^{\circledR}$ arm to be able to reject the null hypothesis that the population means of these groups were equal with probability (power) 0.8 . The type I error probability associated with the test of this null hypothesis was 0.05 .

Microsoft Office Excel 2003 (Microsoft Corporation, Redmond, Washington, USA) and SPSS software 15.0 for Windows (SPSS Inc., Chicago, Illinois, USA) was used for data analysis. 


\section{Finite element bone remodelling study}

Finite element model

We used a validated FEM-model of CT data of a human femur ${ }^{21}$. The bone was CT scanned along with a calibration phantom (solid, 0, 50, 100, $200 \mathrm{mg} / \mathrm{ml}$ calcium hydroxyapatite, Image Analysis, Columbia, KY, USA). The data was processed using a medical imaging software package (MIMICS 11.0). Subsequently, we created two uncemented THA reconstructions implanted with the Omnifit ${ }^{\circledR}$ and the Symax ${ }^{T M}$ stem.
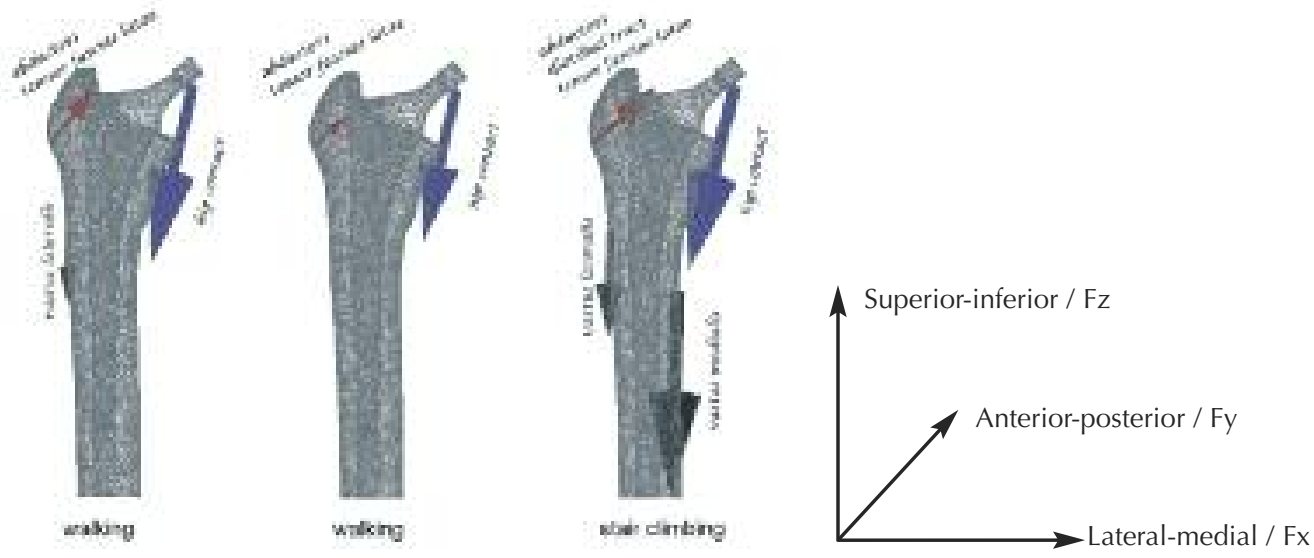

Fig. 4 The reconstruction was subjected to the loading condition of normal walking (toe off and heel strike) and the peak force during stair climbing.

Table 2 Details of joint contact and muscle force vector directions and magnitudes

\begin{tabular}{lccccccccc} 
Loadcase & \multicolumn{3}{c}{ Walking (toe off) } & \multicolumn{3}{c}{ Walking (heel strike) } & \multicolumn{3}{c}{ Stair climbing } \\
\hline Direction & $\mathrm{Fx}$ & $\mathrm{Fy}$ & $\mathrm{Fz}$ & $\mathrm{Fx}$ & $\mathrm{Fy}$ & $\mathrm{Fz}$ & $\mathrm{Fx}$ & $\mathrm{Fy}$ & $\mathrm{Fz}$ \\
Hip Contact & $-432 \mathrm{~N}$ & $-263 \mathrm{~N}$ & $-1833 \mathrm{~N}$ & $-342 \mathrm{~N}$ & $29 \mathrm{~N}$ & $-1575 \mathrm{~N}$ & $-475 \mathrm{~N}$ & $-485 \mathrm{~N}$ & $-1890 \mathrm{~N}$ \\
Abductors & $518 \mathrm{~N}$ & $122 \mathrm{~N}$ & $646 \mathrm{~N}$ & $375 \mathrm{~N}$ & $6 \mathrm{~N}$ & $369 \mathrm{~N}$ & $664 \mathrm{~N}$ & $237 \mathrm{~N}$ & $618 \mathrm{~N}$ \\
Vastus lateralis & $-7 \mathrm{~N}$ & $148 \mathrm{~N}$ & $-743 \mathrm{~N}$ & 0 & 0 & 0 & $-18 \mathrm{~N}$ & $179 \mathrm{~N}$ & $-1081 \mathrm{~N}$ \\
Vastus medialis & 0 & 0 & 0 & 0 & 0 & 0 & $-70 \mathrm{~N}$ & $317 \mathrm{~N}$ & $-2137 \mathrm{~N}$ \\
\hline
\end{tabular}




\section{Chapter 7}

The stems were positioned in the virtual bone by an experienced surgeon (R.t.B.), using in-house software (DCMTK MFC 10.8), which allows manipulation of a solid (stem) model within the visualized CT-data of the femur ${ }^{21}$. The models of the reconstructions were solid meshed using an FEA preprocessor (Mentat 2007r1, MSC Software), and they consisted of $\sim 97.000$ and $\sim 18.000$ linear four-noded tetrahedral elements for the bones and stems, respectively $y^{22}$. The isotropic properties of cortical and trabecular bone were derived from the calibrated CT data. The calibration phantom was used to convert Hounsfield Units ( $\mathrm{HU}$ ) to calcium equivalent densities $\left(\rho_{\mathrm{CHA}}\right)$. An in-house software package was used to assign a calcium equivalent density $\left(\rho_{\mathrm{CHA}}\right)$ to each element, based on the average $\rho_{\mathrm{CHA}}$ value of all pixels in the element volume. The ash density was computed using relationships specific to the type of phantom used ( $\rho_{\text {ash }}=$ $\left.0.0633+0.887 \rho_{\mathrm{CHA}}\right)$. The elastic modulus $(E, \mathrm{MPa})$ was computed for each element from ash density $\left(\rho_{\text {ash }}\right)$ using correlations for trabecular and cortical bone ${ }^{23}$. The elastic modulus of the stems was set to $105 \mathrm{GPa}$. The Poisson's ratio for the bone and implant was set to $0.3^{24}$. The reconstructions were fixed distally and subjected to an alternating loading history of normal walking and stair climbing (Fig. 4 and Table 2$)^{25}$.

\section{Bone remodelling and DEXA simulation}

We used the strain adaptive remodelling theory to simulate changes in bone mineral density in time $(d \rho / d t)^{26}$. The size of 'dead zone' and computer time unit were determined in our previous remodelling study in which we utilized the same bone model $^{21}$. In that study the FE remodelling prediction around the EPOCH FullCoat stem was fitted to 2 year clinical DEXA data in order to define the adequate 'dead zone $^{\prime}$ and to determine the time unit in the simulation ${ }^{27}$. The best fit was obtained for dead zone value 0.35 and time unit 60 (meaning that 60 computer time units correspond to 2 year clinical reality). A further description of the remodelling theory used is given in our previous remodelling study ${ }^{21}$. These previously determined values of 'dead zone' and time unit were used here when performing the remodelling prediction in the reconstructions with the Omnifit ${ }^{\circledR}$ and Symax ${ }^{\mathrm{TM}}$ stems. To allow for clinically relevant interpretation of the remodelling results, we used an in-house software package (DCMTK MFC 10.8) to project the FE results of bone remodelling onto 2D virtual DEXA images. This in-house algorithm maps a 3D voxel mesh onto the FE reconstruction. Each pixel in 2D DEXA image has a calcium 
equivalent value corresponding to the summation of the calcium equivalent values of $3 \mathrm{D}$ voxels along the chosen DEXA scan axis. Detailed description of the in-house algorithm used here is also given in our previous study ${ }^{21}$.

We defined the seven Gruen zones according with the guidelines ${ }^{28}$, adapted for uncemented stems with proximal coating, and computed bone density (BMD) $\left(\mathrm{g} / \mathrm{cm}^{2}\right)$ and local bone mineral content (BMC) (g) at one and two years postoperatively for each implant composition. The bone loss predicted by our simulations was defined as a percentage of the pre-operative bone mass.

\section{Cases analyzed}

The design changes of Symax ${ }^{\mathrm{TM}}$ relative to the Omnifit ${ }^{\circledR}$ stem concerned three aspects: the shape, proximal coating and treatment of distal stem with Dotize ${ }^{\circledR}$ surface process. The geometry and distal surface treatment were modelled in our FE study, but the differences between proximal coatings of both stems were not simulated as both stems were assumed to be bonded at the coated locations. The difference in design (geometry, offset and stem length) was modelled based on CAD-files provided by the manufacturers.

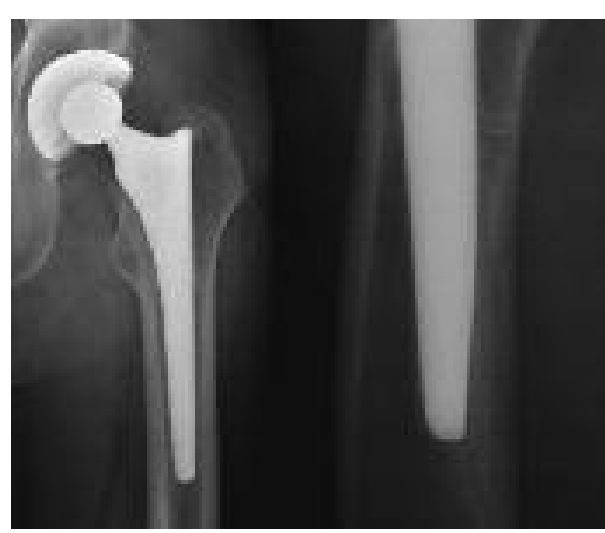

Fig. $5 \quad$ X-rays showing reactive lines in Gruen zone 2 up to and including zone 6 (AP view, left), and zone 9 up to and including zone 13 (lateral view, right) around a Symax ${ }^{\mathrm{TM}}$ stem. This is a sign of absence of bone attachment in the distal anodized part of the stem. surface of the stem (Fig. 5). However, the actual effect of the distal surface treatment of the Symax ${ }^{\mathrm{TM}}$ stem would be difficult to predict pre-clinically. Therefore, we simulated two extreme cases for the Symax ${ }^{\mathrm{TM}}$ stem (with a gap of $0.5 \mathrm{~mm}$ around the distal part of the stem, and without a gap assuming a frictional contact $(\mu=0.3)$ between implant and bone distally). While, in the reconstruction with Omnifit ${ }^{\circledR}$ stem 


\section{Chapter 7}

the distal implant-bone interface was modelled by assuming a frictional contact $(\mu=0.3)$ between implant and bone ${ }^{29}$. Hence, we simulated one case for the Omnifit ${ }^{\circledR}$ stem and two cases for the Symax ${ }^{\mathrm{TM}}$ stem (either with or without a distal gap).

\section{RESULTS}

\section{Clinical DEXA results}

There was no statistical difference in the demographic details and initial bone quality between patients in either group, confirming that preoperative conditions between the two groups were comparable (Table 1). There was one patient (Omnifit ${ }^{\circledR}$ ) withdrawn from the study because of protocol violation, no further patients were lost to follow-up (see flow chart Fig. 6). There was no difference in physical activity among patients postoperatively, as assessed with the Harris Hip Score.

All patients had all their scans performed during the entire follow-up and within the predefined timeframe. At one year follow-up all stems showed radiological evidence of stable bone ingrowth according to the classification of Engh et al. ${ }^{30}$. At one and two years the lumbar spine BMD did not show significant difference between the implant groups, nor between $\mathrm{t}_{0}$ and $\mathrm{t}_{2}$ years values. This illustrates that differences in bone remodelling could not be explained by metabolic bone disease in one or either group, nor by activity or age-related differences in bone density between the groups.

Evolution of BMD in both implant groups is represented graphically in Fig. 7. A decrease in BMD was detected with both stems in all Gruen zones except zone 4, at 3 months after surgery, varying between $-1.9 \%$ and $-9.5 \%$ for the Symax ${ }^{\mathrm{TM}}$ prosthesis and between $-1.0 \%$ and $-13.0 \%$ for the Omnifit ${ }^{\circledR}$ prosthesis. Starting between 3 and 6 months postoperatively, complete recovery of bone loss was initiated in zones 2, 3, 5 and 6. In zone 1 and particularly zone 7 however there was additional bone loss, increasing to $-20.3 \%$ for the Omnifit ${ }^{\circledR}$, and $-14 \%$ for the Symax ${ }^{\mathrm{TM}}$. Only in zone 7 the difference in bone loss between the two stem designs was statistically significant during the entire follow-up, starting from 6 weeks and in favour of the modified stem, with $P$-values of 0.05 (at 1 year) and 0.01 (at 2 years). In all other zones $(1-6)$ there was no statistically significant difference in remodelling, although BMD values were consequently higher in the modified stem group. 


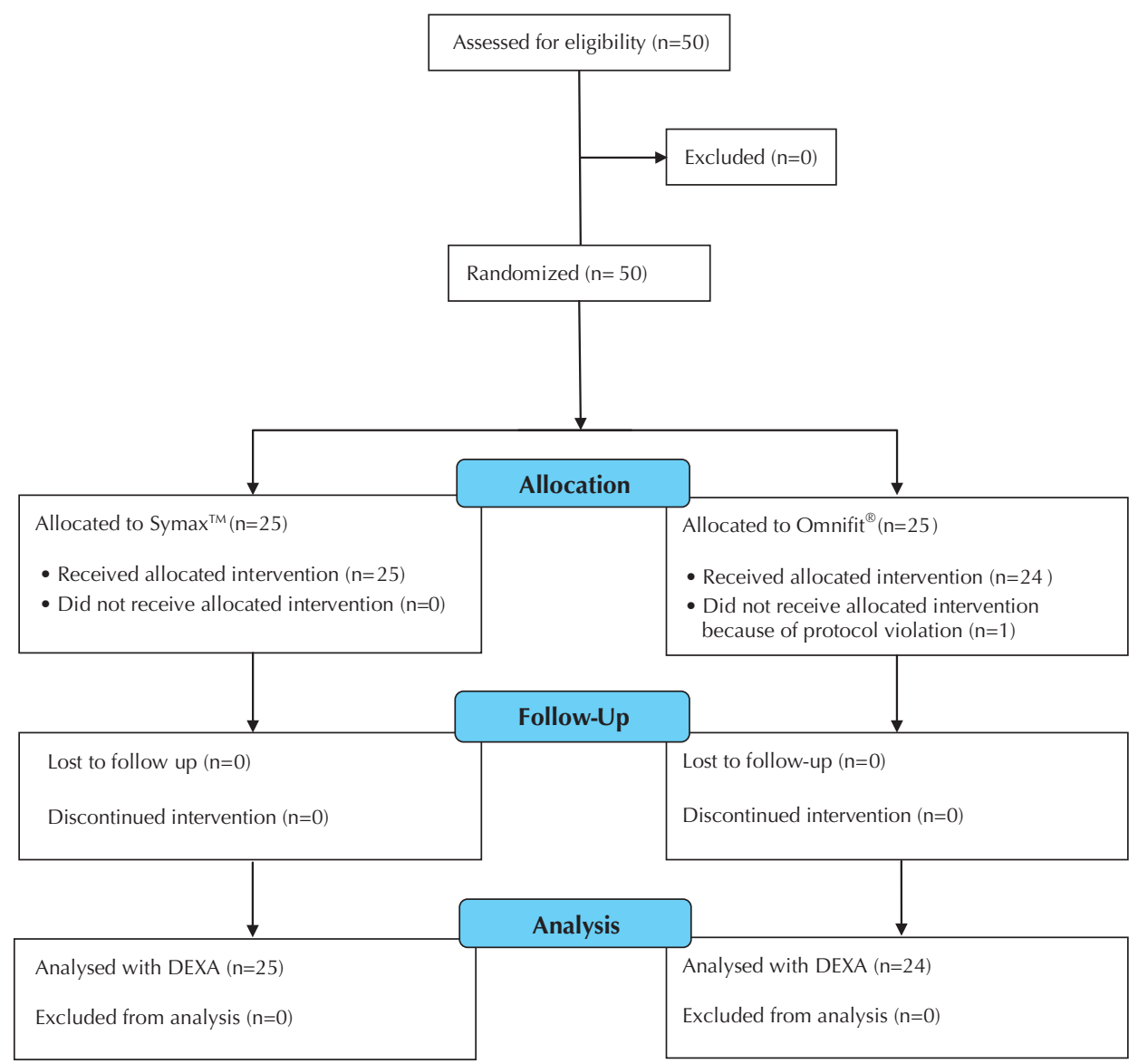

Fig. 6 Patient enrolment flow diagram

\section{Remodelling prediction versus clinical findings}

There were considerable differences in predicted bone loss between the simulated Symax ${ }^{\mathrm{TM}}$ reconstructions with and without direct distal contact between stem and bone (Fig. 8). In the reconstruction without a distal gap (= simulating frictional stem-bone contact), bone resorption was considerably greater especially in Gruen zone 6 and 7. Bone loss at 2 years postoperatively was 35\% in the Gruen zone 7 for the Symax ${ }^{\mathrm{TM}}$ reconstruction without a gap and $28 \%$ in the reconstruction with 


\section{Chapter 7}
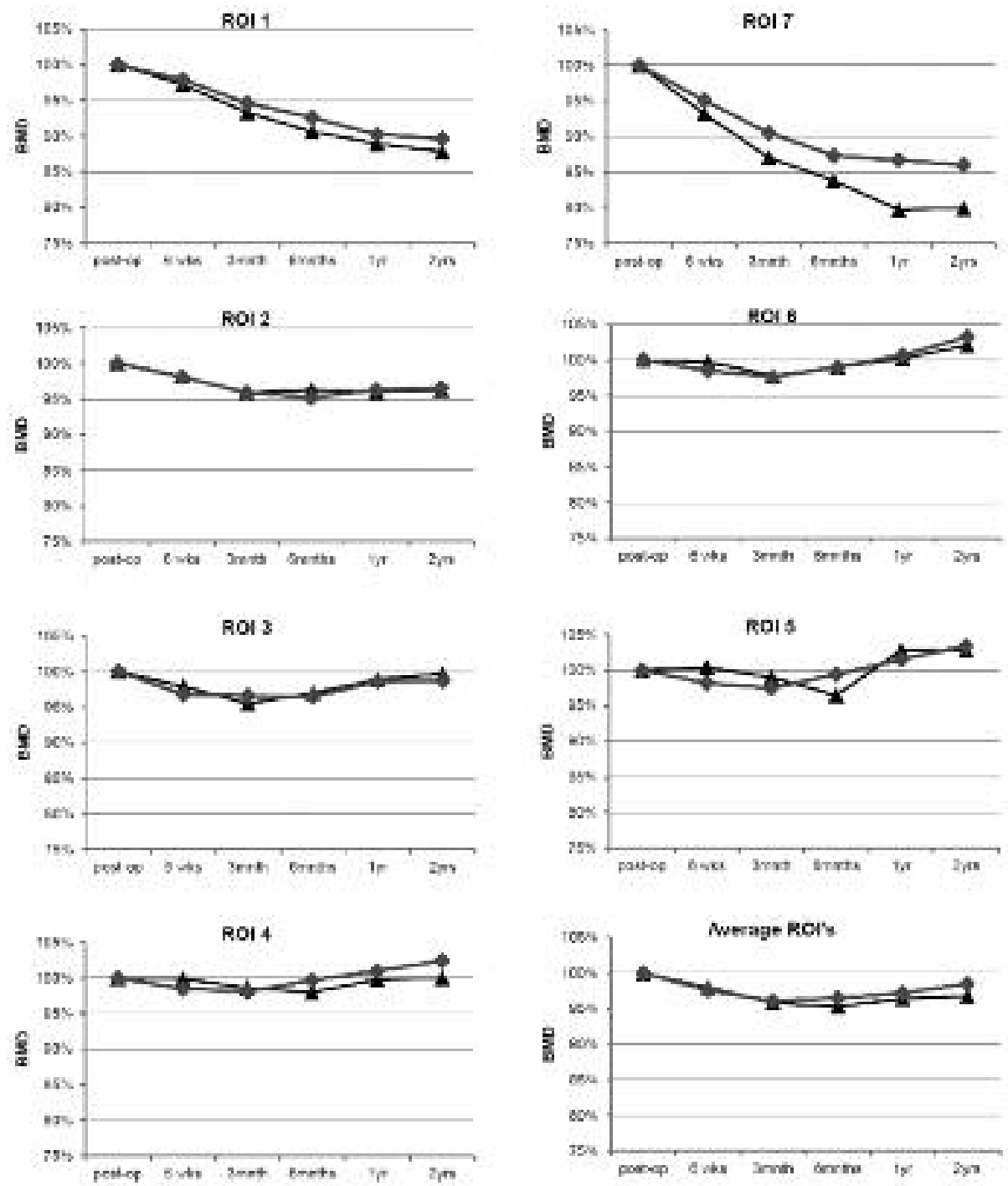

Fig. 7 Graphs showing BMD course of the ROIs 1 to 7 and net average in a longitudinal study for 2 years, comparing the Symax ${ }^{\mathrm{TM}}(\bullet)$ and the Omnifit ${ }^{\oplus}(\mathbf{\Delta})$ stem, with the immediate postoperative BMD set at $100 \%$ (= baseline reference). Only for the differences in ROI 7 statistical significance $(P<0.05)$ was seen at all postoperative time points. 

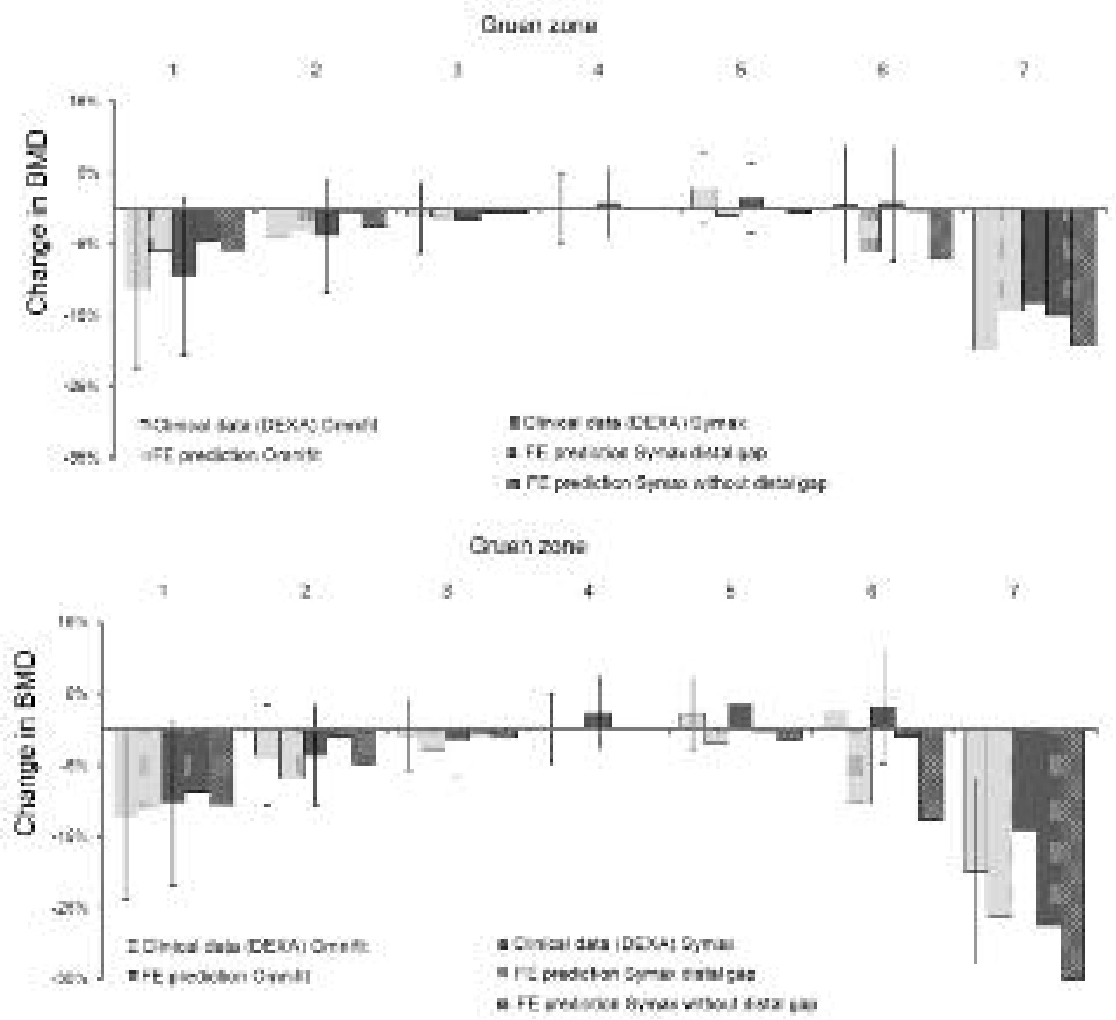

Fig. 8 Clinical DEXA data per Gruen zone (with standard deviation) around the Omnift ${ }^{\oplus}$ and Symax ${ }^{\mathrm{TM}}$ stem at 1 year (top) and 2 years (bottom) postoperatively, combined with the FEM predictions on remodelling. For the Symax ${ }^{\mathrm{TM}}$ predictions are given with a gap around the distal stem (no friction at the interface) and without a simulated gap around the distal stem (in other words with friction at the interface).

a distal gap. FE remodelling prediction for the Symax ${ }^{\mathrm{TM}}$ reconstruction with a gap was better correlated with clinical findings than the prediction for the Symax ${ }^{\mathrm{TM}}$ reconstruction without a distal gap. Thus, the Symax ${ }^{\mathrm{TM}}$ reconstruction with a distal gap was more suitable for FE remodelling prediction, especially as the clinical and retrieval findings confirmed no direct contact between implant and bone distally for the Symax ${ }^{\mathrm{TM}}$ reconstructions. 


\section{Chapter 7}

There were differences in FE-predicted bone loss between the Omnifit ${ }^{\circledR}$ stem and the Symax ${ }^{\mathrm{TM}}$ stem. In Gruen zone 7 slightly greater bone loss at 2 years was predicted for the reconstruction with the Symax ${ }^{\mathrm{TM}}$ stem with a distal gap $(-28 \%$ for Symax ${ }^{\mathrm{TM}}$ versus $-26 \%$ for the Omnifit ${ }^{\circledR}$ stem, see Fig. 8). However, in zones $1-6$ the Symax ${ }^{\mathrm{TM}}$ stem was expected to cause less bone resorption than the Omnifit ${ }^{\circledR}$ stem.

This FE-predicted pattern of bone remodelling matched the clinical findings only partially. The correlation between clinical data and FE-predictions was rather poor for the Symax ${ }^{\mathrm{TM}}$ in zone 7, and for the Omnifit ${ }^{\circledR}$ in zone 6 (both at 2 years). In Gruen zone 7 DEXA-measured bone loss at 2 years was significantly smaller for the Symax ${ }^{\mathrm{TM}}\left(-14 \%\right.$ versus $-20.3 \%$ for the Omnifit $\left.{ }^{\circledR}, P=0.01\right)$, while FE simulations had predicted a slightly larger bone loss $\left(-28 \%\right.$ for the Symax ${ }^{\mathrm{TM}}$ versus $-26 \%$ for the Omnifit ${ }^{\circledR}$ ).

\section{Discussion}

In the clinical part of this study it was tested if the design changes implemented in the modified (Symax ${ }^{\mathrm{TM}}$ ) stem would result in less bone resorption (DEXA) in the proximal Gruen zones when compared to the Omnifit ${ }^{\circledR}$. Secondly, we investigated if a FE model would yield similar results as seen clinically for both stems.

Considering the DEXA-findings of successive generations of uncemented stems with bone loss varying between $15 \%$ and $70 \%$, we found the results of the modified stem promising, with regard to preservation of bone quantity. There was only a modest maximal bone loss (calcar area 14\%, greater trochanter $10.4 \%$ ), which is a normal representation of proximal osseointegration, but it illustrated improved metaphyseal bone loading compared to several other designs. More distally there was hardly any BMD loss at all indicating excellent preservation of bone in the regions where no osseointegration was intended. It could therefore be confirmed that the geometry of the modified stem, based on the proximal "fit and fill" principle, in combination with the proximal BONIT ${ }^{\circledR}-\mathrm{HA}$ coating and the distal Dotize ${ }^{\circledR}$ surface treatment, were able to improve stress transfer from the implant to bone in the important zone 7. DEXA results for the Omnifit ${ }^{\circledR}$ in our clinical trial were similar with earlier assessment performed by Sluimer et al. (16\% 
and $20 \%$ at 2 years for zone 1 and 7 respectively, versus $13 \%$ and $20 \%$ in the present study) ${ }^{31}$. This confirmed reliability and validity of our clinical DEXA data.

In contrast to the clinical findings, the FE simulation calculated greater bone loss in Gruen zone 7 for the Symax ${ }^{\mathrm{TM}}$ stem. Furthermore, in the other Gruen zones FE simulation showed greater bone loss for the Omnifit ${ }^{\circledR}$ when compared to the Symax ${ }^{T M}$ (reconstruction with a distal gap), while clinically no considerable differences were found. Even though the FE remodelling prediction did not yield the same results in individual Gruen zones as the clinical DEXA study, the effect of design changes in the Symax ${ }^{T M}$ stem could be seen in the reduction of bone loss around this stem in the reconstruction with a distal gap.

Given that the same bone model was used for two stems designs, our FE simulations allowed us to make comparisons considering the effect of shape and interface conditions on remodelling. In the present study we showed that the simulation was capable of capturing gross differences in bone remodelling between two THA reconstructions, but was likely not suitable for prediction of minor changes in load transfer patterns. There are several explanations for the discrepancy between these clinical findings and our FE calculations. Firstly, there are differences in bone quality and loading condition between the group of patients and the model. Secondly, we simulated remodelling around only one bone model implanted with one implant size, while the clinical results were averaged over data of 25 patients with variable bone quality and implant size. Thirdly, the loading condition in our simulation was not changed between the pre and postoperative situation. In reality after the post-surgery rehabilitation period patients become more active, which may reduce the resorption rates around both stems.

There are more variables that influence DEXA changes than exclusively those incorporated in the strain adaptive bone remodelling concept. As stimulus to drive the bone remodelling we used the strain energy density, although some authors have suggested to include other stimuli as well such as micro-damage at areas where bone may be overloaded ${ }^{32}$. Inclusion of other stimuli will obviously alter the outcome, although with the types of stems analyzed in this study the amount of micro-damage due to overload would probably have been modest. Furthermore, an immediate stimulus affecting bone remodelling can be expected from the surgical trauma of the reaming and implantation. This causes a catabolic reaction as a result 


\section{Chapter 7}

of the inflammatory changes and degradation of bone ${ }^{33}$. This has to be repaired and neutralized before the (bio)mechanically induced bone apposition and resorption can exclusively be held responsible for further DEXA changes ${ }^{34}$. Therefore during the first three to six months there are more disturbing factors than exclusively biomechanical ones that determine DEXA results. This may explain why the match between FE predictions and DEXA results is not high during the first postoperative year. However, at two years the remodelling balance between apposition and resorption is restored and considered to be mainly mechanically determined. At that moment correlation between predicted and real bone density should be higher.

Another limitation of the FE remodelling simulation is the fact that it neglects the dynamic process of osseointegration. Huiskes recognized that the degree of stress shielding is indeed affected by the bonding conditions of the implant-bone interface $^{35}$. Therefore knowledge about the extent of osseointegration of a new uncemented implant, from retrieval analysis and histomorphometry, is paramount for generating realistic FE-remodelling predictions. As bone remodelling is a longer-term process (in the order of a few years), it is common in FE simulations to assume that coated areas can be considered as bonded ${ }^{11,36,37}$. Hence, in this study we also assumed that the surface area with the proximal coating was fully bonded in both stem cases. However, from retrieval studies this ideal situation has been shown not to be realistic. Porous coated prostheses usually show a bone-implant contact (BIC) of less than $20 \%{ }^{38,39}$. BIC of HA-coated stems varies between $20 \%$ and $78 \%$ depending on the design ${ }^{18,38,39}$. Furthermore osseointegration is not a static but dynamic process in time and will depend on implant geometry, stem stiffness, surface treatment, type of coating and their degradation characteristics. The retrieval study of the Symax ${ }^{\mathrm{TM}}$ hip stem illustrated a progressive direct boneimplant contact in time increasing from $26.5 \%$ (at 3 weeks) to $83.5 \%$ (at 13 months $)^{13}$, which was different from that of the Omnifit ${ }^{\circledR 18}$. Due to the plasmaspray technique the relatively thick (>50 $\mu \mathrm{m}$ ) HA-coating occluded the low porosity surface of the Omnifit ${ }^{\circledR}$, resulting in only superficial ongrowth of bone. However in case of the Symax ${ }^{\mathrm{TM}}$ the electrochemical deposition of the highly bioactive BonitHA created a thin $(10-20 \mu \mathrm{m})$ coating of the entire pore depth of the highly $(60 \%)$ porous TPS layer, leading to accelerated and deep bony ingrowth. This progressive bonding and osseointegration will have an effect on the amount of migration and 
load transfer from implant to bone, and on the resultant remodelling process, but this is typically not incorporated in finite element models. Furthermore it was found that normal contact stiffness and the friction coefficient increase several times as bone grows into the rough surface of the implant and mineralises, thus providing a changing interface with improving secondary stability ${ }^{40}$. At this point, the effect of a gradually fixating bone-implant interface is difficult to estimate. On the one hand a debonded interface transfers higher local loads and therefore triggers more local bone apposition; on the other hand a proximally fixed interface promotes more proximal load-transfer on a more global scale. In any case, the assumption of a bonded interface at coated areas is over-simplified and probably should incorporate a time-dependent change of stem-bone bonding ${ }^{41}$. Dickinson et al. have proposed a FE based algorithm which combined implant-bone interface healing with bone remodelling and confirmed that a more clinically realistic bone remodelling is obtained when these two processes are simulated in concert ${ }^{42}$.

Compared to the Omnifit ${ }^{\circledR}$, the Symax ${ }^{T M}$ is distinctly different in two ways; the geometry and the surface and coating characteristics. Literature has shown that the effects of geometry and material changes can be simulated reliably with the FEtechnique. Amongst the many features held responsible for stress shielding, the mismatch in elasticity modulus between hip stems and bone is considered most important in causing stress mediated disuse atrophy of bone. Therefore focus has been on creating more flexible stems ${ }^{43}$. The metaphyseal fit-and-fill design of the Symax ${ }^{\mathrm{TM}}$, showing larger cross-sectional dimensions, and therefore being stiffer, was expected to cause more stress-shielding ${ }^{26,44}$. However this stem proves to preserve periprosthetic bone at least as good as flexible stems ${ }^{45,46}$, and better than almost all proximally and entirely porous or HA coated stems ${ }^{2,31,47}$. This illustrates that interactions between various determinants of stress shielding and resulting bone remodelling are still not completely understood and hard to capture in an exclusively mechanical model. The same applies for the effect of the distal Dotize ${ }^{\circledR}$ treatment. The effects of new coatings on interface properties appear to be even more difficult to predict. To improve predictions, simultaneous ingrowth simulation and remodelling simulation should be performed. This would require quantification of the mechano-biological aspects of coatings after which this can be implemented in FE simulations. Subsequently, these studies need to be validated with results of 


\section{Chapter 7}

retrievals and measurements of qualitative and quantitative bone changes. Various scenarios can then be simulated, and it can be tested how sensitive the FE-models are for changes in bonding conditions and for the dynamics of the osseointegrationprocess in time.

Several attempts have been conducted to simulate and predict adaptive periprosthetic bone remodelling in computer models that combine bone remodelling theories with finite element analysis. Validation of these FE-simulations were mostly based on animal experiments ${ }^{48,49}$, post mortem retrieval studies ${ }^{10}$, and retrospective clinical densitometry studies with DEXA ${ }^{12,50}$ or 3D-volumetric CT-analysis ${ }^{51}$. Although correlation between predicted density changes and clinical data was mostly low, it was nevertheless concluded that bone remodelling after THA could be explained by a mechanical model ${ }^{10,37}$. Other studies have found higher clinicalmodelling correlations, but these were obtained only after retrospective fitting of the model on DEXA results available from earlier studies ${ }^{11,12,47}$.

This implies that preclinical FE-predictions in new designs triggering unquantified biological processes may be hazardous, because it remains difficult (as in our study) to anticipate on how biological tissues (like bone) will react on, for example, new implant properties (surface treatment, coating morphology, release of Ca-ions). In a recent review it was recognized that in models incorporating biological processes, the number of model parameters that have to be identified and translated into measurable physical or physiological quantities is high. Furthermore these parameters may show considerable variation between subjects of the research population. Therefore several levels of quantification and validation are required to improve the accuracy with which the model can predict physical phenomena ${ }^{52}$.

We conclude that, based on the clinical DEXA results, the theoretical concept for improved proximal bone loading of the femur by the Symax ${ }^{\mathrm{TM}}$ stem is correct, and that the effect of distal stem treatment preventing bone ingrowth appears to have a positive effect on proximal bone maintenance. However, likely due to only partial modelling of differences in implant-bone interface conditions between both reconstructions, the FE-model could not completely match the clinical findings. Further quantitative data about biological phenomena are required to feed the FEmodels in order to advance from case-specific simulations to reliable preclinical 
predictions of bone remodelling (or even implant survival) of new designs in averaged patient populations, particularly if multiple biological aspects are changed in a prosthetic design. Only then recommendations for multifaceted design changes of implants can be reliable. 


\section{Chapter 7}

\section{REFERENCES}

1. Bobyn JD, Mortimer ES, Glassman AH, Engh CA, Miller JE, Brooks CE. Producing and avoiding stress shielding. Laboratory and clinical observations of noncemented total hip arthroplasty. Clin Orthop Relat Res 1992;274:79-96.

2. Kilgus DJ, Shimaoka EE, Tipton JS, Eberle RW. Dual-energy X-ray absorptiometry measurement of bone mineral density around porous-coated cementless femoral implants. Methods and preliminary results. J Bone Joint Surg Br 1993;75(2):279-87.

3. Huiskes R, Chao EY. A survey of finite element analysis in orthopedic biomechanics: the first decade. J Biomech 1983;16(6):385-409.

4. Verdonschot $\mathbf{N}$, Huiskes R. Mechanical effects of stem cement interface characteristics in total hip replacement. Clin Orthop Relat Res 1996;329:326-36.

5. Huiskes R, Boeklagen R. Mathematical shape optimization of hip prosthesis design. J Biomech 1989;22(8-9):793-804.

6. Stolk J, Verdonschot N, Cristofolini L, Toni A, Huiskes R. Finite element and experimental models of cemented hip joint reconstructions can produce similar bone and cement strains in pre-clinical tests. J Biomech 2002;35(4):499-510.

7. Janssen D, Aquarius R, Stolk J, Verdonschot N. Finite-element analysis of failure of the Capital Hip designs. J Bone Joint Surg Br 2005;87(11):1561-7.

8. Heller MO, Bergmann G, Deuretzbacher G, Durselen L, Pohl M, Claes L, Haas NP, Duda GN. Musculo-skeletal loading conditions at the hip during walking and stair climbing. J Biomech 2001;34(7):883-93.

9. Carter DR, Orr TE, Fyhrie DP. Relationships between loading history and femoral cancellous bone architecture. J Biomech 1989;22(3):231-44.

10. Kerner J, Huiskes R, van Lenthe GH, Weinans H, van RB, Engh CA, Amis AA. Correlation between pre-operative periprosthetic bone density and post-operative bone loss in THA can be explained by strain-adaptive remodelling. J Biomech 1999;32(7):695-703.

11. Panisello JJ, Canales V, Herrero L, Herrera A, Mateo J, Caballero MJ. Changes in periprosthetic bone remodelling after redesigning an anatomic cementless stem. Int Orthop 2009;33(2):373-9.

12. Herrera A, Panisello JJ, Ibarz E, Cegonino J, Puertolas JA, Gracia L. Long-term study of bone remodelling after femoral stem: a comparison between dexa and finite element simulation. J Biomech 2007;40(16):3615-25. 
13. ten Broeke RH, Alves A, Baumann A, Arts JJ, Geesink RG. Bone reaction to a biomimetic third-generation hydroxyapatite coating and new surface treatment for the Symax hip stem. J Bone Joint Surg Br 2011;93(6):760-8.

14. Becker P, Neumann HG, Nebe B, Luthen F, Rychly J. Cellular investigations on electrochemically deposited calcium phosphate composites. J Mater Sci Mater Med 2004; 15(4):437-40.

15. Dalton JE, Cook SD, Thomas KA, Kay JF. The effect of operative fit and hydroxyapatite coating on the mechanical and biological response to porous implants. J Bone Joint Surg Am 1995;77(1):97-110.

16. Søballe K, Hansen ES, Brockstedt-Rasmussen H, Bünger C. Hydroxyapatite coating converts fibrous tissue to bone around loaded implants. J Bone Joint Surg $\mathrm{Br}$ 1993;75(2):270-8.

17. Geesink RGT. Hydroxylapatite-coated total hip replacement five year clinical and radiological results. In: Geesink RGT, Manley MT, eds. Hydroxylapatite coatings in orthopaedic surgery. New York: Raven Press, 1993:171-208.

18. Bauer TW, Geesink RC, Zimmerman R, McMahon JT. Hydroxyapatite-coated femoral stems. Histological analysis of components retrieved at autopsy. J Bone Joint Surg Am 1991;73(10):1439-52.

19. Capello WN, D'Antonio JA, Jaffe WL, Geesink RG, Manley MT, Feinberg JR. Hydroxyapatite-coated femoral components: 15-year minimum followup. Clin Orthop Relat Res 2006;453:75-80.

20. Becker P, Baumann A, Lüthen F, Rychly J, Kirbs A, Beck U, Neumann HG. Spark anodization on titanium and titanium alloys. Proceedings of the 10th world conference on titanium vol. V, 3339-3344, 2003.

21. Tarala M, Janssen D, Verdonschot N. Balancing incompatible endoprosthetic design goals: a combined ingrowth and bone remodeling simulation. Med Eng Phys 2011;33(3):374-80.

22. Tarala M, Janssen D, Telka A, Wanders D, Verdonschot N. Experimental versus computational analysis of micromotions at the implant-bone interface. Proc Inst Mech Eng H 2011;225(1):8-15.

23. Keyak JH, Falkinstein Y. Comparison of in situ and in vitro CT scan-based finite element model predictions of proximal femoral fracture load. Med Eng Phys 2003;25(9):781-7.

24. Martin RB, Burr DB, Sharkey NA. Skeletal tissue mechanics. Springer-Verlag, New York 1998. 


\section{Chapter 7}

25. Heller MO, Bergmann G, Kassi JP, Claes L, Haas NP, Duda GN. Determination of muscle loading at the hip joint for use in pre-clinical testing. J Biomech 2005;38(5):1155-63.

26. Huiskes $R$, Weinans $H$, van Rietbergen B. The relationship between stress shielding and bone resorption around total hip stems and the effects of flexible materials. Clin Orthop Relat Res 1992;274:124-34.

27. Akhavan S, Matthiesen MM, Schulte L, Penoyar T, Kraay MJ, Rimnac CM, Goldberg VM. Clinical and histologic results related to a low-modulus composite total hip replacement stem. J Bone Joint Surg Am 2006;88(6):1308-14.

28. Gruen TA, McNeice GM, Amstutz HC. "Modes of failure" of cemented stem-type femoral components: a radiographic analysis of loosening. Clin Orthop Relat Res 1979;141:17.

29. Rancourt D, Shirazi-Adl A, Drouin G, Paiement G. Friction properties of the interface between porous-surfaced metals and tibial cancellous bone. J Biomed Mater Res 1990;24(11):1503-19.

30. Engh CA, Massin P, Suthers KE. Roentgenographic assessment of the biologic fixation of porous-surfaced femoral components. Clin Orthop Relat Res 1990;257:107-28.

31. Sluimer JC, Hoefnagels NH, Emans PJ, Kuijer R, Geesink RG. Comparison of two hydroxyapatite-coated femoral stems: clinical, functional, and bone densitometry evaluation of patients randomized to a regular or modified hydroxyapatite-coated stem aimed at proximal fixation. J Arthroplasty 2006;21(3):344-52.

32. Scannell PT, Prendergast PJ. Cortical and interfacial bone changes around a non-cemented hip implant: simulations using a combined strain/damage remodelling algorithm. Med Eng Phys. 2009;31(4):477-88.

33. Kröger H, Miettinen H, Arnala I, Koski E, Rushton N, Suomalainen O. Evaluation of periprosthetic bone using dual-energy $\mathrm{x}$-ray absorptiometry: precision of the method and effect of operation on bone mineral density. J Bone Miner Res 1996;11(10):1526-30.

34. Bryan JM, Sumner DR, Hurwitz DE, Tompkins GS, Andriacchi TP, Galante JO. Altered load history affects periprosthetic bone loss following cementless total hip arthroplasty. J Orthop Res 1996;14(5):762-8.

35. Huiskes R. The various stress patterns of press-fit, ingrown, and cemented femoral stems. Clin Orthop Relat Res 1990;261:27-38.

36. Weinans H, Huiskes R, Grootenboer HJ. Effects of fit and bonding characteristics of femoral stems on adaptive bone remodeling. J Biomech Eng 1994;116(4):393-400. 
37. Turner AW, Gillies RM, Sekel R, Morris P, Bruce W, Walsh WR. Computational bone remodelling simulations and comparisons with DEXA results. J Orthop Res 2005;23(4):705-12.

38. Porter AE, Taak P, Hobbs LW, Coathup MJ, Blunn GW, Spector M. Bone bonding to hydroxyapatite and titanium surfaces on femoral stems retrieved from human subjects at autopsy. Biomaterials 2004;25(21):5199-208.

39. Coathup MJ, Blunn GW, Flynn N, Williams C, Thomas NP. A comparison of bone remodelling around hydroxyapatite-coated, porous-coated and grit-blasted hip replacements retrieved at post-mortem. J Bone Joint Surg Br 2001;83(1):118-23.

40. Orlik J, Zhurov A, Middleton J. On the secondary stability of coated cementless hip replacement: parameters that affected interface strength. Med Eng Phys 2003;25(10):825-31

41. Folgado J, Fernandes PR, Jacobs CR, Pellegrini VD, Jr. Influence of femoral stem geometry, material and extent of porous coating on bone ingrowth and atrophy in cementless total hip arthroplasty: an iterative finite element model. Comput Methods Biomech Biomed Eng 2009; 12(2):135-45.

42. Dickinson A, Taylor A, Browne M. Implant-bone interface healing and adaptation in resurfacing hip replacement. Comput Methods Biomech Biomed Engin. 2012;15(9):935-47.

43. Glassman AH, Bobyn JD, Tanzer M. New femoral designs: do they influence stress shielding? Clin Orthop Relat Res 2006;453:64-74.

44. Bobyn JD, Glassman AH, Goto H, Krygier JJ, Miller JE, Brooks CE. The effect of stem stiffness on femoral bone resorption after canine porous-coated total hip arthroplasty. Clin Orthop Relat Res 1990;261:196-213.

45. Glassman AH, Crowninshield RD, Schenck R, Herberts P. A low stiffness composite biologically fixed prosthesis. Clin Orthop Relat Res 2001;393:128-36.

46. Kärrholm J, Anderberg C, Snorrason F, Thanner J, Langeland N, Malchau H, Herberts P. Evaluation of a femoral stem with reduced stiffness. A randomized study with use of radiostereometry and bone densitometry. J Bone Joint Surg Am 2002;84(9):1651-8.

47. van Rietbergen B, Huiskes R. Load transfer and stress shielding of the hydroxyapatite-ABG hip: a study of stem length and proximal fixation. J Arthroplasty 2001;16(8 Supp/ 1):55-63.

48. van Rietbergen B, Huiskes R, Weinans H, Sumner DR, Turner TM, Galante JO. ESB Research Award 1992. The mechanism of bone remodeling and resorption around pressfitted THA stems. J Biomech 1993;26(4-5):369-82. 


\section{Chapter 7}

49. Weinans H, Huiskes R, van Rietbergen B, Sumner DR, Turner TM, Galante JO. Adaptive bone remodeling around bonded noncemented total hip arthroplasty: a comparison between animal experiments and computer simulation. J Orthop Res 1993;11(4):500-13.

50. Lerch M, Kurtz A, Stukenborg-Colsman C, Nolte I, Weigel N, Bouguecha A, Behrens BA. Bone remodeling after total hip arthroplasty with a short stemmed metaphyseal loading implant: finite element analysis validated by a prospective DEXA investigation. J Orthop Res. 2012;30(11):1822-9.

51. Lengsfeld M, Gunther D, Pressel T, Leppek R, Schmitt J, Griss P. Validation data for periprosthetic bone remodelling theories. J Biomech 2002;35(12):1553-64.

52. Viceconti M, Olsen S, Nolte LP, Burton K. Extracting clinically relevant data from finite element simulations. Clin Biomech (Bristol, Avon) 2005;20(5):451-54. 
Improving Peri-Prosthetic Bone Adaptation around Cementless Hip Stems 


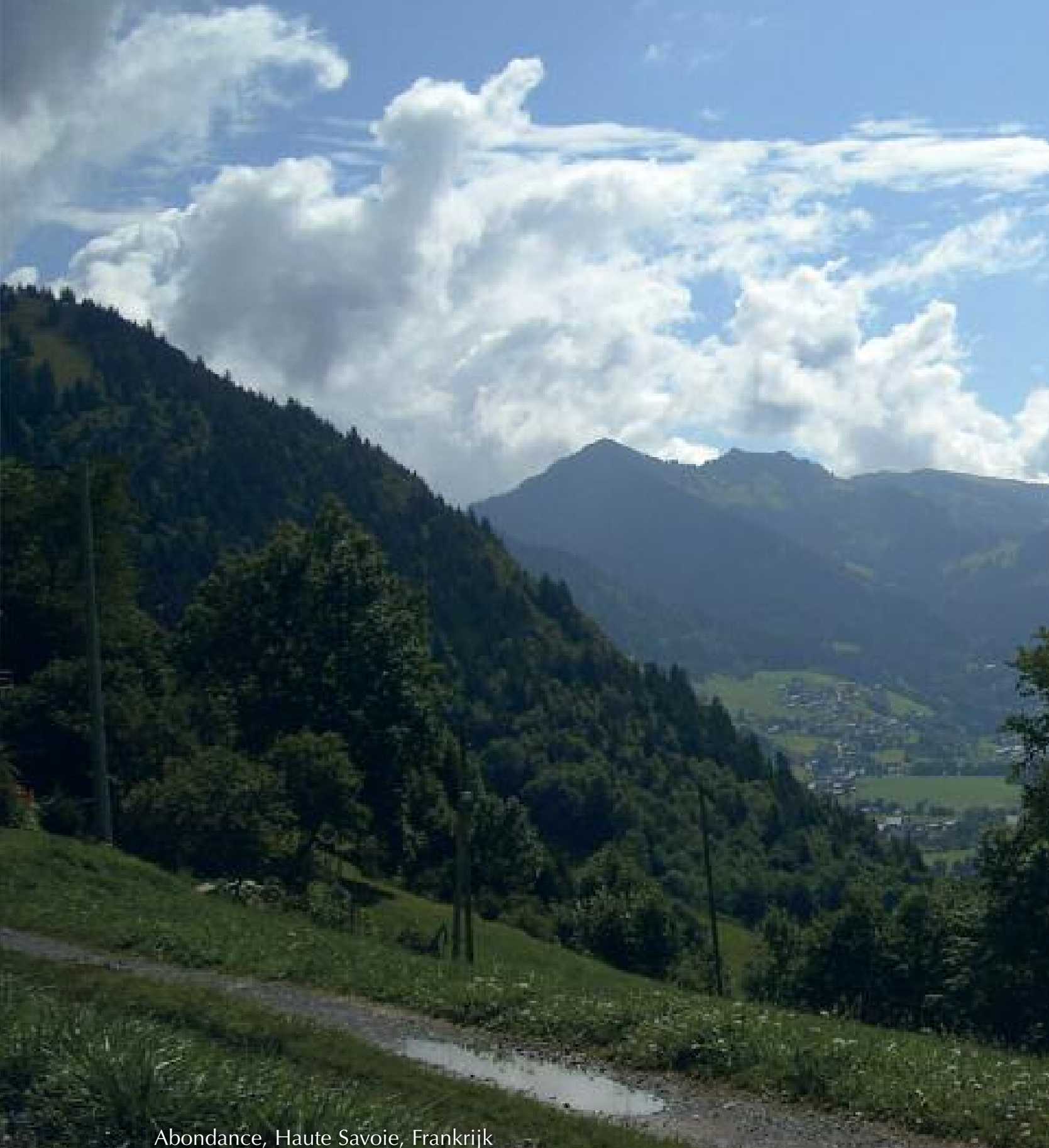

Abondance, Haute Savoie, Frankrijk

$\cos$

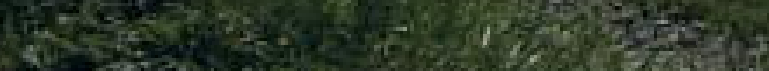

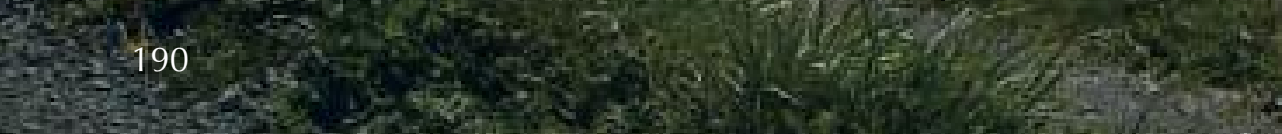




\section{CHAPTER 8}

Application of finite element analysis in total hip design optimizations; a critical appraisal from a surgeons perspective

René ten Broeke

Chris Arts, Lodewijk van Rhijn Rudolph Geesink 


\section{AbStRACT}

Finite element (FE) simulations play an increasing role in design optimization of orthopaedic implants. Bone remodelling after total joint arthroplasty and failure scenarios are simulated in mathematical equations, and it is claimed FE-models can predict implant failure.

However properties of living dynamic tissues, like bone, are inherently complex, and difficult to represent in physical quantities. To integrate biological processes in computerized principally mechanical models, assumptions have to be made on variables of implant, bone, their interfaces, and the way they behave in mechano-biological algorithms under loading and (un)bonded circumstances. This introduces simplifications that may follow biomechanical principles, but of which it is uncertain if it represents physiological strain adaptive bone remodelling, and consequently how realistic predictions of bone and implant behaviour can be.

Refinements in FE-meshes, and more realistic translations of dynamic bone properties and biochemical interface interactions are necessary. Better understanding of clinical failure scenarios, and improved assessment of bone changes are imperative. Finally realistic validations of the FE-technique are needed, particularly through prospective comparison of computational simulations with clinical results, to establish the additional value of the FE-method in improving implant designs. 


\section{INTRODUCTION}

The success of total hip arthroplasty both clinically and socio-economically can explain the continuously growing number of this surgical operation worldwide..$^{1-3}$ Considering these large numbers and the potential impact of implant failure on the quality of life, monitoring of total hip prostheses has become mandatory to improve their longevity. Quality assurance of existing and new designs has become a core issue, seen in the light of old, ${ }^{4-7}$ and recent clinical disasters. ${ }^{8-11}$ There is a need for tools that can identify factors that contribute to adverse implant and periprosthetic bone behaviour. Preferably these tools should be able to detect inferior designs in the preclinical phase, to prevent implantation of high volumes before first suspicion of implant failure arises. ${ }^{12}$

Finite element analysis (FEA) has frequently been used in combination with bone remodelling theories, to simulate periprosthetic adaptive bone remodelling after total hip arthroplasty (THA) in computer models. Strains and stresses in joint implants, bone and interfaces were calculated, and combined with mathematical models of biological processes related to adaptive bone remodelling. By incorporating these mathematical translations of feed-back mechanisms of biological processes in these models, it is claimed that long-term behaviour of orthopaedic implants fixed to bone, can be calculated and predicted as far as mechanical influences are concerned. ${ }^{13}$

Bone is a complex non-homogeneous, anisotropic, visco-elastic material that can adjust its structure by resorption (through osteoclast activity) or apposition (through osteoblast activity). Adaptations are driven by environmental stimuli, of which mechanical loading is an important one. One of the first to recognize this was the surgeon Julius Wolff, who observed that the organization of trabecular bone corresponds to the mechanical load transfer (1892). ${ }^{14}$ The idea that 'form follows function' is based on the assumption that bone can detect mechanical stimuli and deformations as a result of loading, and react on it with adapting bone turn over by adjusting the balance between osteoblastic and osteoclastic activity. After introduction of a hip stem in the femoral shaft, a reduction of bone stresses and strains in the bone, called 'stress shielding', leads to a new equilibrium between bone apposition and resorption, adapting its structure in accordance with the changed mechanical environment. Efforts have been made to describe this process, 


\section{Chapter 8}

referred to as 'adaptive bone remodelling', in mathematical equations, relating the input (a mechanical signal) to the output (resulting bone loss or gain). In this way it was tried to predict these morphological changes in a quantitative manner, in order to prevent adverse bone remodelling through improvements in the orthopaedic implants, with the goal to prolong their survival. ${ }^{15-18}$ In this overview we will discuss what computerized simulations have contributed to improvements of implant designs, and how reliable predictions based on this technique have proven to be. Recommendations are made to enhance the added value of this tool for the clinical practice of the orthopaedic surgeon.

\section{The FE-technique in orthopaedic implant design}

Contemporary finite element studies on hip prostheses essentially consist of four steps; 1) image processing, 2) importation of CAD data, 3) FE mesh generation and 4) model analysis with FE software and post-processing.

Originally in the first step two-dimensional (conventional radiography) or threedimensional (CT or MRI) imaging was performed of bone morphology of the proximal femur and the acetabulum. Cross-sectional morphology was digitized of both cortical dimensions and the endosteal envelope (= medullary dimensions). From this and from backscattered scanning electron microscope images of the femur, the area of cortical and cancellous bone at different sections was determined. ${ }^{19}$ Nowadays mostly CT-voxels are used and converted into tetrahedral or hexahedral brick elements that constitute the FE-mesh of the femur.

In the same way the space taken by the prosthesis can be calculated, after digitizing prosthetic contours. An improvement for contemporary FE-based simulations is that physical prototypes of the implants are no longer required. Instead of manual or computerized digitization nowadays mostly CAD files from the hip implants, derived from the manufacturer or from the Medical Device Agency, are used to export the prosthetic geometry into the FE mesh.

During the process of mesh generation the digitized contours of the crosssectioned slices of the implant are plotted on the digitized femurs with the use of computers. Using a finite element pre-processor, the cortical and implant contours are divided into a finite element mesh, originally consisting of 2D-surface meshes (with or without side-plate) but at present mostly of 3D-volumetric meshes. For this 
step of mesh generation, which should preferably be patient-specific, many commercially available software packages are capable of bridging the gap between 3D imaging and CAD files on one hand, and simulation technologies on the other. Mesh parameters are assigned to the elements representing bone or implant. Assumptions are made on material properties like the elastic or Young's modulus, the Poison's ratio, yield and ultimate strength, and the degree of anisotropy. Values for the Young's modulus of cortical and cancellous bone are usually taken from the literature, as well as for the bone density, and for the direct relation between density and Young's modulus. ${ }^{20,21}$ Alternatively from known elasticity moduli, the density of cortical and cancellous brick elements can be calculated and is considered uniform throughout the entire bone compartment. In later models apparent density per brick element is 'calculated' from the measured Hounsfield Units from CT-pictures of the femur, assuming that the highest true bone density corresponds with the maximal value as illustrated on CT-scans. ${ }^{22}$ Particularly in earlier studies these relationships between bone morphology and bone elastic properties were inaccurate, because inhomogeneities in trabecular bone architecture were not accounted for and resolutions of CT-reconstructions were too low. ${ }^{23}$ Later CT-based stereomorphometric bone parameters showed higher correlations with apparent elastic properties of bone samples, provided however that anisotropy would have negligible effects on these apparent properties. For the orientation, magnitude and points of application of the loads and relevant muscle forces on both operated and contralateral femur, values are also mostly taken from the literature. ${ }^{24}$

The fourth step is the actual analysis of the model in a FE-software package for the computational evaluation of a variety of experimental conditions, for which purpose also several formats are available. With this software it is possible to simulate mechanical tests and/or physiological loading and calculate the associated stresses, strains and energy densities in the bone and at their interface, and predict the resulting bone behaviour in terms of remodelling.

\section{FE-theory and periprosthetic bone remodelling}

After implantation of the femoral component, the strain energy density in the bone changes, creating altered mechanical signals in its tissue. It is assumed that these signals are detected by sensors in the bone, most likely osteocytes, as changes in 


\section{Chapter 8}

stress or strain, and translated in a biochemical signal that induces remodelling. Mechano-regulation models have been introduced in FE-analysis to provide for the (missing) link between these mechanical stimuli (tissue shear strain and interstitial fluid flow) and their biological effect (proliferation and differentiation of mesenchymal stem cells). ${ }^{25-28}$ In these mechano-biological algorithms assumptions are made on the number and diffusion-coefficient of cells into the interface, their proliferation rate, the deformation of these precursor cells as a result of the mechanical stimuli, their subsequent differentiation into either fibroblasts, chondroblasts or osteoblasts as a function of predefined thresholds of these stimuli, and their cell death rate. ${ }^{26,28}$ As a consequence the amount of bone ingrowth and bony or fibrous implant fixation are then simulated. The mechanical stimulus itself is calculated from variables as shear strain, fluid velocity and some empirical constants.

Current remodelling theories are based on the idea that the bone tries to equalize this signal by adapting periprosthetic bone density through resorption or apposition to such an extent that a new equilibrium is achieved between bone mineral density (with related elasticity modulus) and strains, so that strain energy per unit of bone mass (SED) is brought back to a preset reference value. This direct relationship between the remodelling signal $S$, the strain energy per unit of bone mass (= strain energy density $U$ ) and the bone density is represented in the mathematical equation: ${ }^{29}$

$$
S=\frac{U}{p}
$$

A schematic representation of this hypothetical chain of steps in the adaptive remodelling process is given in figure 1 , and adapted from Weinans. ${ }^{22}$

\section{Validation of the FE-technique}

Whether FE-calculations, and the predictions derived from them, are realistic has to be tested and depends on the agreement between the model, experimental responses and clinical results. This will determine whether virtual processing can sufficiently and reliably simulate in vivo conditions.

The predicted results of bone remodelling after implantation of hip stems were initially validated by animal experiments, in which bone changes were studied on 


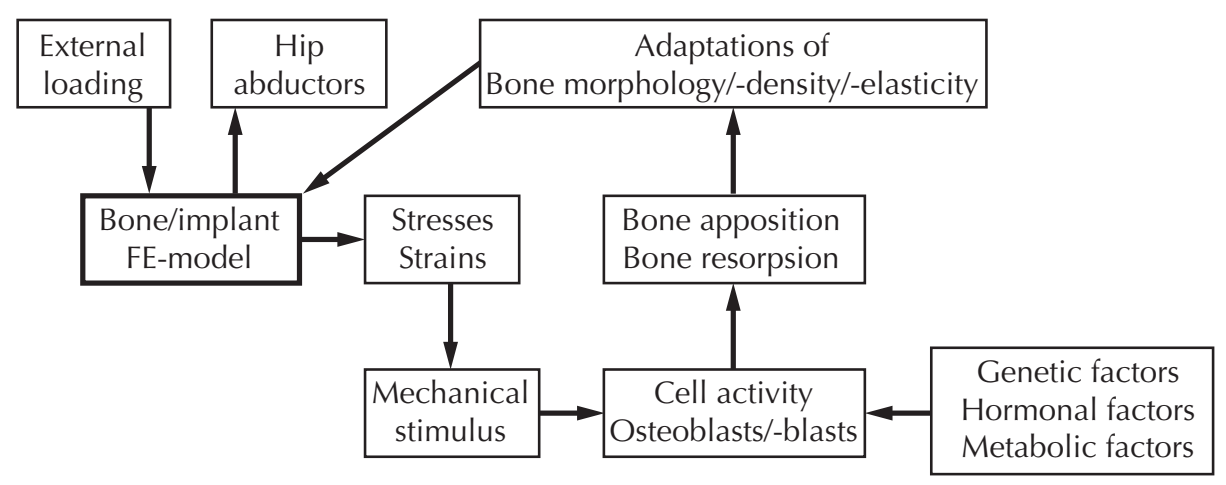

Fig. 1 Remodelling scheme representing biological reactions on mechanical stimuli, leading to adaptive bone changes to reinstall a new equilibrium around an orthopaedic implant

micrographs of femoral cross-sections of the same animal cadavers that were used to create the FE-model. ${ }^{18,19,30,31}$ Because initial experiments showed satisfactory similarity between calculations of the model and morphological changes of the bone around the experimental prostheses, it was concluded that the latter could indeed be explained as an effect of a mechanical adaptive process, and could be predicted by the strain adaptive bone-remodelling theory. Consequently the computersimulation models were considered versatile tools for pre-clinical testing of prosthetic designs, and realistic enough to substitute animal experiments entirely, in other words to predict bone behaviour around new designs prospectively. ${ }^{22,32-34}$

However in the early years of FE-predictions of bone density after THA in simulated human femora, the resulting density distributions proved to be unrealistic, and could only show bone morphology remotely similar with known human femora from X-rays and retrievals. $22,29,32,35,36$ Later, validation of FE-predictions of periprosthetic bone density was performed through analysis of conventional radiographs after implantation of the analyzed component. ${ }^{37}$ In this retrospective way it was investigated whether resorption patterns of periprosthetic bone were consistent with computer simulations. This proved to be an inaccurate method, as from several studies it had already been shown that visual processing of roentgenograms could only detect periprosthetic bone loss with sufficient reproducibility when it exceeded at least 25 to $30 \%,{ }^{38-40}$, due to change of parameters of conventional X-ray imaging during follow-up. ${ }^{41}$ 


\section{Chapter 8}

An important step in quantitative measurement of bone mass was the introduction of dual energy X-ray absorptiometry (DEXA) which, compared to earlier techniques of bone density measurement, improved image resolution resulting in higher precision and accuracy. ${ }^{42}$ Since the availability of periprosthetic densitometry, several studies have been performed to correlate computed FE-stresses in two- and threedimensional models of implanted femora (in vitro), with the effects on bone density as measured with DEXA (in vivo). Attempts were focused on finding a quantitative relationship between absolute values of stress in the bone at implantation, and subsequent remodelling changes in terms of BMD-values. ${ }^{43}$ Patient-specific 3D FEmodels of retrieved bone specimens from earlier bone densitometry studies were constructed and bone remodelling simulations performed. Because patterns of predicted bone loss corresponded well with the DEXA-measurements on the retrievals, it was concluded that the applicability of numerical pre-clinical testing of the interaction between implant design and bone could be extended. ${ }^{44}$ More recently 3D FE-models were developed retrospectively to analyse the mechanical loading of bone by a known design (uncemented ABG-I, Stryker), and the correlation with BMD changes as detected in earlier, ${ }^{45-46}$ and new DEXA studies of the same implant. ${ }^{47}$ Nowadays software packages are available to allow for conversion of results of remodelling simulation into DEXA images (Fig. 2). This enables a clinical interpretation of the in vitro periprosthetic remodelling process, and a direct comparison with in vivo DEXA studies. Hence it provides retrospective information on how realistic the chosen FE model could simulate in vivo bone adaptations, and consequently if it may prospectively predict bone changes around new hip designs. ${ }^{48} \mathrm{~A}$ different concept for validation was a computerized visualization of postoperative trabecular bone adaptation based on a different remodelling algorithm, design space optimization (DSO). ${ }^{49,50}$ The 3-D finite element simulation was validated through comparison of the computational results with simulated radiographs, and with radiographic (conventional x-rays) and densitometry (DXA) results from the literature. This however showed large discrepancies between predicted magnitude of these effects and clinical results. ${ }^{50}$

Another way to further validate the FE-model was to perform a retrospective simulated-based analysis of an already failed hip design (cemented Capital Hip, 3M), to investigate whether the simulation was able to detect the cause for limited survival. 
The agreement between the reconstructed failure scenario from FEA, with the findings of the loosened retrievals was considered a support for the method. ${ }^{51}$

Although these studies have suggested that the improved FE-models are able to predict bone adaptations following THA, on theoretical grounds there is reason for doubt if this claim is sustainable.

Fig. 2 Software package (DCMTK MFC 10.8) for conversion of $3 D$ remodelling simulation onto 2D DEXA images. Figure reprinted from 'Balancing incompatible endoprosthetic design goals: A combined ingrowth and bone remodelling simulation'.

Medical Engineering \& Physics 2011, Vol 33(3), page 374-380, by Tarala M et

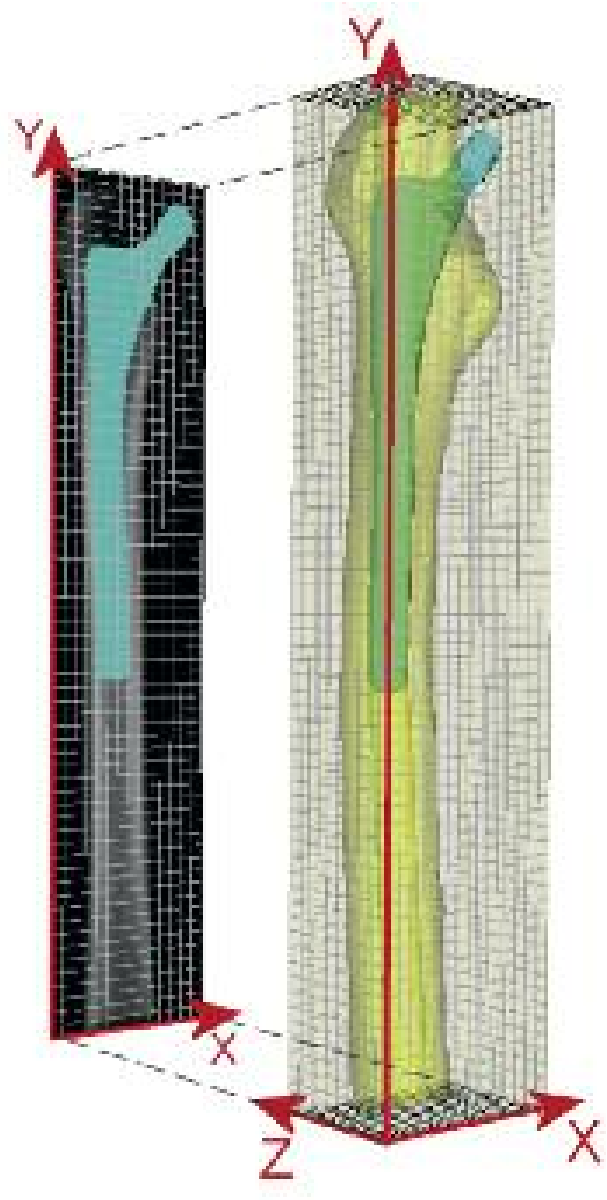
al. with permission from Elzevier. 


\section{Chapter 8}

\section{Critical appraisal of the FE-technique}

\section{Static versus dynamic.}

Validation and verification of bone adaptation theories has been a problem, due to some intrinsic imperfections of the method. The finite element method is principally based on calculations in which static information on several variables is used as input for mathematical equations that should represent biological processes playing a role in bone remodelling. However these bone adaptations are a continuous sequence of changes and therefore are intrinsically dynamic. From DEXA-analysis it is clear that BMD after THA, particularly in the important proximal femoral areas, changes constantly for at least 2 years, and to a lesser extent thereafter. So the starting point for these bone parameters should therefore be adapted continuously. In an attempt to deal with this, more recent and advanced FE-models of the femur consist of many more brick elements ( $>60000$ for macro-FE models and $>10$ million for micro-FE models) than the early ones. ${ }^{47,48,50-52}$ In this way distinction between cortical and cancellous bone is possible, with their own properties (elastic modulus, Poisson ratio, compression and tension stress). In order to adjust the mechanical properties of the bone along the course of time, they were estimated by the correlation between measured bone mass values and apparent bone density. Starting with a known relationship between bone mass, elasticity modulus and bone density at $\mathrm{t}_{0}$, the change in Young's modulus with the passing of time is concluded from the change in BMD. In this way adjustments are made for the changing mechanical properties of bone during follow-up to mimic reality as much as possible. ${ }^{47}$

Another dynamic process concerns osseointegration itself. The original finite element models for uncemented hips were based on porous-coated designs, ${ }^{30,31}$ and assumed complete bonding of the stem to bone. ${ }^{43,53}$ Even modern computational simulation algorithms assume immediate postoperative fully ingrown implants with full friction, which resist all interface shear and traction forces. ${ }^{50}$ However from retrieval studies this ideal situation has been shown not to be realistic, and furthermore it is not a static but dynamic process in time and will depend on implant geometry, stem stiffness, surface treatment, type of coating, and degradation characteristics of biological coatings. ${ }^{54-59}$ The retrieval study of the Symax hip stem illustrated a proximal direct bone-implant contact in time increasing from $26.5 \%$ 
(at 3 weeks) to $83.5 \%$ (at 13 months), while distally bonding was prevented by a particular surface treatment. ${ }^{60}$ This progressive proximal osseointegration without distal osseointegration may be expected to have an effect on the amount of load transfer from implant to bone and resultant remodelling. In a recent study the extent of these coating effects were not yet known. Therefore they could not be correctly incorporated in the FE model, resulting in inaccurate simulations of bone remodelling (Fig.3). ${ }^{61}$

From several FE studies it was found that normal contact stiffness and the friction coefficient increases several times as bone grows into the rough surface of the implant and mineralises, thus providing a changing interface with improving secondary stability. ${ }^{62}$ So for computational models of remodelling to be realistic, an ongoing synchronization of interface conditions during the process is indispensable..$^{63}$ In the light of this, modelling of biochemical interactions at the implant surface also is still a missing link. Particularly the role of cells (osteoblast adhesion properties and osteoblast activity) and the influence of growth factors may be important to simulate

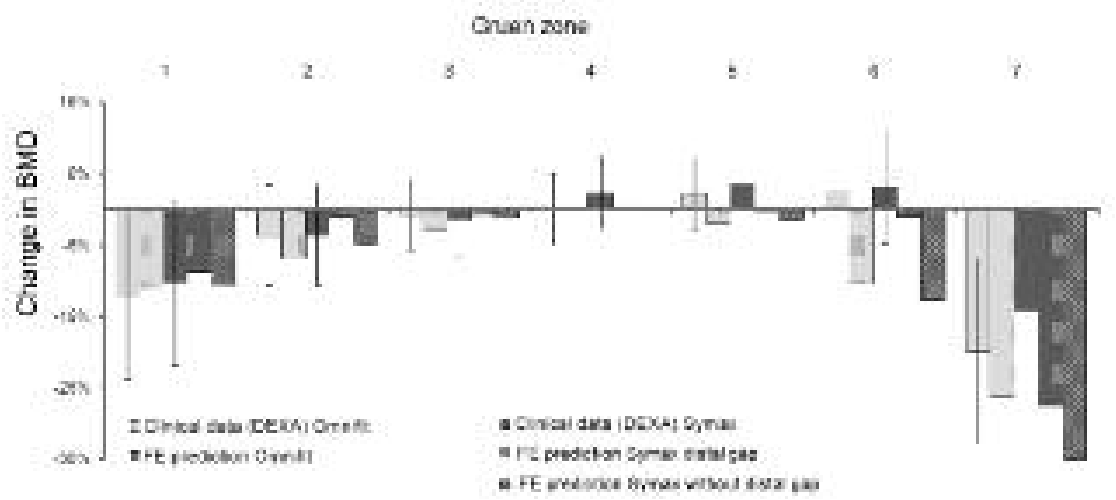

Fig. 3 Clinical DEXA data per Gruen zone (with standard deviation) around an existing hip stem (Omnift ${ }^{\oplus}$ ) and newly designed (Symax ${ }^{\mathrm{TM}}$ ) stem at 2 years, combined with the FEM predictions on remodelling. For the new stem predictions are given with a gap (simulating no friction at the distal interface) and without a gap (simulating friction at the interface). Illustration shows discrepancy between predicted and real bone loss around the new stem. 


\section{Chapter 8}

in a mechanobiological model that describes biochemical interactions between the implant and its environment. In this way it may be theoretically possible to estimate the amount of mineralized tissue on the implant surface and to predict osseointegration itself. Consequently predictions on time-dependent changes in related parameters (like friction coefficient) will be more reliable. ${ }^{64}$ At the same time it has to be recognized that, depending on the choice of mechanoregulation model, the predicted influence of several parameters on the tissue differentiation around loaded implants appeared to be qualitatively and quantitatively different. ${ }^{25,65,66}$

\section{Bonded versus unbonded.}

It was illustrated with FE-analysis that stem-cement debonding was responsible for high stresses in the cement mantle. Therefore it was predicted that increased surface roughness of the stem would reduce these stresses, and should result in better survival of these implants. ${ }^{67}$ For this reason the Scientific Hip Prosthesis ${ }^{\circledR}\left(\mathrm{SHP}^{\circledR}\right)$ was designed accordingly. However clinical and registry results of other cemented stems with rough finish showed the contrary. ${ }^{68,69}$ In retrospect this could be explained by the incapacity of the models to predict debonding at the stem-cement interface.

Later attempts to create a FE-model in which partial bonding or an intermediate fibrous tissue layer was simulated, were again based on an expected load-transfer mechanism with assumptions concerning (the magnitude and relevance of) several variables, to be able to represent them in mathematical equations. ${ }^{70}$ Examples of variables that had to be simulated were the normal (=tensile or compression) stresses, shear stresses, bending stresses, Youngs (elastic) modulus, stiffness and Poisson's ratio of the fibrous layer, strain in the layer, and bonded or loose interface connection with transfer of respectively all forces or only normal compressive forces, and simple uni-directional loading protocols etc.. For some of these discrepancies between complex biological processes and their mathematical representation, more or less 'artificial' solutions have been created like defining contact conditions between implant and bone with friction (and an estimated friction coefficient) instead of considering the real union between them ${ }^{47}$ However this static coefficient of friction between the implant and the bone (or bone cement), necessary to characterize the interface conditions in the numerical models, is not reproducibly provided in the literature, and there is no consensus on the method of measurement. ${ }^{71,72}$ And when 
available, it is known only for the completely debonded stem.

From studies on the mechanical properties of the fibrous tissue at the bone-cement interface it was shown that in compression the membrane was relatively compliant, but the resistance against shear stresses was very low. Both tensile forces and shear forces were not transmitted to the bone, but were responsible for debonding and slip of the implant. ${ }^{73}$

Huiskes recognized that the degree of stress shielding is indeed affected by the bonding conditions of the implant-bone interface. ${ }^{74}$ Therefore knowledge about the extent of osseointegration or fibrous anchorage of a new uncemented implant, from retrieval analysis and histomorphometry, is paramount for generating realistic FEcalculations and remodelling predictions. The same applies for the distal part of proximally integrating uncemented stems. Although intended to remain unbonded distally (through polishing or other surface treatments to prevent protein absorption and osseointegration), some of these designs gradually still lead to bony fixation in the distal part as well. Pedestal formation and diaphyseal cortical hypertrophy may also result in altered load transfer than theoretically expected and integrated in the FE model.

For FE-simulations of cemented THA on the other hand, often from the start of the calculations the cement-bone interface is assumed to be completely bonded and the cement-stem interface to be debonded..$^{51,75,76}$ Dependent on the surface finish of the stem (polished, satin or rough) friction coefficients of the interfaces are then chosen accordingly. However from revision surgery it is known that these assumptions do not represent the direct postoperative in vivo situation.

\section{Bone density.}

A simplification of early FE models seems to be the choice of initial bone density at a fixed and uniform value for the entire periprosthetic femur. ${ }^{22}$ Although by some authors it is supposed an unimportant determinant for the end result of the remodelling process, ${ }^{77}$ there are indications from hip replacements in osteoporotic patients that the amount and rate of postoperative periprosthetic BMD loss - and perhaps even the chance of aseptic loosening - is related to the initial bone density. ${ }^{45,78-84}$ It could be illustrated that varying quality and modulus of cortical and cancellous bone has an effect on initial implant osseointegration and stability, and as such influences interface 


\section{Chapter 8}

bone strains as well. ${ }^{85}$ This suggests that for FE studies to be truly predictive, a range of bone qualities must be examined to study the performance envelope of a particular implant. From a theoretical point of view the remodelling potential of bone is dependent on the amount of internal pore surface for bone apposition or resorption, as was also assumed earlier by Martin. ${ }^{86}$ This may explain why osteoporotic bone tends to remodel more extensively, and bone resorption due to stress-shielding can compromise implant support and fixation more easily in these patients. Besides the issue of osteoporosis, also other metabolic, hormonal and genetic factors that play a role in remodelling, are difficult to incorporate in the biomechanical model.

\section{Bone elasticity \& (an)isotropicity.}

In FE-calculations bone is mostly characterized as an (at least transversely) isotropic material. ${ }^{13,51,76}$ For this the elastic properties of bone should not depend on the orientation of the material with respect to the loading condition, and are characterized by a single elasticity modulus (Young's modulus). The other parameter to fully characterize the elastic behaviour of an isotropic material is Poisson's ratio. This is a measure for the amount of transverse bulging during compression, or contraction during stretching of the material. In general the elastic properties of anisotropic materials depend on their orientation with respect to the loading direction. This is particularly true for bone.

Apart from the elastic behaviour of bone, the strength properties of bone also depend on the loading direction (in tension, compression or torsion). Typical stressstrain curves for uni-axial loading of cortical bone, both in the longitudinal and transverse directions, show for example that cortical bone is stronger in compression than in tension. ${ }^{87-89}$ This implies that strength as well as elasticity properties of bone are rather complex and should therefore not be characterized as entirely isotropic.

The implicit assumption that tissue anisotropy has a negligible effect on the elastic properties of cancellous bone has been tested in micro-FE models. The insufficient correlation between predicted Young's moduli or Poisson's ratio and experimental results however did not support the assumption of isotropy. ${ }^{90}$ The recognition that cancellous bone architecture and mechanics are intimately related, led to the understanding that at least some measure of architectural anisotropy is needed ${ }^{91} \mathrm{At}$ the same time the degree of anisotropy seems to decrease, and tends to a more 
isotropic behaviour after total hip replacement, particularly in the proximal femur. The reason for this is probably that bone microstructure and local stiffness tend to align with the stress principal directions. So while originally cancellous bone should be considered as anisotropic, this property changes through adaptations after THR. ${ }^{92}$

Furthermore the elasticity modulus of bone not only varies according to the type of bone, but also with age and the region in the skeleton. Cortical bone has a modulus of approximately 17,000 MPa. The modulus of trabecular bone however can vary from approximately $10 \mathrm{MPa}$ to $2,000 \mathrm{MPa}$, depending on the anatomic site and age. It has been demonstrated that the modulus $E$ of trabecular bone is related to its apparent density $\rho$ by a power-law relationship of the form $E=a+\rho b^{c}$, where $\mathrm{a}, \mathrm{b}$ and $\mathrm{c}$ are constants that depend on the architecture of the tissue. ${ }^{89}$ This illustrates that modulus $\mathrm{E}$ is, besides by bone density $\rho$, largely affected by the shape and orientation of trabecular bone. Important variables are the general connectivity of the trabeculae, their mean thickness and the mean spacing between them. In conclusion, the different and heterogeneous architectures that exist for trabecular bone result in a dynamic anisotropy of elastic properties, and therefore make it difficult to generalize about its properties in FE-equations.

\section{Muscle forces.}

Natural loading of the proximal femur is a complex of combined forces in different directions and changing magnitudes, caused by weightbearing and hip muscle forces. ${ }^{20,93}$ The effects of hip musculature on bone remodelling were not considered in early FE models, that consisted merely of simple, two-dimensional static loading protocols. In later two-dimensional models all included loading cases acted in the mid-frontal plane, thus excluding torsional components and muscle loads that acted out of this plane. ${ }^{24}$ In nowadays three-dimensional models there is still controversy over which muscle groups around the hip should be included in pre-clinical tests, in order to ensure an adequate representation of the in vivo loading of the reconstruction. ${ }^{94,95}$ Recent simulations confirmed that results of FE-models for periimplant remodelling are considerably different depending on the chosen force loading configurations. ${ }^{96,97}$ Many data on the role of muscle forces are available in the literature, but for the majority they are derived from mathematical models. Only some of them were validated by comparison of predicted mathematical estimates 


\section{Chapter 8}

derived from gait laboratory observations made in a patient with an instrumented hip implant, ${ }^{98,99}$ or comparison with in vitro strain gauge measurements performed on composite hip reconstructions. ${ }^{13}$

There is particularly no agreement on the issue if load-transfer to the bone is mainly generated by the hip joint force alone, or if hip muscles play an additional role, and if so whether this is confined to exclusively abductors, or also to the iliotibial tract, the adductors, the quadriceps femoris, the iliopsoas and the quadratus femoris. Furthermore there is no clear consensus on during which phase of the walking gait cycle (heel strike, mid stance, toe off) which muscles are active, and how their origin and insertion are positioned at that moment, in other words along which vector the muscle forces will act. ${ }^{98,100,101}$ Stolk found that for cemented THR besides the hip joint contact force, a loading configuration including abductor forces can realistically reproduce in vivo loading in FE testing, and that other muscle groups had relatively small effects. ${ }^{13}$ It was concluded that only including the abductors in the loading protocol of pre-clinical tests would be sufficient. This choice was in accordance with previous and later works. ${ }^{37,44,47,102}$ However others showed the effect of the iliotibial tract to be important for simulating the in vivo bone loading more accurately. ${ }^{103,104}$ In addition there is no consensus on how large the contribution of the muscle groups actually is in terms of percentage bodyweight and how this varies during the gait cycle. ${ }^{105,106}$ For the iliotibial tract values between $4 \%$ and $76 \%$ bodyweight are mentioned, depending on the way this muscle is modelled in the FE-analysis (as a tension band or otherwise). ${ }^{13,95,101,107,108}$ Furthermore, due to computational limitations, often only the effects of the proximal part of the muscles are modelled, excluding the forces of distal attachments, which may decrease the realistic value of the simulation. In conclusion there is still much debate about which muscle groups should be incorporated in normal hip loading simulations, and during which part of the gait cycle. Therefore it is unclear which amount of bone change can realistically be explained by this factor, and which part by the implant.

\section{Generalizability versus individuality.}

FE-models of the femur are nowadays based on the bony dimensions taken from CTanalysis of one chosen cadaver femur or a reconstructed mean of several femurs, mostly elected from a database of femurs on the consideration that it/they approache(s) 
the average closely. ${ }^{13}$ But from microfinite element models of healthy and osteoporotic human femora it was demonstrated that strain levels in the osteoporotic bone were much higher and less uniformly distributed than those in the healthy one. ${ }^{109}$

Theoretically the relationship between bone changes and mechanical stimuli is typical for a particular case, and cannot be generalized to all hip reconstructions. It has been demonstrated that results of FE-simulations vary strongly dependent on chosen initial bone quality, cortical and cancellous bone modulus, subject-specific femoral geometry, initial implant positioning, and patient-specific loading conditions. Biological properties, and the effect of internal and external factors influencing them, may vary so much between individuals, that the outcome of FE models to study them will be extremely sensitive for these subject dependent variations. Therefore for FE studies to be truly predictive, patient-specific modelling, creating individual meshes, is essential. This will generate individually calculated stress distributions, and hence determine individual instead of generalized changes in bone mineral density. ${ }^{85,110}$ Therefore it is uncertain if an intrinsically simplified model, based on several assumptions, can predict quantitative changes for individual cases or merely indicate a qualitative trend. Attempts have been made to make predictions of migration of cemented stems in individually designed computational models, and in this indirect way predict implant failure. In the process, simulations were created for the cement creep, fatigue damage, and long term loading equivalents. Although this may result in conclusions about migration risk in the individual case, it will not provide information on the loosening risk of an implant in a broader population. ${ }^{111}$ Retrospective validations in well-described cases do not guarantee the value of the model for prospective predictions of new hip designs in a wide variety of femoral anatomies, with different initial bone properties, and under different and changing loading conditions. The value of future simulations may be in subject-specific modelling of geometry and loading conditions which may provide us with more accurate input for the analysis of bone stresses after total hip replacement. This could prove clinically useful in supporting surgeons to optimize the preoperative plan for the individual patient.

\section{Conclusion and suggestions for improvement}

Over the years the FE-method for pre-clinical testing and optimising of orthopaedic hip implants has become a useful tool for analysis of implant behaviour and 


\section{Chapter 8}

remodelling of the periprosthetic bone. This is due to validation of the technique and verification of its predictions through methods more and more approaching in vivo circumstances; coming from in vitro measurements on artificial implant-femur composites, through animal experiments, human retrievals and ultimately in vivo assessment of related outcome variables (BMD). In recent studies high correlations were found between computer calculations of strains and stresses in implant, bone and interfaces, and the end results of adaptive bone remodelling. This knowledge was retrospectively used to further adapt the technique.

In physics and engineering the FE-technique was successful, due to the application of clear guidelines and to the fact that only physical materials with stable material properties had to be considered. In mechanobiology the properties of living dynamic tissues may inherently be too complex to be correctly represented in physical quantities. Their behaviour is variable, changes in time and depends on patient-specific characteristics. The complexity of these biological processes has made it clear that attempts to represent them in mathematical models is based on a series of abstractions and assumptions, making the FE-simulations per definition less realistic. Furthermore the lack of uniformity between FE studies up to date, and the absence of validation with real prospective patient series, illustrates the many questions that still remain unsolved. Because of dynamic changes so characteristic for living tissues, accurate predictions inherently may not be possible, and FE models should not be guiding if the clinical consequence of being incorrect is too riskful.

Considering the completely mechanical character of contemporary models and the exclusively mechanical simulations of the failure mechanisms held responsible for limited survival, we probably cannot predict failure of total hip replacements. Strong recommendations for or against the use of new orthopaedic implants, only based on the results of current FE simulations, should therefore be considered with care. Although there is growing insight in some failure mechanisms in which mainly material properties are involved (i.e. cement damage accumulation), not all failure scenarios of total hip replacements are well understood, let alone well incorporated in the computer models (i.e. the role of debonding, the effect and behaviour of a fibrous tissue interface during micro-instability, the role of wear products, the effects of normal versus excessive interface loading, and the direct and indirect influence of these factors on bone biology). 
Furthermore the role of biological variables (like -stem- cell differentiation, the role of growth factors, BMP's and cytokines, and cell mobility, activity and decay of osteoblasts, osteocytes and osteoclasts) in the process of bone apposition and resorption, is dependent of many factors (hormonal, genetic, metabolic and environmental). This needs further study to improve translation into mathematical equations.

Improvements can be realised by generating FE meshes of higher quality. Particularly the extraction of FE models from high-resolution computed datasets (CT or MRI), like the modelling of the cortical shell from 2D or 3D digitised geometrical contours, and the trabecular bone from voxel based information on bone density, contains some challenging steps. A multi level refinement is necessary to increase and resample the number of elements. This will create high density meshes that allow more detailed translation of anatomical characteristics and physiological and biomechanical properties. These models have to be validated to clinical data, and retrospective validation from experimental studies should be replaced by prospective trials to really asses their predictive value.

A next step may be to better define an ingrowth model for uncemented implants. Interface bonding, mesenchymal cell migration and tissue differentiation should be better translated into mechanical equations. The relationship between interface micromotions and the threshold values that determine osseointegration or fibrous fixation, have to be more accurately analysed. Emphasis must therefore be on models that describe factors that influence differentiation to either osteoblasts, fibroblasts or chondroblasts, and their translation in time dependent properties of the elements of the FE mesh. In this way it should be able to calculate the effects on bone and implant fixation as a result of this adaptive remodelling. Assumptions on material and bone properties that remain necessary for the translation into biomechanical quantities, must be validated with clinically relevant biological values that can accurately be assessed. Otherwise it will not be possible to determine if the numerical model predicts the physical phenomenon it was designed to replicate, and if predictions concerning this phenomenon are indeed in line with in vivo results.

In conclusion, growing knowledge has become available on the links between mechanical stimuli, material and coating properties, bone properties and (normal and pathological) bone biology. However further research concerning these issues 


\section{Chapter 8}

is necessary to fully understand and predict implant failure. Then it may be possible to influence clinical performance of existing and new implants with designadaptations or drugs that can influence bone metabolism, in a more rationale way, and prevent the disastrous complication of implant failure. Currently the value of the technique is mainly in individually computational simulations, with personalized and not generalized predictions on implant performance. To improve the accuracy with which computer simulations can predict physical phenomena around orthopaedic implants in larger patient groups, more complex models and prospective validations are indispensable through randomized clinical trials. For this a more intense collaboration between biomechanics and orthopaedic clinicians should be encouraged. Of course the reverse of this process will inevitably be an increase in computational costs. The balance between the potential improvements of the implant and the risk of design failure should be considered to determine if these costs are justified. 


\section{Application of finite element analysis in total hip design optimizations}

\section{REFERENCES}

1. Garellick G, Malchau H, Herberts $P$, et al. Life expectancy and cost utility after total hip replacement. Clin Orthop 1998;346:141-51.

2. Dormont B, Grignon M, Huber H. Health expenditure growth: reassessing the threat of aging. Health Econ 2006; 15:947-63.

3. Learmonth ID, Young C, Rorabeck C. The operation of the century: total hip replacement. Lancet 2007; 370:1508-19.

4. Massoud SN, Hunter JB, Holdsworth BJ, Wallace WA, Juliusson R. Early femoral loosening in one design of cemented hip replacement. J Bone Joint Surg [Br] 1997;79-B:603-8.

5. Howie DW, Middleton RG, Costi K. Loosening of matt and polished cemented femoral stems. J Bone Joint Surg [Br] 1998; 80: 573-6.

6. Hodge W, Harman M, Fulford B, Dorrance L, Banks S. Early failure of cemented femoral stems in total hip arthroplasty. Transactions of the Combined Meeting of the Orthopaedic Research Societies 2001, Rhodos, Greece.

7. Sylvain GM, Kassab S, Coutts R, Santore R. Early failure of a roughened surface, precoated femoral component in total hip arthroplasty. J Arthroplasty 2001;16:141-8.

8. Cohen D. Revision rates for metal on metal hip joints are double that of other materials. BMJ 2011;343:d5977.

9. Langton DJ, Jameson SS, Joyce TJ, Gandhi JN, Sidaginamale R, Mereddy P, Lord J, Nargol AV. Accelerating failure rate of the ASR total hip replacement. JBone Joint Surg [Br] 2011;93B:1011-6.

10. Steiger de RN, Hang JR, Miller LN, Graves SE, Davidson DC. Five-year results of the ASR XL acetabular system and the ASR hip resurfacing system: an analysis from the Australian Orthopaedic Association National Joint Replacement Registry. J Bone Joint Surg [Am] 2011;93-A:2287-93.

11. Smith AJ, Dieppe P, Vernon K, Porter M, Blom AW. Failure rates of stemmed metal-on-metal hip replacements: analysis of the National Joint Registry of England and Wales. Lancet 2012;379:1199-204.

12. Bulstrode CJ, Murray DW, Carr AJ, Pynsent PB, Carter SR. Designer hips. BMJ 1993;306(6880):732-3.

13. Stolk J. A computerized pre-clinical test for cemented hip prostheses based on finite element techniques. Thesis, University of Nijmegen, The Netherlands 2002. 


\section{Chapter 8}

14. Wolff, J. Das Gesetz der Transformation der Knochen. Hirschwald, Berlin, 1892 (translated as: The law of bone remodelling. Springer-Verlag, Berlin, 1986).

15. Huiskes $\mathbf{R}$, Weinans $\mathrm{H}$, van Rietbergen $\mathbf{B}$. The relationship between stress shielding and bone resorption around total hip stems and the effects of flexible materials. Clin Orthop 1992;274:124-34.

16. Huiskes R, van Rietbergen B. Preclinical testing of total hip stems. The effects of coating placement. Clin Orthop 1995;319:64-76.

17. Rietbergen van B, Huiskes R, Weinans H, Sumner DR, Turner TM, Galante JO. The mechanism of bone remodeling and resorption around press-fitted THA stems. J Biomech 1993;26:369-82.

18. Weinans H, Huiskes R, van Rietbergen B, Sumner DR, Turner TM, Galante JO. Adaptive bone remodeling around bonded noncemented total hip arthroplasty: a comparison between animal experiments and computer simulation. J Orthop Res 1993;11:500-13.

19. Sumner DR, Turner TM, Urban RM, Galante JO. Remodelling and ingrowth of bone at two years in a canine cementless total hip arthroplasty model. J Bone Joint Surg [Am] 1992;74A:239-50.

20. Carter DR, Hayes WC. The behaviour of bone as a two-phase porous structure. J Bone Joint Surg [Am] 1977;59-A:954-62.

21. Davis JR. Handbook of materials for medical devices. ASM International, Materials Park, Ohio 2003.

22. Weinans H. Mechanically induced bone adaptations around orthopaedic implants. Thesis, University of Nijmegen, The Netherlands 1992.

23. Rietbergen van B, Odgaard A, Kabel J, Huiskes R. Relationships between bone morphology and bone elastic properties can be accurately quantified using high-resolution computer reconstructions. J Orthop Res 1998;16:23-8.

24. Bergmann G, Siraky J, Rohlmann A, Koelbel R. A comparison of hip joint forces in sheep, dog and man. J Biomech 1984;12:907-21.

25. Prendergast PJ, Huiskes R, Søballe K. Biophysical stimuli on cells during tissue differentiation at implant interfaces. J Biomech 1997;30:539-48.

26. Lacroix D, Prendergast PJ. A mechano-regulation model for tissue differentiation during fracture healing: analysis of gap size and loading. J Biomech 2002;35:1163-71.

27. Andreykiv A, Prendergast PJ, van Keulen F, Swieszkowski W, Rozing PM. Bone ingrowth simulation for a concept glenoid component design. J Biomech 2005;38:1023-33. 
28. Kelly DJ, Prendergast PJ. Mechano-regulation of stem cell differentiation and tissue regeneration in osteochondral defects. J Biomech 2005;38:1413-22.

29. Carter DR, Orr TE, Fyhrie DP. Relationships between loading history and femoral cancellous bone architecture. J Biomech 1989;22:231-44.

30. Turner TM, Sumner DR, Urban RM, Rivero MD, Galante JO. A comparative study of porous coatings in a weight-bearing total hip-arthroplasty model. J Bone Joint Surg [Am] 1986;68A:1396-1409.

31. Sumner DR, Galante JO. Bone ingrowth. In: McCollister Evarts, ed. Surgery of the musculoskeletal system. Vol. I Churchill Livingstone, NY, 1990.

32. Beaupré GS, Orr TE, Carter DR. An approach for time-dependent bone remodeling and remodeling-application: A preliminary remodeling simulation. J Orthop Res 1990;8:662-70.

33. Orr TE, Beaupré GS, Carter DR, Churman DJ. Computer predictions of bone-remodeling around porous-coated implants. J Arthroplasty 1990;5:191-200.

34. Huiskes R, Weinans H, van Rietbergen B, Sumner DR, Turner TM, Galante JO. Validation of strain-adaptive bone-remodeling analysis to predict bone morphology around noncemented THA. Trans. $37^{\text {th }}$ ORS, Anaheim, CA, USA, 1991;105.

35. Huiskes R, Weinans H, Grootenboer HJ, Dalstra M, Fudala B, Sloof TJ. Adaptive boneremodeling theory applied to prosthetic-design analysis. J Biomech 1987;20:1135-50.

36. Huiskes R, Weinans $\mathbf{H}$, Dalstra M. Adaptive bone remodeling and biomechanical design considerations for noncemented total hip arthroplasty. Orthopedics 1989;12:1255-67.

37. Rietbergen van B, Huiskes R. Load transfer and stress shielding of the hydroxyapatite ABG hip. A study of stem length and proximal fixation. J Arthroplasty 2001;16:55-63.

38. Wahner HW, Dunn WL, Riggs BL. Assessment of bone mineral. J Nucl Med 1984;25:1134-41.

39. Finsen V, Anda S. Accuracy of visually estimated bone mineralization in routine radiographs of the lower extremity. Skeletal Radiol 1988;17:270-5.

40. Robertson DD, Minzer CM, Weissman BN, Ewald FC, LeBoff M, Spector M. Distal loss of femoral bone following total knee arthroplasty. J Bone Joint Surg [Am] 1994;76-A:66-76.

41. West JD, Mayor MB, Collier JP. Potential errors inherent in quantitative densitometric analysis of orthopaedic radiographs. A study after total hip arthroplasties. J Bone Joint Surg [Am] 1987;69-A:58-64.

42. Bonnick SL. Bone densitometry in clinical practice. Application and interpretation. Second edition. Humana Press Inc., Totowa, New Jersey, 2004. 


\section{Chapter 8}

43. Skinner HB, Kilgus DJ, Keyak J, Shimaoka EE, Kim AS, Tipton JS. Correlation of computed finite element stresses to bone density after remodelling around cementless femoral implants. Clin Orthop 1994;305:178-89.

44. Kerner J, Huiskes R, van Lenthe GH, Weinans H, van Rietbergen B, Engh CA, Amis AA. Correlation between pre-operative periprosthetic BMD and post-operative bone loss in THA can be explained by strain-adaptive remodelling. JBiomech 1999;32:695-703.

45. Rahmy AIA, Gosens T, Blake GM, Tonino A, Fogelman I. Periprosthetic bone remodelling of two types of uncemented femoral implant with proximal hydroxyapatite coating: a 3-year follow-up study addressing the influence of prosthesis design and preoperative bone density on periprosthetic bone loss. Osteoporos Int 2004;15:281-9.

46. Panisello JJ, Canales V, Herrero L, Mateo J, Caballero MJ. Changes in periprosthetic bone remodelling after redesigning an anatomic cementless stem. Int Orthop 2008;/an 11 (Epub ahead of print).

47. Herrera A, Panisello JJ, Ibarz E, Cegoñino J, Puértolas JA, Gracia L. Long-term study of bone remodelling after femoral stem: A comparison between dexa and finite element simulation. J Biomech 2007;40:3615-25.

48. Tarala M, Janssen D, Verdonschot N. Balancing incompatible endoprosthetic design goals: a combined ingrowth and bone remodeling simulation. Med Eng Phys 2011;33(3):374-380.

49. Boyle C, Kim IY. Three-dimensional micro-level computational study of Wolff's law via trabecular bone remodeling in the human proximal femur using design space topology optimization. J Biomech 2011a;44:935-42.

50. Boyle C, Kim IY. Comparison of different hip prosthesis shapes considering micro-level bone remodeling and stress-shielding criteria using three-dimensional design space topology optimization. J Biomech 2011b;44:1722-8.

51. Janssen D, Aquarius R, Stolk J, Verdonschot N. Finite-element analysis of failure of the Capital Hip designs. J Bone Joint Surg [Br] 2005;87-B:1561-7.

52. Lengsfeld M, Günther D, Pressel T, Leppek R, Schmitt J, Griss P. Validation data for periprosthetic bone remodelling theories. J Biomech 2002;35:1553-64.

53. Rohlmann A, Cheal EJ, Hayes WC, Bergmann G. A nonlinear finite element analysis of interface conditions in porous coated hip endoprostheses. J Biomech 1987;21:605-11.

54. Cook SD, Barrack RL, Thomas KA, Haddad RJ, Jr. Quantitative analysis of tissue growth into human porous total hip components. J Arthroplasty 1988;3:249-62. 


\section{Application of finite element analysis in total hip design optimizations}

55. Schimmel JW, Huiskes R. The primary fit of the Lord cementless total hip. Acta Orthop Scand 1988;59:638-42.

56. Bauer TW, Geesink RGT, Zimmerman R, McMahon JT. Hydroxyapatite-coated femoral stems. Histological analysis of components retrieved at autopsy. J Bone Joint Surg [Am] 1991;73-A:1439-52.

57. Tonino AJ, Therin M, Doyle C. Hydroxyapatite-coated femoral stems. Histology and histomorphometry around five components retrieved at post mortem. J Bone Joint Surg [Br] 1999;81-B:148-54.

58. Coathup MJ, Blunn GW, Flynn N, Williams C, Thomas NP. A comparison of bone remodelling around hydroxyapatite-coated, porous-coated and grit-blasted hip replacements retrieved at post-mortem. J Bone Joint Surg [Br] 2001;83-B:118-23.

59. Porter AE, Taak P, Hobbs LW, Coathup MJ, Blunn GW, Spector M. Bone bonding to hydroxyapatite and titanium surfaces on femoral stems retrieved from human subjects at autopsy. Biomaterials 2004;25:5199-208.

60. Broeke ten RHM, Alves A, Baumann A, Arts JJC, Geesink RGT. Bone reaction to a biomimetic third-generation coating and new surface treatment for the Symax hip stem. J Bone Joint Surg [Br] 2011;93-B:760-8.

61. Broeke ten RHM, Tarala M, Arts JJC, Janssen DW, Verdonschot N, Geesink RGT. Improving peri-prosthetic bone adaptation around cementless hip stems; a clinical and finite element study. Med Eng Phys 2013, http://dx.doi.org/10.1016/j.medengphy.2013.12.006.

62. Orlik J, Zhurov A, Middleton J. On the secondary stability of coated cementless hip replacement: parameters that affected interface strength. Med Eng Phys 2003;25:825-31.

63. Folgado J, Fernandes PR, Jacobs CR, Pellegrini VD Jr. Influence of femoral stem geometry, material and extent of porous coating on bone ingrowth and atrophy in cementless total hip arthroplasty: an iterative finite element model. Comput Methods Biomech Biomed Engin 2009;12:135-45.

64. Guérin G, Ambard D, Swider P. Cells, growth factors and bioactive surface propereties in a mechanobiological model of implant healing. J Biomech 2009;42:2555-61.

65. Huiskes R, van Driel WD, Prendergast PJ, Søballe K. A biomechanical regulatory model for periprosthetic fibrous-tissue differentiation. J Mater Sci Mater Med 1997;8:785-8.

66. Geris L, van Oosterwyck H, Vander Sloten J, Duyck J, Naert I. Assessment of mechanobiological models for the numerical simulation of tissue differentiation around immediately loaded implants. Comput Methods Biomech Biomed Engin 2003;6:277-88. 


\section{Chapter 8}

67. Verdonschot N, Tanck E, Huiskes R. Effects of prosthesis surface roughness on the failure process of cemented hip implants after stem-cement debonding. J Biomed Mater Res 1998;42:554-9.

68. Sporer SM, Callaghan JJ, Olejniczak JP, Goetz DD, Johnston RC. The effects of surface roughness and polymethylmethacrylate precoating on the radiographic and clinical results of the lowa hip prosthesis. A study of patients less than fifty years old. J Bone Joint Surg [Am] 1999; 81-A:481-92.

69. Collis DK, Mohler CG. Comparison of clinical outcomes in total hip arthroplasty using rough and polished cemented stems with essentially the same geometry. J Bone Joint Surg [Am] 2002;84-A:586-92.

70. Waide V, Cristofolini L, Stolk J, Verdonschot N, Boogaard GJ, Toni A. Modelling the fibrous tissue layer in cemented hip replacements: experimental and finite element methods. J Biomech 2004;37:13-26.

71. Lewis G, Duggineni R. Finite element analysis of a three-dimensional model of a proximal femur-cemented femoral THJR component construct: influence of assigned interface conditions on stain energy density. Biomed Mater Eng 2006;16:319-27.

72. Nuño N, Groppetti R, Senin N. Static coefficient of friction between stainless steel and PMMA used in cemented hip and knee implants. Clin Biomech (Bristol Avon) 2006;21:956-62.

73. Hori RY. Investigation of the bone-prosthesis interface following total joint replacement. Thesis, North Western University, Chicago, Illinois, USA 1981.

74. Huiskes R. The differing stress patterns of press-fit, ingrown and cemented femoral stems. Clin Orthop 1990;261:27-38.

75. Stolk J, Verdonschot N, Cristofolini L, Toni A, Huiskes R. Finite element and experimental models of cemented hip joint reconstructions can produce similar bone and cement strains in pre-clinical tests. J Biomech 2002;35:499-510.

76. Janssen DW. Macro- and micro-mechanics of cemented total hip arthroplasty. Thesis, University of Nijmegen, The Netherlands 2009.

77. Weinans H, Huiskes R, Grootenboer HJ. Convergence and uniqueness of adaptive boneremodeling. Trans. $35^{\text {th }}$ ORS, Las Vegas, USA, 1989:310.

78. Sychterz CJ, Engh CA. The influence of clinical factors on periprosthetic bone remodelling. Clin Orthop 1996;322:285-92.

79. Kobayashi S, Saito N, Horiuchi H, lorio R, Takaoka K. Poor bone quality or hip structure as risk factors affecting survival of total-hip arthroplasty. Lancet 2000;355:1499-504. 
80. Venesmaa PK, Kröger HP, Miettinen HJ, Jurvelin JS, Suomalainen OT, Alhava EM. Monitoring of periprosthetic BMD after uncemented total hip arthroplasty with dual-energy X-ray absorptiometry - a 3-year follow-up study. J Bone Miner Res 2001;16:1056-61.

81. Glowacki J, Hurwitz S, Thornhill TS, Kelly M, LeBoff MS. Osteoporosis and vitamin-D deficiency among postmenopausal women with osteoarthritis undergoing total hip arthroplasty. J Bone Joint Surg [Am] 2003;85-A:2371-7.

82. Ohta H, Kobayashi S, Saito N, Nawata M, Horiuchi H, Takaoka K. Sequential changes in periprosthetic bone mineral density following total hip arthroplasty: a 3-year follow-up. J Bone Miner Metab 2003;21:229-33.

83. Muller S, Irgens F, Aamodt A. A quantitative and qualitative analysis of bone remodelling around custom uncemented femoral stems: a five-year DEXA follow-up. Clin Biomech $2005 ; 20: 277-82$.

84. Nixon M, Taylor G, Sheldon P, Iqbal SJ, Harper W. Does bone quality predict loosening of cemented total hip replacements? J Bone Joint Surg [Br] 2007;89-B:1303-8.

85. Wong AS, New AM, Isaacs G, Taylor M. Effect of bone material properties on the initial stability of a cementless hip stem: a finite element study. Proc Inst Mech Eng H 2005;219:265-75.

86. Martin RB. The effects of geometric feedback in the development of osteoporosis. J Biomech 1972;5:447-55.

87. Reilly DT, Burstein AH. The elastic and ultimate properties of compact bone tissue. J Biomech $1975 ; 8: 393-405$.

88. Currey JD. The mechanical adaptations of bones. Princeton University Press, Princeton, NJ, 1984.

89. Keaveny TM, Hayes WC. A 20-year perspective on the mechanical properties of trabecular bone. J Biomech Eng 1993;115:534-42.

90. Kabel J, van Rietbergen B, Dalstra M, Odgaard A, Huiskes R. The role of an effective isotropic tissue modulus in the elastic properties of cancellous bone. J Biomech 1999;32:673-80.

91. Odgaard A, Kabel J, van Rietbergen B, Dalstra M, Huiskes R. Fabric and elastic principal directions of cancellous bone are closely related. J Biomech 1997;30:487-95.

92. Doblaré M, Garcia JM. Application of an anisotropic bone remodelling model based on a damage-repair theory to the analysis of the proximal femur before and after total hip replacement. J Biomech 2001;34:1157-70.

93. Heller MO, Bergmann G, Deuretzbacher G, Dürselen L, et al. Musculo-skeletal loading conditions at the hip during walking and stair climbing. J Biomech 2001;34:883-93. 


\section{Chapter 8}

94. Colgan D, Trench P, Slemon D, McTague D, Finlay JB, O'Donnell P, Little EG. A review of joint and muscle load simulation relevant to in-vitro stress analysis of the hip. Strain 1994;30:47-60.

95. Cristofolini L. A critical analysis of stress shielding evaluation of hip prostheses. Crit Rev Biomed Eng 1997;25:409-83.

96. Bitsakos C, Kerner J, Fisher I, Amis AA. The effect of muscle loading on the simulation of bone remodelling in the proximal femur. J Biomech 2005;38:133-9.

97. Behrens BA, Nolte I, Wefstaedt P, Stukenborg-Colsman C, Bouguecha A. Numerical investigations on the strain-adaptive bone remodelling in the periprosthetic femur: influence of the boundary conditions. Biomed Eng Online 2009;8:7.

98. Brand RA, Pedersen DR, Davy DT, Kotzar GM, Heiple KG, Goldberg VM. Comparison of hip force calculations and measurements in the same patient. J Arthroplasty 1994;9:45-51.

99. Heller M, Bergmann G, Kassi J, Claes L, Haas N, Duda GN. Determination of muscle loading at the hip joint for use in pre-clinical testing. J Biomech 2005;38:1155-63.

100. Brand RA, Pedersen DR, Friederich JA. The sensitivity of muscle force predictions to changes in physiologic cross-sectional area. J Biomech 1986;19:589-96.

101. Duda GN. Influence of muscle forces on the internal loads in the femur during gait. Thesis, Shaker Verlag, Aachen, Germany 1996.

102. Cristofolini L, Viceconti M, Toni A, Giunti A. Influence of thigh muscles on the axial strains in a proximal femur during early stance in gait. J Biomech 1995;28:617-24.

103. Ling RSM, O'Connor JJ, Lu TW, Lee AJC. Muscular activity and the biomechanics of the hip. Hip International 1996;6:91-105.

104. Duda GN, Heller M, Albinger J, Schulz O, Schneider E, Claes L. Influence of muscle forces on femoral strain distribution. J Biomech 1998;31:841-6.

105. McLeish RD, Charnley J. Abduction forces in the one-legged stance. J Biomech 1970;3:191-209.

106. Jacob HAC, Huggler AH, Rüttiman B. In-vivo investigations on the mechanical function of the tractus iliotibialis. In: Huiskes R, Van Campen D, De Wijn J eds. Biomechanics: Principles and Applications. Martinus Nijhoff Publishers, The Hague 1982:161-7.

107. Rybicki EF, Simonen FA, Weis EB Jr. On the mathematical analysis of stress in the human femur. J Biomech 1972; 5:203-15.

108. Finlay JB, Chess DG, Hardie WR, Rorabeck CH, Bourne RB. An evaluation of three loading configurations for the in vivo testing of femoral strains in total hip arthroplasty. J Orthop Res 1991;9:749-59. 
109. Rietbergen van B, Huiskes R, Eckstein F, Rüegsegger P. Trabecular bone tissue strains in the healthy and osteoporotic human femur. J Bone Miner Res 2003;18:1781-8.

110. Jonkers I, Sauwen N, Lenaerts G, Mulier M, Van der Perre G, Jaecques S. Relation between subject-specific hip loading, stress distribution in the proximal femur and bone mineral density changes after total hip replacement. J Biomech 2008;41:3405-13.

111. Lennon AB, Britton JR, MacNiocaill RF, Byrne DP, Kenny PJ, Prendergast PJ. Predicting revision risk for aseptic loosening of femoral components in total hip arthroplasty in individual patients - a finite element study. J Orthop Res 2007;25:779-88. 

Chapter 9 


\section{Summary and Conclusions}

Total hip arthroplasty has brought both patients and society an extremely successful and cost-effective treatment for degenerative, traumatic and congenital destructions of the hip joint. Consequently many manufacturers and designers have not been able to restrain themselves from the introduction of a continuous flow of new designs. Too many of them failed, mainly due to a hasty and widespread introduction onto the market, driven by a sometimes opportunistic motivation without proper preclinical research and sound consideration concerning the need for yet another implant. This left the orthopaedic community with a tremendous loss of good will, a burden of legal claims, and the need for a reorientation on the original values of scientific integrity and patient safety. Rules for a sound pathway for stepwise introduction of new prostheses were redefined and gradually adopted, as well as the choice of diagnostic and imaging modalities for monitoring the performance of innovative designs.

The success of both cemented and uncemented hip stems is related to their mechanical stability in, and sustainable fixation to the periprosthetic bone. In this way the longevity of the prosthesis may possibly be predicted by acquiring direct and indirect information on these implant-bone interface properties. The most valuable tools to study them currently are functional hip scores, patient reported outcome measures, conventional radiography, scintigraphy, densitometry, histology and migration analysis. In this thesis we have presented several studies in which we tried to evaluate the additional value of these techniques, their correlation with clinical change, and their contribution to early recognition of (ultimate) implant failure. Furthermore it was attempted to validate the role of computerized simulations of implant driven strain adaptive bone remodelling, as a guideline for adaptations in implant design.

In Chapter 1 several scoring systems, both surgeon dependent functional scores and patient dependent outcome measures, were evaluated for their capacity to detect clinical change and predict prosthetic survival. Because of the strong variability within patient populations, and the subjectivity in surgeon and patient scoring, the necessity to follow-up a vast number of patients for a substantial 


\section{Chapter 9}

period, with scores that are characterized by ceiling effects, sensitivity is low for identifying factors that adversely affect implant fixation. Consequently these tools are not suitable to detect inferior designs in an early stage. High scores on PROM's have not shown to correlate well with good survival either, and probably score high on issues that may even be inversely related to good long term performance. Lack of sensitivity and specificity, and the trend to be influenced by ageing and changing co-morbidities, make them unfit for this purpose.

For the same reason hip registries are a very blunt instrument that play an important role in long term post market surveillance, but are insensitive for early discrimination between designs.

Postoperative radiography can only in some cases provide information on bone changes and implant fixation that refer to or are even pathognomonic for (a)septic loosening. For most radiographic phenomena however, clinical correlation is low and implant loosening cannot be reliably predicted from them. In addition the meaning and relevance of these radiographic signs should be interpreted differently dependent on the design philosophy of the implant. Finally the interpretation of $\mathrm{x}$-rays is subject to intra- and interobserver variability, and to precision issues making the instrument too insensitive to detect or quantify discriminative phenomena.

Bone scintigraphy also suffers from limited sensitivity and specificity in the diagnostic assessment of phenomena known to correlate with early failure. Furthermore bone physiology around implants with new surface and coating may behave differently, without correlating to clinical performance. Consequently the technique will prove unreliable for judging long-term effects of new implant features.

Bone densitometry as a tool for assessment of periprosthetic bone remodelling has shown good accuracy and precision, but changes in postoperative BMD do not correlate clearly to clinical results or long-term survival. Only extreme bone loss will obviously be related to compromised implant fixation and loosening risk, while 
on the other hand stable bone density appeared to correlate with well fixed and well performing stems. Although DEXA is a sensitive diagnostic tool, discrete early bone changes alone have not proven to be predictive for long-term performance and can therefore not recognize superiority of one implant over the other.

Currently the two instruments that are supposed to correlate with clinical outcome and (self) proclaim to have predictive capacity for long-term performance and survival, and are supposed to have discriminative power between implants, are finite element simulations and migration assessment with radiostereometry. However the number of studies in which this has been established is only small and mostly retrospective in nature. Real prospective confirmation of predicted outcome in long-term follow-up has hardly been presented. Therefore blindly relying on early RSA results seems too naive, even though renowned RSA researchers have expressed an almost absolute believe in the technique and it's capacity to determine if a new implant should or should no longer be used, based only on migration characteristics during the first two years after implantation. It has become clear however that migration patterns vary between stem designs, and may not uniformly correlate with long-term clinical results.

In Chapter 2 we have described the results of a prospective randomized comparative study between the cemented $\mathrm{SHP}^{\circledR}$ and Omnifit ${ }^{\circledR}$ hip stem. The study was performed to evaluate if preclinical considerations on implant optimization and early migration patterns could predict bone remodelling, clinical outcome and implant survival. From an earlier RSA study on the SHP ${ }^{\circledR}$ stem it was predicted that due to the combination of the rough surface of the stem and early debonding and migration, the implant would cause abrasive wear and osteolysis, and higher failure rates than for most used cemented stems. In addition the numerical optimization of the stem shape was aiming at minimizing periprosthetic stresses, from which lower stress transfer to the bone with again lower BMD could be expected. However the 2-year DEXA study showed higher BMD in the proximal femur for the $\mathrm{SHP}^{\circledR}$, migration of only 1 stem on conventional radiography, $100 \%$ survival at minimum 11 year follow-up and only 1 radiographic loosening for both the $\mathrm{SHP}^{\circledR}$ and Omnifit ${ }^{\circledR}$. Furthermore clinical scores were significantly better for 


\section{Chapter 9}

the $\mathrm{SHP}^{\circledR}$ during the entire follow-up. It was concluded that predicted inferior outcome of the $\mathrm{SHP}^{\circledR}$, both in terms of clinical performance, survival and bone remodelling, could not be validated in this long-term study. This indicates the importance of clinical trials to determine the value of these 'predictive' tools, and validate their use in early quality assessment of new prostheses.

In the $\mathrm{SHP}^{\circledR}$ versus Omnifit ${ }^{\circledR}$ study it was decided to assess bone remodelling in a standardized perimeter outside the cement mantle, in an attempt to reveal the real bone changes and prevent the masking effect of the cement. To illustrate this, the influence of inclusion of the cement mantle in the region of interest (ROI) on periprosthetic BMD measurement using DEXA was evaluated in Chapter 3. The study was performed to determine the artefactual increase in BMD while including the cement layer, which might erroneously suggest less bone loss after cemented total hip arthroplasty. Using the data of the $\mathrm{SHP}^{\circledR}$ versus Omnifit ${ }^{\circledR}$ study (see Chapter 2), BMD was assessed within a $3 \mathrm{~mm}$ offset zone including the cement mantle ('BMD-cement'), secondly in the perimeter outside the offset, including only bone ('BMD-bone'), and thirdly in the entire ROI including both the cement layer and bone ('BMD-total'). It was observed that including the cement mantle consistently resulted in significantly higher $\mathrm{BMD}$, suggesting better bone preservation. However this result should be ascribed to the density effect of the radiopaque cement, but it does not realistically represent the implant driven adaptive bone remodelling. Therefore we recommend automated and precise exclusion of the cement mantle for which tools are available in the densitometry software.

In Chapter 4 we shifted to uncemented total hip arthroplasty and used conventional radiography and functional scores to investigate the effect of a hydroxyapatite coating on particle wear driven periprosthetic osteolysis in a young and active patient group. In addition it was evaluated if hip scores and radiographic results correlated to the survival of the implant. It could be shown that although the higher activity level of these young patients could potentially lead to higher particle wear, the hydroxyapatite coating was able to seal the implant-bone interface, protect against osteolysis, and guarantee long-term implant fixation. Particularly the presence of spotwelds and the absence of radiolucent and reactive 
lines in the HA-coated Gruen zones 1 and 7 confirmed sound osseointegration, and appeared to have predictive value for persistent fixation, in other words absence of loosening in the long-term. This strong correlation was illustrated with survival of the stem in $98.5 \%$ and the cup in $95.5 \%$ of cases at minimum 10 year follow-up. We have learned that the more extensive osteolysis in de Lee-Charnley zone 2 of the acetabulum at longer follow-up, correlated strongly with inferior survival of this particular cup design and lead to relatively high revision rates. This initiated a change in cup design to prevent backside wear through a central gap.

Chapter 5 introduced the Symax TM hip stem that features an improved geometry and a more bioactive biomimetic hydroxyapatite coating on the proximal part of the stem (Bonit-HA ${ }^{\circledR}$ ), and a Dotize ${ }^{\circledR}$ surface treatment on the distal part. Histology, histomorphometry and scanning electron microscopy were applied to qualitatively and quantitatively assess the effect and behaviour of the new, electrochemically deposited Bonit-HA ${ }^{\circledR}$ coating and Dotize ${ }^{\circledR}$ surface treatment, on 4 retrieved Symax ${ }^{\mathrm{TM}}$ stems. Rapid and extensive osseointegration was seen around the HA-coated part of the stem. Bone-implant surface contact progressed from $26.5 \%$ at three weeks to $83.5 \%$ at 13 months, with increasing bone density per ROI from $24.6 \%$ at three weeks to $41.1 \%$ at 32 months. The coating appeared to remodel rapidly but without negative effect on bone-implant coupling. This deep and extensive ingrowth of bone into the open surface texture of the Symax ${ }^{\mathrm{TM}}$ stem, leads to optimal sealing of the bone-implant interface and stable bony anchorage. Based on the experience from stems with first and second generation plasmaspray HA coatings, persistent long-term osseointegration may be anticipated for this new design with predictable results in terms of survival.

The Dotize ${ }^{\circledR}$ surface treatment on the other hand could completely prevent bone apposition on the distal part of the stem. This combination guarantees an exclusive proximal stem ingrowth, contributing to an optimal proximal stress transfer to bone, which was expected to diminish stress shielding of the femur metaphysis. 


\section{Chapter 9}

This effect was confirmed in Chapter 6, where bone remodelling of the Symax ${ }^{\mathrm{TM}}$ stem was studied with DEXA, and compared to the Omnifit ${ }^{\circledR}$ stem in a 2 year randomized clinical trial. For a more valid comparison of remodelling around stems with different design, a modification of the Gruen zones as regions of interest was introduced, to allow for improved representation of implant effects on bone mineral density (BMD). Results showed consistently higher BMD values for the Symax ${ }^{\top M}$ stem, which difference became statistically significant in zone 7 from one year onward. This improved preservation of bone around the Symax ${ }^{\mathrm{TM}}$ stem, together with the enhanced osseointegration as proven with histological investigation, can be predictive for good long-term performance.

Finally we wanted to determine whether the finite element method has the potential of reliable preclinical simulation, and has valid predictive properties for anticipating in vivo clinical results. Therefore the remodelling study of chapter 6 was compared with a numerical simulation study in Chapter 7, to decide the accuracy of the finite element technique, and the value of this tool in the process of improving implants. DEXA measurements showed BMD-loss in Gruen zone 7 of $14 \%$ and $20 \%(P<0.05)$ for the Symax ${ }^{\mathrm{TM}}$ and Omnifit ${ }^{\circledR}$ stem respectively, while FE models predicted a $28 \%$ (Symax ${ }^{\mathrm{TM}}$ ) and $26 \%\left(\mathrm{Omnifit}^{\circledR}\right)$ bone loss. When the Dotize ${ }^{\circledR}$ surface treatment was not modeled in the simulation, the bone loss in Gruen zone 7 was even predicted to be $35 \%$. Although numerical simulation showed a trend of enhanced proximal bone loading by the Symax ${ }^{\mathrm{TM}}$ design, which was confirmed by the DEXA results, there was no quantitative match, implying that FE remodelling prediction was poorly correlated with clinical findings in larger patient groups, and is likely not suitable for accurate prediction of minor changes in load transfer patterns. This is probably due to incomplete assumptions concerning the biological and mechanical effects of the new coating and surface treatment, and to the incapacity of the FE technique to adequately translate dynamic interface variables into pure mechanical equations.

Summarizing it can be said that the phased innovation with the stepwise testing and evaluating procedure of new total hip prostheses, has provided the orthopaedic community undoubtedly with a protocol for a safer introduction of new designs. The 
trial and error method has proven to be irrational and intrinsically risky. The chance of being confronted with yet another orthopaedic disaster may be expected to be diminished following this adapted pathway. However the assumption of complete safety of any diagnostic modality to detect future failures in an early phase, is unrealistic and still unproven. Most techniques are too insensitive, indecisive and irrelevant to discriminate (small) improvements or potential failures. Even for RSA the link between the migration patterns and future loosening is not established for most implants. And the finite element translation of dynamic biologic processes at the interface between implant and bone is still too abstracted from reality, so that numerical simulations can represent natural physiology only to some extent.

Therefore the clinical value of RSA could benefit from a larger number of studies that should focus on recognizing aberrant migration patterns from the most used implants, and prospectively link them to clinical outcome and survival studies. For the finite element method, dynamic biochemical interface interactions have to be better understood and translated into mechanical algorithms, and subsequently validated with prospective clinical results.

Nevertheless at this stage we are still more or less in the dark, and quality assurance is dependent of the combined information from several available diagnostic techniques, instead of one decisive tool. These modalities play a role in different stages of the pre-clinical and clinical testing of the prosthesis (Fig. 1). Recent orthopaedic disasters have learned us once again that in the modern orthopaedic world there is no place for unsubstantiated believe in potential superiority of any new design. Orthopaedic surgeons are obliged to follow up any new implant with great scrutiny, consider 'studies' performed by manufacturers with professional suspicion, and feel personal responsibility for the patients that they include in any trial of a new implant or surgical technique. There is an important task for the national scientific orthopaedic societies to play the role of supervisor with surveillance of their members, to improve the professional standard and prevent further loss of goodwill. However this task should be balanced with the intrinsic drive for innovation that also justifies the existence of the very same scientific societies. 
Chapter 9

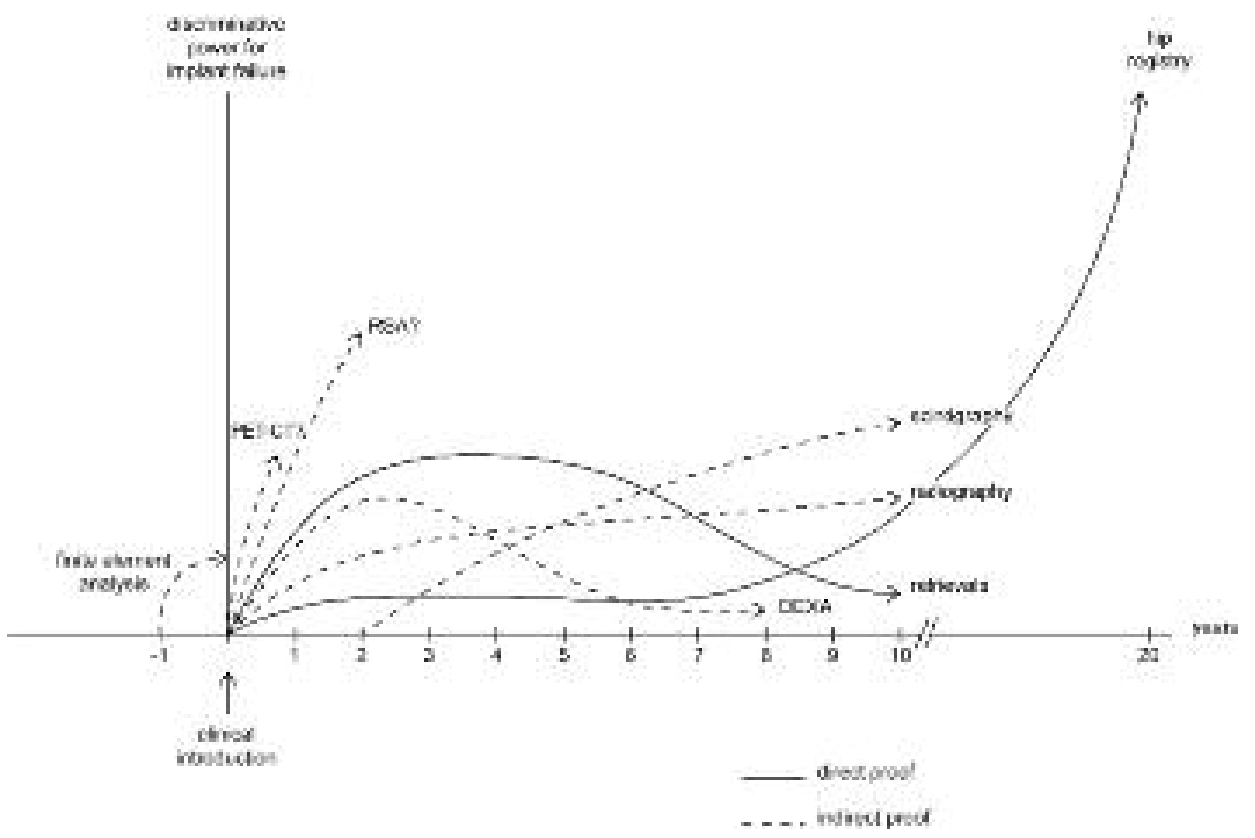

Fig. 1 
Summary and Conclusions 


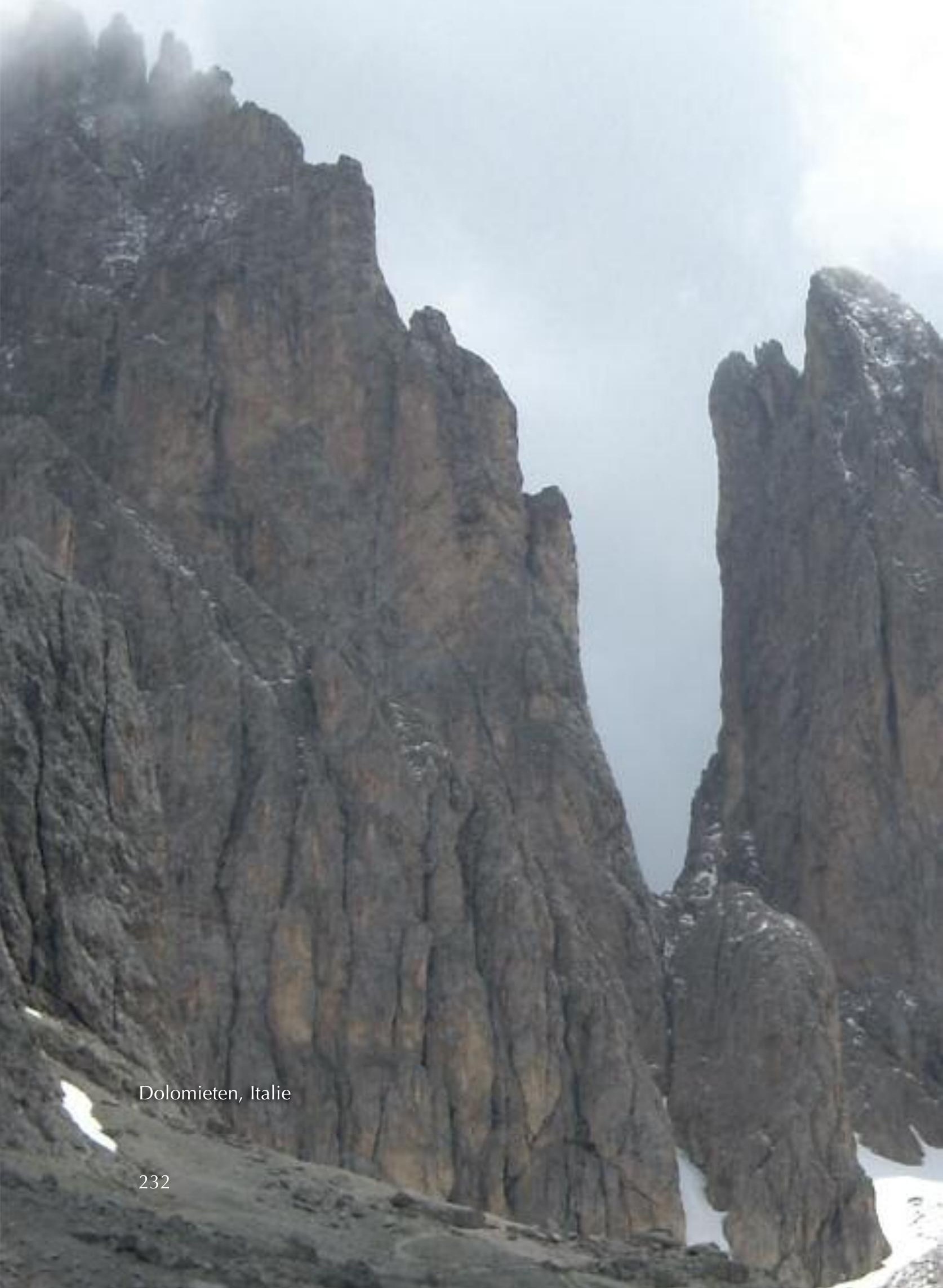




\section{CHAAPTER U O}

\section{Samenvatiting en Conclusies}

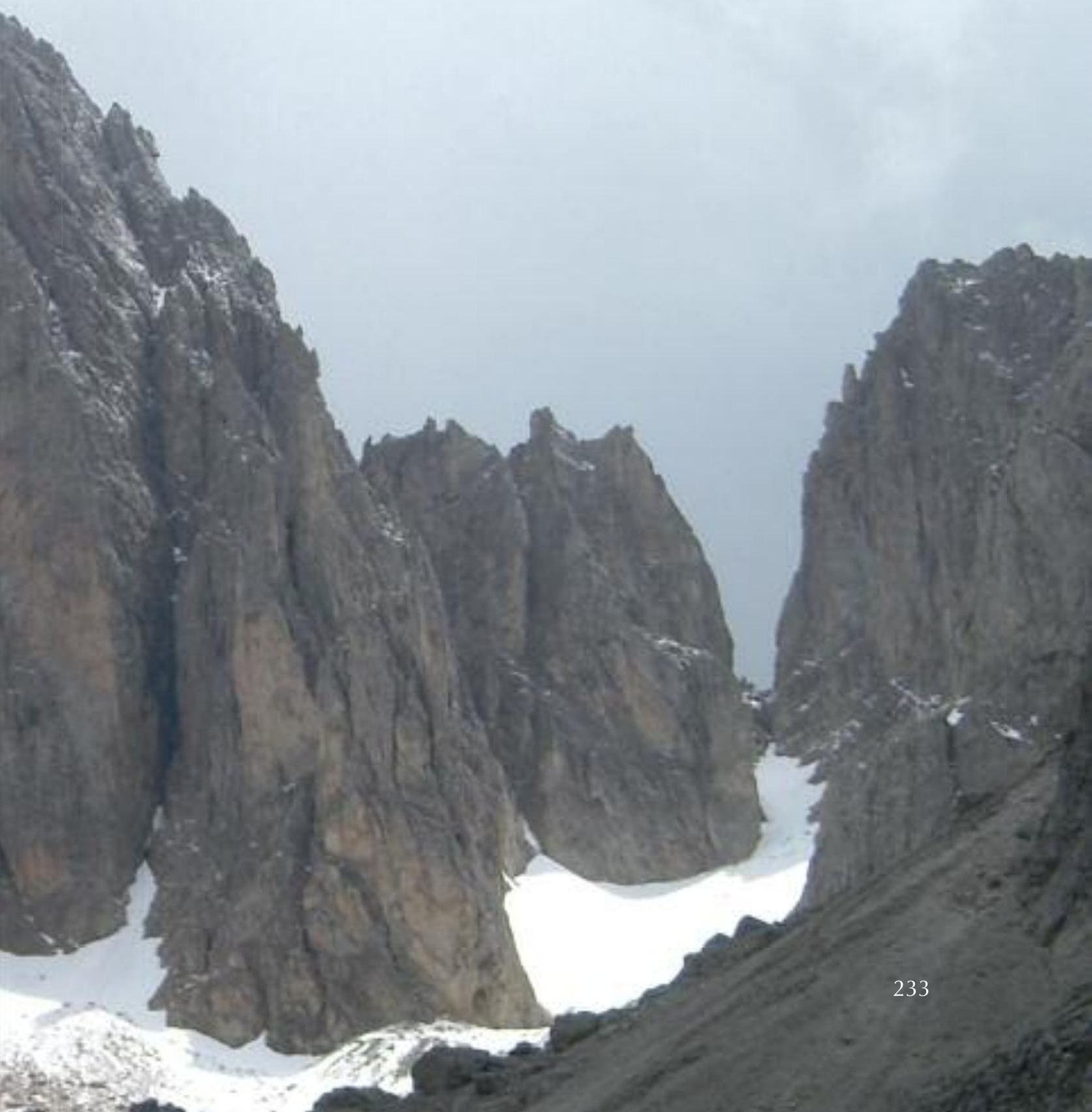


Chapter 10 


\section{Samenvatting en Conclusies}

De totale heup arthroplastiek heeft zowel de patiënt als de samenleving een zeer succesvolle en kosteneffectieve behandeling gebracht voor degeneratieve, traumatische en congenitale destructies van het heupgewricht. Als gevolg hiervan konden vele producenten en ontwerpers de verleiding niet weerstaan een continue stroom aan nieuwe designs te genereren. Te veel van deze designs faalden, voornamelijk ten gevolge van een te haastige en breed verbreide introductie op de markt, gedreven door een soms opportunistische motivatie zonder degelijk preklinisch onderzoek en zonder overweging betreffende de behoefte aan wederom een ander implantaat. Dit heeft geresulteerd in een groot verlies van goodwill voor de orthopaedische gemeenschap, een enorme last aan juridische claims, en een behoefte aan heroriëntatie op de oorspronkelijke waarden van wetenschappelijke integriteit en patiëntveiligheid. Regels voor een betrouwbare en stapsgewijze introductie van nieuwe prothesen werden geherdefinieerd en geleidelijk geadopteerd, alsmede richtlijnen voor de keus van diagnostische en beeldvormende modaliteiten voor het monitoren van de kwaliteit van innovatieve designs.

Het succes van zowel gecementeerde als ongecementeerde heupstelen is gerelateerd aan hun mechanische stabiliteit in, en hun blijvende fixatie aan het periprosthetische bot. Derhalve zou de levensduur van een prothese mogelijk voorspeld kunnen worden middels directe en indirecte informatie omtrent deze implantaat-bot interface eigenschappen. De meest waardevolle hulpmiddelen om deze eigenschappen te bestuderen zijn functionele heupscores, patiënt gerelateerde uitkomstmaten (PROM's), conventionele radiografie, scintigrafie, botdichtheidmetingen, histologie en migratie onderzoek. In dit proefschrift hebben we verschillende studies gepresenteerd waarin we probeerden de toegevoegde waarde van deze technieken te evalueren, hun correlatie met klinische veranderingen vast te stellen, en hun bijdrage aan de vroege herkenning van (uiteindelijk) implantaatfalen. Bovendien werd geprobeerd de rol van computersimulaties van implantaat gestuurde 'strain adaptive bone remodelling', als een leidraad voor aanpassingen in implantaat design, te valideren. 


\section{Chapter 10}

In hoofdstuk 1 werden verschillende scoringssystemen, zowel chirurg afhankelijke functionele scores als patiënt afhankelijke uitkomstmaten, geëvalueerd op hun vermogen om klinische veranderingen te detecteren en de overleving van prothesen te voorspellen. Vanwege grote variabiliteit in patiëntenpopulaties, de subjectiviteit in chirurg- en patiëntenscores, de noodzaak om grote aantallen patiënten te vervolgen gedurende een lange follow-up, met scores die bovendien gekenmerkt worden door 'plafond-effecten', is de sensitiviteit laag voor het identificeren van factoren die implantaatfixatie negatief kunnen beïnvloeden. Dientengevolge zijn deze scores niet geschikt om inferieure designs vroegtijdig te identificeren. Hoge scores bij PROM's bleken eveneens niet te correleren met goede prothese survival, en PROM's scoren zelfs hoog op kenmerken die juist omgekeerd evenredig zijn met goede lange termijn prothesesurvival. Een relatief lage sensitiviteit en specificiteit, en de trend om beïnvloed te worden door veroudering en veranderende comorbiditeiten, maken hen ongeschikt voor dit doel.

Vanwege dezelfde reden zijn (inter)nationale heupregisters een weinig gevoelig instrument. Zij spelen weliswaar een belangrijke rol in lange termijn 'postmarket' bewaking, maar zijn ongevoelig voor vroege discriminatie tussen designs.

Postoperatieve radiografie kan in beperkte mate informatie verschaffen over botveranderingen en implantaatfixatie welke correleren met, of zelfs pathognomonisch zijn voor, (a)septische loslating. Voor de meeste radiografische bevindingen echter is deze correlatie met de kliniek laag en kan implantaatloslating op grond daarvan niet betrouwbaar worden voorspeld. Bovendien dient de betekenis en relevantie van deze röntgenbevindingen verschillend geïnterpreteerd te worden afhankelijk van de ontwerpfilosofie van het implantaat. Tot slot is de interpretatie van röntgenfoto's onderhevig aan intra- en interobserver variabiliteit, en derhalve aan zaken als reproduceerbaarheid, welke dit instrument te ongevoelig maken voor het vaststellen of kwantificeren van criteria die onderscheidend kunnen zijn tussen designs.

Botscintigrafie heeft ook te leiden onder beperkte sensitiviteit en specificiteit in de diagnostiek van fenomenen welke correleren met vroegtijdig falen van 
heupprothesen. Bovendien kan de botremodellering alleen al verschillen tussen implantaten door toepassing van andere oppervlakte- en coatingeigenschappen, zonder dat dit hoeft te correleren met klinische resultaten. Derhalve blijkt deze techniek onbetrouwbaar voor het beoordelen van lange termijn effecten van nieuwe ontwerpen.

Botdensitometrie als een middel voor het onderzoeken van periprosthetische botremodellering, is een accurate en precieze techniek gebleken, maar (kleine) veranderingen in bot minerale dichtheid (BMD) correleren niet duidelijk met klinische resultaten of lange termijn survival. Alleen extreem botverlies is vanzelfsprekend gerelateerd aan een gecompromitteerde implantaatfixatie en een verhoogd risico op loslating, terwijl aan de andere kant een stabiele botdichtheid blijkt te correleren met goed gefixeerde en functionerende stelen. Hoewel DEXA een sensitieve diagnostische techniek is, zijn discrete vroege botveranderingen alleen niet een goede voorspeller gebleken voor lange termijn resultaten, en ook niet voor het aantonen van de superioriteit van het ene boven het andere implantaat.

Op dit moment zijn de twee instrumenten die verondersteld worden te correleren met klinische resultaten en een voorspellende waarde te hebben voor lange termijn survival, en bovendien een discriminerend vermogen tussen implantaten, de techniek die gebruik maakt van eindige elementen simulaties, en migratie metingen met radiostereometrie (RSA). Echter het aantal studies waarin dit vastgesteld is kunnen worden is slechts beperkt en voornamelijk retrospectief van aard. Een werkelijk prospectieve bevestiging van voorspelde resultaten in een lange termijn follow-up onderzoek is nog nauwelijks gepubliceerd. Daarom lijkt het vooralsnog voorbarig om blind te vertrouwen op vroege RSA resultaten, ook al hebben vermaarde RSA onderzoekers een bijna absoluut geloof in de techniek en zijn capaciteit om te bepalen of een nieuw implantaat wel of niet gebruikt zou moeten worden, dit alles gebaseerd op alleen migratie karakteristieken gedurende de eerst twee jaar na implantatie. Het is echter duidelijk geworden dat migratiepatronen variëren tussen steel designs, en niet eenduidig hoeven te correleren met lange termijn klinische resultaten. 


\section{Chapter 10}

In hoofdstuk 2 hebben we de resultaten beschreven van een prospectieve gerandomiseerde studie waarbij de gecementeerde $\mathrm{SHP}^{\circledR}$ en Omnifit ${ }^{\circledR}$ steel worden vergeleken. De studie werd uitgevoerd om te evalueren of preklinische overwegingen over implantaat optimalisatie enerzijds en vroege migratiepatronen anderzijds gebruikt kunnen worden om botremodellering, klinische resultaten en implantaat survival te kunnen voorspellen. Op basis van een vroegere RSA studie met de $\mathrm{SHP}^{\circledR}$ steel werd voorspeld dat door de combinatie van het ruwe steeloppervlak en de vroege 'debonding' met migratie, het implantaat 'abrasive wear' met osteolyse zou veroorzaken, en dientengevolge een hogere faalratio zou vertonen dan de meest gebruikte gecementeerde stelen. Bovendien beoogde de numerieke optimalisatie van de steelgeometrie verminderde periprosthetische stresses, op grond waarvan lagere stressoverdracht naar het bot met als gevolg een lagere BMD kon worden verwacht. Echter de 2-jaars DEXA-studie toonde een hogere in plaats van lagere $\mathrm{BMD}$ in het proximale femur voor de $\mathrm{SHP}^{\circledR}$, migratie van slechts 1 steel bij conventionele radiografie, $100 \%$ survival op minimaal 11 jaar follow-up, en slechts 1 radiografische loslating voor zowel SHP ${ }^{\circledR}$ als Omnifit ${ }^{\circledR}$. Verder waren klinische scores significant beter voor de $\mathrm{SHP}^{\circledR}$ gedurende de hele follow-up. Er werd geconcludeerd dat de voorspelde inferieure uitkomst van de SHP ${ }^{\circledR}$, zowel op gebied van klinische resultaten, survival en botremodellering, niet kon worden gevalideerd met deze lange termijn studie. Deze uitkomst geeft het belang aan van klinische trials om de waarde van deze 'voorspellende' technieken te bepalen, en hun gebruik te valideren ten behoeve van vroege kwaliteitsbepaling van nieuwe prothesen.

In de $\mathrm{SHP}^{\circledR}$ versus Omnifit ${ }^{\circledR}$ studie werd besloten om botremodellering te bestuderen in een gestandaardiseerde perimeter buiten de cement mantel, in een poging de werkelijke botveranderingen te detecteren en het maskerend effect van cement te voorkomen. Om dit te illustreren werd in hoofdstuk 3 de invloed geëvalueerd van inclusie van de cementmantel in de 'region of interest' (ROI) op periprosthetische BMD metingen met behulp van DEXA. De studie was gericht op het bepalen van de toename in BMD ten gevolge van cement inclusie, welke ten onrechte minder botverlies zou suggereren in geval van gecementeerde totale heup arthroplastieken. Gebruik makend van de data van de $\mathrm{SHP}^{\circledR}$ versus Omnifit ${ }^{\circledR}$ studie (zie hoofdstuk 2), werd de BMD gemeten in een $3 \mathrm{~mm}$ offsetzone welke de 
cementmantel bevatte ('BMD-cement'), op de tweede plaats in de perimeter buiten deze offsetzone, alleen bot bevattend ('BMD-bone'), en ten derde in de gehele ROI met zowel de cementlaag als het periprosthetische bot samen ('BMD-total'). Het includeren van de cementmantel resulteerde consistent in een significant hogere $\mathrm{BMD}$, hetgeen beter botbehoud suggereerde. Dit resultaat dient echter te worden toegeschreven aan het effect van het radiopaque cement op de dichtheidsmetingen, en is geen realistische weergave van de door het implantaat veroorzaakte adaptieve botremodellering. Daarom is het advies om bij densitometrie rond gecementeerde heupprothesen gebruik te maken van de software mogelijkheden ten behoeve van geautomatiseerde en precieze exclusie van de cementmantel.

In hoofdstuk 4 verschoof de aandacht naar ongecementeerde totale heup arthroplastieken, in het bijzonder de Omnifit ${ }^{\circledR} \mathrm{HA}$ prothese, en werd gebruik gemaakt van conventionele röntgenfoto's en functionele heupscores om het effect te bestuderen van een hydroxyapatiet (HA) coating op door partikel wear veroorzaakte periprothetische osteolyse bij jonge actieve patiënten. Verder werd geëvalueerd of heupscores en radiografische resultaten correleerden met de survival van het implantaat. Er kon worden aangetoond dat hoewel het hogere activiteitenniveau van deze jonge patiënten potentieel zou kunnen leiden tot een hogere mate van partikel wear, de hydroxyapatiet coating in staat was de implantaat-bot interface af te dichten, te beschermen tegen osteolyse, en een lange termijn implantaatfixatie te garanderen. Met name de aanwezigheid van spotwelds en de afwezigheid van radiolucente en reactieve lijnen in de HA-gecoate Gruen zones 1 en 7, bevestigden goede osseointegratie, en blijken van voorspellende waarde te zijn voor blijvende fixatie, met andere woorden het uitblijven van loslating op de lange termijn. Deze sterke correlatie werd geïllustreerd door een steel survival van 98,5\% en cup survival van 95,5\% na een minimale follow-up van 10 jaar. We constateerden dat de meer omvangrijke osteolyse in de LeeCharnley zone 2 van het acetabulum bij langere follow-up, sterk correleerde met een inferieure survival van dit specifieke cupdesign en oorzaak was voor een relatief hoge revisie-ratio. Dit was de aanleiding voor een verandering in cup design om 'backside wear' door een centraal gat in de cup-shell te voorkomen. 


\section{Chapter 10}

Hoofdstuk 5 introduceerde de Symax ${ }^{\mathrm{TM}}$ steel die gekenmerkt wordt door een verbeterde geometrie en een meer bioactieve, biomimetische hydroxyapatiet coating op het proximale deel van de steel (Bonit- $\mathrm{HA}^{\circledR}$ ), alsmede een Dotize ${ }^{\circledR}$ oppervlaktebehandeling op het distale deel. Histologie, histomorphometrie en scanning electronen microscopie werden toegepast om kwalitatief en kwantitatief het effect en gedrag te bestuderen op 4 geretrievde Symax ${ }^{\mathrm{TM}}$ stelen van deze nieuwe, electrochemisch gedeponeerde Bonit-HA ${ }^{\circledR}$ coating en de Dotize ${ }^{\circledR}$ oppervlaktebehandeling. Snelle en uitgebreide osseointegratie werd gezien rond het HA-gecoate deel van de steel. Bot-implantaat oppervlakte contact verbeterde van $26,5 \%$ na drie weken tot $83,5 \%$ na 13 maanden, met een toenemende botdichtheid per ROI van $24,6 \%$ (drie weken), tot $41,1 \%$ (32 maanden). De coating bleek snel te remodelleren maar zonder dat dit resulteerde in een negatief effect op de bot-implantaat koppeling. Deze diepe en uitgebreide ingroei van bot in de open oppervlakte structuur van de Symax ${ }^{\mathrm{TM}}$ steel leidt tot een optimale afdichting van de bot-implantaat interface en een stabiele benige verankering. Gebaseerd op de ervaring van stelen met eerste en tweede generatie plasmaspray HA-coatingen, mag blijvende lange termijn osseointegratie worden verwacht voor dit nieuwe design, met voorspelbare resultaten ten aanzien van survival.

Anderzijds bleek de Dotize ${ }^{\circledR}$ oppervlakte behandeling botappositie op het distale deel van de steel volledig te kunnen voorkomen. Deze combinatie garandeert een uitsluitend proximale steelingroei, bijdragend aan een optimale proximale stress overdracht op bot, met een verwachte vermindering van de stress shielding van de femur metaphyse.

Dit effect kon worden bevestigd in hoofdstuk 6, waarin de botremodellering rondom the Symax ${ }^{\mathrm{TM}}$ steel werd bestudeerd met behulp van DEXA, en werd vergeleken met de Omnifit ${ }^{\circledR}$ steel in een 2 jaar gerandomiseerde klinische trial. Ten behoeve van een verbeterde weergave van het implantaateffect op de bot minerale dichtheid (BMD) werd een modificering van de Gruen zones als 'regions of interest' geïntroduceerd. Hiermee werd een correctere vergelijking van remodellering rond stelen met een verschillend design beoogd. De resultaten toonden consistent hogere BMD-waarden voor de Symax ${ }^{\mathrm{TM}}$ steel, welk verschil statistisch significant 
werd in zone 7 vanaf 1 jaar follow-up. Deze verbeterde botpreservatie rond de Symax ${ }^{\mathrm{TM}}$ steel, in combinatie met de verbeterde osseointegratie zoals aangetoond met histologisch onderzoek, werd geacht een goed lange termijn resultaat te kunnen voorspellen.

Tot slot wilden we nagaan of de eindige elementen methode (Finite Element, FE) de mogelijkheid heeft om een betrouwbare preklinische simulatie te verrichten, en valide eigenschappen heeft om klinische in vivo resultaten te kunnen voorspellen. Daartoe werd de remodelleringstudie van hoofdstuk 6 vergeleken met een numerieke simulatie studie in hoofdstuk 7 , om de nauwkeurigheid van de eindige elementen techniek te bepalen, alsmede de waarde van deze techniek in het verbeteringsproces van implantaatdesigns. DEXA metingen toonden een BMD verlies in Gruen zone 7 van $14 \%$ en $20 \%(P<0.05)$ voor respectievelijk de Symax ${ }^{\mathrm{TM}}$ en Omnifit ${ }^{\circledR}$ steel, terwijl de FE-modellen een botverlies voorspelden van $28 \%$ (SymaxTM) en $26 \%$ (Omnifit $\left.{ }^{\circledR}\right)$. Wanneer de Dotize ${ }^{\circledR}$ oppervlaktebewerking niet in de simulatie werd gemodelleerd, werd er zelfs een botverlies van $35 \%$ voorspeld in Gruen zone 7. Alhoewel de numerieke simulatie weliswaar een trend van verbeterde proximale botbelasting toonde door het Symax ${ }^{\mathrm{TM}}$ ontwerp, welke werd bevestigd door DEXA resultaten, was er geen kwantitatieve match. Dit impliceert dat de FE-voorspelling van botremodellering onvoldoende correlatie vertoonde met klinische bevindingen in grotere patiëntengroepen, en waarschijnlijk niet geschikt is voor nauwkeurige voorspelling van discrete veranderingen in belastingspatronen. Dit moet worden toegeschreven aan incomplete aannames betreffende de biologische en mechanische effecten van de nieuwe coating en oppervlaktebewerking, en het onvermogen van de FE-techniek om de dynamische interface variabelen adequaat te vertalen in puur mechanische, mathematische vergelijkingen.

Concluderend kan worden gezegd dat de gefaseerde innovatie van nieuwe totale heupprothesen met de daaraan gekoppelde stapsgewijze test- en evaluatie procedure, de orthopaedische gemeenschap ongetwijfeld een protocol heeft verstrekt voor een veiligere introductie van nieuwe designs. De 'trial en error' methode is niet rationeel gebleken en is intrinsiek riskant. De kans om opnieuw 


\section{Chapter 10}

met een orthopaedische ramp geconfronteerd te worden zal kleiner zijn indien dit aangepaste traject wordt gevolgd. Echter de aanname van volledige veiligheid van welke diagnostische modaliteit dan ook om toekomstige mislukkingen in een vroege fase te detecteren, is onrealistisch en vooralsnog niet bewezen. De meeste technieken zijn te weinig sensitief, niet discriminerend genoeg en irrelevant om (kleine) verbeteringen of potentiële failures te detecteren. Ook voor RSA is de link tussen het migratiepatroon en toekomstige loslating niet vastgesteld voor de meeste implantaten. En de eindige elementen vertaling van dynamische biologische processen op de interface tussen implantaat en bot is nog te ver geabstraheerd van de realiteit, zodanig dat numerieke modellen de natuurlijke fysiologie slechts ten dele kunnen simuleren.

Derhalve zou de klinische waarde van RSA kunnen toenemen door een groei in het aantal studies waarbij het focus dient te liggen op het herkennen van afwijkende migratiepatronen in vergelijking met die van de meest gebruikte implantaten, en deze vervolgens prospectief te correleren aan klinische resultaten en survival studies. Voor de eindige elementen methode dienen dynamische biochemische interface interacties beter begrepen en vertaald te worden in mechanische algoritmes, en vervolgens gevalideerd met behulp van klinische resultaten uit prospectieve studies.

Niettemin tasten we nog steeds enigszins in het duister, en blijft kwaliteitonderzoek vooralsnog afhankelijk van de combinatie van meerdere beschikbare diagnostische technieken, in plaats van één enkele methode. Deze modaliteiten spelen een rol in verschillende fasen van de preklinische en klinische testprocedure van de prothese (Fig. 1).

Recente orthopaedische mislukkingen hebben ons andermaal geleerd dat er in de moderne orthopaedische wereld geen plaats is voor ongefundeerd geloof in de potentiële superioriteit van welk nieuw design dan ook. Orthopaedisch chirurgen hebben de verplichting ieder nieuw implantaat met grote zorgvuldigheid op te volgen, 'studies' uitgevoerd door producenten en/of designers te beschouwen met professionele achterdocht, en een persoonlijke verantwoordelijkheid te ervaren voor 
de patiënten die door hen worden geïncludeerd in elk onderzoek van een nieuw implantaat of chirurgische techniek. Er is tevens een belangrijke taak voor de nationale wetenschappelijke orthopaedische verenigingen om de rol van supervisor op zich te nemen en toezicht op haar leden te houden, met het doel de professionele standaard te verbeteren en verder verlies aan goodwill te voorkomen. Deze taak dient echter in balans te blijven met het stimuleren van de intrinsieke drang tot innovatie, welke tegelijkertijd het bestaan van dezelfde wetenschappelijke verenigingen rechtvaardigt.

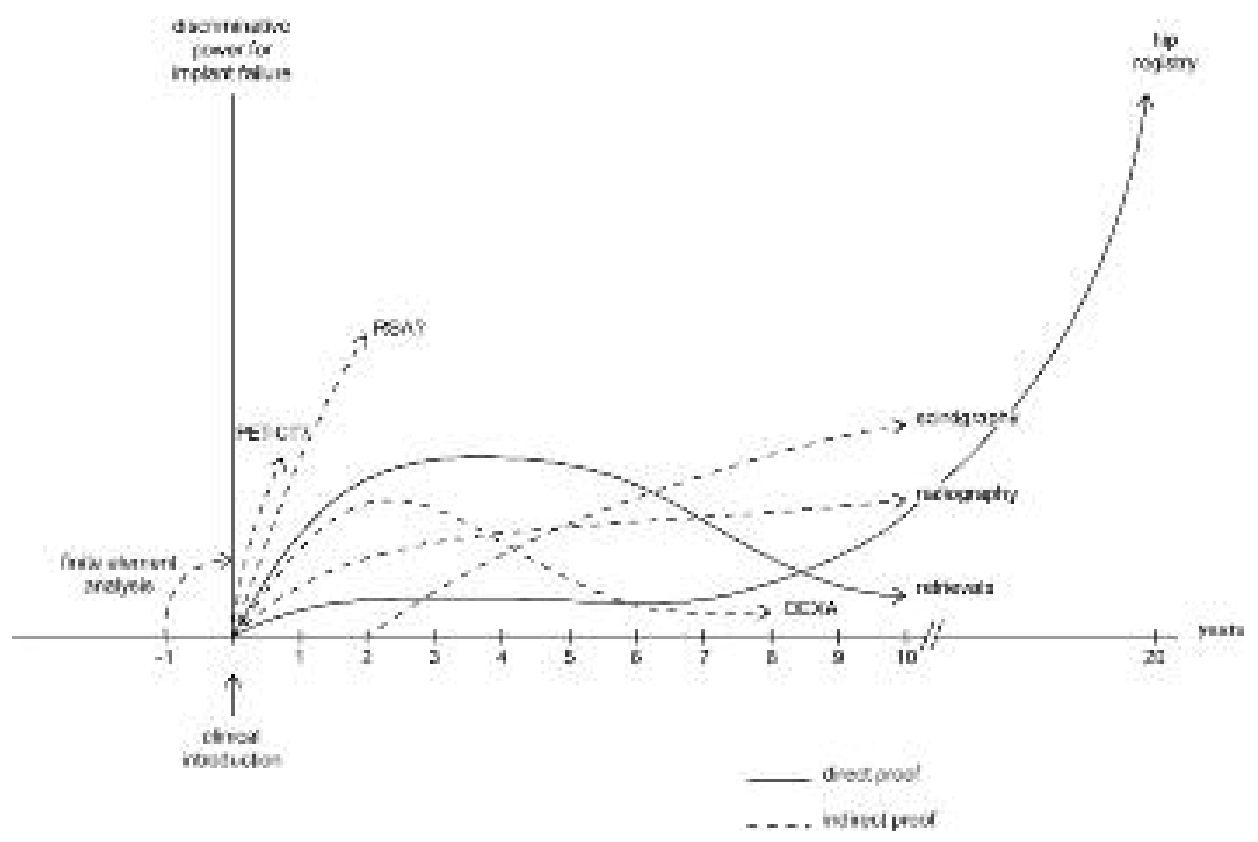

Fig. 1 


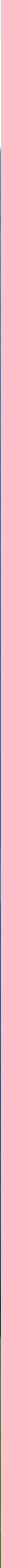




\section{Curstcullum Vitae}
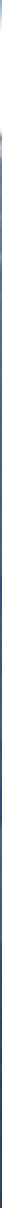

atis

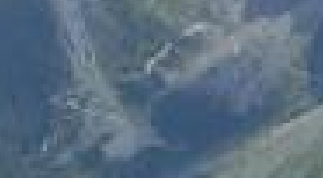

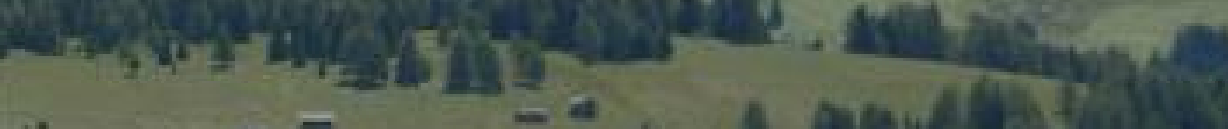

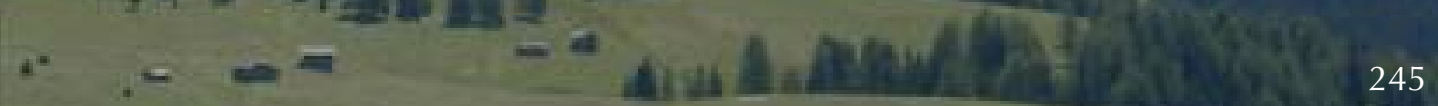


René ten Broeke was born in Haaksbergen, the Netherlands, on September 4, 1957.

After graduating from high school (Atheneum, Mendel College) in Haarlem, he studied at the faculty of Human movement sciences ('Bewegingswetenschappen') at the Free University of Amsterdam (1976-1978). His medical study was also done at the Free University of Amsterdam (1978-1987), interrupted by 2 years of research at the laboratory of anatomy.

He commenced his clinical career as a resident in general surgery in Den Bosch (1987-1989), followed by a residency in orthopaedic surgery in Den Haag (1989-1991) and Maastricht (1991-1992). His specialisation in orthopaedics started with a 2 year training in general surgery under the guidance of Dr. P.R.G. Brink at the Wever Hospital (now Atrium Medical Centre) in Heerlen (1992-1994). After that he received his surgical orthopaedic training at the Maastricht University Medical Centre supervised by Prof. A.J. van der Linden and Prof. R.G.T. Geesink (1994-1997), and did a half non-academic year at the Wever Hospital under the guidance of Dr. A.J. Tonino (in 1995).

In September 1997, René ten Broeke registered as a specialist in orthopaedic surgery, and started as a junior specialist at the University Medical Centre in Maastricht. In March 1998 he became a consultant senior staff member at this institute, where he specialized in complex hip and revision surgery and traumatology. In 2010 he was appointed as vice chairman of the department of orthopaedic surgery. He is founding board member of the Dutch Hip Society and is member of several scientific societies and the Educational Committee of the Dutch Orthopaedic Society.

The author is married to Annet Broodman. They have two lovely daughters: Charlotte and Juliëtte. 


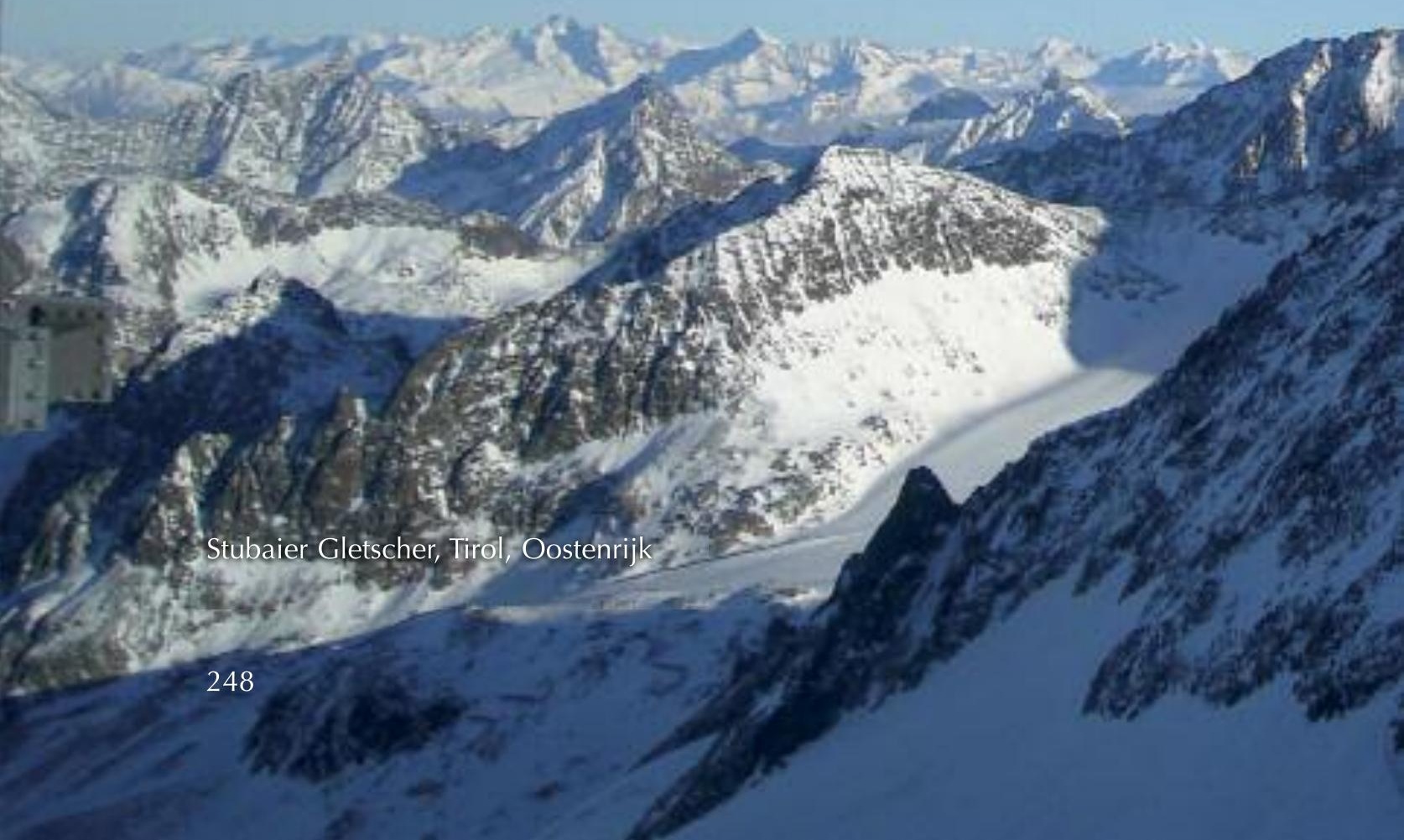




\section{Dankwoord}

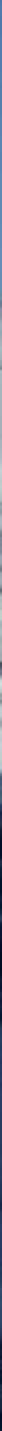


Dankwoord 
Uiteindelijk is het dan zover. Het is mooi geweest, ik zet er een punt achter. En ach, eigenlijk was het best leuk. Dat de 's' er nu van af is maakt me niet heel veel gelukkiger, maar dat ik dit kan nalaten als dank voor allen die mij hierin hebben gesteund, wel.

In de meeste dankwoorden wordt begonnen met de promotor, maar wat mij betreft komen anderen eerst.

Lieve Annet, al 24 jaar mijn Zeeuwse maatje, mijn steun en toeverlaat. Jou komt de meeste dank toe. Je hebt me de vrijheid gegeven om me steeds weer terug te trekken op mijn kamer, in een jong opgroeiend gezin dat eigenlijk de aandacht verdiende die de wetenschap opeiste. Deze spagaat is van alle tijden en waarschijnlijk moeilijk te omzeilen, maar toch. Je was en bent de motor die bij ons alles draaiend houdt, zorgzaam en liefdevol, moeder en vader tegelijk. Dit alles terwijl ik schitterde door 'afwezigheid', en zat te worstelen achter de computer, of weer zo nodig een verhaaltje moest vertellen in binnen- of buitenland. Maar je vond het goed, dank je. En soms ook niet, en dan had je gelijk, Annet, je bent een kanjer, ik zou dit vaker moeten zeggen ...

Lieve Charlotte en Juliëtte, jullie zijn het mooiste dat ik heb, en kleuren dagelijks mijn leven. Ik heb veel niet meegemaakt van jullie jonge jaren, en het moment dat jullie er op uittrekken is al zo dichtbij. Ik zie op tegen het moment dat Annet en ik onze dochters niet dagelijks meer om ons heen hebben, maar goed zo moet het gaan, zegt men. Lot ik vind het geweldig dat je in mijn voetsporen wilt treden, ondanks dat je hebt gezien hoeveel je voor dit vak ook moet opgeven. Je zult een goede dokter zijn, rustig en begripvol. Je patiënten zullen van je houden. En Juul, mijn eeuwige plaaggeest, maar ook mijn kleine meid, want dat zul je blijven. Ik bewonder je volharding en de groei die je doormaakt, van een onzeker meisje naar een zelfbewuste jonge vrouw. Ik denk niet dat ik daar veel aan bijgedragen heb, het is voornamelijk mama's werk. Maar ik ben ontzettend trots op jullie, ook dat zou ik vaker moeten zeggen. We gaan een feestje vieren, er komen nog wat mensen, maar het is voor ons vieren.

Lieve pa en ma, ik ben ontzettend blij dat jullie deze dag beide nog mee kunnen maken. Door mijn 'gedegen' voorbereiding had het zomaar anders kunnen zijn. Jullie interesse in mijn werk en onderzoek was altijd hartverwarmend, en ma je zorgen over dat ik zo hard moest werken, aandoenlijk. Het verheugt me dat ik langs 


\section{Dankwoord}

deze weg jullie nog kan danken voor de mogelijkheid die jullie al jullie kinderen hebben geboden om vanuit een warm nest de weg te kiezen die we wilden, ook al duurde hij lang en was hij kostbaar. Het verdriet mij dat Henriëtte niet meer bij ons is, zij zou van deze dag genoten hebben. Ergens feest ze wel met ons mee, denk ik.

Prof. Dr. R.G.T. Geesink, beste Ruud. Hoewel je als co-promotor in mijn boekje staat, ben jij toch eigenlijk mijn promotor. Jij was voor mij het voorbeeld van hoe een begaafd clinicus en begenadigd operateur die kwaliteiten kon laten samengaan met het doen van innovatief wetenschappelijk onderzoek. Veel van mijn werk ligt in het verlengde van waar jij onze vakgroep internationaal mee op de kaart hebt gezet. Toen je hoogleraar werd heb je mij gevraagd om jouw werk over te nemen en toe te treden tot de staf, ik ben je daar nog altijd dankbaar voor. Het meest erkentelijk ben ik je echter voor de wijze waarop je mij de schoonheid van de revisiechirurgie hebt bijgebracht, en de overtuiging dat ieder probleem oplosbaar is. Beschouw dit boekje een beetje als een terugbetaling daarvoor.

Prof. Dr L.W. van Rhijn, beste Lodewijk, toen duidelijk werd dat Ruud reeds te lang met emeritaat was om nog mijn promotor te kunnen zijn, nam jij die rol voortvarend op je en begeleidde het laatste stuk van de reis. De tijd evolueert snel, in 1997 startten we samen in de staf, een aantal jaar geleden mocht ik jouw paranimf zijn, nu ben je mijn promotor. Dank voor je interesse in mijn werk en de stimulans die je mij en vele andere promovendi geeft en in de toekomst zult geven. Je verstaat de kunst om in iedere 'uitdaging' een kans te zien en zo heb je van onze groep een groeimodel gemaakt dat gezien wordt in binnen- en buitenland. Het is goed dat we als hoofd en waarnemend hoofd af en toe eens stevig kunnen sparren, maar ons ook met enige ironie kunnen amuseren over het betrekkelijke van de academische wereld.

Dr. J.J.C. Arts, beste Chris als tweede co-promotor raakte je pas in een later stadium bij mijn onderzoek betrokken. Dank voor de energieke wijze waarop je hebt bijgedragen aan het leveren van commentaren en verbeteringen van mijn manuscripten. Als wetenschappelijke duizendpoot stuiter je op de afdeling op en neer, en het is goed dat je Tim als bedachtzame tegenhanger hebt. Samen vormen jullie een goed tandem waar in de toekomst nog vele originele onderzoeksideeën aan zullen ontspruiten. Ik vertrouw erop dat jullie enthousiasme Maastricht steeds prominenter op de kaart zal zetten. 
Drs. L Jutten-Brouwer, beste Liesbeth, jij verdient een belangrijke plaats in dit dankwoord. Bijna vanaf het begin van mijn onderzoek, ben je er bij betrokken en je hebt er bijzonder veel werk voor geleverd. Klinische studies zonder jouw accurate en toegewijde ondersteuning zijn op onze afdeling eenvoudigweg niet mogelijk. Jouw grote verantwoordelijkheidsgevoel en integere onderzoeksmentaliteit blijkt iedere keer weer een garantie voor een kwalitatief hoogwaardige follow-up, en dit wordt inmiddels ook erkend buiten onze kliniek. Je zorgvuldige data-management (ondersteund door Margareth), het verzorgen van tabellen, grafieken, kortom de 'hardware' van mijn onderzoek was bij jouw in veilige handen. Dank voor je hulp.

Beste Steffie (Harings), Pieter (Emans), Alfons (Kessel), Jeroen (van Mulken), Roel (Kuijer), Pieter (Leffers), Nico (Verdonschot), Dennis (Janssen), gewaarde overige co-auteurs . Jullie allen leverden een bijdrage aan de onderzoeken die aan de basis stonden van mijn manuscripten. Dank voor jullie inzichten, meningen, adviezen, correcties en vooral jullie geduld en doorzettingsvermogen. En Nico, dank dat je jouw nek hebt uitgestoken en het aangedurfd hebt om met open vizier mijn kritische blik tegemoet te treden. Je hebt samen met Maria en Dennis van mijn complexe onderzoeksvoorstel een coherent geheel weten te maken. Ik hoop dat de Nijmeegs-Maastrichtse as in de toekomst meer mooie projecten op gaat leveren.

Dear Maria (Tarala), Antoine (Alves), Axel (Baumann), dear co-authors I am very grateful for your contributions to my research. Your expertise in the field of biomechanics, histological techniques and coating technology was indispensable. Antoine and Axel thank you very much for taking the effort to join the meetings at Amsterdam airport to discuss the histological slides and help me understand what I was actually looking at.

Prof. Dr. A.J. van der Linden, beste Ton. Ik herinner me mijn sollicitatiegesprek in de barakken van het oude Annadal nog als een bijzondere gebeurtenis. Met het aannemen van mij voor de opleiding tot orthopaedisch chirurg bepaalde je voor een belangrijk deel mijn levensloop. Ik ben je daar dankbaar voor, het heeft mij veel gebracht. Met wijsheid, humor, gezond relativeringsvermogen en soms niet mis te verstane duidelijkheid, wist je sturing te geven aan de opleiding van een diverse schakering assistenten. De oprechte belangstelling van Lida en jou voor het thuisfront werd door ons zeer gewaardeerd. Helaas kunnen Annet en ik niet bij de 
viering van je 85 ste verjaardag zijn, maar we wensen jullie beide een mooie dag toe en nog vele goede jaren.

Beste Jan, gewaardeerde collega, dank dat je mijn paranimf wilt zijn. Met jou als opvolger van Geert Walenkamp heeft onze groep een prima heup-orthopaed en infectioloog aangetrokken. Dank voor je collegialiteit, het is een plezier om met je samen te werken. Er liggen heel wat uitdagingen voor ons, maar ik ben er van overtuigd dat we ze prima het hoofd zullen kunnen bieden.

Beste André, fijn dat je op deze dag aan mijn zijde wilt staan. Het is goed je op zo'n moment gesteund te weten door iemand van eigen vlees en bloed. Onze levenslijn kent vele parallellen; een mooie gemeenschappelijke jeugd, samen gestudeerd, beide een opgroeiend gezin en een hectische baan. Het doet me ook goed deze dag met mijn dierbaren te kunnen vieren, mijn familie en schoonfamilie. Dank voor de belangstelling die jullie altijd voor mijn werk getoond hebben, en het geduld, het vele geduld. Het is nu klaar, ik kom weer eens wat vaker langs.

Tot slot wil ik ook mijn collega oud-stafleden (Geert Walenkamp, André van Ooij, Jan Verhaar, Sjoerd Bulstra, Henk Arens, Jan Willem Duyzings + , Mike van Steijn en Patrick Deckers) en huidige stafleden (Paul Willems, Heleen Staal, Jan Geurts, Peter Feczko, Pieter Emans, Joris Hermus, Mark van den Boogaart en Adhiambo Witlox) danken voor de gelegenheid om mij door de jaren heen te wijden aan dit onderzoek, en voor de mogelijkheid ons vak op inspirerende en saamhorige wijze uit te oefenen. 'The future is ours."

Ik heb gezegd. 
Dankwoord 
